\title{
Non-alcoholic steatohepatitis : second hit or strike out?
}

Citation for published version (APA):

Wouters, K. A. M. (2008). Non-alcoholic steatohepatitis : second hit or strike out? [Doctoral Thesis, Maastricht University]. Maastricht University. https://doi.org/10.26481/dis.20081203kw

Document status and date:

Published: 01/01/2008

DOI:

10.26481/dis.20081203kw

Document Version:

Publisher's PDF, also known as Version of record

\section{Please check the document version of this publication:}

- A submitted manuscript is the version of the article upon submission and before peer-review. There can be important differences between the submitted version and the official published version of record.

People interested in the research are advised to contact the author for the final version of the publication, or visit the DOI to the publisher's website.

- The final author version and the galley proof are versions of the publication after peer review.

- The final published version features the final layout of the paper including the volume, issue and page numbers.

Link to publication

\footnotetext{
General rights rights.

- You may freely distribute the URL identifying the publication in the public portal. please follow below link for the End User Agreement:

www.umlib.nl/taverne-license

Take down policy

If you believe that this document breaches copyright please contact us at:

repository@maastrichtuniversity.nl

providing details and we will investigate your claim.
}

Copyright and moral rights for the publications made accessible in the public portal are retained by the authors and/or other copyright owners and it is a condition of accessing publications that users recognise and abide by the legal requirements associated with these

- Users may download and print one copy of any publication from the public portal for the purpose of private study or research.

- You may not further distribute the material or use it for any profit-making activity or commercial gain

If the publication is distributed under the terms of Article $25 \mathrm{fa}$ of the Dutch Copyright Act, indicated by the "Taverne" license above, 
Non-alcoholic steatohepatitis: second hit or strike out? 
Non-alcoholic steatohepatitis: second hit or strike out?

Kristiaan Wouters

ISBN: 978-90-6464-312-5

Cover design by Paul Wouters

Printed by Ponsen \& Looijen B.V.

(C) Kristiaan Wouters, Maastricht 2008 


\section{Non-Alcoholic Steatohepatitis: Second Hit or Strike Out?}

\section{Proefschrift}

Ter verkrijging van de graad van doctor aan de Universiteit Maastricht, op gezag van de Rector Magnificus, Prof. mr. G.P.M.F. Mols

volgens het besluit van het college van Decanen, in het openbaar te verdedigen op woensdag 3 december 2008 om 16.00 uur

$$
\text { door }
$$

Kristiaan Arthur Melania Wouters

Geboren te Hasselt op 8 maart 1981 


\section{PROMOTOR}

Prof. Dr. Marten H Hofker (UMCG - Groningen / UM)

\section{COPROMOTORES}

Dr. Marc van Bilsen

Dr. Ronit Shiri-Sverdlov

\section{BEOORDELINGSCOMMISSIE}

Prof. Dr. Wout Lamers (Voorzitter)

Prof. Dr. Wim A Buurman

Prof. Dr. Cees HC Dejong

Prof. Dr. Folkert Kuipers (UMCG - Groningen)

The study described in this thesis was supported by a grant of the Netherlands Heart Foundation (NHS-2002B018).

Financial support by the Netherlands Heart Foundation and the Dutch Diabetes Fund for the publication of this thesis is gratefully acknowledged.

Additional financial support by Eli Lilly Nederland. 


\section{Contents}

Chapter 1 General Introduction.

p. 7

Chapter 2 Understanding hyperlipidemia and atherosclerosis: lessons

p. 33 from genetically modified apoe and ldlr mice.

Clin Chem Lab Med. 2005;43(5):470-9. Review.

Chapter 3 Early diet-induced non-alcoholic steatohepatitis in APOE2 knock-in mice and its prevention by fibrate.

p. 53

J Hepatol. 2006 Apr;44(4): 732-41.

Chapter 4 A central role for cholesterol metabolism and inflammation during the inhibition of non-alcoholic steatohepatitis with a synthetic PPAR alpha agonist.

Submitted.

Chapter 5 Dietary cholesterol, rather than liver steatosis, leads to p. 93 hepatic inflammation in hyperlipidemic mouse models of NASH.

Hepatology. 2008 Aug;48(2):474-86.

Chapter 6 The role of scavenger receptor A and CD36 in diet induced non-alcoholic steatohepatitis in $1 \mathrm{ldl}^{-/-}$mice.

Chapter 7 Hyperactivation of inflammatory signaling inhibits hepatic p. 133 steatosis during high fat feeding in hyperlipidemic mice.

Chapter 8 General discussion.

Summary/Samenvatting.

Curriculum Vitae.

Dankwoord.

List of abbreviations. 



\section{General I ntroduction}




\section{The Metabolic Syndrome}

The Metabolic Syndrome (MetS) is characterized by a clustering of several metabolic disturbances that are highly prevalent in industrialized countries, such as insulin resistance (IR), dyslipidemia, central obesity and hypertension [1]. The coexistence of these disorders appears to be more frequent than would be expected by chance [2]. Clustering of these disorders has been suggested by several scientists independently as early as from the 1920's and different definitions and names have been given to them [2], such as syndrome $\mathrm{X}$, insulin resistance syndrome, Reaven's syndrome and CHAOS.

The underlying causes of the MetS are thought to be: excess body weight (especially visceral / central / android obesity), physical inactivity/sedentary lifestyle, an atherogenic diet (high carbohydrates, low fiber, high saturated fat), high alcohol intake, and smoking [3]. Additionally, genetic factors can contribute to increased susceptibility to develop the MetS [2]. The MetS is especially related to the development of IR [4], which may be considered the pathogenic denominator that links all components of the MetS [1]. Individuals with MetS are at higher risk for developing heart disease (2- to 3fold), stroke (2-fold), and type 2 diabetes (5-fold). MetS is becoming more common, with a prevalence of $10 \%$ to $30 \%$ of the adult population in industrialized countries [57] and it may therefore be considered as a major health hazard.

Currently, there are two major definitions for MetS, provided by the revised National Cholesterol Education Program (NCEP) and the International Diabetes Federation (IDF), respectively. The Third Report of the NCEP Expert Panel on Detection, Evaluation, and Treatment of High Blood Cholesterol in Adults (Adult Treatment Panel III; ATP III), defines the MetS as the presence of three or more of the following risk factors: increased waist circumference, increased fasting serum glucose or triglyceride levels, hypertension, or low levels of high density lipoprotein (HDL) cholesterol $[8,9]$. The current definition by the IDF however, relies on the fact that abdominal obesity is so highly correlated with the development of IR that additional measurements of IR are unnecessary. Waist circumference as a measure for abdominal obesity has consequently become an indispensable hallmark for the MetS, in combination with two of the other risk factors mentioned above [8].

MetS is associated with other diseases, such as non-alcoholic fatty liver disease (NAFLD). The liver is an important organ in whole-body lipid and glucose homeostasis and therefore may play an essential role in the MetS. This thesis will focus on diet-induced liver pathology. 


\section{The liver in the metabolic syndrome}

\section{Liver function and morphology}

The liver is a central organ in an organism's metabolism. It has indispensable functions in lipid homeostasis, such as triglyceride (TG) and cholesterol biosynthesis and uptake, to maintain an equilibrium in the body during both the fed and the fasted state. It also produces bile to aid in the digestion and uptake of lipids from the intestine. Additionally, the liver has central roles in carbohydrate homeostasis via gluconeogenesis (de novo synthesis of glucose), glycogenesis (synthesis of glycogen from glucose for storage) and glycogenolysis (breakdown of glycogen to glucose). The liver has also important functions in protein metabolism, detoxification, the breakdown of several hormones and other substances, as well as synthesizing coagulation factors and several important proteins, such as albumin (the major transport protein in the circulation), and several acute phase proteins.

Macroscopically, the liver is divided into four lobes, i.e. left lobe, right lobe, quadrate lobe and caudate lobe. The liver parenchyma can be divided into functional units, called hepatic lobules, which can be defined in different ways (Fig. 1):

- classic lobule: hexagonal shape centred around a hepatic venule with portal triads (portal vein, artery, bile duct) on its edges, divided into centrilobular, midzonal, periportal parts.

- acinus: diamond shape centred around a portal triad and adjacent two central veins at the periphery of the lobule, divided into zones based on oxygen supply.

In zone 1, encircling the portal triads, hepatocytes are best oxygenized while they are poorest oxygenized in the proximity of the central vein (zone 3 ). This is caused by the fact that oxygen- and nutrient rich blood enters the liver via a hepatic artery and portal vein respectively, and flows through the sinuses to the central vein.

Microscopically, the liver consists of several cell types, i.e. hepatocytes, which are up to $70 \%$ of the total mass, stellate cells, and Kupffer cells (KCs). Stellate cells or Ito cells are pericytes located in the perisinusoidal space (also called Disse space), which is the space between the sinusoids and the hepatocytes. They represent 5 to $8 \%$ of the total population in the liver. Stellate cells are the main cellular source of extracellular matrix proteins in the liver $[10,11]$.

KCs are specialized tissue macrophages in the sinusoids (adherent to endothelial cells), representing about $35 \%$ of non-parenchymal cells in the liver. They are resident liver macrophages, first described by Karl Wilhelm von Kupffer in 1876 [12] and correspond to approximately $10-15 \%$ of the total liver cell population [13]. These cells 
are the first macrophage population that are encountered by several pathogens from the gastrointestinal tract coming into the liver via the portal vein [14] and are hence an important part of the innate immune system of the body. KCs originate from circulating monocytes that migrate into several tissues and subsequently differentiate to different tissue macrophages [15], although they are described to be able of limited self-renewal [16]. Studies on the lifespan of KCs have yielded conflicting results, spanning from 2 weeks to one year [15]. KCs have a major role in clearing senescent and malformed red blood cells from the circulation via scavenger receptors class $\mathrm{A}$ type 1 and 2 [17]. The major activating pathways of KCs act via the complement factors $\mathrm{C} 3 \mathrm{a}$ and $\mathrm{C} 5 \mathrm{a}, \beta$-glucans from both bacteria and fungi, and via lipopolysacharide (LPS). They have been implicated to have differential roles in host defense, liver regeneration, and several forms of liver injury via the secretion of several mediators, such as cytokines $[11,15]$.

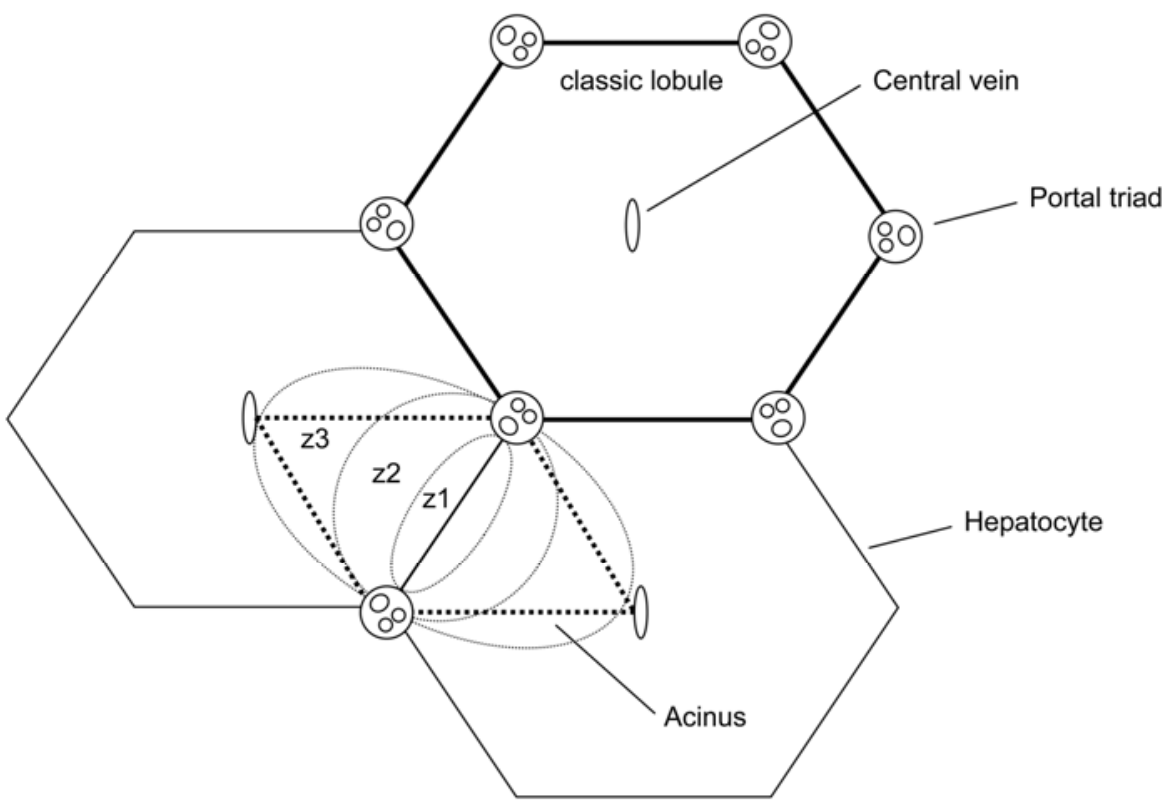

Figure 1. Functional units of the liver. Liver parenchyma is divided in several functional units. Either as a classic lobule, indicated with a bold line, or as an acinus, indicated with a dashed line and which is divided into three zones according to the oxygen supply (z1, z2, and z3). 


\section{Fatty liver as the hepatic event of the Metabolic Syndrome}

MetS was found to be a strong predictor for the development of NAFLD [18], a condition that represents a wide spectrum of liver disorders. It is hallmarked by hepatic lipid accumulation (steatosis) of more than $5 \%$ to $10 \%$ of total liver weight. All components of the MetS were found to correlate with NAFLD [19]. Clear correlations were found especially with obesity, but also with type 2 diabetes mellitus and hyperlipidemia [20]. It is estimated that $75 \%$ of type 2 diabetic patients have some form of fatty liver [21, 22].

The exact relation between obesity and NAFLD is still under debate. Steatosis prevalence increases to $57.5 \%$ [23] and $74 \%$ [24] in obese persons. Also in children there is a clear link with obesity and NAFLD, as it affects only $2.6 \%$ of children with normal weight and $22.5 \%$ [25] to $52.8 \%$ [26] of obese children. However, several reports claim that steatosis can develop independently from obesity [27, 28], but rather is affected by fat distribution. In this regard, waist circumference correlates closely to steatosis development, indicating that abdominal fat is the most harmful fat depot [19]. These observations suggest a close relationship between steatosis and MetS. Accordingly, it has been postulated that steatosis may simply represent the hepatic manifestation of the MetS [1].

\section{Non-alcoholic steatohepatitis}

NAFLD can progress to non-alcoholic steatohepatitis (NASH), which is hallmarked by the presence of an inflammatory response in the fatty liver. NASH has been first observed in 1980 by Ludwig et al. [29], describing liver biopsy specimens of 20 patients with a thus far unnamed liver disease that histologically mimicked alcoholic hepatitis.

Steatosis itself is generally considered a rather benign and reversible condition, like seen during prolonged fasting and re-feeding. The presence of inflammation in a fatty liver is the key feature of NASH and represents an irreversible step that makes prognosis poorer. The inflamed liver preludes further disease progression and allows for later stages of the disease to develop, such as IR and possibly fibrosis, cirrhosis, and liver cancer. Triggers that cause inflammation can activate $\mathrm{KCs}$, possibly via the release of transforming growth factor beta (TGF- $\beta$ ), which activates stellate cells [30, 31]. The activated stellate cells will synthesize and deposit collagen in between hepatic cells, causing hepatic fibrosis, leading to increased liver stiffness and eventually cirrhosis and liver failure. Moreover, chronic inflammation is known to be a risk factor 
for the development of cancer. Indeed, patients with cirrhosis have an increased incidence of hepatocellular carcinoma [32, 33].

Both inflammation and steatosis have been reported to induce IR in several ways [34], making NASH also an important factor contributing to the development of type 2 diabetes.

\section{Clinical outline and epidemiology of NASH}

NASH closely resembles alcoholic steatohepatitis (ASH), a condition caused by excessive alcohol consumption. Given their histological similarity, it is believed that the pathogenesis of ASH and NASH have common mechanisms [29].

The major histological hallmarks of NASH include micro- and macrovesicular steatosis, infiltration of inflammatory cells and hepatocyte ballooning mostly in zone 3, with or without the presence of deposition of collagen strands (fibrosis) [35]. Ballooning of hepatocytes is a form of liver cell injury that may result from intracellular fluid accumulation and other toxic cell damage, characterized by swelling of hepatocytes displaying pale to clear cytoplasm $[35,36]$. Collagen deposition can progress from periportal expansion to septal fibrosis to complete cirrhotic remodeling of the liver [37]. Additionally, other abnormalities may be present, such as hepatocellular glycogenated nuclei (mostly in zone 1), Mallory bodies and megamitochondria in the hepatocytes. Glycogenated nuclei appear to be somewhat bigger in size and are vacuolated [36]. Mallory bodies contain Mallory hyaline, which are abnormal cytokeratins, usually associated with components of the proteosomal degradative pathway, like ubiquitin and p62. They can be identified as intracytoplasmatic inclusions within hepatocytes. Megamitochondria or giant mitochondria are thought to reflect injury or adaptive changes of the mitochondria [36]. NAFLD is perhaps the most common of all liver disorders [35] as it affects $10 \%$ to 24 $\%$ of the population in various countries, while NASH is estimated to be found only in $2 \%$ to $3 \%[38,39]$. Why simple steatosis progresses to NASH in some, but not most, individuals with NAFLD remains currently unclear.

\section{Diagnosis of NASH}

Most patients with the diagnosis of NAFLD are asymptomatic [38]. Of those who do have symptoms, fatigue, malaise and right upper quadrant discomfort are the most common complaints [1]. Only a few obesity-independent circulating markers for NAFLD and NASH are reported [40]. Elevated levels of liver enzymes may be a 
marker of liver damage, but this may not be exclusive as a fraction of patients with fatty livers were found to have normal liver enzyme levels [1, 41].

Several non-invasive imaging techniques are frequently performed to diagnose lipid accumulation in the liver. Among these, ultrasound is the least costly and least invasive one. A more sensitive, but also more expensive way to determine steatosis is magnetic resonance imaging (MRI). However, both approaches have the major shortcoming that they cannot distinguish benign steatosis from steatohepatitis, nor can they estimate inflammation severity, degree of fibrosis, or stage of disease [1].

The golden standard for the diagnosis of NASH is a liver biopsy. A histological assessment is performed and the severity of the disease is classified into several classes and stages, thereby correlating certain histological features with long term prognosis. Class 1 constitutes simple steatosis, class 2 is steatosis with lobular inflammation, class 3 requires the additional presence of ballooned hepatocytes, and class 4 requires the presence of either Mallory's hyaline or fibrosis. To specifically estimate fibrosis severity, staging (stage 1 to 4) of liver biopsies is also performed [35]. However, taking liver biopsies also has several drawbacks. First, this procedure is invasive and does not allow for repetitive sampling. Second, the location from which the biopsy is taken within the liver is critical because parenchymal injury and fibrosis vary in different regions of the liver $[36,42]$, which may lead to false diagnosis.

Additional knowledge of the development of NASH is needed to discover good diagnostic markers and to determine risk factors to identify patients in need of invasive sampling.

\section{Pathogenesis of NASH}

A currently popular hypothesis of NASH development was proposed by Day and James in 1998 [43]. They proposed that NASH develops following a sequence of events or 'hits', constituting the 'two-hit hypothesis' (Fig. 2). According to this hypothesis, NASH development requires a double hit, of which the '1st hit' leads to steatosis [20,43]. At this stage, liver disease is thought to be relatively benign and reversible. This first hit is thought to sensitize the liver, making it more prone for additional insults, collectively termed ' 2 nd hit'. The second hit represents all factors that promote inflammation in the liver and subsequent fibrosis [20, 43]. In this manner, the normal liver can progress towards steatosis and even further to damaging NASH, which may lead to further liver injury, like fibrosis. 


\section{First hit in NASH: lipid metabolism}

The liver contributes to whole body glucose, TG, fatty acid (FA) and cholesterol homeostasis in concert with other organs (Fig. 3). It is the central organ in TG metabolism through the uptake, oxidation and synthesis of FAs, TG synthesis and their subsequent incorporation in very low density lipoprotein (VLDL) particles for secretion. Moreover, the liver is involved in cholesterol metabolism via de novo synthesis, uptake (in the form of VLDL and low density lipoprotein (LDL) remnants) and excretion (in the form of VLDL particles) of cholesterol. The liver also disposes cholesterol in the form of bile via the biliary system. Additionally, the liver can synthesize and oxidize glucose, as well as converting it into FAs for further oxidation or storage. In normal conditions, during the fed state, TG-rich lipoproteins (chylomicrons (CM) and VLDL) circulate the body and TGs are hydrolyzed by lipoprotein lipase $(\mathrm{LpL})$ in peripheral tissues, like adipose and muscle tissue and the heart [44, 45]. LpL is stimulated by insulin in adipose tissue [46] and by exercise [47]. In this manner, peripheral tissues take up FAs which are subsequently either oxidized (mainly in muscle and heart tissue) or esterified to form TGs for storage (mainly in adipose tissue). After TG hydrolysis, lipoproteins become more dense and cholesterolrich, and they develop into CM-remnants and LDL, which can be taken up by the liver, mainly via the LDL receptor (LDLR) [48, 49]. In the fasting state, stored TGs from the adipose tissue are hydrolyzed by hormone sensitive lipase (HSL) [50]. HSL is inhibited by insulin, making its activity low in the fed state and increased in the fasting state. In this way, insulin thus regulates the need of storage or hydrolysis of FAs in adipose tissue. Most of the resulting FAs will enter the circulation and are then redistributed to peripheral organs, especially towards muscle and heart tissue. When the amount of available FAs is bigger than the demand in the peripheral tissue, e.g. in resting conditions, excess FAs are taken up by the liver, where they can either be oxidized or re-esterified to TGs [44].

Clearly, any disturbance in this continuous cycling of lipids throughout the body may lead to excessive lipid accumulation in the liver. The liver can accumulate lipids by both intra- and extrahepatic mechanisms (Fig. 2 and Fig. 3). Several mechanisms are known to induce steatosis, involving increased uptake and production of FAs, and a decreased utilization and efflux of FA from the liver. 


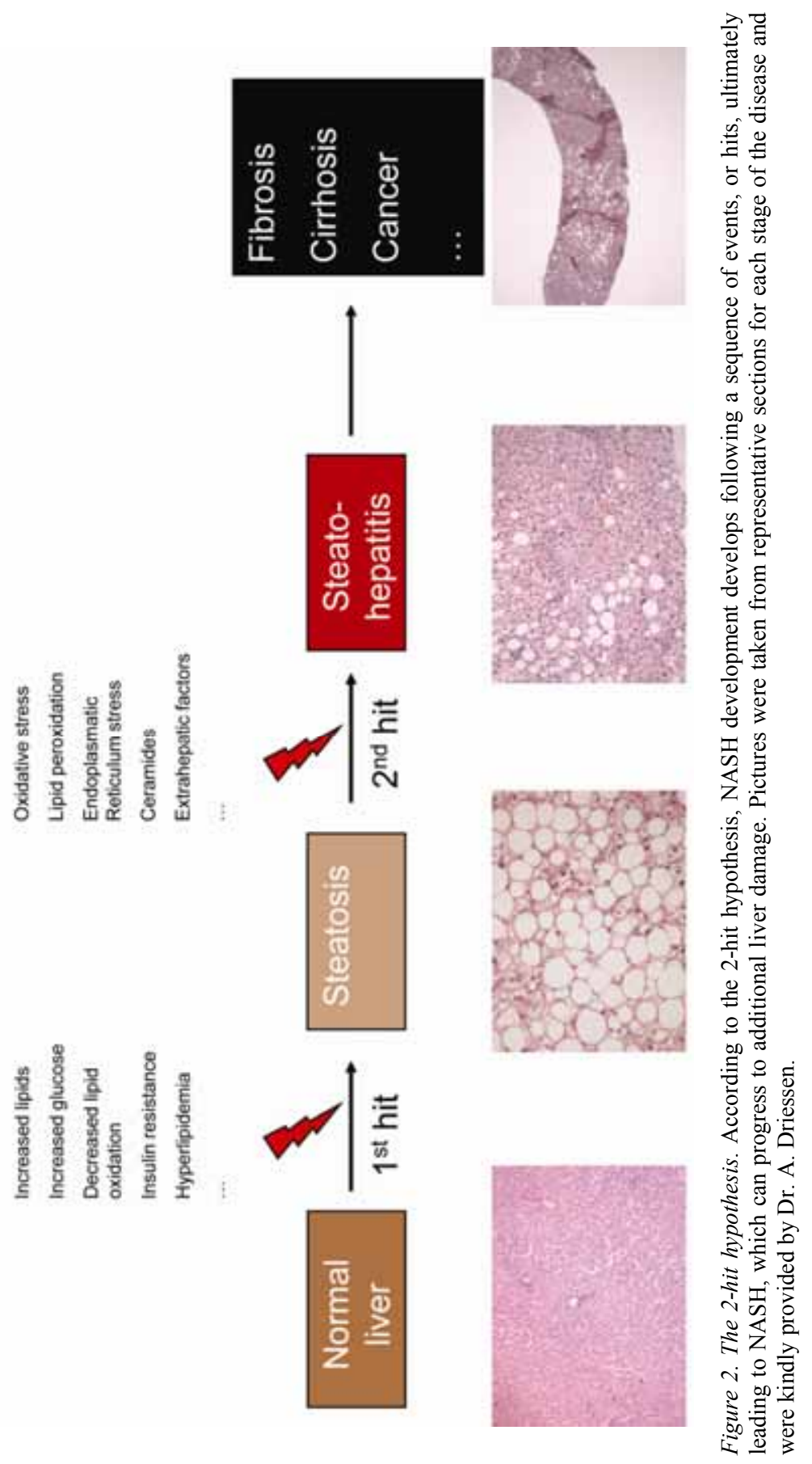




\section{FA uptake}

It has been reported that about $60 \%$ of TG accumulation in the liver is derived from the plasma albumin-bound FA pool. Increased plasma FAs are therefore thought to be the primary contributor to hepatic TG levels [51]. Additionally, increased uptake of CM remnants may also contribute to liver TG levels [52] and hyperlipidemia. More specifically, hypertriglyceridemia has been shown to be associated with higher incidence of steatosis [53]. Major causes of these disturbances are excessive uptake of nutrients, leading to increased depots of TGs in the adipose tissue and plasma on the one hand, and the lack of physical exercise, limiting utilization of FAs, on the other hand [51]. The uptake of lipids by the liver can be altered by for example the increased expression levels of FA transporters by the liver, like CD36 [54]. Additionally, IR has been proposed to contribute to hepatic FA uptake as it can increase lipolysis of adipose tissue TGs and reduce LpL activity [46]. Increased adipose tissue lipolysis may lead to an amplified FA flux to the liver while the decreased LpL-mediated TG hydrolysis in CMs and VLDL could lead to the hepatic uptake of TG-enriched lipoproteins [55].

\section{FA $\beta$-oxidation}

A reduction of hepatic FA oxidation may originate from mitochondrial dysfunction, causing a decreased number of FAs entering oxidation pathways or by increased levels of malonyl-CoA. The latter is the major inhibitor of carnitine acyl-carnitine translocase 1 (cpt1), a key enzyme for import of FAs into the mitochondria for oxidation [56].

\section{FA synthesis}

Increased de novo production of FAs and subsequent esterification into TGs can lead to increased hepatic lipid levels and may result from an increased activity of lipogenic enzymes in the liver. There may be an increased lipogenesis in the IR state as increased insulin levels can stimulate the transcription factor sterol regulatory element-binding protein 1c (SREBP-1c), leading to increased transcription of lipogenic genes. Alternatively, increased plasma glucose levels may also contribute to increased lipogenesis by stimulating the transcription factor Carbohydrate response element binding protein (ChREBP) [57], which induces lipogenic gene expression.

\section{FA efflux}

FA efflux from the liver can be decreased via impaired VLDL synthesis or transport, e.g. by reduced hepatic production of Apolipoprotein B, which is necessary for the packaging of TGs into VLDL [1,44]. Moreover, IR can influence lipid efflux from the liver as insulin can target apolipoprotein B (ApoB) for translational degradation. As 
ApoB is necessary for VLDL assembly, increased insulin levels may decrease TG efflux from the liver in this manner [55].

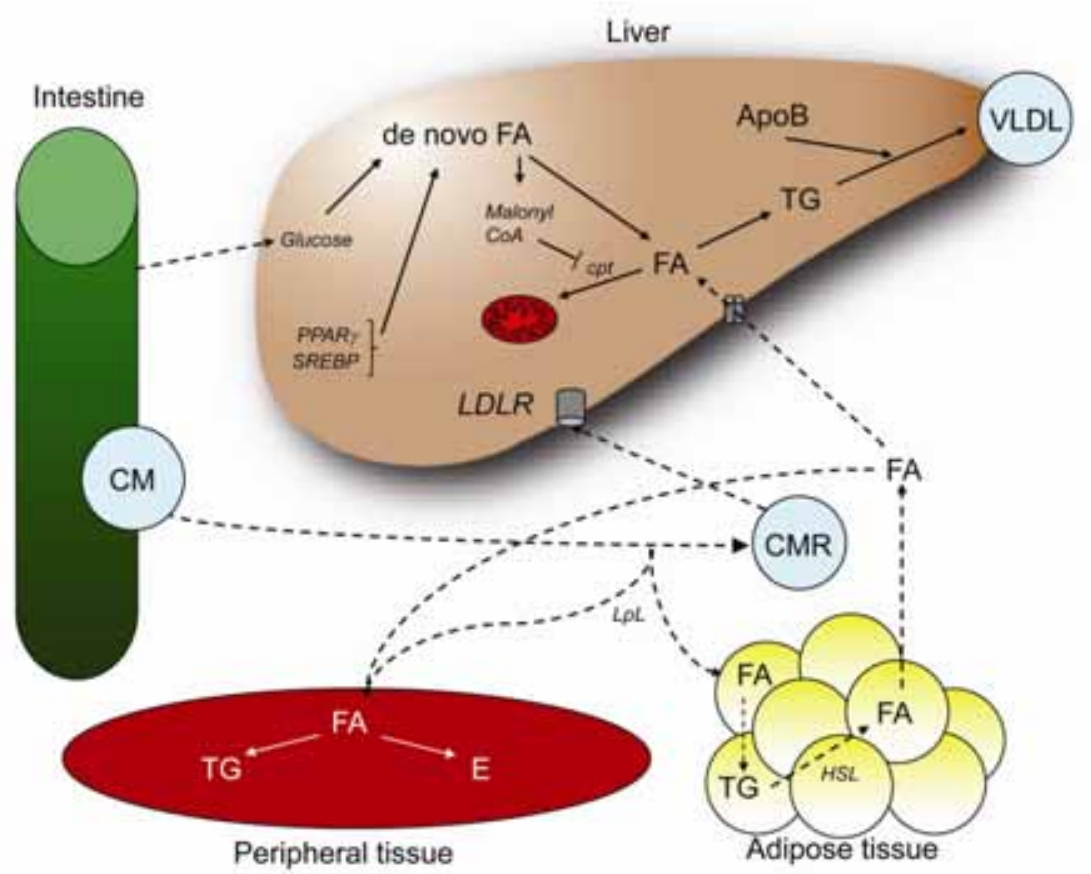

Figure 3. Mechanisms contributing to hepatic accumulation. This figure summarizes hepatic lipid metabolism as described in the text. Dashed arrows indicate extrahepatic mechanisms that can influence liver lipid content and full arrows indicate intrahepatic mechanisms that may contribute to hepatic steatosis development.

\section{Mechanisms during the second hit towards hepatic inflammation}

Several mechanisms have been described to occur during the transition from benign steatosis to NASH and may therefore contribute to inflammation development. These include oxidative stress/lipid peroxidation, endoplasmatic reticulum (ER) stress, increased intrahepatic ceramide levels, membrane integrity, and extrahepatic risk factors such as increased plasma FA and cytokine levels (Fig. 2). These factors may all contribute significantly to hepatic inflammation and are responsible for the selfsustainability of the inflammatory response. However, the actual trigger that determines why inflammation develops remains to be determined. 


\section{Oxidative stress and lipid peroxidation}

Increased lipid loads have been shown to have a critical role in causing oxidative stress during NASH progression [58]. Even in the basal, fat-free state, hepatocytes produce large amounts of reactive oxygen species (ROS). These ROS are formed at different sites, including mitochondrial cytochrome P450 2E1 (CYP2E1) and the mitochondrial respiratory chain [59]. Liver ROS formation is increased in fatty livers due to the increased $\beta$-oxidation rate of FAs in fatty livers [60]. ROS can directly damage mitochondrial DNA and proteins, leading to further mitochondrial injury which can lead to a further increase in ROS formation and to cell death. Moreover, ROS can cause nuclear factor kappa B (NF-kB) activation, which directly leads to increased inflammatory signaling.

Next to their direct role in NF- $\mathrm{\kappa B}$ activation, ROS can attack polyunsaturated FAs and thereby initiate lipid peroxidation in the cell [61], resulting in the formation of aldehyde by-products such as trans-4-hydroxy-2-noneal (HNE) and malondialdehyde (MDA). These molecules have longer half-lifes than ROS and can have deleterious effects on cellular function. Additionally, they can deplete the natural antioxidant glutathione, increase the production of the pro-inflammatory cytokine tumor necrosis factor (TNF), promote the influx of inflammatory cells and activate stellate cells [57]. All of these mechanisms can directly induce apoptosis, necrosis, inflammation and fibrosis: all of the histologic hallmarks of NASH.

\section{Endoplasmatic reticulum stress}

The ER is a network of membranes in the cell in which proteins are assembled into their tertiary and quaternary structures. When a protein is misfolded or remains unfolded, it is normally removed from the ER and targeted for degradation by the $26 \mathrm{~S}$ proteasome pathway [62]. When excess unfolded proteins accumulate, the ER activates a complex response system which is known as the unfolded protein response (UPR). The UPR is mediated mainly through 3 molecules that act as ER stress sensors: inositol-requiring enzyme 1 (IRE-1), PKR-like endoplasmatic reticulum kinase (PERK) and activating transcription factor 6 (ATF6) [63, 64]. Two pro-inflammatory pathways are linked to IRE-1 and PERK activity during ER-stress, i.e. activating

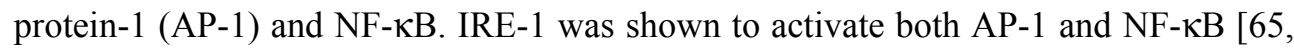
66] and PERK activation was shown to activate the NF-אB pathway [67]. Several conditions linked to obesity have been postulated to trigger ER stress in the liver, among which lipid accumulation [68-70]. Additionally, existing inflammatory mediators may initiate ER stress [71] and thereby intensify an existing inflammatory response. Moreover, the ER is a major source of ROS in the cell [72]. Taken together, 
ER stress may be viewed as a major contributor in the initiation of an inflammatory response.

\section{Ceramides}

Ceramide is generated as a by-product of sphingomyelin hydrolysis via the action of sphingomyelinase, by de novo pathways involving ceramide synthase, by the breakdown of complex glycosphingolipids, or by the conversion of other sphingolipid molecules such as sphingosine [73]. Ceramide content can be increased in the steatotic liver. Besides the well known ability of ceramides to induce cell death [74], these compounds can initiate signaling pathways that lead to the activation of both C-Jun Nterminal kinase (JNK) and IкB kinase beta $(\mathrm{IKK} \beta)$ [73].

\section{Membrane integrity}

It has been postulated that alterations in membrane integrity can lead to hepatic inflammation. Phosphatidylcholine (PC) and phosphatidylethanolamine (PE) are major phospholipids in mammalian membranes. The $\mathrm{PC} / \mathrm{PE}$ ratio has been shown to influence membrane integrity and reductions in $\mathrm{PC} / \mathrm{PE}$ ratio increased hepatic inflammation in mice. Moreover, $\mathrm{PC} / \mathrm{PE}$ ratio was found to be altered in many patients with NASH [75].

\section{Extrahepatic risk factors}

In addition to increasing hepatic FA content, obesity is associated with increases of several cytokines, such as TNF and interleukin 6 (IL6) [76]. Therefore, in obese persons, the liver may be exposed to elevated levels of these cytokines, produced in their adipose tissue, contributing to the development of liver inflammation. Next to these mechanisms, obesity may induce inflammation in the liver directly via its increased FA release in the circulation. FAs have been found to directly activate Tolllike receptor (Tlr) 4 signaling, consequently activating several inflammatory pathways [77], possibly in KCs. Additionally, there have been reports of bacterial overgrowth in the small intestine of NASH patients which may contribute to the development of $\mathrm{NASH}$, perhaps by increasing intestinal permeability and promoting the absorption of endotoxin or other enteric bacterial products [78].

\section{Treatment of NASH}

\section{Targeting the metabolic syndrome}

Given the close relationship between obesity, the MetS and NAFLD, treatment of suspected NASH is mainly aimed to target several parameters of the MetS, such as 
obesity, hyperlipidemia, and IR. Treatment of NASH is an important issue because NASH readily progresses to cirrhosis, leaving no option but liver transplantation. Furthermore, NASH markedly increases the risk of developing liver cancer.

Weight loss undoubtedly and effectively reduces steatosis [79]. However, its effect on the other parameters of NASH, like inflammation and fibrosis, is still unclear [40, 80]. Next to weight loss via a restricted diet and exercise, weight loss via bariatric surgery has been shown to improve NASH in a large subset of severely obese patients [81]. Alternatively, weight loss can be achieved through pharmacotherapy. Recent studies describe the effects of Orlistat (Xenical) and Sibutramine (Meridia) as potential weight-reducing agents. While Orlistat inhibits gastric and pancreatic lipase, thereby reducing fat absorption by about 30\% [82], Sibutramine is a serotonergic and noradrenergic reuptake inhibitor that enhances satiety [83, 84]. Small scale experiments and pilot studies point out that these agents might be useful to treat NASH as in general, liver enzymes in the plasma, hepatic fat, and liver histology were improved [85-87].

To target IR, several insulin-sensitizing agents have been examined for their efficacy in treatment of NASH. Metformin, a insulin-sensitizing agent, was shown to improve both histological and biochemical features in a mouse model of NASH [88], and in human studies $[89,90]$. Additionally, several known insulin-sensitizers are agonists for the nuclear receptor peroxisome proliferator activated receptor gamma (PPAR $\gamma$ ), like thiazolidinediones (TZDs). TZDs bind and activate PPAR $\gamma$. Despite the fact that PPAR $\gamma$ activation promotes adipogenesis and FA storage, they exert their therapeutic effects by reducing IR at adipose tissue, muscle and liver levels. TZDs are now widely used for the treatment of type 2 diabetes [91], although some side effects remain to be considered, such as fluid retention, edema, and increased risk of heart failure [92, 93]. Treatment of NASH patients with a TZD, pioglitazone, has been recently reported to improve steatosis [94, 95], hepatic inflammation and necrosis [94]. The use of another nuclear receptor as a therapeutic target, i.e. PPAR $\alpha$, will be discussed in more detail in the next section.

\section{PPAR $\alpha$ and NASH}

PPARs are transcriptional regulators involved in lipid metabolism whose natural ligands consist of FAs and their derivative. PPARs are therefore considered to be FA sensors [96]. There are three PPAR isoforms, i.e. PPAR $\alpha$, PPAR $\gamma$ (discussed above), and PPAR $\beta / \delta$. PPARs play important roles in the control of lipid and glucose metabolism and have been implicated in the described metabolic diseases related to 
obesity. PPAR $\alpha$ is most highly expressed in the liver and is especially known for its central role in systemic and hepatic lipid metabolism and inflammation.

PPAR $\alpha$ is a ligand-activated transcription factor that can stimulate the gene transcription by binding to specific peroxisome proliferator response elements (PPREs) in the promoter regions of target genes. There are numerous target genes of PPAR $\alpha$, but most of these are involved lipid uptake and oxidative breakdown [97, 98]. Activation of PPAR $\alpha$ by increased FAs thus results in their increased oxidation [99], thereby preventing lipid activation. Under physiological conditions, the function of PPAR $\alpha$ is mainly evoked during fasting, which is associated with increased hepatic PPAR $\alpha$ activation and mRNA transcription, due to increased plasma FA levels released from the adipose tissue, to supply substrates that can be metabolized by other tissue [100]. Next to the up-regulation of specific target genes, PPAR $\alpha$ can inhibit gene transcription by interacting and interference with other transcription factors. In this manner, PPAR $\alpha$ is known to bind and inhibit NF- $\mathrm{KB}$ and AP-1, thereby reducing the inflammatory response. Therefore, PPAR $\alpha$ is a promising target for therapeutical strategies against NASH development.

A class of synthetic PPAR $\alpha$ agonists, fibrates, has been used for several years, mainly to control hyperlipidemia [101]. Fibrates were shown to decrease plasma TGs, increase plasma HDL levels, and decrease levels of the pro-atherogenic small dense LDL in human subjects [102]. The use of synthetic PPAR $\alpha$ agonists has not yet been tested for the efficacy towards the development of NASH in human subjects, despite reports of beneficial results in mice. In mice, PPAR $\alpha$ activation has been reported to prevent and even reverse NASH in a dietary mouse model $[103,104]$. Additionally, steatosis can be ameliorated by polyunsaturated FAs, at least in part through the activation of PPAR $\alpha$ [105].

However, mice are no men, and notable differences between these two species have to be appreciated. It has been shown that humans only express $5 \%$ to $10 \%$ of the amount of PPAR $\alpha$ in their livers compared to mice [106], making their liver less responsive to PPAR $\alpha$ ligands, but still enough to influence plasma TG levels. A possible contribution of PPAR $\alpha$ to liver lipids remains to be addressed.

\section{Mouse models of NASH}

Due to ethical issues and practical difficulties, e.g. in diagnosis, of human subjects, animal models are crucial to elucidate the mechanisms causing NASH. Mostly, the model of choice is the mouse, as it has several advantages over other animals. These advantages include large litter size, easy handling and short generation span. 
Additionally, mice are commonly used to investigate the function of specific genes in disease by transgenesis and gene-targeting [107].

Until now, the best characterized and most known models for NASH are mice deficient for leptin $(\mathrm{Ob} / \mathrm{Ob})$ or mice fed a diet deficient in methionine and choline (MCD) [108], which will be briefly discussed below. The mice used in the studies described in this thesis are fed a diet resembling the one that is consumed by humans in industrialized countries, containing increased levels of TGs, carbohydrates and cholesterol.

\section{$\mathrm{Ob} / \mathrm{Ob}$ mice}

$\mathrm{The} \mathrm{Ob} / \mathrm{Ob}$ mouse carries a spontaneous genetic defect and was first described in 1950 [109]. These animals carry an autosomal recessive mutation in the leptin gene and are hyperphagic, inactive, obese and highly insulin resistant. Leptin is normally produced and secreted by white adipose tissue and acts in the brain to induce satiety. Normally, it drives a neuroendocrine response to starvation: as adipose tissue is depleted, leptin levels fall, which drives a desire to seek food [110]. Additionally, leptin can influence several other physiological processes, among which the inflammatory response [111]. Leptin deficient $\mathrm{Ob} / \mathrm{Ob}$ mice remain thus in a continuous state of physiological starvation and hypothermia, which drives these animals to overeat.

$\mathrm{Ob} / \mathrm{Ob}$ mice develop severe steatosis but fail to develop spontaneous hepatic inflammation. An inflammatory response can only develop by administrating these animals a second hit. This second hit can include a small dose of LPS that is insufficient to induce inflammation in wild-type animals, or via ethanol exposure or ischemia-reperfusion injury [112-114]. These observations are in line with the two-hit hypothesis and may confirm that steatosis sensitizes the liver for further injury [108]. This animal model has several disadvantages. First, $\mathrm{Ob} / \mathrm{Ob}$ mice fail to develop hepatic inflammation spontaneously, unlike humans. Second, mutation of the leptin gene is not common in human obese NASH patients and leptin levels were shown to correlate very poorly with the development of NASH [115]. Third, due to the many functions known to be attributed to leptin, this mouse represents a complex model of obesity-related steatosis as both lipid and glucose metabolism, as well as immunity are disturbed in several manners [108].

\section{Mice fed a methionine/ choline deficient diet}

Both choline and methionine are essential nutrients. The MCD diet leads to an impaired synthesis of phosphatidylcholine, which is an essential part of the outer phospholipid component of lipoproteins, leading to reduced secretion of liver TGs as 
VLDL, resulting in accumulation of liver TGs [116, 117]. Additionally, it was shown that MCD diet impairs mitochondrial $\beta$-oxidation [118]. Both these processes lead to steatosis development [118]. Moreover, choline deficiency has been shown to deplete hepatic anti-oxidant defences, thereby inducing hepatic inflammation via an increase in oxidative stress [119].

MCD fed mice display all the hallmarks of late-stage NASH, from steatosis to inflammation and fibrosis development and are probably the best-established and most widely used mouse model to study NASH development [108]. However, MCD fed animals tend to lose weight (up to 50\%), and display lowered plasma TG levels and cholesterol levels [108, 120]. In this regard, they are very dissimilar from human NASH patients, who are mostly obese and/or hyperlipidemic. Additionally, this mouse model is not overtly insulin resistant, although there are reports indicating these animals might develop hepatic IR only [121].

\section{Hyperlipidemic mice fed a high fat diet}

MetS and steatosis development are associated with high fat feeding and hyperlipidemia [122]. Therefore, there is a need for animal models for NASH that incorporate these features. Feeding hyperlipidemic mice a diet resembling the atherogenic diet frequently consumed in industrialized countries, enriched in carbohydrates, lipids and cholesterol has been shown to induce severe steatosis and hepatic inflammation [123, 124]. Moreover, one of these mouse models, i.e. the low density lipoprotein receptor deficient $\left(\mathrm{ldlr}^{-/-}\right)$mouse, has been shown to develop IR upon high fat feeding [125]. These mouse models are thus of particular interest to study NASH.

Hyperlipidemic mouse models are constructed based on key genes involved in the transport and uptake of dietary lipids in the body. Because lipids are insoluble in water, they are packaged into lipoproteins during their transport throughout the body via the blood. Lipoproteins generally consist of a hydrophobic core composed of cholesterol esters and TGs. This hydrophobic core is surrounded by a monolayer of phospholipids, unesterified cholesterol, and apolipoproteins (Apo). These Apos serve to solubilise and stabilize the lipid content and also have specialized functions in lipoprotein metabolism.

One of the mouse models used in this thesis bears a (human) mutation in the gene encoding ApoE. In the fed state, dietary lipid uptake results in the packaging of TGs and cholesterol together with ApoB48 into CM [126]. Via the lymph, CM reach the circulation, where they acquire ApoE from HDL particles. ApoC-II, also present in $\mathrm{CM}$, activates $\mathrm{LpL}$ present on the vessel wall. $\mathrm{LpL}$ hydrolyzes TGs from the 
lipoproteins to produce FAs, which can be taken up by the peripheral tissues for oxidation or storage (as described above). The resulting CM remnants are depleted in TGs and thus relatively enriched in cholesterol. They are rapidly cleared from the plasma by the liver by uptake via the LDL receptor (Ldlr) [127], which is specific for ApoB ad ApoE, and by the LDLR related protein (Lrp) [128]. Clearly, loss of function in ApoE will undoubtedly lead to an accumulation of these lipoproteins in the plasma, as will be discussed in more detail in chapter 2 .

As was mentioned before, the liver can secrete lipids into the circulation by synthesizing VLDL particles in an ApoB100-dependent manner for the delivery of lipids to peripheral tissues to sustain their energy needs. VLDL contains both TGs and cholesterol taken up from the plasma and from hepatic de novo synthesis. These VLDL particles undergo a similar hydrolysis as CM particles, yielding IDL and LDL. LDL particles contain mostly cholesterol and only ApoB100. Most of LDL is taken up by the liver through binding of ApoB tot the LDLR [129]. The internalized cholesterol is further processed in the liver to either cholesterol esters, bile acids, vitamins or free cholesterol [130]. The LDLR deficient mouse, which is also used in the experiments described in this thesis, is thus not capable of efficiently removing both CM and LDL remnants from the plasma and will also display hyperlipidemia when fed a high fat diet.

Next to the delivery of TGs and cholesterol from the liver towards peripheral organs, cholesterol is transported back to the liver from the periphery in the form of HDL. HDL can take up cholesterol in an ApoA-I dependent manner via the cholesterol transporter ATP binding cassette (Abc) [131]. HDL particles can transfer their cholesterol content to TG-rich lipoproteins by cholesteryl ester transfer protein (CETP) [132] or it can be taken up by the liver [133]. As HDL cholesterol transport is the only manner in which cholesterol is removed from the body it is often referred to as 'good' cholesterol.

The mouse models used in this thesis are genetically modified animals that are commonly used in atherosclerosis research and they rely on mutations in genes critical in whole-body lipoprotein metabolism. Each of these mouse models has specific characteristics as a result of the nature of the introduced mutation and are explained in detail in chapter 2 .

\section{Approaches used in this thesis}

This section will briefly introduce the technique of bone marrow transplantation (BMT) and genomics, which are utilized in several of our studies which are described in this thesis. 


\section{Bone marrow transplantation}

Nowadays, numerous mouse models exist that bear mutations in one of their genes to study the role of this gene product in vivo. To study the role of macrophages (and KCs) specifically, we used mouse models that have mutations specifically in their immune cell population. Since cells from the immune system originate from the bone marrow, BMT was used in several of our experiments. This technique depends on the fact that after maturation in bone marrow and entering the circulation, these cells retain their capacity to repopulate the bone marrow, a process referred to as homing.

Acceptor mice are subjected to a lethal dose of irradiation to eradicate the endogenous bone marrow stem cells. After irradiation, donor bone marrow from donor mice, carrying the desired mutation, are injected in the tail vein of acceptor mice. The donor cells will repopulate the bone marrow of the acceptor animals. After BMT, mice will be allowed to recover for several weeks as the recipient bone marrow cells are gradually replaced [134].

In this manner, murine recipients can be provided with a new and functioning hematopoietic system, making it feasible to study the role of specific genes in immune cells. It has been reported that KCs are replaced in this manner within 14 to 21 days [135]. An additional advantage of this approach is that there is no need to perform complicated and long-lasting crossings and breeding of different strains of mice, which can take up to several years.

\section{Genomics}

The development of microarrays has made it feasible to measure complete transcriptomes [136, 137]. Microarray technology consists of an array with spotted sequences to which labelled RNA samples from different cells or tissues are hybridized. Since the exact location of each spotted sequence is known, measuring the light intensities of the hybridized labels to the arrays shows how much RNA from a particular gene has hybridized with the complementary sequence on the array. The Affymetrix GeneChip ${ }^{\circledR}$ arrays used in this thesis are single color oligonucleotide arrays. Compared to cDNA arrays, these arrays bear oligonucleotide sequences of 25 basepairs instead of complete cDNA sequences. These oligos are much smaller than complete strands of cDNA and allow for a higher density of the array. The Affymetrix GeneChip $^{\circledR}$ arrays used in this thesis contain sets of oligos representing 29000 different transcripts. In single colour arrays, each expression profile is generated on a different chip using a single fluorescent label and scanned, after which different images are compared. In dual color arrays, two different RNA samples are labeled separately 
with different fluorescent tags and then hybridized to a single array, yielding an image representing up- and down-regulated genes between these two samples only. In general, Affymetrix GeneChip ${ }^{\circledR}$ arrays use 11 to 16 probes of 25 bp to represent each transcript. Computer models are used to select these probes based on their specificity and cross-hybridization. For each probe designed, a partner probe is generated that is identical except for one single base mismatch, making it possible to estimate and subtract non-specific cross hybridization [138]. After extraction of RNA, cDNA is generated and transcribed in vitro to generate biotin labelled cRNA. The cRNA is then fragmented and subsequently hybridized to the Affymetrix GeneChip ${ }^{\circledR}$ arrays. Hereafter the chips are washed and stained. Scanning of the chips allows estimating the abundance of each represented mRNA species.

This described technique allows for enormous amounts of knowledge to be gathered about the complete set of genes that are expressed at any given moment in any given organ, and in response to any given treatment. With several bioinformatical tools, biological relevant information is collected which allows increased understanding of how an organism responds to a particular treatment, for example (like in this thesis] a high fat diet. Genes that are found to be differentially expressed can be clustered according to biological function or according to their expression pattern. This clustering allows to identify the pathways responsible for a specific response or to identify genes that are likely to be regulated by shared regulators, due to their equal expression patterns. Moreover, genomics allows tissues to be classified according to their gene expression pattern, for example to identify the developmental stage of cancers. In this thesis, clustering of data was mainly done according to biological function and regulation.

\section{Thesis outline}

The experimental models that are used in this thesis are hyperlipidemic mice. In chapter 2, several hyperlipidemic mouse models are introduced and compared to each other. Since these mice are known models of atherosclerosis, their contribution to this field of research is also evaluated.

The first aim of this thesis is to elucidate mechanisms during the early progression of NASH by using hyperlipidemic mouse models fed a high fat diet as a physiological model for this condition. We specifically focus on the progression from benign steatosis to NASH in chapter 3. This chapter describes the early development of NASH in the APOE2ki mouse, a humanized mouse model of hyperlipidemia, and its prevention by fenofibrate, a PPAR $\alpha$ agonist. 
To further determine which pathways are of specific importance during the early progression of NASH, whole-transcriptome analysis was performed in livers of APOE2ki mice during progression of diet-induced NASH. This is further described in chapter 4.

Currently, the reason why some, but not all, people with steatosis will progress towards NASH remains unclear. Therefore, knowledge of the mechanisms driving inflammation is crucial. Chapter 5 describes dietary cholesterol to be causal in the early inflammation found previously in APOE2ki mice. The results were compared with another hyperlipidemic mouse model, i.e. $1 \mathrm{ldl}^{-/-}$mice, and to the response of normolipidemic control mice.

In Chapter 6, experiments are described that further elucidate the mechanisms by which cholesterol may act as a risk factor for developing NASH. BMT was used to create hyperlipidemic mice with a deficiency in the two major cholesterol scavenging receptors specifically in macrophages, i.e. CD36 and scavenger receptor A1 (SRA-1). As we found inflammation to be an early player during the progression of NASH, the possible contribution of the inflammatory response to development of steatosis was investigated in chapter 7 . Here, we describe the results obtained in hyperlipidemic $\mathrm{LDLR}^{-/-}$mice with hyper-inflammation in their livers with respect to their liver lipid levels.

Finally, chapter 8 will discuss the major findings of this thesis, place them in the current state of the field, and address the clinical implications of the results.

\section{References}

1. Parekh S, Anania FA. Abnormal lipid and glucose metabolism in obesity: implications for nonalcoholic fatty liver disease. Gastroenterology. 2007 May;132(6):2191-207.

2. Sarafidis PA, Nilsson PM. The metabolic syndrome: a glance at its history. J Hypertens. 2006 Apr;24(4):6216.

3. Israili ZH, Lyoussi B, Hernandez-Hernandez R, Velasco M. Metabolic syndrome: treatment of hypertensive patients. Am J Ther. 2007 Jul-Aug;14(4):386-402.

4. Ferrannini E, Haffner SM, Mitchell BD, Stern MP. Hyperinsulinaemia: the key feature of a cardiovascular and metabolic syndrome. Diabetologia. 1991 Jun;34(6):416-22.

5. Tkac I. Metabolic syndrome in relationship to type 2 diabetes and atherosclerosis. Diabetes Res Clin Pract. 2005 Jun;68 Suppl1:S2-9.

6. Koren-Morag N, Goldbourt U, Tanne D. Relation between the metabolic syndrome and ischemic stroke or transient ischemic attack: a prospective cohort study in patients with atherosclerotic cardiovascular disease. Stroke. 2005 Jul;36(7):1366-71.

7. Isomaa B, Almgren P, Tuomi T, Forsen B, Lahti K, Nissen M, et al. Cardiovascular morbidity and mortality associated with the metabolic syndrome. Diabetes Care. 2001 Apr;24(4):683-9.

8. Grundy SM, Cleeman JI, Daniels SR, Donato KA, Eckel RH, Franklin BA, et al. Diagnosis and management of the metabolic syndrome: an American Heart Association/National Heart, Lung, and Blood Institute Scientific Statement. Circulation. 2005 Oct 25;112(17):2735-52.

9. Executive Summary of The Third Report of The National Cholesterol Education Program (NCEP) Expert Panel on Detection, Evaluation, And Treatment of High Blood Cholesterol In Adults (Adult Treatment Panel III). Jama. 2001 May 16;285(19):2486-97. 
10. Gabele E, Brenner DA, Rippe RA. Liver fibrosis: signals leading to the amplification of the fibrogenic hepatic stellate cell. Front Biosci. 2003 Jan 1;8:d69-77.

11. Kolios G, Valatas V, Kouroumalis E. Role of Kupffer cells in the pathogenesis of liver disease. World J Gastroenterol. 2006 Dec 14;12(46):7413-20.

12. Szymanska R, Schmidt-Pospula M. [Studies of liver's reticuloendothelial cells by Tadeusz Browicz and Karl Kupffer. A historical outline]. Arch Hist Med (Warsz). 1979;42(3):331-6.

13. Bouwens L, Baekeland M, De Zanger R, Wisse E. Quantitation, tissue distribution and proliferation kinetics of Kupffer cells in normal rat liver. Hepatology. 1986 Jul-Aug;6(4):718-22.

14. Fox ES, Thomas P, Broitman SA. Comparative studies of endotoxin uptake by isolated rat Kupffer and peritoneal cells. Infect Immun. 1987 Dec;55(12):2962-6.

15. Bilzer M, Roggel F, Gerbes AL. Role of Kupffer cells in host defense and liver disease. Liver Int. 2006 Dec;26(10):1175-86.

16. Naito M, Hasegawa G, Takahashi K. Development, differentiation, and maturation of Kupffer cells. Microsc Res Tech. 1997 Nov 15;39(4):350-64.

17. Terpstra V, van Berkel TJ. Scavenger receptors on liver Kupffer cells mediate the in vivo uptake of oxidatively damaged red blood cells in mice. Blood. 2000 Mar 15;95(6):2157-63.

18. Hamaguchi M, Kojima T, Takeda N, Nakagawa T, Taniguchi H, Fujii K, et al. The metabolic syndrome as a predictor of nonalcoholic fatty liver disease. Ann Intern Med. 2005 Nov 15;143(10):722-8.

19. Kotronen A, Westerbacka J, Bergholm R, Pietilainen KH, Yki-Jarvinen H. Liver fat in the metabolic syndrome. J Clin Endocrinol Metab. 2007 Sep;92(9):3490-7.

20. Angulo P, Lindor KD. Non-alcoholic fatty liver disease. J Gastroenterol Hepatol. 2002 Feb; 17 Suppl:S186-90.

21. Marchesini G, Brizi M, Morselli-Labate AM, Bianchi G, Bugianesi E, McCullough AJ, et al. Association of nonalcoholic fatty liver disease with insulin resistance. Am J Med. 1999 Nov;107(5):450-5.

22. Silverman JF, O'Brien KF, Long S, Leggett N, Khazanie PG, Pories WJ, et al. Liver pathology in morbidly obese patients with and without diabetes. Am J Gastroenterol. 1990 Oct;85(10):1349-55.

23. Nomura H, Kashiwagi S, Hayashi J, Kajiyama W, Tani S, Goto M. Prevalence of fatty liver in a general population of Okinawa, Japan. Jpn J Med. 1988 May;27(2):142-9.

24. Bellentani S, Saccoccio G, Masutti F, Croce LS, Brandi G, Sasso F, et al. Prevalence of and risk factors for hepatic steatosis in Northern Italy. Ann Intern Med. 2000 Jan 18;132(2):112-7.

25. Tominaga K, Kurata JH, Chen YK, Fujimoto E, Miyagawa S, Abe I, et al. Prevalence of fatty liver in Japanese children and relationship to obesity. An epidemiological ultrasonographic survey. Dig Dis Sci. 1995 Sep;40(9):2002-9.

26. Franzese A, Vajro P, Argenziano A, Puzziello A, Iannucci MP, Saviano MC, et al. Liver involvement in obese children. Ultrasonography and liver enzyme levels at diagnosis and during follow-up in an Italian population. Dig Dis Sci. 1997 Jul;42(7):1428-32.

27. Seppala-Lindroos A, Vehkavaara S, Hakkinen AM, Goto T, Westerbacka J, Sovijarvi A, et al. Fat accumulation in the liver is associated with defects in insulin suppression of glucose production and serum free fatty acids independent of obesity in normal men. J Clin Endocrinol Metab. 2002 Jul;87(7):3023-8.

28. Tiikkainen M, Tamminen M, Hakkinen AM, Bergholm R, Vehkavaara S, Halavaara J, et al. Liver-fat accumulation and insulin resistance in obese women with previous gestational diabetes. Obes Res. 2002 Sep;10(9):859-67.

29. Ludwig J, Viggiano TR, McGill DB, Oh BJ. Nonalcoholic steatohepatitis: Mayo Clinic experiences with a hitherto unnamed disease. Mayo Clin Proc. 1980 Jul;55(7):434-8.

30. Fadok VA, Bratton DL, Konowal A, Freed PW, Westcott JY, Henson PM. Macrophages that have ingested apoptotic cells in vitro inhibit proinflammatory cytokine production through autocrine/paracrine mechanisms involving TGF-beta, PGE2, and PAF. J Clin Invest. 1998 Feb 15;101(4):890-8.

31. Leonarduzzi G, Scavazza A, Biasi F, Chiarpotto E, Camandola S, Vogel S, et al. The lipid peroxidation end product 4-hydroxy-2,3-nonenal up-regulates transforming growth factor beta1 expression in the macrophage lineage: a link between oxidative injury and fibrosclerosis. Faseb J. 1997 Sep;11(11):851-7.

32. Marrero JA, Fontana RJ, Su GL, Conjeevaram HS, Emick DM, Lok AS. NAFLD may be a common underlying liver disease in patients with hepatocellular carcinoma in the United States. Hepatology. 2002 Dec;36(6):1349-54.

33. Ratziu V, Bonyhay L, Di Martino V, Charlotte F, Cavallaro L, Sayegh-Tainturier MH, et al. Survival, liver failure, and hepatocellular carcinoma in obesity-related cryptogenic cirrhosis. Hepatology. 2002 Jun;35(6):1485-93.

34. Shoelson SE, Lee J, Goldfine AB. Inflammation and insulin resistance. J Clin Invest. 2006 Jul;116(7):1793801 . 
35. Neuschwander-Tetri BA, Caldwell SH. Nonalcoholic steatohepatitis: summary of an AASLD Single Topic Conference. Hepatology. 2003 May;37(5):1202-19.

36. Yeh MM, Brunt EM. Pathology of nonalcoholic fatty liver disease. Am J Clin Pathol. 2007 Nov;128(5):83747.

37. Brunt EM. Grading and staging the histopathological lesions of chronic hepatitis: the Knodell histology activity index and beyond. Hepatology. $2000 \mathrm{Jan} ; 31(1): 241-6$.

38. Falck-Ytter Y, Younossi ZM, Marchesini G, McCullough AJ. Clinical features and natural history of nonalcoholic steatosis syndromes. Semin Liver Dis. 2001;21(1):17-26.

39. Ruhl CE, Everhart JE. Epidemiology of nonalcoholic fatty liver. Clin Liver Dis. 2004 Aug;8(3):501-19, vii.

40. Kotronen A, Yki-Jarvinen H. Fatty Liver. A Novel Component of the Metabolic Syndrome. Arterioscler Thromb Vasc Biol. 2007 Aug 9.

41. Donati G, Stagni B, Piscaglia F, Venturoli N, Morselli-Labate AM, Rasciti L, et al. Increased prevalence of fatty liver in arterial hypertensive patients with normal liver enzymes: role of insulin resistance. Gut. 2004 Jul;53(7):1020-3.

42. Goldstein NS, Hastah F, Galan MV, Gordon SC. Fibrosis heterogeneity in nonalcoholic steatohepatitis and hepatitis C virus needle core biopsy specimens. Am J Clin Pathol. 2005 Mar;123(3):382-7.

43. Day CP, James OF. Steatohepatitis: a tale of two "hits"? Gastroenterology. 1998 Apr;114(4):842-5.

44. den Boer M, Voshol PJ, Kuipers F, Havekes LM, Romijn JA. Hepatic steatosis: a mediator of the metabolic syndrome. Lessons from animal models. Arterioscler Thromb Vasc Biol. 2004 Apr;24(4):644-9.

45. Farese RV, Jr., Yost TJ, Eckel RH. Tissue-specific regulation of lipoprotein lipase activity by insulin/glucose in normal-weight humans. Metabolism. 1991 Feb;40(2):214-6.

46. Fried SK, Russell CD, Grauso NL, Brolin RE. Lipoprotein lipase regulation by insulin and glucocorticoid in subcutaneous and omental adipose tissues of obese women and men. J Clin Invest. 1993 Nov;92(5):2191-8.

47. Ong JM, Simsolo RB, Saghizadeh M, Goers JW, Kern PA. Effects of exercise training and feeding on lipoprotein lipase gene expression in adipose tissue, heart, and skeletal muscle of the rat. Metabolism. 1995 Dec;44(12):1596-605.

48. Brown MS, Kovanen PT, Goldstein JL. Regulation of plasma cholesterol by lipoprotein receptors. Science. 1981 May 8;212(4495):628-35.

49. Rubinstein A, Gibson JC, Paterniti JR, Jr., Kakis G, Little A, Ginsberg HN, et al. Effect of heparin-induced lipolysis on the distribution of apolipoprotein e among lipoprotein subclasses. Studies with patients deficient in hepatic triglyceride lipase and lipoprotein lipase. J Clin Invest. $1985 \mathrm{Feb}$;75(2):710-21.

50. Holm C, Osterlund T, Laurell H, Contreras JA. Molecular mechanisms regulating hormone-sensitive lipase and lipolysis. Annu Rev Nutr. 2000;20:365-93.

51. Donnelly KL, Smith CI, Schwarzenberg SJ, Jessurun J, Boldt MD, Parks EJ. Sources of fatty acids stored in liver and secreted via lipoproteins in patients with nonalcoholic fatty liver disease. J Clin Invest. 2005 May;115(5):1343-51.

52. Tamura S, Shimomura I. Contribution of adipose tissue and de novo lipogenesis to nonalcoholic fatty liver disease. J Clin Invest. 2005 May;115(5):1139-42.

53. de Bruin TW, Georgieva AM, Brouwers MC, Heitink MV, van der Kallen CJ, van Greevenbroek MM. Radiological evidence of nonalcoholic fatty liver disease in familial combined hyperlipidemia. Am J Med. 2004 Jun 15;116(12):847-9.

54. Koonen DP, Jacobs RL, Febbraio M, Young ME, Soltys CL, Ong H, et al. Increased hepatic CD36 expression contributes to dyslipidemia associated with diet-induced obesity. Diabetes. 2007 Dec;56(12):2863-71.

55. Ginsberg HN. Is the slippery slope from steatosis to steatohepatitis paved with triglyceride or cholesterol? Cell Metab. 2006 Sep;4(3):179-81.

56. McGarry JD, Foster DW. Regulation of hepatic fatty acid oxidation and ketone body production. Annu Rev Biochem. 1980;49:395-420.

57. Browning JD, Horton JD. Molecular mediators of hepatic steatosis and liver injury. J Clin Invest. 2004 Jul;114(2):147-52.

58. Matsuzawa N, Takamura T, Kurita S, Misu H, Ota T, Ando H, et al. Lipid-induced oxidative stress causes steatohepatitis in mice fed an atherogenic diet. Hepatology. 2007 Oct 10.

59. Pessayre D, Fromenty B, Mansouri A. Mitochondrial injury in steatohepatitis. Eur J Gastroenterol Hepatol. 2004 Nov;16(11):1095-105.

60. Miele L, Grieco A, Armuzzi A, Candelli M, Forgione A, Gasbarrini A, et al. Hepatic mitochondrial betaoxidation in patients with nonalcoholic steatohepatitis assessed by $13 \mathrm{C}$-octanoate breath test. Am J Gastroenterol. 2003 Oct;98(10):2335-6. 
61. Esterbauer H, Schaur RJ, Zollner H. Chemistry and biochemistry of 4-hydroxynonenal, malonaldehyde and related aldehydes. Free Radic Biol Med. 1991;11(1):81-128.

62. Schroder M, Kaufman RJ. The mammalian unfolded protein response. Annu Rev Biochem. 2005;74:739-89.

63. Harding HP, Zhang Y, Ron D. Protein translation and folding are coupled by an endoplasmic-reticulumresident kinase. Nature. 1999 Jan 21;397(6716):271-4.

64. Harding HP, Zhang Y, Bertolotti A, Zeng H, Ron D. Perk is essential for translational regulation and cell survival during the unfolded protein response. Mol Cell. 2000 May;5(5):897-904.

65. Urano F, Wang X, Bertolotti A, Zhang Y, Chung P, Harding HP, et al. Coupling of stress in the ER to activation of JNK protein kinases by transmembrane protein kinase IRE1. Science. 2000 Jan 28;287(5453):664-6.

66. Hu P, Han Z, Couvillon AD, Kaufman RJ, Exton JH. Autocrine tumor necrosis factor alpha links endoplasmic reticulum stress to the membrane death receptor pathway through IRE1alpha-mediated NF-kappaB activation and down-regulation of TRAF2 expression. Mol Cell Biol. 2006 Apr;26(8):3071-84.

67. Deng J, Lu PD, Zhang Y, Scheuner D, Kaufman RJ, Sonenberg N, et al. Translational repression mediates activation of nuclear factor kappa B by phosphorylated translation initiation factor 2. Mol Cell Biol. 2004 Dec;24(23):10161-8.

68. Nakatani Y, Kaneto H, Kawamori D, Yoshiuchi K, Hatazaki M, Matsuoka TA, et al. Involvement of endoplasmic reticulum stress in insulin resistance and diabetes. J Biol Chem. 2005 Jan 7;280(1):847-51.

69. Marx J. Cell biology. A stressful situation. Science. 2006 Sep 15;313(5793):1564-6.

70. Ozcan U, Cao Q, Yilmaz E, Lee AH, Iwakoshi NN, Ozdelen E, et al. Endoplasmic reticulum stress links obesity, insulin action, and type 2 diabetes. Science. 2004 Oct 15;306(5695):457-61.

71. Zhang K, Shen X, Wu J, Sakaki K, Saunders T, Rutkowski DT, et al. Endoplasmic reticulum stress activates cleavage of CREBH to induce a systemic inflammatory response. Cell. 2006 Feb 10;124(3):587-99.

72. Xue X, Piao JH, Nakajima A, Sakon-Komazawa S, Kojima Y, Mori K, et al. Tumor necrosis factor alpha (TNFalpha) induces the unfolded protein response (UPR) in a reactive oxygen species (ROS)-dependent fashion, and the UPR counteracts ROS accumulation by TNFalpha. J Biol Chem. 2005 Oct 7;280(40):3391725.

73. Ruvolo PP. Intracellular signal transduction pathways activated by ceramide and its metabolites. Pharmacol Res. 2003 May;47(5):383-92.

74. Summers SA. Ceramides in insulin resistance and lipotoxicity. Prog Lipid Res. 2006 Jan;45(1):42-72.

75. Li Z, Agellon LB, Allen TM, Umeda M, Jewell L, Mason A, et al. The ratio of phosphatidylcholine to phosphatidylethanolamine influences membrane integrity and steatohepatitis. Cell Metab. 2006 May;3(5):321-31.

76. Weisberg SP, McCann D, Desai M, Rosenbaum M, Leibel RL, Ferrante AW, Jr. Obesity is associated with macrophage accumulation in adipose tissue. J Clin Invest. 2003 Dec;112(12):1796-808.

77. Shi H, Kokoeva MV, Inouye K, Tzameli I, Yin H, Flier JS. TLR4 links innate immunity and fatty acidinduced insulin resistance. J Clin Invest. 2006 Nov;116(11):3015-25.

78. Wigg AJ, Roberts-Thomson IC, Dymock RB, McCarthy PJ, Grose RH, Cummins AG. The role of small intestinal bacterial overgrowth, intestinal permeability, endotoxaemia, and tumour necrosis factor alpha in the pathogenesis of non-alcoholic steatohepatitis. Gut. 2001 Feb;48(2):206-11.

79. Luyckx FH, Lefebvre PJ, Scheen AJ. Non-alcoholic steatohepatitis: association with obesity and insulin resistance, and influence of weight loss. Diabetes Metab. 2000 Apr;26(2):98-106.

80. Ueno T, Sugawara H, Sujaku K, Hashimoto O, Tsuji R, Tamaki S, et al. Therapeutic effects of restricted diet and exercise in obese patients with fatty liver. J Hepatol. 1997 Jul;27(1):103-7.

81. Dixon JB, Bhathal PS, Hughes NR, O'Brien PE. Nonalcoholic fatty liver disease: Improvement in liver histological analysis with weight loss. Hepatology. 2004 Jun;39(6):1647-54.

82. Foxcroft DR, Milne R. Orlistat for the treatment of obesity: rapid review and cost-effectiveness model. Obes Rev. 2000 Oct;1(2):121-6.

83. McMahon FG, Fujioka K, Singh BN, Mendel CM, Rowe E, Rolston K, et al. Efficacy and safety of sibutramine in obese white and African American patients with hypertension: a 1-year, double-blind, placebocontrolled, multicenter trial. Arch Intern Med. 2000 Jul 24;160(14):2185-91.

84. Bray GA, Blackburn GL, Ferguson JM, Greenway FL, Jain AK, Mendel CM, et al. Sibutramine produces dose-related weight loss. Obes Res. 1999 Mar;7(2):189-98.

85. Harrison SA, Fincke C, Helinski D, Torgerson S, Hayashi P. A pilot study of orlistat treatment in obese, nonalcoholic steatohepatitis patients. Aliment Pharmacol Ther. 2004 Sep 15;20(6):623-8.

86. Harrison SA, Ramrakhiani S, Brunt EM, Anbari MA, Cortese C, Bacon BR. Orlistat in the treatment of NASH: a case series. Am J Gastroenterol. 2003 Apr;98(4):926-30. 
87. Sabuncu T, Nazligul Y, Karaoglanoglu M, Ucar E, Kilic FB. The effects of sibutramine and orlistat on the ultrasonographic findings, insulin resistance and liver enzyme levels in obese patients with non-alcoholic steatohepatitis. Rom J Gastroenterol. 2003 Sep;12(3):189-92.

88. Lin HZ, Yang SQ, Chuckaree C, Kuhajda F, Ronnet G, Diehl AM. Metformin reverses fatty liver disease in obese, leptin-deficient mice. Nat Med. 2000 Sep;6(9):998-1003.

89. Uygun A, Kadayifci A, Isik AT, Ozgurtas T, Deveci S, Tuzun A, et al. Metformin in the treatment of patients with non-alcoholic steatohepatitis. Aliment Pharmacol Ther. 2004 Mar 1;19(5):537-44.

90. Marchesini G, Brizi M, Bianchi G, Tomassetti S, Zoli M, Melchionda N. Metformin in non-alcoholic steatohepatitis. Lancet. 2001 Sep 15;358(9285):893-4.

91. Serfaty L. Pioglitazone: the beginning of a new era for NASH? J Hepatol. 2007 Jul;47(1):160-2.

92. Rubenstrunk A, Hanf R, Hum DW, Fruchart JC, Staels B. Safety issues and prospects for future generations of PPAR modulators. Biochim Biophys Acta. 2007 Aug;1771(8):1065-81.

93. Heikkinen S, Auwerx J, Argmann CA. PPARgamma in human and mouse physiology. Biochim Biophys Acta. 2007 Aug;1771(8):999-1013.

94. Belfort R, Harrison SA, Brown K, Darland C, Finch J, Hardies J, et al. A placebo-controlled trial of pioglitazone in subjects with nonalcoholic steatohepatitis. N Engl J Med. 2006 Nov 30;355(22):2297-307.

95. Juurinen L, Kotronen A, Graner M, Yki-Jarvinen H. Rosiglitazone Reduces Liver Fat and Insulin Requirements While Improving Hepatic Insulin Sensitivity And Glycemic Control In Patients With Type 2 Diabetes Requiring High Insulin Doses. J Clin Endocrinol Metab. 2007 Oct 23.

96. Willson TM, Brown PJ, Sternbach DD, Henke BR. The PPARs: from orphan receptors to drug discovery. J Med Chem. 2000 Feb 24;43(4):527-50.

97. Duval C, Muller M, Kersten S. PPARalpha and dyslipidemia. Biochim Biophys Acta. 2007 Aug;1771(8):96171.

98. Zandbergen F, Plutzky J. PPARalpha in atherosclerosis and inflammation. Biochim Biophys Acta. 2007 Aug;1771(8):972-82.

99. Patsouris D, Reddy JK, Muller M, Kersten S. Peroxisome proliferator-activated receptor alpha mediates the effects of high-fat diet on hepatic gene expression. Endocrinology. 2006 Mar;147(3):1508-16.

100.Kersten S, Seydoux J, Peters JM, Gonzalez FJ, Desvergne B, Wahli W. Peroxisome proliferator-activated receptor alpha mediates the adaptive response to fasting. J Clin Invest. 1999 Jun;103(11):1489-98.

101. Tenenbaum A, Fisman EZ, Motro M, Adler Y. Atherogenic dyslipidemia in metabolic syndrome and type 2 diabetes: therapeutic options beyond statins. Cardiovasc Diabetol. 2006;5:20.

102. Staels B, Dallongeville J, Auwerx J, Schoonjans K, Leitersdorf E, Fruchart JC. Mechanism of action of fibrates on lipid and lipoprotein metabolism. Circulation. 1998 Nov 10;98(19):2088-93.

103.Ip E, Farrell GC, Robertson G, Hall P, Kirsch R, Leclercq I. Central role of PPARalpha-dependent hepatic lipid turnover in dietary steatohepatitis in mice. Hepatology. $2003 \mathrm{Jul} ; 38(1): 123-32$.

104.Ip E, Farrell G, Hall P, Robertson G, Leclercq I. Administration of the potent PPARalpha agonist, Wy-14,643, reverses nutritional fibrosis and steatohepatitis in mice. Hepatology. 2004 May;39(5):1286-96.

105. Sekiya M, Yahagi N, Matsuzaka T, Najima Y, Nakakuki M, Nagai R, et al. Polyunsaturated fatty acids ameliorate hepatic steatosis in obese mice by SREBP-1 suppression. Hepatology. 2003 Dec;38(6):1529-39.

106. Holden PR, Tugwood JD. Peroxisome proliferator-activated receptor alpha: role in rodent liver cancer and species differences. J Mol Endocrinol. 1999 Feb;22(1):1-8.

107.Wouters K, Shiri-Sverdlov R, van Gorp PJ, van Bilsen M, Hofker MH. Understanding hyperlipidemia and atherosclerosis: lessons from genetically modified apoe and ldlr mice. Clin Chem Lab Med. 2005;43(5):470-9.

108.Anstee QM, Goldin RD. Mouse models in non-alcoholic fatty liver disease and steatohepatitis research. Int J Exp Pathol. 2006 Feb;87(1):1-16.

109. Ingalls AM, Dickie MM, Snell GD. Obese, a new mutation in the house mouse. J Hered. 1950 Dec;41(12):317-8.

110. Ahima RS, Saper CB, Flier JS, Elmquist JK. Leptin regulation of neuroendocrine systems. Front Neuroendocrinol. 2000 Jul;21(3):263-307.

111.Fantuzzi G, Faggioni R. Leptin in the regulation of immunity, inflammation, and hematopoiesis. J Leukoc Biol. 2000 Oct;68(4):437-46.

112.Faggioni R, Fantuzzi G, Gabay C, Moser A, Dinarello CA, Feingold KR, et al. Leptin deficiency enhances sensitivity to endotoxin-induced lethality. Am J Physiol. 1999 Jan;276(1 Pt 2):R136-42.

113. Yang SQ, Lin HZ, Lane MD, Clemens M, Diehl AM. Obesity increases sensitivity to endotoxin liver injury: implications for the pathogenesis of steatohepatitis. Proc Natl Acad Sci U S A. 1997 Mar 18;94(6):2557-62.

114.Koteish A, Diehl AM. Animal models of steatosis. Semin Liver Dis. 2001;21(1):89-104. 
115.Chalasani N, Crabb DW, Cummings OW, Kwo PY, Asghar A, Pandya PK, et al. Does leptin play a role in the pathogenesis of human nonalcoholic steatohepatitis? Am J Gastroenterol. 2003 Dec;98(12):2771-6.

116.Yao ZM, Vance DE. The active synthesis of phosphatidylcholine is required for very low density lipoprotein secretion from rat hepatocytes. J Biol Chem. 1988 Feb 25;263(6):2998-3004.

117.Raubenheimer PJ, Nyirenda MJ, Walker BR. A choline-deficient diet exacerbates fatty liver but attenuates insulin resistance and glucose intolerance in mice fed a high-fat diet. Diabetes. 2006 Jul;55(7):2015-20.

118.Weltman MD, Farrell GC, Hall P, Ingelman-Sundberg M, Liddle C. Hepatic cytochrome P450 $2 \mathrm{E} 1$ is increased in patients with nonalcoholic steatohepatitis. Hepatology. 1998 Jan;27(1):128-33.

119.Hensley K, Kotake Y, Sang H, Pye QN, Wallis GL, Kolker LM, et al. Dietary choline restriction causes complex I dysfunction and increased $\mathrm{H}(2) \mathrm{O}(2)$ generation in liver mitochondria. Carcinogenesis. 2000 May;21(5):983-9.

120.London RM, George J. Pathogenesis of NASH: animal models. Clin Liver Dis. 2007 Feb;11(1):55-74, viii.

121.Rinella ME, Green RM. The methionine-choline deficient dietary model of steatohepatitis does not exhibit insulin resistance. J Hepatol. 2004 Jan;40(1):47-51.

122.Ludwig J, McGill DB, Lindor KD. Review: nonalcoholic steatohepatitis. J Gastroenterol Hepatol. 1997 May;12(5):398-403.

123. Yoshimatsu M, Terasaki Y, Sakashita N, Kiyota E, Sato H, van der Laan LJ, et al. Induction of macrophage scavenger receptor MARCO in nonalcoholic steatohepatitis indicates possible involvement of endotoxin in its pathogenic process. Int J Exp Pathol. 2004 Dec;85(6):335-43.

124.Tous M, Ferre N, Camps J, Riu F, Joven J. Feeding apolipoprotein E-knockout mice with cholesterol and fat enriched diets may be a model of non-alcoholic steatohepatitis. Mol Cell Biochem. 2005 Jan;268(1-2):53-8.

125.Schreyer SA, Vick C, Lystig TC, Mystkowski P, LeBoeuf RC. LDL receptor but not apolipoprotein E deficiency increases diet-induced obesity and diabetes in mice. Am J Physiol Endocrinol Metab. 2002 Jan;282(1):E207-14.

126. Hussain MM. A proposed model for the assembly of chylomicrons. Atherosclerosis. 2000 Jan;148(1):1-15.

127. Choi SY, Fong LG, Kirven MJ, Cooper AD. Use of an anti-low density lipoprotein receptor antibody to quantify the role of the LDL receptor in the removal of chylomicron remnants in the mouse in vivo. J Clin Invest. 1991 Oct;88(4):1173-81.

128. Rohlmann A, Gotthardt M, Hammer RE, Herz J. Inducible inactivation of hepatic LRP gene by cre-mediated recombination confirms role of LRP in clearance of chylomicron remnants. J Clin Invest. 1998 Feb 1;101(3):689-95.

129.Ginsberg HN. Lipoprotein physiology. Endocrinol Metab Clin North Am. 1998 Sep;27(3):503-19.

130. Marzetta CA, Foster DM, Brunzell JD. Conversion of plasma VLDL and IDL precursors into various LDL subpopulations using density gradient ultracentrifugation. J Lipid Res. 1990 Jun;31(6):975-84.

131.Timmins JM, Lee JY, Boudyguina E, Kluckman KD, Brunham LR, Mulya A, et al. Targeted inactivation of hepatic Abcal causes profound hypoalphalipoproteinemia and kidney hypercatabolism of apoA-I. J Clin Invest. 2005 May;115(5):1333-42.

132.Tall AR, Sammett D, Vita GM, Deckelbaum R, Olivecrona T. Lipoprotein lipase enhances the cholesteryl ester transfer protein-mediated transfer of cholesteryl esters from high density lipoproteins to very low density lipoproteins. J Biol Chem. 1984 Aug 10;259(15):9587-94.

133.Acton S, Rigotti A, Landschulz KT, Xu S, Hobbs HH, Krieger M. Identification of scavenger receptor SR-BI as a high density lipoprotein receptor. Science. 1996 Jan 26;271(5248):518-20.

134.de Winther MP, Heeringa P. Bone marrow transplantations to study gene function in hematopoietic cells. Methods Mol Biol. 2003;209:281-92.

135.Paradis K BB, Sharp HL. Rapid repopulation and maturation of Kupffer cells from the bone marrow in a murine bone marrow transplant model. Wisse E, Knoonk DL, eds Cells of the Hepatic Sinusoid. 1989;2(Rijswijk: Kupffer Cell Foundation):410-2.

136.DeRisi J, Penland L, Brown PO, Bittner ML, Meltzer PS, Ray M, et al. Use of a cDNA microarray to analyse gene expression patterns in human cancer. Nat Genet. 1996 Dec;14(4):457-60.

137.Lockhart DJ, Dong H, Byrne MC, Follettie MT, Gallo MV, Chee MS, et al. Expression monitoring by hybridization to high-density oligonucleotide arrays. Nat Biotechnol. 1996 Dec;14(13):1675-80.

138.www.affymetrix.com. 


\section{Understanding hyperlipidemia and atherosclerosis: lessons from genetically modified apoe and Idlr mice}

Kristiaan Wouters ${ }^{1}{ }^{*}$, Ronit Shiri-Sverdlov ${ }^{1}{ }^{*}$, Patrick J. van Gorp ${ }^{1}$, Marc van Bilsen ${ }^{2}$ and Marten H. Hofker ${ }^{1}$

1) Dept. of Molecular Genetics, Universiteit Maastricht, Maastricht, the Netherlands; 2) Dept. of Physiology, Universiteit Maastricht, Maastricht, the Netherlands

* Both authors contributed equally to this paper

Clin Chem Lab Med. 2005;43(5):470-9 


\section{Abstract}

Hyperlipidemia is the most important risk factor for atherosclerosis, which is the major cause of cardiovascular disease. The etiology of hyperlipidemia and atherosclerosis is complex and governed by multiple interacting genes. However, mutations in two genes have been shown to be directly involved, i.e. the genes coding for the low density protein receptor (Ldlr) and apolipoprotein E (ApoE). Genetically modified mouse models have been instrumental to elucidate the underlying molecular mechanisms in lipid metabolism. In this review, we will focus on two of the most widely used mouse models, i.e. the ApoE and Ldlr deficient mice. After almost a decade of applications, it is clear that each model has unique strengths and drawbacks when carrying out studies on the role of additional genes and environmental factors such as nutrition and lipidlowering drugs. Importantly, we will elaborate on mice expressing mutant forms of ApoE, including the APOE3Leiden (APOE3L) and the APOE2 knock-in (APOE2ki) mouse models. These models have an outstanding potential as they are highly responsive to dietary factors and pharmacological interventions. 


\section{Introduction}

Atherosclerosis is the major cause of cardiovascular disease (CVD) and is considered a complex condition caused by various genetic and environmental factors. It proved to be very difficult to identify the responsible hereditary factors. Susceptibility to CVD varies among individuals because the genetic component is the result of complex interactions among many genes. Only in rare cases, single gene mutations lead to atherosclerosis, often in genes with key roles in lipid homeostasis. The best known examples are the genes encoding the low density lipoprotein receptor (Ldlr) and apolipoprotein E (ApoE). In the early 1980s, the discovery of mutations within these genes initiated a major effort scrutinizing the entire set of lipid genes for mutations. A more recent example includes the discovery of the role of the $A B C A 1$ gene in Tangiers disease, a heritable deficiency of the high-density lipoproteins (HDL).

Despite the large number of genes linked to lipid disorders, it is still difficult to explain the common mild hyperlipidemias at the genetic and molecular level, and genes associated with atherosclerosis are even more difficult to identify via human genetic studies.

At present, however, research on mouse models for atherosclerosis is providing crucial insights into the role of additional genes and environmental factors. Unfortunately, the wild-type (WT) mouse is quite resistant to CVD, due to high levels of anti-atherogenic HDL and low levels of pro-atherogenic lipoproteins, i.e. very low density lipoprotein (VLDL) and low density lipoprotein (LDL). The definite introduction of the mouse in the cardiovascular field, however, became only feasible when technologies, capable of generating transgenic and knock-out mice, became generally available. The most widely used mouse models were developed using the $l d l r$ and apoe genes. By using these mice as sensitized background strains, it became possible to investigate the role of additional genes, diets and other environmental factors.

First, we will introduce the human hyperlipidemias caused by mutations in the $L D L R$ and $A P O E$ genes. Second, we will describe the models which were based on these mutations, and finally, we will delineate how these models are instrumental in further delineating dyslipidemias and atherosclerosis.

\section{Lipoprotein disorders}

The most common genetic hyperlipidemic disorder is type II hyperlipoproteinemia (type II HLP), also referred to as familial hypercholesterolemia (FH), which is characterized by elevated plasma LDL levels. FH patients suffer from yellowish lipid deposits in the skin and subcutaneous tissue, called xanthomas. Xanthoma tuberosum 
and tendinosum are characteristic of FH [1]. These patients are also at higher risk of developing atherosclerosis. One of several types of $\mathrm{FH}$ is a monogenic form, with a frequency of 1 in 500 individuals. This form is caused by defects in the gene coding for the Ldlr, resulting in a defective clearance of LDL from the plasma. Consequently, this lipoprotein, containing large amounts of cholesterol, accumulates in the circulation [2]. Type III hyperlipidemia (type III HLP) represents a more rare condition than FH, with a frequency of 1 to 4 in 10,000 individuals in the Caucasian population. The cause of this abnormality is either ApoE deficiency or a defective form of ApoE, which cannot fully bind to their receptors. This malfunctioning ApoE has also variable binding capacities to heparin sulfated proteoglycans (HSPG), which is needed for the uptake via the LDLR related protein (LRP)-mediated secretion-recapture process [3-5]. It is hallmarked by an accumulation of chylomicron remnants (CMR), which originate from intestine-derived lipoproteins, and VLDL remnants (VLDLR), originating from liverderived VLDL. These lipoprotein remnants are collectively called $\beta$-VLDL. The disorder is therefore also called familial dysbetalipoproteinemia (FD) [3, 6]. FD patients have elevated levels of triglycerides (TGs) and total cholesterol (TC) in the plasma and also suffer from xanthomas, mainly palmar crease xanthoma, which is indicative of this condition [1,3]. Similar to FH, type III HLP patients have an increased susceptibility to atherosclerosis.

ApoE was initially found to be a component of VLDL [7] and later of the type III hyperlipidemia-associated $\beta$-VLDL as well [8]. VLDL and $\beta$-VLDL were shown to have far higher affinity for the LDL receptor than LDL itself, which contains ApoB instead of ApoE [9]. ApoE thus serves for the clearance of chylomicrons and VLDL from the plasma. Several other functions for ApoE have also been described. It is a ligand for hepatic clearance via the LRP $[10,11]$, it modulates Lipoprotein Lipase $(\mathrm{LpL})$ activity, presumably by masking APOCII, an activator of $\mathrm{LpL}[12,13]$. Furthermore, it can stimulate VLDL production in the liver $[12,14]$ in an isoform specific manner [15] and modulate cholesterol efflux from different cells and tissues $[16,17]$ (see figure 1: Major functions of APOE). Therefore it is clear that any malfunctioning of the APOE protein could have drastic consequences for lipoprotein metabolism.

The most common cause of FD is homozygosity of the allele for the ApoE2 isoform. $A P O E 2$ has a gene frequency of $10 \%$ in the human population. It contains a cystein instead of an arginine at residue 158 [3]. Due to this mutation, ApoE has lost more than $99 \%$ of its binding capacity to its receptor compared to ApoE3, the common isoform. ApoE2 is proposed to be associated with a recessive mode of inheritance. Most isoforms are preferentially confined to the VLDL fraction, whereas the ApoE2 isoform 
seems to be more present in HDL. If ApoE2 and the common isoform would be present in the plasma at equal levels (heterozygosity), ApoE2 would preferentially associate with HDL, leading to VLDL containing mostly the normal ApoE3 and making them more suitable for clearance from the blood (reviewed by Mahley, Huang and Rall [18]). Nevertheless, a very small percentage (5\%) of homozygote individuals will eventually develop FD. This probably means that, due to the low penetrance of FD, other genes and environmental factors have a modulatory effect on this disorder.

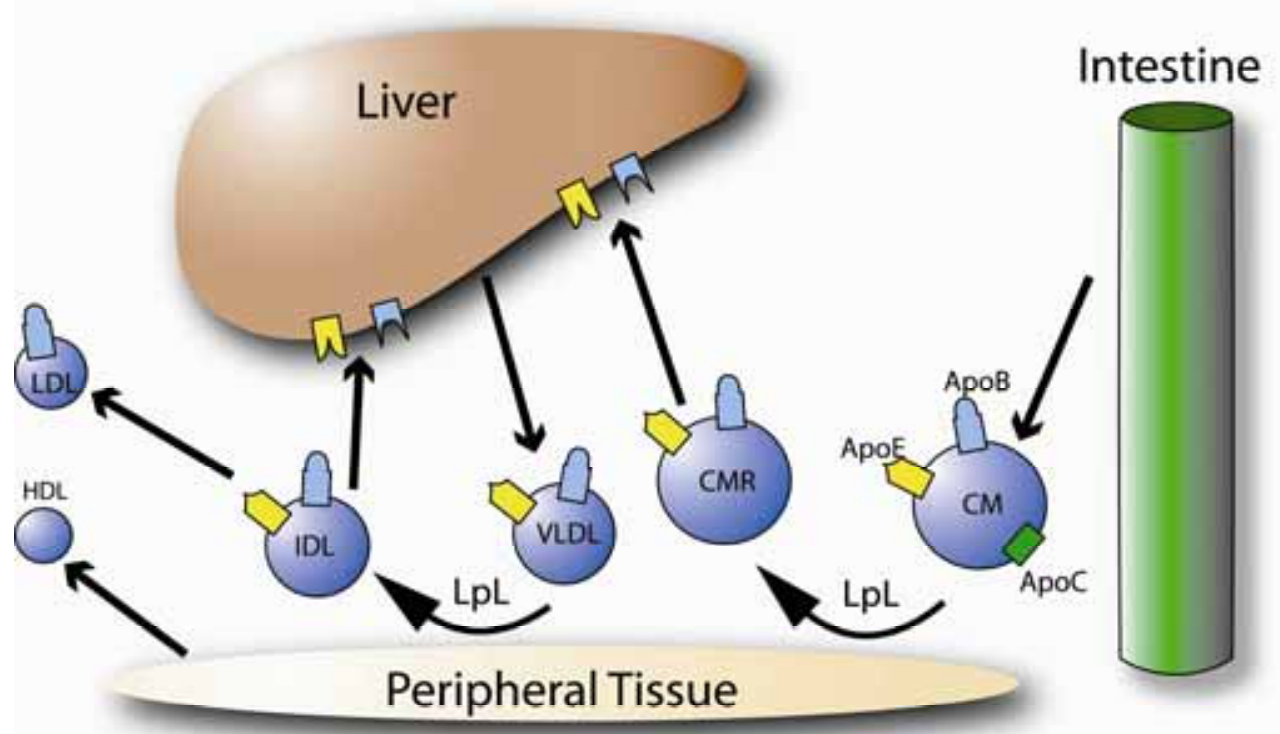

Figure 1. Major functions of ApoE. Triglycerides (TGs), cholesterol and other lipids are packaged into chylomicrons (CM) after digestion and absorption in the intestine. CMs contain the apolipoprotein ApoB, ApoC and ApoE. The CMs enter the circulation where their TGs get hydrolyzed by LpL, which can be modulated by apoE. The resulting CM remnants (CMR) are rapidly taken up by the liver trough the binding of apoe to the LDLR and the LRP. ApoE can also stimulate VLDL production in and secretion out of the liver. Circulating VLDL particles, which contain ApoE and ApoB, also undergo lipolysis, turning them into VLDL remnants or IDL. IDLs get internalized by the liver trough binding to the LDLR and the LRP, which makes this process also dependent on ApoE. Further lipolysis of remaining IDLs results in LDL. These lipoproteins can be taken up by the LDLR trough binding with the ApoB particles present in LDLs. ApoE can also modulate cholesterol efflux out of the peripheral tissues to small circulating HDL.

Other defective ApoE isoforms lead to a dominant pattern of inheritance, but are rarer. An example of this is the ApoE3Leiden (ApoE3L) isoform, which has an extra 7amino acid tandem repeat sequence at residues 121-127. This leads to a conformational change in the protein which prevents adequate binding to hepatic receptors [19]. 
There are also several other lipoprotein disorders besides these two diseases, including type I, type IV and type V hyperlipoproteinemia. Some risk factors for these conditions are very well known, like LpL and ApoCII deficiency, while others remain to be found.

\section{The use of hyperlipidemic mouse models in cardiovascular research}

Using mice in atherosclerosis research has many advantages such as easy handling, short generation span and large litter size. On the other hand, differences between mice and men in terms of susceptibility for atherosclerosis, lipoprotein metabolism and plaque morphology have to be appreciated.

Normally, mice are resistant to atherosclerosis, but Paigen et al. [20] demonstrated a huge variation in atherosclerosis formation in ten different inbred mice strains upon feeding a pro-atherogenic diet. Due to this diet, the mice all developed hyperlipidemia although the formation of atherosclerosis differed enormously between the different inbred strains with no correlation with plasma lipid levels. The $\mathrm{C} 57 \mathrm{Bl} / 6$ strain appeared to be most susceptible for atherosclerotic lesion formation. Despite the large amount of cholesterol $(1,25 \%)$ and the presence of (sodium) cholate $(0,5 \%)$ in the atherogenic diet, these mice showed very simple and small lesions, mainly consisting of lipid laden macrophages, also called foam cells. This plaque morphology did not resemble the advanced human plaque, which consists of altered endothelial cells, foam cells and proliferating smooth muscle cells that form fibrous tissue. This fibrous tissue forms a fibrotic cap which overlies a core of lipid and necrotic tissue. Eventually, the fibrotic cap may rupture, which can cause thrombosis, thus leading to an acute coronary event and/or stroke [21, 22].

The Paigen diet [20] was determined to be unphysiological [23] and it has been demonstrated that the high cholesterol and the addition of cholate in the atherogenic diet causes an inflammatory response in the liver and other tissues, possibly arteries $[24,25]$. Atherosclerosis is becoming increasingly known as a disease in which inflammation plays a major role in its development [21], so the use of the proinflammatory, cholate-containing diet is controversial. Moreover, the application of the mouse in atherosclerosis research remained limited.

This situation changed dramatically, when genetically modified animals where generated lacking certain genes important for lipid metabolism, like the apoe knock-out $\left(\right.$ apoe $\left.^{-/-}\right)$and the $l d l r$ knock-out $\left(\operatorname{ldlr}^{-/-}\right)$mice $[26,27]$. Other mice were created with human genes inserted into the mouse genome, e.g. the transgenic APOE3Leiden mouse [28]. It became also possible to specifically replace mouse genes with their human 
counterparts like the APOE2 knock-in (APOE2ki) mouse [29]. The properties and application of these mouse models will be discussed below. Table 1 shows a short overview of the cholesterol distributions in the lipoprotein factions of these mice.

\section{apoe $^{-/-}$mouse model}

A mouse deficient for the apoe gene was created in different laboratories [26, 27]. On a normal chow diet, these animals display plasma cholesterol levels of at least five times more than their WT counterparts. When given a high-fat diet (HFD), mildly elevated in cholesterol without added cholate, the mice had even a further 3-fold rise. TGs were lowered to half of the level that was observed in chow-fed animals [26]. A HFD containing higher amounts of cholesterol and cholate resulted in a very large increase of TC levels, while TG levels did not change [27, 30]. Cholesterol was mainly found in VLDL/IDL fractions in apoe $e^{-/-}$mice when fed chow and high-fat feeding. To a lesser extent it was in the LDL fraction of these animals (table 1). This lipid distribution resembles the lipid profiles found in type III hyperlipidemia patients although the composition of VLDL particles differs dramatically [4, 6]. Even heterozygous expression of the apoe gene caused hyperlipidemia [31].

Spontaneous plaque formation was found in these animals [27] but, in line with their enormous response to high fat feeding, it is possible to induce accelerated and more severe atherosclerotic plaques in many vascular areas when given a HFD [26, 28, 30]. Lesions consisted of foam cells and a lipid containing necrotic core. A proliferative cellular response was found in the vessel wall as well as a fibrous cap [26]. Accordingly, the lesions closely resemble advanced human plaques and therefore, the availability of the apoe ${ }^{-/-}$mouse can be considered an important landmark in the use of mouse models to study atherosclerosis.

Due to these responses upon high fat feeding, the apoe $e^{-/-}$mouse has been become the most widely used mouse model for hyperlipidemia and atherosclerosis. This model is therefore particularly useful as a sensitized strain to investigate the role of additional genes. In particular, insights can be obtained in the role of genes that are unrelated to lipid metabolism. Such genes will be crucial to study in the absence of very severe diets, and in those cases the apoe ${ }^{-/-}$model is the preferred alternative. Using this strategy, various genes that are implicated in atherogenesis, ranging from genes related to inflammation, hyperglycemia, hypertension and coagulation, have been identified (for review see [32]).

Mice carrying "candidate genes", which are suspected to be involved in atherogenesis, can be crossed with apoe ${ }^{-/-}$mice. These crosses may lead to a better understanding of the role of that specific mutation in atherosclerosis. Unfortunately, when using such 
crosses between transgenic mice, one remains confined to studying these candidate genes. It is also possible to follow an unbiased approach using mouse genetics. By doing a series of crosses between mice, several quantitative trait loci (QTL) can be found. In this manner, several loci on the mouse genome have been identified to carry genes likely to be involved in the pathology of atherogenesis [33, 34].

The clinical relevance to human atherosclerosis remained questionable since common clinical events such as plaque rupture and thrombosis could not be identified until, not so long ago, these events were found in the innominate artery by Rosenfeld et al. [35]. As reviewed by Cullen et al. [36] a few more mouse models of plaque rupture emerged, however, these models are still rather controversial. In addition, the sitespecifity of atherosclerotic plaques remains subject of debate. Probably due to differences in blood flow, specific parts of the vasculature are more prone to atherosclerosis. Therefore, it is possible that plaque formation at some sites in the mouse arterial tree is more relevant to human atherogenesis than others. However, up until recently, no more than one site was the subject of intensive research, i.e. the murine aortic sinus, while this site shows no atherosclerosis in humans (for review see [37]). This review notes that it is necessary to study more than only one site in the circulation. Of particular interest is the fact that even opposite results can be found at different sites of the artery [38].

As recently reviewed by Meir and Leitersdorf [39], over the past few years the apoe ${ }^{-/-}$ mice have been extensively used to examine the effects of nutritional and pharmacological interventions on atherosclerosis. However, a major shortcoming of the apoe $^{-/-}$mouse is that their lipoprotein profiles are dissimilar from human individuals, who have most of their cholesterol in LDL particles. Another drawback is that these mice do not have any ApoE, while, as stated earlier, this lipoprotein has many different functions in the organism. This will complicate studies and results directed to elucidate the mechanism of lipid metabolism, in particularly the mechanisms of drug and dietary action.

A good example of this complication are statins (for review see [40]). Normally these drugs lower cholesterol levels drastically, by inhibiting 3-hydroxy-3-methylglutarylcoenzyme A (HMG-CoA) reductase, but in apoe ${ }^{-/-}$mice cholesterol levels and plaque area rise upon treatment with this drug [41]. Although this phenomenon may seem a major disadvantage, it provides a chance of studying the effects of statins on plaque formation despite the paradoxical hyperlipidemic effect. This was shown in an interesting study by Bea et al. who showed that simvastatin has a stabilizing effect on the atherosclerotic plaque [42].

Another unique feature in the apoe ${ }^{-/-}$mouse model was observed when these mice received fibrates. This drug normally causes an increased oxidation and a decreased 
hepatic VLDL secretion in WT mice by serving as a ligand for the nuclear receptor peroxisome proliferator activated receptor alpha (PPAR $\alpha)$, thereby lowering plasma lipid levels. In the apoe ${ }^{-/-}$mice, however, cipofibrate and other fibrates caused a 3- to 4fold increase in plasma cholesterol levels [43]. Remarkably, this study concluded that atherosclerotic lesions were also more advanced upon fibrate treatment (90 days) than in control animals. These observations are supported by a study using PPAR $\alpha /$ apoe double knock-out mice, in which the PPAR $\alpha$ deficiency resulted in less atherosclerosis than in the apoe ${ }^{-/-}$mice [44]. However, it was also shown that short-term treatment with a PPAR $\alpha$ ligand can decrease atherosclerosis slightly [45]. The lipid-raising effect of fibrates could be attributed to a fibrate-induced down-regulation of the hepatic scavenger receptor B type I (SRBI) [46]. This receptor mediates cholesterol uptake from HDL particles, but also was found to bind $\mathrm{ApoB}$, therefore possibly playing a role as backup for VLDL and LDL uptake, and to bind modified LDL [47, 48].

\section{Idlr ${ }^{-/-}$mouse model}

By eliminating the functional gene for the Ldlr, Ishibashi et al. [49] created a mouse model that displayed mildly elevated cholesterol levels on a diet containing elevated fat and cholesterol levels, but no cholate. A very small part of this cholesterol was confined to the VLDL fraction, but the biggest rise was present in the IDL/LDL fraction (table 1). Compared to WT mice, HDL cholesterol was slightly augmented on a chow diet. In contrast to the WT lipoprotein profile, where most cholesterol is present in the HDL fraction, this profile is more comparable with the human plasma lipoprotein profile, in which cholesterol is mainly confined to the LDL fraction.

Quantification of atherosclerosis showed mild to moderate atherosclerotic lesions in the aortic root and coronary arteries of mice fed a mild atherogenic diet lacking excessive amounts of cholesterol and cholate [20]. Despite the rise in plasma cholesterol in these mice, the effect was not as dramatic as expected. This is probably due to the fact that mice, unlike humans, produce approximately $70 \%$ of their liver apoB as the truncated apoB48 form [50]. ApoB48 cannot bind the LDLR, but together with ApoE, it does mediate clearance via the LRP [11]. Since the LDLR binds LDL via ApoB100, these mice have a rescue pathway through which the lipoproteins, containing ApoB48, can be taken up. LRP plays only a significant role in the uptake of ApoB48 containing lipoproteins but not of ApoB100 lipoproteins [51]. Other papers also have described an important role for additional receptors. The LRP pathway could function as a backup mechanism for the clearance of remnants when the LDLR is 
genetically deficient [52]. Notably, in the absence of both LDLR and LRP, still additional routes for the uptake of lipoproteins through the liver exist [53].

Like in the case of models involving apoe, the ldll $^{-/-}$mice have served as a model to study the role of additional genes in atherosclerosis, although to a lesser extent than apoe $^{-/-}$mice $[32,54]$.

However, the $\operatorname{ldlr}^{-/-}$mice are becoming more appreciated, serving as excellent host for bone marrow transplantation (BMT) experiments [55]. Using this technique, mice are depleted from white blood cells (WBCs) by irradiation and subsequently injected with WBCs isolated from mice carrying a certain (transgenic/knock-out) mutation, leading to an organism that contains WBCs carrying defects, which are not present in the remaining tissues. Since WBCs, and in particular macrophages and T-cells, have an established role in the pathogenesis of atherosclerosis [22], this technology is widely applied. The apoe $e^{-/-}$mouse is a less preferred host for BMT experiments, because the ApoE produced by the BMT cells will rescue the apoe deficiency, and the transplanted mice are no longer susceptible to develop atherosclerosis [56]. Therefore, apoe ${ }^{-/}$mice can only be transferred with apoe-deficient bone marrow, requiring complex breeding schemes. A good example of the use of the $1 \mathrm{dlr}^{-/-}$mice in BMT experiments includes a

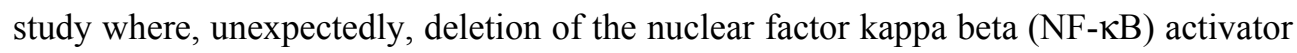
I $\kappa \mathrm{B}$ kinase beta $(\mathrm{IKK} \beta)$ in macrophages caused a significant worsening of atherosclerosis in these mice [57]. This could be explained by the observed reduction in the anti-inflammatory cytokine interleukin 10 (IL10). These data suggest a dual role for $\mathrm{NF}-\kappa \mathrm{B}$ in inflammation, not only promoting the inflammatory response, but also controlling it.

We have to keep in mind that in the ldlr knock-out mouse model a complete gene was deleted from the genome, which, as with the apoe ${ }^{-/}$mice, may uncover the role of backup systems, like the LRP pathway. This route can serve as a backup mechanism for lipoprotein clearance in the $1 \mathrm{dlr}^{-/-}$mice [58], yielding unforeseen side effects.

\section{APOE3Leiden mouse model}

The mouse model expressing the $A P O E 3 L$ gene was created by transgenesis using DNA from one of the $A P O E 3 L$ carriers to generate the gene construct [28]. The transgenic mouse carries a gene construct consisting of the $A P O E 3 L$ gene, the APOC1 gene and a hepatic control element that was found to regulate the expression of both the $A P O E$ and $A P O C 1$ genes in the liver [59]. Although the APOE3L mouse still expresses the endogenous ApoE, it exhibits a hyperlipidemic phenotype, which is in line with the dominant manner of inheritance as observed in humans [28]. Mice over- 
expressing the APOC1 gene have elevated TG and TC levels (for review see [60]). This is mainly due to the impairment of VLDL uptake by both the LDLR and the LRP. Consequently, ApoC1 serves to further increase the level of plasma TGs [61].

When fed on chow, the APOE3L mice show a small increase in cholesterol levels and a doubling of plasma TGs. However, these animals seemed to be very responsive to a HFD containing cholate, displaying an increase in plasma cholesterol levels of about 10 -fold, mainly in the VLDL fraction. TG levels decreased to almost half of the value compared to the value when fed on chow [62] (table 1). After a period of only 14 days feeding an atherogenic diet, atherosclerotic plaques were found in these mice at the sinus valves, the carotid arteries and other parts of the aorta. A positive correlation was seen between lesion area and serum cholesterol levels, indicating the hyperlipidemia to be an important determinant in lesion formation [62]. However, APOE3L mice were found to be less susceptible to atherosclerosis than the apoe ${ }^{-/-}$mouse [63].

\begin{tabular}{llllll} 
& & $\begin{array}{l}\text { mutant vs WT } \\
\text { (chow) }\end{array}$ & WTD vs chow & HFC vs chow & refs \\
apoe $^{-/-}$ & VLDL & $\uparrow \uparrow \uparrow$ & $\uparrow \uparrow$ & $\uparrow \uparrow \uparrow$ & {$[27,28,30]$} \\
& LDL & $\uparrow \uparrow$ & $\uparrow$ & $\uparrow \uparrow$ & \\
\hline $\mathrm{ldlr}^{-/-}$ & VLDL & $\uparrow$ & $\uparrow$ & $\uparrow \uparrow$ & {$[45,81]$} \\
& LDL & $\uparrow$ & $\uparrow \uparrow$ & $\uparrow \uparrow$ & \\
\hline APOE3L VLDL & $\uparrow$ & $\uparrow$ & $\uparrow \uparrow \uparrow$ & {$[58]$} \\
& LDL & $\uparrow$ & $\uparrow \uparrow$ & $\uparrow \uparrow$ & {$[26,70]$} \\
\hline \multirow{2}{*}{ APOE2ki VLDL } & $\uparrow \uparrow \uparrow$ & $\uparrow \uparrow *$ & - & \\
\hline
\end{tabular}

Table 1. Cholesterol distribution in lipoprotein fractions of different lipoprotein fractions of the genetically altered mouse models. The first column ('mutant vs WT') indicates the levels in the mouse model when fed a normal chow diet compared to a wild-type (WT) mouse on a chow diet. The two other columns ('WTD vs chow' and 'HFC vs chow') both indicate cholesterol levels of the mouse model on a certain diet compared to cholesterol levels of that mouse model on a normal chow diet. Arrows indicate the amount of rising or lowering of the specific mouse models on specific diets: $\uparrow:$ small rise; $\uparrow \uparrow:$ considerable rise; $\uparrow \uparrow \uparrow:$ extreme rise. WTD: Western Type Diet containing moderately elevated cholesterol levels; HFC: High fat diet containing cholate (pro-atherogenic diet). * Only data from male mice

The most valuable property of this model is the excellent response to drugs and diet interventions. In part, this is due to the fact that the main cause of the hyperlipidemia in 
this model is a reduction of the VLDL turnover, due to decreased LDLR binding and decreased lipolysis of VLDL. This modification is subtler than the complete ApoE deficiency in the apoe ${ }^{-/-}$model.

Importantly, unlike the apoe $e^{-/-}$mouse, the APOE3L mouse shows a hypolipidemic response to known lipid lowering drugs as statins, like lovastatin, and to PPAR $\alpha$ agonists, like gemfibrozil [64]. As mentioned before, a positive correlation was found between the lesion area and the serum cholesterol exposure [63], so lipid lowering using a statin treatment significantly retarded the progression of atherosclerotic lesions $[65,66]$. The APOE3L model is therefore an excellent model to test the hypolipidemic properties of these kinds of drugs.

The effects of dietary fish oil were tested in this hyperlipidemic mouse model [67]. In contrast to the apoe ${ }^{-/-}$mouse, the APOE3L mouse seemed to be highly responsive to this treatment. There was a strong reduction in serum VLDL, due to a decrease in hepatic VLDL-TG production, induced by n-3 poly unsaturated fatty acids (PUFAs).

The APOE3L mouse is well suited to study protein function and interaction with other genes. Since this gene is found in humans, the nature of disease can become clearer using these mice. It has to be kept in mind that the mouse apoe gene is still functional. A major disadvantage of this mouse is that they have to be fed a cholate containing atherogenic diet in order to develop a large increase of plasma lipids and atherosclerosis. Cholate containing diets have been proven to promote inflammation, liver fatty acid and cholesterol changes and gall stone formation [24, 25, 68], which makes research of the plaque itself and its development, especially regarding to inflammation, very difficult.

\section{Common APOE alleles in mouse models}

The ApoE2 isoform causes the same phenotype in humans as ApoE3L isoform does, but in a recessive way, as described earlier in this review. The recessive properties of APOE2 also become apparent in the mouse. When fed a chow diet, the APOE2 transgenic mouse (APOE2TG) [69] showed no higher cholesterol levels when compared with non-transgenic mice. Also on a HFD these mice did not develop hyperlipidemia. This was due to the presence of the endogenous ApoE. However, when expressed at very high levels (more than $50 \mathrm{mg} / \mathrm{dl}$ ), cholesterol levels were $50 \%$ higher [70]. When mice were bred on an apoe ${ }^{-/-}$background, they became severely hyperlipidemic, even when given a chow diet. This is quite remarkable, because in humans, only a small percentage of homozygotes develops FD [3]. It was proposed that the reduced availability of apoB-100 could be the cause of the pronounced phenotype, 
making the APOE2TG/apoe ${ }^{-/-}$mice much more dependent on ApoE-mediated lipoprotein clearance via the LDLR.

The APOE2TG mouse was used together with the APOE3L and the apoe ${ }^{-/-}$mouse models to assess binding of $\beta$-VLDL to HSPG, a process necessary for the LRPmediated secretion-recapture process for lipoprotein uptake [11]. It showed that LpL enhances this process and that ApoE is no absolute requirement for binding, but results in an, isoform-dependent, increased binding [71]. Crossing the APOE2TG and the APOE3L mice on a apoe ${ }^{-/} \mathrm{ldlr}^{-/-}$background showed that clearance of ApoE2 and ApoE3L containing lipoproteins in absence of the LDLR, thus via alternative pathways such as LRP, is inefficient [72]. This shows the pivotal role of the LDLR for clearance of VLDL remnants.

Models containing the most common human $A P O E$ alleles, i.e. E2, E3, E4, have been generated in mice $[29,73,74]$. Using homologous recombination in embryonic stem cells, the mouse apoe gene has been replaced by the human gene. This approach has the advantage that the gene precisely replaces the endogenous apoe gene. Hence, the human ApoE isoform is expressed according to the normal physiological regulation.

The APOE2ki mice show a phenotype very similar to human Type III HLP: a 2- to 3fold elevation of TC and TG plasma levels, confined to the $\beta$-VLDL fraction. These mice respond markedly to diets containing mildly elevated levels of fat and cholesterol. An advantage of this mouse model is that no cholate is needed in the diet to obtain severe diet-induced hyperlipidemia and atherosclerosis. Interestingly, the knock-in mice show the full spectrum of atherosclerotic lesions, even on a regular diet [29].

The APOE2 knock-in mice show a complete penetrance of the type III HLP phenotype. To test whether the ApoB-48 hypothesis was correct, APOE2ki mice were used in a study where ApoB-100 instead of ApoB-48 was expressed, by deleting the gene responsible for ApoB-100 editing. This study showed that expression of solely ApoB100 was not sufficient to reverse the hyperlipidemic phenotype, probably because ApoB-48 and ApoB-100 influence lipoprotein metabolism differently [75]. These results indicate that the strong phenotype of APOE2ki mice is not entirely dependent on the difference in ApoB editing. Using these mice, it should be possible to determine which conditions predispose to the development of type III HLP in humans. A reduced expression of the LDLR could be one of many possible explanations. It was shown that plasma lipoprotein profile in mice could be ameliorated by over-expression of the human LDLR in APOE2ki mice [76], again suggesting an important role for this receptor, as also shown in the other $A P O E$ mouse models [72]. The APOE2ki mouse model has not yet been intensively studied, but may prove to be a good mouse model for hyperlipidemia and atherosclerosis. Unlike the $a p o e^{-/-}$mouse, this mouse model has 
a lipoprotein profile that mimics that of Type III HLP patients. Another advantage over apoe $^{-/-}$mice is the responsiveness to fibrates, indicating that this mouse model may also serve as a good model for drug-testing. Sullivan et al. [73] found large variations in the response on a HFD between male and female APOE2ki mice. However, it is not clear whether these differences are due to the difference in sex or to different administered diets.

The APOE3 knock-in (APOE3ki) mouse, expressing the most common human ApoE isoform, and APOE4 knock-in (APOE4ki) mice show phenotypes similar to each other, although there are some differences in lipoprotein distribution. Both show lower plasma lipid levels than APOE2ki when fed on a chow diet [74]. Combining data from those three models led to conclude that differences in ApoE structure alone can be sufficient to cause differences in VLDL metabolism and atherosclerosis risk in mice [74]. In animals that over-express the human LDLR, a remarkable observation was made. It was found that APOE4ki mice with higher LDLR expression showed accumulation of lipoprotein remnant proteins and increased atherosclerosis, despite the higher affinity of this isoform for the LDLR. This could not be found in APOE3ki mice. The postulated explanation is that ApoE4 becomes trapped in the liver due to its high affinity for the LDLR. Hence newly-synthesized lipoproteins cannot acquire the trapped ApoE and it will become deficient in this apolipoprotein, resulting in slower clearance from the plasma [77, 78]. Another possible way of manipulating mice genetically to study ApoE function in vivo in mice is by using adenovirus-mediated gene transfer. This technique uses genetically modified adenoviruses to deliver exogenous genes to several tissues in an organism (for reviews see [78, 79]). Several studies have proven the use of this technique to gain more insight in lipoprotein metabolism [49]. This approach has been effectively used to determine which ApoEdomains are required for cholesterol and TG homeostasis in vivo [80] as well as to investigate the relative importance of this apolipoprotein in remnant clearance and the pathology of type III HLP.

\section{Conclusions and future prospects}

Before setting up an animal experiment, great thought has to be put into the choice of the right mouse model, weighing possible advantages against the disadvantages, keeping the principal aim of the study in mind.

In this review, we have demonstrated that mouse models based on two pivotal genes of the lipid metabolism, i.e. $A P O E$ and $L D L R$, have provided us with models to study the mechanism of lipid metabolism and atherosclerosis. For the applicability of each mouse model, see an overview in table 2 . 


\begin{tabular}{|c|c|c|c|}
\hline & $\underline{\mathbf{I d l r}^{-/-}}$ & apoe $^{-/-}$ & APOE3L \\
\hline \multicolumn{4}{|l|}{ atherosclerosis } \\
\hline lipoprotein & ++ & + & ++ \\
\hline plaque formation & +++ & +++ & +++ \\
\hline drug-intervention & + & $++^{1}$ & ++ \\
\hline inflammation & ++ & ++ & - \\
\hline \multicolumn{4}{|l|}{ lipoprotein metabolism } \\
\hline lipid lowering drugs & + & - & +++ \\
\hline nutritional intervention & + & $+^{2}$ & +++ \\
\hline gene-gene interaction & $++^{3}$ & $++^{3}$ & $++^{3}$ \\
\hline
\end{tabular}

Table 2. Application of mouse models of hyperlipidemia and atherosclerosis. Table representing suitability of several discussed mouse models for the experimental use in atherosclerotic research, such as the effect of lipoprotein levels and types, inflammation and drug-intervention on the formation of atherogenesis as well as for the study of atherosclerotic plaques. Also the applicability in research of lipoprotein metabolism is assessed: i.e. the effect of lipid lowering drugs, nutritional intervention and gene-gene interactions. Applicability is shown according to following legend: +: fair mouse model, ++: good mouse model; +++: excellent mouse model; -: mouse model not suitable. Remarks: 1: ApoE-independent mechanisms: in this way effects of drugs can be investigated without considering their lipid-lowering effect. 2: except for ApoE-dependent mechanisms as was shown that the lipid lowering effect of some nutritional interventions is of no effect in apoe $e^{-/-}$mice. 3: All models are more or less equal, however, sometimes complementary studies are necessary (e.g. knock-out model together with over-expressing transgene) to study full gene effect.

It appeared to be particularly useful to use genetically engineered strains as a tool to expose the role of additional genes in atherosclerosis. Genetic combinations can be easily obtained by crossing different transgenic and knock-out models. Thereby, the models emphasize the polygenetic nature of atherogenesis. At present, many gene-gene combinations have been tested. An overview of these studies has been published [39, 81], and falls beyond the scope of this review. In the near future, the emphasis is likely to shift towards combining the transgenic models with mouse genetics and genome wide expression analysis. In each of these areas, progress has been made recently. Dansky et al. used two inbred strains of mice, which were both deficient for the apoe gene. Using these mice, that are sensitized for atherosclerosis, he was able to find several unique QTLs in addition to already described QTLs [82]. Taking it a step further, Schadt et al. combined classical genetics with expression studies [83]. They found so called expression QTLs (eQTL) by correlating DNA variations with gene 
expression levels, tracking down possible causes of differential expression in sequence variations. These studies may unravel unidentified gene-gene interactions, group individuals that resemble genetically and discover biochemical pathways [84].

A further integration of these approaches will eventually provide us with detailed insight in the complex genetics of CVD.

\section{Acknowledgements}

Authors are supported by the Netherlands Heart Foundation (NHS) (Grant $\mathrm{n}^{\circ}$ 2002B018), and are part of the European Vascular Genomics Network (EVGN, LSHM-CT-2003-503254). Marten Hofker and Marc van Bilsen are established investigators of the NHS.

\section{References}

1. Lugo-Somolinos A, Sanchez JE. Xanthomas: a marker for hyperlipidemias. Bol Asoc Med P R 2003;95:12-6.

2. Hobbs HH, Brown MS, Goldstein JL. Molecular genetics of the LDL receptor gene in familial hypercholesterolemia. Hum Mutat 1992;1:445-66.

3. Mahley RW, and S. C. Rall, Jr. Type III hyperlipoproteinemia (dysbetalipoproteinemia): the role of apolipoprotein E in normal and abnormal lipoprotein metabolism. 7th Edition ed. New York: McGraw-Hill; 1995.

4. Schaefer EJ, Gregg RE, Ghiselli G, Forte TM, Ordovas JM, Zech LA, et al. Familial apolipoprotein E deficiency. J Clin Invest 1986;78:1206-19.

5. Ji Z, Fazio S, Mahley R. Variable heparan sulfate proteoglycan binding of apolipoprotein E variants may modulate the expression of type III hyperlipoproteinemia. J. Biol. Chem. 1994;269:13421-13428.

6. Brewer HB, Jr., Zech LA, Gregg RE, Schwartz D, Schaefer EJ. NIH conference. Type III hyperlipoproteinemia: diagnosis, molecular defects, pathology, and treatment. Ann Intern Med 1983;98:62340 .

7. Shore VG, Shore B. Heterogeneity of human plasma very low density lipoproteins. Separation of species differing in protein components. Biochemistry 1973;12:502-7.

8. Mahley RW, Innerarity TL, Bersot TP, Lipson A, Margolis S. Alterations in human high-density lipoproteins, with or without increased plasma-cholesterol, induced by diets high in cholesterol. Lancet 1978;2:807-9.

9. Innerarity TL, Mahley RW. Enhanced binding by cultured human fibroblasts of apo-E-containing lipoproteins as compared with low density lipoproteins. Biochemistry 1978;17:1440-7.

10. Ji ZS, Brecht WJ, Miranda RD, Hussain MM, Innerarity TL, Mahley RW. Role of heparan sulfate proteoglycans in the binding and uptake of apolipoprotein E-enriched remnant lipoproteins by cultured cells. $\mathrm{J}$ Biol Chem 1993;268:10160-7.

11. Ji ZS, Fazio S, Lee YL, Mahley RW. Secretion-capture role for apolipoprotein E in remnant lipoprotein metabolism involving cell surface heparan sulfate proteoglycans. J Biol Chem 1994;269:2764-72.

12. Huang Y, Liu XQ, Rall SC, Jr., Taylor JM, von Eckardstein A, Assmann G, et al. Overexpression and accumulation of apolipoprotein E as a cause of hypertriglyceridemia. J Biol Chem 1998;273:26388-93.

13. Rensen PC, van Berkel TJ. Apolipoprotein E effectively inhibits lipoprotein lipase-mediated lipolysis of chylomicron-like triglyceride-rich lipid emulsions in vitro and in vivo. J Biol Chem 1996;271:14791-9.

14. Huang Y, Ji ZS, Brecht WJ, Rall SC, Jr., Taylor JM, Mahley RW. Overexpression of apolipoprotein E3 in transgenic rabbits causes combined hyperlipidemia by stimulating hepatic VLDL production and impairing VLDL lipolysis. Arterioscler Thromb Vasc Biol 1999;19:2952-9.

15. Mensenkamp AR, Havekes LM, Romijn JA, Kuipers F. Hepatic steatosis and very low density lipoprotein secretion: the involvement of apolipoprotein E. J Hepatol 2001;35:816-22. 
16. Huang Y, von Eckardstein A, Wu S, Maeda N, Assmann G. A plasma lipoprotein containing only apolipoprotein E and with gamma mobility on electrophoresis releases cholesterol from cells. Proc Natl Acad Sci U S A 1994;91:1834-8.

17. Zhu Y, Bellosta S, Langer C, Bernini F, Pitas RE, Mahley RW, et al. Low-dose expression of a human apolipoprotein $\mathrm{E}$ transgene in macrophages restores cholesterol efflux capacity of apolipoprotein E-deficient mouse plasma. Proc Natl Acad Sci U S A 1998;95:7585-90.

18. Mahley RW, Huang Y, Rall SC, Jr. Pathogenesis of type III hyperlipoproteinemia (dysbetalipoproteinemia). Questions, quandaries, and paradoxes. J Lipid Res 1999;40:1933-49.

19. de Knijff P, van den Maagdenberg AM, Stalenhoef AF, Leuven JA, Demacker PN, Kuyt LP, et al. Familial dysbetalipoproteinemia associated with apolipoprotein E3-Leiden in an extended multigeneration pedigree. $J$ Clin Invest 1991;88:643-55.

20. Paigen B, Morrow A, Brandon C, Mitchell D, Holmes P. Variation in susceptibility to atherosclerosis among inbred strains of mice. Atherosclerosis 1985;57:65-73.

21. Ross R. Atherosclerosis--an inflammatory disease. N Engl J Med 1999;340:115-26.

22. Glass CK, Witztum JL. Atherosclerosis. the road ahead. Cell 2001;104:503-16.

23. Breslow JL. Genetic differences in endothelial cells may determine atherosclerosis susceptibility. Circulation 2000;102:5-6.

24. Liao F, Andalibi A, deBeer FC, Fogelman AM, Lusis AJ. Genetic control of inflammatory gene induction and NF-kappa B-like transcription factor activation in response to an atherogenic diet in mice. J Clin Invest 1993;91:2572-9.

25. Vergnes L, Phan J, Strauss M, Tafuri S, Reue K. Cholesterol and cholate components of an atherogenic diet induce distinct stages of hepatic inflammatory gene expression. J Biol Chem 2003;278:42774-84.

26. Plump AS, Smith JD, Hayek T, Aalto-Setala K, Walsh A, Verstuyft JG, et al. Severe hypercholesterolemia and atherosclerosis in apolipoprotein E-deficient mice created by homologous recombination in ES cells. Cell 1992; 71:343-53.

27. Zhang SH, Reddick RL, Piedrahita JA, Maeda N. Spontaneous hypercholesterolemia and arterial lesions in mice lacking apolipoprotein E. Science 1992;258:468-71.

28. van den Maagdenberg AM, Hofker MH, Krimpenfort PJ, de Bruijn I, van Vlijmen B, van der Boom H, et al. Transgenic mice carrying the apolipoprotein E3-Leiden gene exhibit hyperlipoproteinemia. J Biol Chem 1993;268:10540-5.

29. Sullivan PM, Mezdour H, Quarfordt SH, Maeda N. Type III hyperlipoproteinemia and spontaneous atherosclerosis in mice resulting from gene replacement of mouse Apoe with human Apoe*2. J Clin Invest 1998;102:130-5.

30. Zhang SH, Reddick RL, Burkey B, Maeda N. Diet-induced atherosclerosis in mice heterozygous and homozygous for apolipoprotein E gene disruption. J Clin Invest 1994;94:937-45.

31. van Ree JH, van den Broek WJ, Dahlmans VE, Groot PH, Vidgeon-Hart M, Frants RR, et al. Diet-induced hypercholesterolemia and atherosclerosis in heterozygous apolipoprotein E-deficient mice. Atherosclerosis 1994;111:25-37.

32. Knowles JW, Maeda N. Genetic modifiers of atherosclerosis in mice. Arterioscler Thromb Vasc Biol 2000;20:2336-45.

33. Smith JD, James D, Dansky HM, Wittkowski KM, Moore KJ, Breslow JL. In silico quantitative trait locus map for atherosclerosis susceptibility in apolipoprotein E-deficient mice. Arterioscler Thromb Vasc Biol 2003;23:117-22.

34. Smith JD, Dansky HM, Breslow JL. Genetic modifiers of atherosclerosis in mice. Ann N Y Acad Sci 2001;947:247-52; discussion 252-3.

35. Rosenfeld ME, Polinsky P, Virmani R, Kauser K, Rubanyi G, Schwartz SM. Advanced atherosclerotic lesions in the innominate artery of the ApoE knockout mouse. Arterioscler Thromb Vasc Biol 2000;20:2587-92.

36. Cullen P, Baetta R, Bellosta S, Bernini F, Chinetti G, Cignarella A, et al. Rupture of the atherosclerotic plaque: does a good animal model exist? Arterioscler Thromb Vasc Biol 2003;23:535-42.

37. VanderLaan PA, Reardon CA, Getz GS. Site specificity of atherosclerosis: site-selective responses to atherosclerotic modulators. Arterioscler Thromb Vasc Biol 2004;24:12-22.

38. Reardon CA, Blachowicz L, Lukens J, Nissenbaum M, Getz GS. Genetic background selectively influences innominate artery atherosclerosis: immune system deficiency as a probe. Arterioscler Thromb Vasc Biol 2003;23:1449-54.

39. Meir KS, Leitersdorf E. Atherosclerosis in the apolipoprotein E-deficient mouse: a decade of progress. Arterioscler Thromb Vasc Biol 2004;24:1006-14.

40. Maron DJ, Fazio S, Linton MF. Current perspectives on statins. Circulation 2000;101:207-13. 
41. Wang YX, Martin-McNulty B, Huw LY, da Cunha V, Post J, Hinchman J, et al. Anti-atherosclerotic effect of simvastatin depends on the presence of apolipoprotein E. Atherosclerosis 2002;162:23-31.

42. Bea F, Blessing E, Bennett B, Levitz M, Wallace EP, Rosenfeld ME. Simvastatin promotes atherosclerotic plaque stability in apoE-deficient mice independently of lipid lowering. Arterioscler Thromb Vasc Biol 2002;22:1832-7.

43. Fu T, Kashireddy P, Borensztajn J. The peroxisome-proliferator-activated receptor alpha agonist ciprofibrate severely aggravates hypercholesterolaemia and accelerates the development of atherosclerosis in mice lacking apolipoprotein E. Biochem J 2003;373:941-7.

44. Tordjman K, Bernal-Mizrachi C, Zemany L, Weng S, Feng C, Zhang F, et al. PPARalpha deficiency reduces insulin resistance and atherosclerosis in apoE-null mice. J Clin Invest 2001;107:1025-34.

45. Zuckerman SH, Kauffman RF, Evans GF. Peroxisome proliferator-activated receptor alpha,gamma coagonist LY465608 inhibits macrophage activation and atherosclerosis in apolipoprotein E knockout mice. Lipids 2002;37:487-94.

46. Fu T, Kozarsky KF, Borensztajn J. Overexpression of SR-BI by adenoviral vector reverses the fibrateinduced hypercholesterolemia of apolipoprotein E-deficient mice. J Biol Chem 2003;278:52559-63.

47. Tai ES, Adiconis X, Ordovas JM, Carmena-Ramon R, Real J, Corella D, et al. Polymorphisms at the SRBI locus are associated with lipoprotein levels in subjects with heterozygous familial hypercholesterolemia. Clin Genet 2003;63:53-8.

48. Acton S, Rigotti A, Landschulz KT, Xu S, Hobbs HH, Krieger M. Identification of scavenger receptor SR-BI as a high density lipoprotein receptor. Science 1996;271:518-20.

49. Ishibashi S, Brown MS, Goldstein JL, Gerard RD, Hammer RE, Herz J. Hypercholesterolemia in low density lipoprotein receptor knockout mice and its reversal by adenovirus-mediated gene delivery. J Clin Invest 1993;92:883-93.

50. Greeve J, Altkemper I, Dieterich JH, Greten H, Windler E. Apolipoprotein B mRNA editing in 12 different mammalian species: hepatic expression is reflected in low concentrations of apoB-containing plasma lipoproteins. J Lipid Res 1993;34:1367-83.

51. Veniant MM, Zlot CH, Walzem RL, Pierotti V, Driscoll R, Dichek D, et al. Lipoprotein clearance mechanisms in LDL receptor-deficient "Apo-B48-only" and "Apo-B100-only" mice. J Clin Invest 1998;102:1559-68.

52. Jong MC, Dahlmans VE, van Gorp PJ, van Dijk KW, Breuer ML, Hofker MH, et al. In the absence of the low density lipoprotein receptor, human apolipoprotein $\mathrm{C} 1$ overexpression in transgenic mice inhibits the hepatic uptake of very low density lipoproteins via a receptor-associated protein-sensitive pathway. J Clin Invest 1996;98:2259-67.

53. Mahley RW, Ji Z-S. Remnant lipoprotein metabolism: key pathways involving cell-surface heparan sulfate proteoglycans and apolipoprotein E. J. Lipid Res. 1999;40:1-16.

54. Daugherty A. Mouse models of atherosclerosis. Am J Med Sci 2002;323:3-10.

55. de Winther MP, Heeringa P. Bone marrow transplantations to study gene function in hematopoietic cells. Methods Mol Biol 2003;209:281-92.

56. Fazio S, Babaev VR, Burleigh ME, Major AS, Hasty AH, Linton MF. Physiological expression of macrophage apoE in the artery wall reduces atherosclerosis in severely hyperlipidemic mice. J. Lipid Res. 2002;43:1602-1609.

57. Kanters E, Pasparakis M, Gijbels MJ, Vergouwe MN, Partouns-Hendriks I, Fijneman RJ, et al. Inhibition of NF-kappaB activation in macrophages increases atherosclerosis in LDL receptor-deficient mice. J Clin Invest 2003;112:1176-85.

58. Jong MC, Dahlmans VEH, van Gorp PJJ, van Dijk KW, Breuer ML, Hofker MH, et al. In the Absence of the Low Density Lipoprotein Receptor, Human Apolipoprotein C1 Overexpression in Transgenic Mice Inhibits the Hepatic Uptake of Very Low Density Lipoproteins via a Receptor-associated Protein-sensitive Pathway. J. Clin. Invest. 1996;98:2259-2267.

59. Shachter NS, Zhu Y, Walsh A, Breslow JL, Smith JD. Localization of a liver-specific enhancer in the apolipoprotein E/C-I/C-II gene locus. J Lipid Res 1993;34:1699-707.

60. Jong MC, Hofker MH, Havekes LM. Role of ApoCs in lipoprotein metabolism: functional differences between ApoC1, ApoC2, and ApoC3. Arterioscler Thromb Vasc Biol 1999;19:472-84.

61. Jong MC, Dahlmans VE, van Gorp PJ, Breuer ML, Mol MJ, van der Zee A, et al. Both lipolysis and hepatic uptake of VLDL are impaired in transgenic mice coexpressing human apolipoprotein E*3Leiden and human apolipoprotein C1. Arterioscler Thromb Vasc Biol 1996;16:934-40. 
62. van Vlijmen BJ, van den Maagdenberg AM, Gijbels MJ, van der Boom H, HogenEsch H, Frants RR, et al. Diet-induced hyperlipoproteinemia and atherosclerosis in apolipoprotein E3-Leiden transgenic mice. J Clin Invest 1994;93:1403-10.

63. Groot PH, van Vlijmen BJ, Benson GM, Hofker MH, Schiffelers R, Vidgeon-Hart M, et al. Quantitative assessment of aortic atherosclerosis in $\mathrm{APOE}^{*} 3$ Leiden transgenic mice and its relationship to serum cholesterol exposure. Arterioscler Thromb Vasc Biol 1996;16:926-33.

64. van Vlijmen BJ, Pearce NJ, Bergo M, Staels B, Yates JW, Gribble AD, et al. Apolipoprotein E*3-Leiden transgenic mice as a test model for hypolipidaemic drugs. Arzneimittelforschung 1998;48:396-402.

65. van de Poll SW, Delsing DJ, Jukema JW, Princen HM, Havekes LM, Puppels GJ, et al. Raman spectroscopic investigation of atorvastatin, amlodipine, and both on atherosclerotic plaque development in APOE*3 Leiden transgenic mice. Atherosclerosis 2002;164:65-71.

66. van de Poll SW, Delsing DJ, Wouter Jukema J, Princen HM, Havekes LM, Puppels GJ, et al. Effects of amlodipine, atorvastatin and combination of both on advanced atherosclerotic plaque in APOE*3-Leiden transgenic mice. J Mol Cell Cardiol 2003;35:109-18.

67. van Vlijmen BJ, Mensink RP, van 't Hof HB, Offermans RF, Hofker MH, Havekes LM. Effects of dietary fish oil on serum lipids and VLDL kinetics in hyperlipidemic apolipoprotein E*3-Leiden transgenic mice. J Lipid Res 1998;39:1181-8.

68. Bergman F, Juul AH, Van der Linden W. Development and regression of morphological and biochemical changes in hamsters and mice fed a cholesterol cholic acid containing diet. Acta Pathol Microbiol Scand [A] 1970;78:179-91.

69. van Vlijmen BJ, van Dijk KW, van't Hof HB, van Gorp PJ, van der Zee A, van der Boom H, et al. In the absence of endogenous mouse apolipoprotein E, apolipoprotein $E^{*} 2$ (Arg-158 --> Cys) transgenic mice develop more severe hyperlipoproteinemia than apolipoprotein $\mathrm{E}^{*} 3$-Leiden transgenic mice. J Biol Chem 1996;271:30595-602.

70. Huang Y, Schwendner SW, Rall SC, Jr., Mahley RW. Hypolipidemic and hyperlipidemic phenotypes in transgenic mice expressing human apolipoprotein E2. J Biol Chem 1996;271:29146-51.

71. de Beer F, Hendriks WL, van Vark LC, Kamerling SWA, van Dijk KW, Hofker MH, et al. Binding of BVLDL to Heparan Sulfate Proteoglycans Requires Lipoprotein Lipase, Whereas ApoE Only Modulates Binding Affinity. Arterioscler Thromb Vasc Biol 1999;19:633-637.

72. van Dijk KW, van Vlijmen BJ, de Winther MP, van 't Hof B, van der Zee A, van der Boom $\mathrm{H}$, et al. Hyperlipidemia of ApoE2(Arg(158)-Cys) and ApoE3-Leiden transgenic mice is modulated predominantly by LDL receptor expression. Arterioscler Thromb Vasc Biol 1999;19:2945-51.

73. Sullivan PM, Mezdour H, Aratani Y, Knouff C, Najib J, Reddick RL, et al. Targeted Replacement of the Mouse Apolipoprotein E Gene with the Common Human APOE3 Allele Enhances Diet-induced Hypercholesterolemia and Atherosclerosis. J. Biol. Chem. 1997;272:17972-17980.

74. Knouff C, Hinsdale ME, Mezdour H, Altenburg MK, Watanabe M, Quarfordt SH, et al. Apo E structure determines VLDL clearance and atherosclerosis risk in mice. J Clin Invest 1999;103:1579-86.

75. Hinsdale ME, Sullivan PM, Mezdour H, Maeda N. ApoB-48 and apoB-100 differentially influence the expression of type-III hyperlipoproteinemia in APOE*2 mice. J Lipid Res 2002;43:1520-8.

76. Knouff C, Malloy S, Wilder J, Altenburg MK, Maeda N. Doubling Expression of the Low Density Lipoprotein Receptor by Truncation of the 3'-Untranslated Region Sequence Ameliorates Type III Hyperlipoproteinemia in Mice Expressing the Human ApoE2 Isoform. J. Biol. Chem. 2001;276:3856-3862.

77. Malloy SI, Altenburg MK, Knouff C, Lanningham-Foster L, Parks JS, Maeda N. Harmful effects of increased LDLR expression in mice with human APOE*4 but not APOE*3. Arterioscler Thromb Vasc Biol 2004;24:917.

78. Havel RJ, Hamilton RL. Hepatic catabolism of remnant lipoproteins: where the action is. Arterioscler Thromb Vasc Biol 2004;24:213-5.

79. Zannis VI, Chroni A, Kypreos KE, Kan HY, Cesar TB, Zanni EE, et al. Probing the pathways of chylomicron and HDL metabolism using adenovirus-mediated gene transfer. Curr Opin Lipidol 2004;15:151-66.

80. Kypreos KE, van Dijk KW, van Der Zee A, Havekes LM, Zannis VI. Domains of apolipoprotein E contributing to triglyceride and cholesterol homeostasis in vivo. Carboxyl-terminal region 203-299 promotes hepatic very low density lipoprotein-triglyceride secretion. J Biol Chem 2001;276:19778-86.

81. Veniant MM, Withycombe S, Young SG. Lipoprotein Size and Atherosclerosis Susceptibility in Apoe-/- and Ldlr-/- Mice. Arterioscler Thromb Vasc Biol 2001;21:1567-1570.

82. Dansky HM, Shu P, Donavan M, Montagno J, Nagle DL, Smutko JS, et al. A phenotype-sensitizing Apoedeficient genetic background reveals novel atherosclerosis predisposition loci in the mouse. Genetics 2002;160:1599-608. 
83. Schadt EE, Monks SA, Drake TA, Lusis AJ, Che N, Colinayo V, et al. Genetics of gene expression surveyed in maize, mouse and man. Nature 2003;422:297-302.

84. Darvasi A. Genomics: Gene expression meets genetics. Nature 2003;422:269-70. 


\section{III}

\section{Early diet-induced non-alcoholic steatohepatitis in APOE2 knock- in mice and its prevention by fibrates}

Kristiaan Wouters ${ }^{1,7)}{ }^{*}$, Ronit Shiri-Sverdlov ${ }^{1,7,8)}$ * , Patrick J. van Gorp ${ }^{1,7,8)}$, Marion J. Gijbels $^{1,2,7)}$, Benoit Noel $^{3)}$, Laurent Buffat ${ }^{4)}$, Bart Staels ${ }^{3)}$, Nobuyo Maeda ${ }^{5)}$, Marc van Bilsen $^{6,7)}$, and Marten H. Hofker ${ }^{1,7,8)}$

1) Dept. of Molecular Genetics, University Maastricht, Maastricht, The Netherlands; 2) Department of Pathology, University of Maastricht, Maastricht, The Netherlands; 3) U.545 Inserm, Institut Pasteur de Lille, Departement d'Atherosclérose and Université de Lille2, Lille, France ; 4) IT Omics, Lille, France; 5) Dept of Pathology, University of North Carolina, Chapel Hill, USA; 6) Dept. of Physiology, University Maastricht, Maastricht, The Netherlands; 7) Cardiovascular Research Institute Maastricht; 8Nutrition and Toxicology Research Institute Maastricht

* Both authors contributed equally to this paper

J Hepatol. 2006 Apr;44(4):732-41 


\section{Abstract}

Background/aims: The molecular mechanisms leading to non-alcoholic steatohepatitis (NASH) are not fully understood. In mice, NASH can be inhibited by fenofibrate, a synthetic agonist for the nuclear receptor peroxisome proliferator activated receptor alpha, which regulates hepatic triglyceride metabolism. This study aimed to elucidate the relation between steatosis and inflammation in NASH in a human-like hyperlipidemic mouse model.

Methods: Liver phenotype and gene expression were assessed in APOE2 knock-in mice that were fed a western-type high fat diet with or without co-administration of fenofibrate.

Results: In response to a western diet, APOE2 knock-in mice developed NASH characterized by steatosis and inflammation. Strikingly, macrophage accumulation in the liver preceded the steatosis during progression of the disease. This phenotype was in line with gene expression patterns, which showed regulation of two major groups of genes, i.e. inflammatory and lipid genes. Fenofibrate treatment decreased hepatic macrophage accumulation and abolished steatosis. Moreover, a marked reduction in the expression of inflammatory genes occurred immediately after fibrate treatment.

Conclusions: These data indicate that inflammation might play an instrumental role during the development of NASH in this mouse model. Inhibition of NASH by fenofibrate may be due, at least in part, to its inhibitory effect on pro-inflammatory genes. 


\section{I ntroduction}

Non-alcoholic steatohepatitis (NASH) is characterized by pathological alterations ranging from steatosis and inflammation to cell degeneration, fibrosis and cirrhosis [1]. The pathogenesis of NASH remains poorly understood. It is a component of the metabolic syndrome and therefore frequently associated with hyperlipidemia [2]. Indeed, several mouse models of hyperlipidemia, such as $\operatorname{ldlr}^{-/-}$and apoe $\mathrm{e}^{-/-}$mice develop steatohepatitis upon high-fat feeding [3, 4].

In order to study the development of NASH and the relationship of steatosis and inflammation, we used the 'humanized' APOE2 knock-in (APOE2ki) mouse, in which the human APOE2 allele replaces the murine apoe gene. These mice express human APOE2 under the control of the endogenous promoter sequences in a tissue specific manner and at physiological levels. APOE2 has a markedly reduced affinity for the low density lipoprotein (LDL) receptor, leading to a plasma lipoprotein profile resembling human type III hyperlipoproteinemia (HLP) [5].

Similar to humans, APOE2ki mice are responsive to lipid-lowering drugs such as fibrates, ligands for peroxisome proliferator activated receptor (PPAR $\alpha$ ) [5]. This nuclear receptor enhances the expression of genes involved in fatty acid (FA) uptake, esterification and beta-oxidation [6] and has been shown to reverse steatohepatitis in mice [7]. Accordingly, fenofibrate (FF) was administrated to investigate the molecular mechanisms leading to the inhibition of NASH.

In this study, APOE2ki mice were fed a high-fat diet in the absence or presence of fenofibrate. The changes in plasma lipids, liver phenotype and gene expression were followed in time to discriminate between early (primary) and late (secondary) events related to NASH.

\section{Materials and methods}

\section{Mice and diet}

APOE2ki mice [5] were housed under standard conditions given free access to food and water. Experiments were performed according to Dutch laws, approved by the Committee for Animal Welfare of Maastricht University.

Ninety homozygote female mice, 13 weeks old, were divided into groups of 10 mice. One group was kept on standard chow. Four groups were fed a western diet, containing $17 \%$ casein, $0.3 \%$ DL-methionine, $34 \%$ sucrose, $14.5 \%$ cornstarch, $0.2 \%$ cholesterol, $5 \%$ cellulose, $7 \%$ CM 205B, $1 \%$ vit 200, 21\% butter (diet 1635, Scientific Animal Food and Engineering, Villemoisson-sur-orge, France) for 2, 4, 7 and 21 days. Four 
groups were put on the western-diet completed with $0.2 \%$ fenofibrate (F6020, Sigma Aldrich, Zwijndrecht, the Netherlands) for 2, 4, 7 and 21 days. Blood samples were taken from the tail after a 4-h fast and collected in glass capillaries, coated with heparin and diethyl p-nitrophenyl phosphate [8] (D9286, Sigma Aldrich, Zwijndrecht, the Netherlands). Mice were sacrificed by cervical dislocation. Tissues were isolated, snapfrozen in liquid nitrogen and stored at $-80^{\circ} \mathrm{C}$ or fixed in $4 \%$ formaldehyde/PBS.

\section{Plasma parameters}

Plasma total cholesterol (TC) and triglyceride (TGs) were measured (1489232, cholesterol CHOD-PAP, Roche, Almere, the Netherlands; 337-B, TG GPO-trinder, Sigma Aldrich, Zwijndrecht, the Netherlands) according to manufacturer's protocols on a Benchmark 550 Micro-plate Reader (170-6750XTU, Bio-Rad, Veenendaal, the Netherlands).

Lipoprotein profiles were determined on pooled plasma samples from 10 mice using an AKTA Basic chromatography system with a Superose 6PC 3.2/30 column (Amersham Biosciences, Roosendaal, The Netherlands).

\section{RNA isolation}

Total RNA was isolated from frozen tissues homogenized in TriReagent (T9424, Sigma Aldrich, Zwijndrecht, the Netherlands) with the MiniBeadBeater (3110BXEUR, Biospec Products, Bartlesville, USA). RNA clean-up was performed using Qiagen RNeasy Mini Kit (74104, Qiagen, Venlo, the Netherlands). Quality and quantity were determined with Agilent2100 Bioanalyzer and RNA 6000 NanoLabChip (5065-4476, AgilentTechnologies, Amstelveen, the Netherlands). Applications were done according to manufacturer's instructions.

\section{CDNA synthesis and microarray hybridization}

Pools of 10 mice were made from equal amounts of RNA from each mouse. $6 \mu \mathrm{g}$ of pooled liver RNA was used in cDNA synthesis. Samples were hybridized to Affymetrix Mouse Expression Array 430A (900412, Affymetrix UK Ltd, High Wycombe, UK) according to manufacturer's protocols.

\section{Microarray analysis}

Raw data from the microarrays was analyzed using GeneChip Microarray Suite 5.0 (MAS 5.0, Affymetrix) and Data Mining Tools 3.1 (DMT 3.1, Affymetrix). To identify 
regulated genes, ANOVA analysis was applied based on probe level information with, $\mathrm{R}$ (http://www.r-project.org) and Bioconductor (http://www.bioconductor.org) was used. After normalization, a model was developed, based on probe level intensity for each probe set.

Genes were selected according to the p-value of the diet/treatment effect for each delay coefficient ( 4 p-values per probe set) and for the multi-testing problem Bonferroni correction with a threshold of 1e-6 ( $0.05 /(22000 * 3)$ (Number of probe set * number of test by probe set) was used. Genes with a p-value lower than $10^{-6}$ were selected.

\section{I mmunohistochemistry}

Four $\mu \mathrm{m}$ paraffin embedded liver sections were stained with Haematoxillin/Eosin (HE). Seven $\mu \mathrm{m}$ frozen-cut liver sections were fixated in acetone and stained with CD68 (FA11), Mac1 (M1/70) and Nimp1 antibodies (granulocytes) as described before [9].

\section{Hepatic lipid analysis}

Approximately $50 \mathrm{mg}$ of frozen liver tissue was homogenized for $30 \mathrm{~s}$ at $5000 \mathrm{rpm}$ in a closed tube with $5.0 \mathrm{~mm}$ glass beads and $1.0 \mathrm{ml}$ SET buffer (Sucrose 250mM, EDTA 2 $\mathrm{mM}$ and Tris $10 \mathrm{mM}$ ) [10]. Complete cell destruction was done by two freeze-thaw cycles and 3 times passing through a 27-gauge syringe needle and a final freeze-thaw cycle. Protein content was measured with the BCA method (23225, Pierce, Rockford, IL, USA). TGs were measured as described above. Protocols were done according to manufacturer's instructions.

\section{Real-Time quantitative PCR}

Prior to Real-Time quantitative PCR (QPCR), liver RNA pools of each group were reverse transcribed with the iScript cDNA synthesis kit (170-8891, Bio-Rad, Veenendaal, the Netherlands) according to manufacturer's instructions. cDNA quantification was done by QPCR on an ABI Prism 7700 (Applied Biosystems, Nieuwerkerk a/d IJssel, the Netherlands) with Mastermix Plus kit for Sybr Green I (RT-SN2X-03+*, Eurogentec, Seraing, Belgium). For each gene, a standard curve was generated. Normalization was done with cyclophillin A. Specific primers sets were developed with Primer Express 1.5 (Applied Biosystems): 
Lipoprotein lipase $(L p L)$ Forward (fw) 5'- GAT GCC CTA CAA AGT GTT CCA - 3' and reverse (rv) 5'- GCC ACT GTG CCG TAC AGA GA - 3'; Cytosolic acyl-CoA thioesterase 1(Ctel) fw 5'- GCA GCC ACC CCG AGG TAA A - 3' and rv 5'- GCC ACG GAG CCA TTG ATG - 3'; Farnesyl diphosphate farnesyl transferase $1(f d f t 1) \mathrm{fw}$ 5'- CCC TGA CGT CCT CAC CTA CCT - 3' and rv 5'- GGC CAT TAC CTG TGG AAT AGC A - 3'; Acyl-Coenzyme A dehydrogenase very long chain (acadvl) fw 5'AGA CGG AGG ACA GGA ATC GG - 3' and rv 5'- ACC ACG GTG GCA AAT TGA TC - 3'; Acyl-CoA Oxidase 1(acoxl) fw 5'- CTT GAG GGG AAC ATC ATC ACA - 3' and rv 5'- GCC AAG GGT CAC ATC CTT AAA GT - 3'; Cyclin D1 (ccndl) fw 5'- TAC CGC ACA ACG CAC TTT CTT -3' and rv 5'- CGC AGG CTT GAC TCC AGA AG -3'; Carnitine palmitoyltransferase 1a (cpt1a) fw 5'- TGA CCT GCT CTC TCT AAG GCT ACA -3' and rv 5'- GCC AGC GCC CGT CAT -3'; CD68 antigen fw 5'- TGA CCT GCT CTC TCT AAG GCT ACA -3' and rv 5'- TCA CGG TTG CAA GAG AAA CAT; Nuclear factor of kappa light chain gene (nfkbia) fw 5'- TGG AAG TCA TTG GTC AGG TGA A -3' and rv 5'- TCA CGG TTG CAA GAG AAA CAT G - 3'; Cyclosporin A-binding protein fw 5'- CAA ATG CTG GAC CAA ACA CAA - 3' and rv 5'- GCC ATC CAG CCA TTC AGT CT - 3'. Data were analyzed with SDS 1.9.1 (Applied Biosystems).

\section{Statistical analysis}

Data were analysed using Graphpad Prism 4.0. Groups were compared using Welchcorrected 2-tailed non-paired t-tests. Data is expressed as means \pm SEM and considered significant at $\mathrm{p}<0.05$.

\section{Results}

\section{Effects of high-fat diet on lipid levels}

Western diet, containing $21 \%$ fat and $0.2 \%$ cholesterol, induced a nearly 4 -fold increase in plasma TC levels already after 2 days (Fig. 1A), which continued to rise to 7-fold after 21 days. Cholesterol was mainly present in very low density lipoproteins (VLDL) and low density lipoprotein (LDL), while on chow it was mainly present in high density lipoprotein (HDL) (Fig. 1C). TG levels (Fig. 1B) decreased as the high-fat feeding progressed, as observed previously [5]. This slight decrease was only significant after 3 weeks of high-fat feeding. Free fatty acid (FFA) glucose levels were not affected (data not shown). 


\section{Response to fenofibrate treatment}

The western diet-induced rise in plasma cholesterol levels was completely abolished upon fenofibrate treatment. Cholesterol levels decreased markedly already at 2 days and were kept at basal level after 4, 7 and 21 days (Fig. 1A). Similarly, fenofibrate had a rapid lowering effect on TGs (Fig. 1B). FF-treatment induced a substantial decrease in VLDL-cholesterol. These alterations in plasma lipids levels are similar to hyperlipidemic patients treated with fibrates [11].
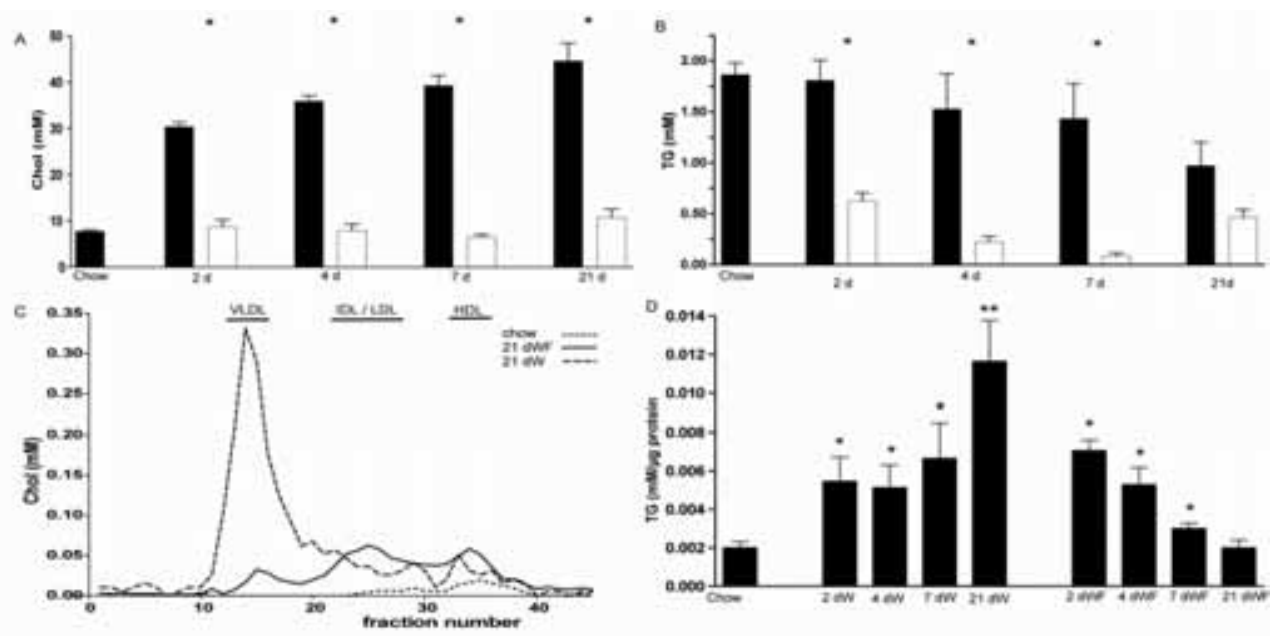

Figure 1. Lipid parameters of the APOE2ki mice upon high-fat feeding with and without fenofibrate addition. At each time point ( 2 days (d), $4 \mathrm{~d}, 7 \mathrm{~d}$ and $21 \mathrm{~d}$ ), mice treated with a high-fat diet (black bars) and mice treated with a high-fat diet with fenofibrate (white bars) are shown in panels A and B. The chow group is added as a black bar. Significant differences are shown with *. Plasma values are shown in panels A (Cholesterol) and B (TGs). Panel C shows cholesterol concentration in each lipoprotein fraction. Panel D shows the amount of hepatic TGs at the several time points of high fat feeding (W) with and without fibrate (dWF and dW). A significant difference between the group and the normal chow diet is indicated by *, and ** indicates significant difference with both the chow group and the former time point.

\section{Liver histology}

HE staining was performed to investigate the effect of the western diet in the liver. Sections showed a gradual fat accumulation in liver cells upon high-fat feeding (Fig. 2A). After 4-7 days of high-fat feeding, lipid droplets became visible (Fig. 2A, white arrows). The number and size of the droplets increased with time. Consistent with the 
morphological observations, biochemical analysis demonstrated a gradual increase in the hepatic content of TGs while fenofibrate treatment prevented fat accumulation (Fig. 1D, 2A). Unexpectedly, already after 2 days of high-fat feeding, aggregates of inflammatory cells became visible in the HE stained-livers of the mice fed the western diet (Fig. 2A, black arrows). Immunohistochemical staining was performed to define the nature of these inflammatory cells. Compared to animals on a chow diet, already after 2 days of high-fat feeding an increase in CD68-positive cells was detectable (Fig. 2B), reflecting an increased number of Kupffer cells and macrophages. Within time, CD68-positive cells increased even further and aggregates of inflammatory cells became larger. Remarkably, fibrate treatment strongly opposed this effect (Fig. 2B).

To investigate whether the increase in CD68 marker was due to increase in the number of macrophages or proliferation of Kupffer cells, liver tissues were stained for Mac1 (Fig. 3). The number of Mac1-positive cells was corrected for granulocytes (also positive for Mac1), using the granulocyte-specific Nimp1 antibody. The combined data demonstrate a significant increase in the number of liver macrophages (10.3 fold) already after 2 days. At 4 days the number of macrophages further increased to a maximal level (17.8 fold). Fibrate treatment reduced the amount of macrophages substantially. Altogether, these data indicate that the increase in the number of macrophages is an early event during development of NASH and that it is prevented upon PPAR $\alpha$-activation.

\section{Diet-regulated genes}

Large scale gene expression analysis showed 294 genes to be regulated; 180 (61\%) showed up-regulation upon high-fat feeding, whereas 114 genes (39\%) were downregulated. We focused on genes involved in inflammation and lipid metabolism, as these two classes of genes comprised the largest groups of regulated genes (table 1) and are directly linked to the pathological phenotype of these mice. The increase in inflammatory genes is in line with other studies in which western diet was applied to different types of mice such as C57Bl/6 and APOE3-Leiden [12, 13]. Strikingly, in our model, inflammation appeared already after 2 days. Many of these inflammatory genes are regulated via the transcription factor nuclear factor kappa beta (NF- $\mathrm{\kappa B})$ (i.e. vascular cell adhesion molecule 1, phospolipase A2, serum amyloid genes). Among the inflammatory genes, the acute phase response genes (i.e. serum amyloid A1, A2, A3, A4) were induced rapidly, followed by up-regulation of interferon-induced genes (i.e. interferon gamma inducible protein 30 , interferon induced transmembrane protein 2 , interferon -induced protein with tetratricopeptide) and heat shock proteins, indicative for the development of a stress response. 


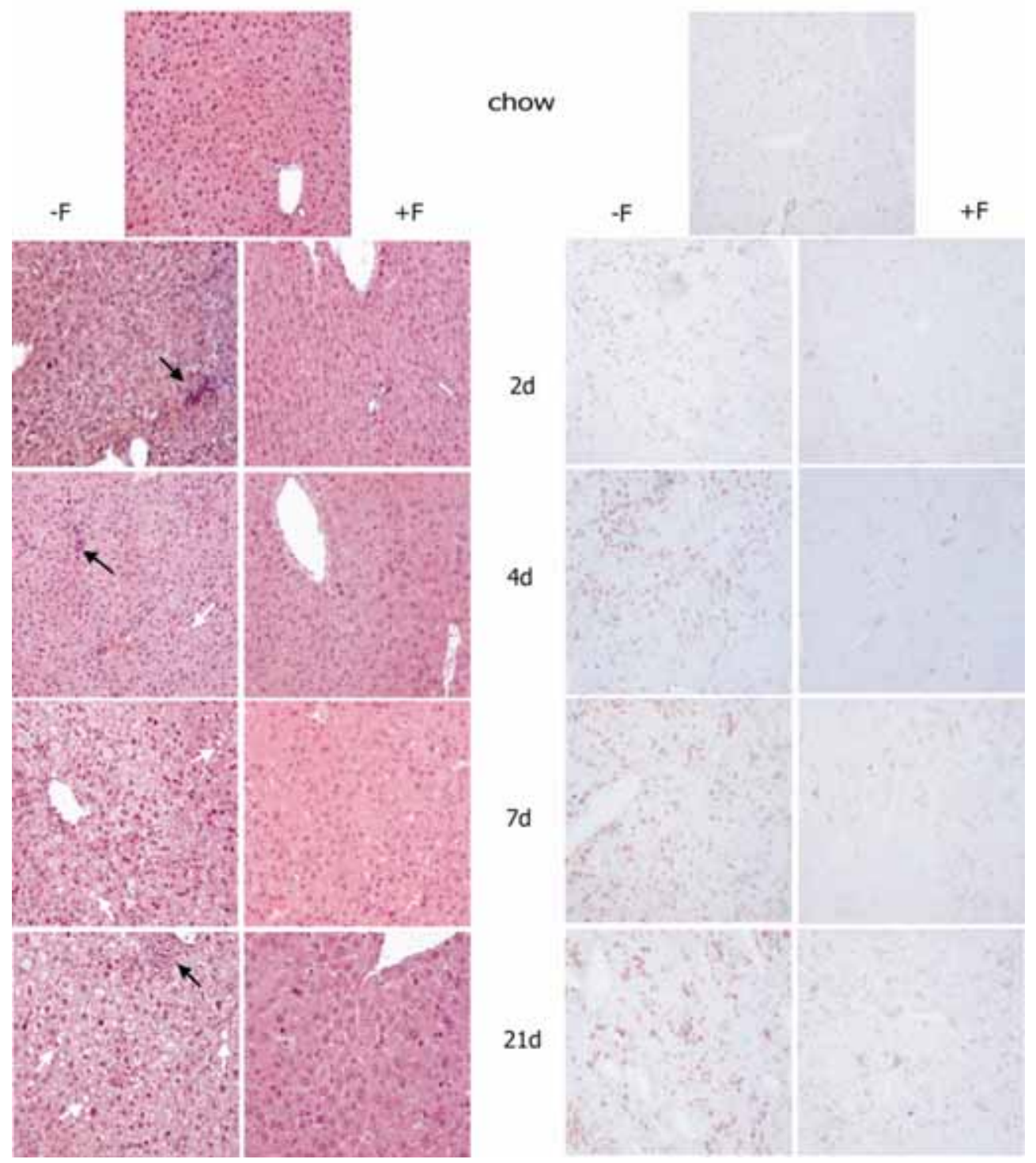

Figure 2. Morphology of liver tissue. Panel A shows HE-stained paraffin slides. White arrows indicate fat droplets, black arrows point at inflammatory clusters. At all time points, left pictures of mice on the high-fat diet (-F), right pictures of mice treated with fenofibrate $(+F)$ are shown. Panel B. Immunostaining with antibodies against CD68 and counterstained with haematoxylin. 
Among the lipid genes, mainly genes involved in FA biosynthesis such as stearoylCoenzyme A desaturase 2, lipid transport (e.g. ATP binding cassette G5 and A1; ABCG5, ABCA1) and lipid metabolism (e.g. lipoprotein lipase [LpL] and granulin), were up-regulated.

In addition, within time the expression of collagen synthesis genes like procollagen type 1 was also up-regulated, indicating the development of fibrosis.

The number of inflammatory genes went up rapidly until day four, indicating a quick inflammatory response in the liver. After four days, the increase became less pronounced. In contrast, the number of lipid genes increased steadily with time (Fig. 4). These data indicate that the early phenotypic changes in liver histology and blood parameters of APOE2ki mice fed a western diet are accompanied by massive regulation in hepatic expression of inflammatory genes followed by lipid genes.

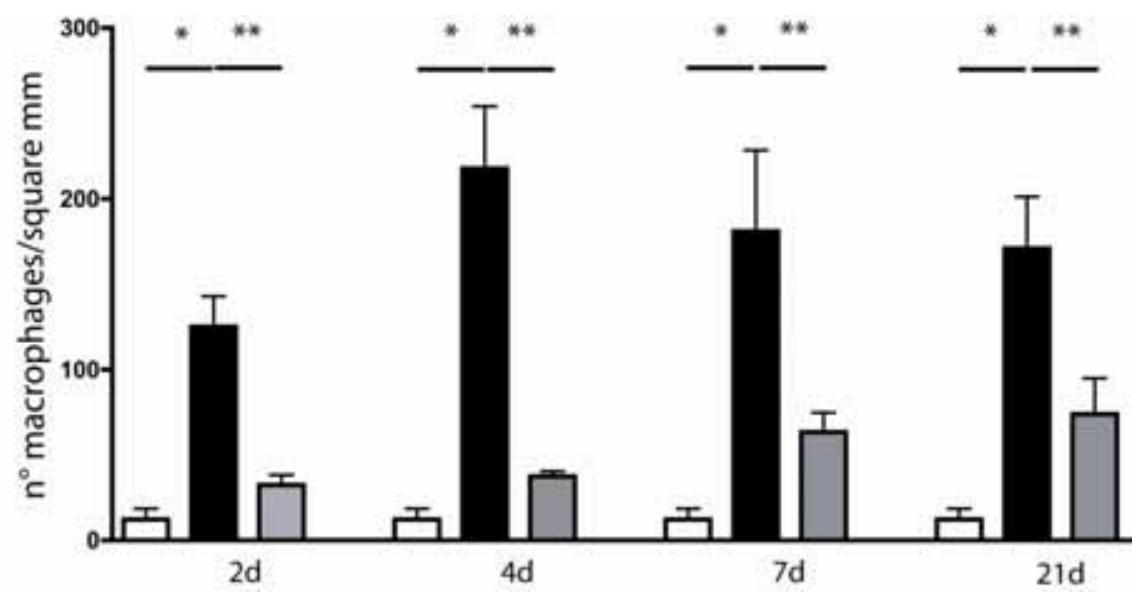

Figure 3. Macrophages in the liver. Hepatic cryoslides were stained with antibodies against Mac1 and counted. The counting was corrected for stained granulocytes, which also express this marker. White bars indicate animals on a chow diet, black bars show data from mice fed the high-fat diet and gray bars indicate mice fed the high-fat diet supplemented with fenofibrate. Significant differences compared to the chow group are indicated by *, while ** shows significance between the fibrate-treated group and the high-fat diet-treated group. Scale expressed as cells per $\mathrm{mm} 2$. 


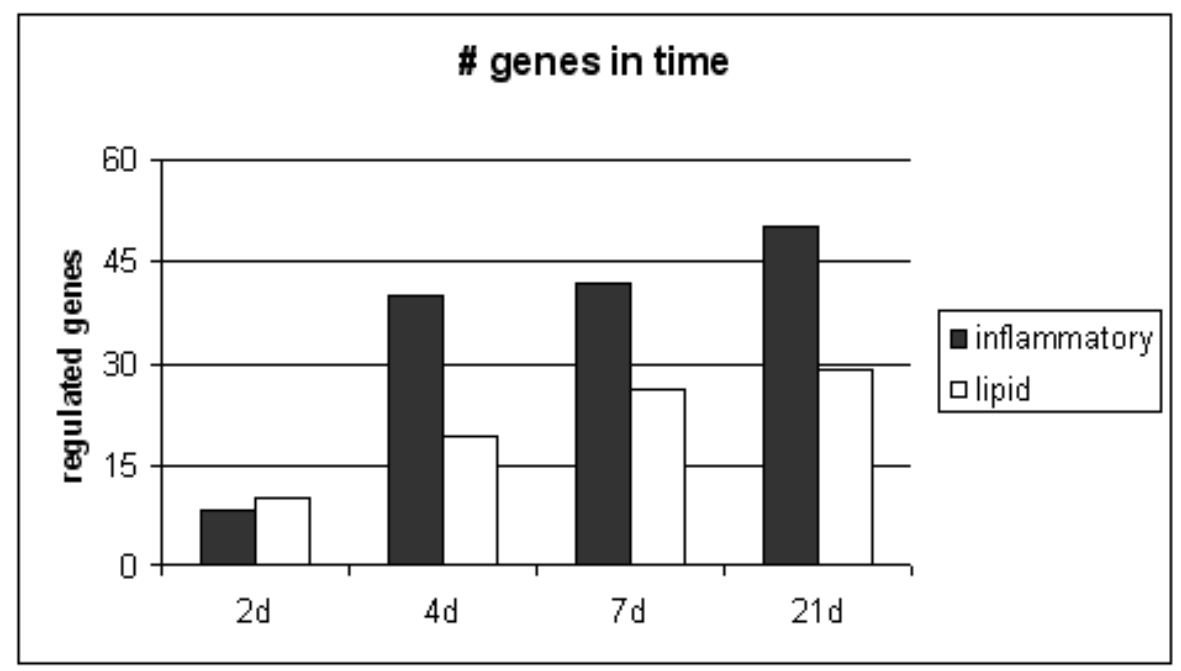

Figure 4. Amount of lipid and inflammation genes regulated in time. This figure shows the total number of genes that are regulated by the diet at all time points. White bars indicate the lipid genes, while the black bars indicate the inflammation-related genes. Both up-and down-regulated genes are included in this figure.

\section{Fibrate-regulated genes}

Liver RNA from mice fed a western diet enriched with fenofibrate at two time points ( 2 days and 7 days) was collected and hybridized to Affymetrix arrays. These time points were chosen to identify early effects, and to avoid indirect effects. Comparison to the diet-regulated genes revealed relatively small overlap, suggesting a more important role for nuclear receptors other than PPAR $\alpha$ in diet-induced expression (table 1). As expected, fibrate changed the expression of many genes, including previously known PPAR $\alpha$ responsive genes. Many of these genes are involved in processes such as lipid metabolism and inflammation. Upon fenofibrate treatment, a total of 1023 genes were regulated (compared with western diet at the corresponding time-points). Among these genes, 830 (81\%) were up-regulated and $193(19 \%)$ were down-regulated. The majority of up-regulated genes included lipid metabolism genes, such as genes involved in FA $\beta$-oxidation and lipid transport. In contrast, downregulated genes belong to inflammatory pathways, mainly under control of NF- $\mathrm{KB}$. These results are in agreement with previous studies reporting the hepatic response of other mice models to fibrate treatment [14]. In addition, the expression of procollagen synthesis genes, like procollagen type 1 , was inhibited by fibrate. 
Table 1. Lipid- and inflammation-related genes upon feeding a high-fat diet.

\begin{tabular}{|c|c|c|c|c|c|c|}
\hline gene & $2 \mathrm{dW}$ & $4 \mathrm{dW}$ & $7 \mathrm{dW}$ & $21 \mathrm{dW}$ & $2 \mathrm{dF}$ & $7 \mathrm{dF}$ \\
\hline \multicolumn{7}{|l|}{ Lipid metabolism genes } \\
\hline insulin induced gene 2 & -1.5 & ns & ns & ns & 1.8 & 1.6 \\
\hline RIKEN cDNA $1600020 \mathrm{H} 07$ gene & ns & ns & -1.5 & -1.6 & ns & 1.7 \\
\hline farnesyl diphosphate farnesyl transferase 1 & ns & -2.1 & -3.1 & -2.4 & ns & 1.9 \\
\hline 3-hydroxy-3-methylglutaryl-Coenzyme A synthase 1 & ns & ns & -3 & -4 & ns & 2.9 \\
\hline pancreatic lipase-related protein 2 & -1.2 & -2.4 & -7.3 & -8.4 & -7 & -1.2 \\
\hline pancreatic lipase related protein 1 & 1 & -2.3 & -11 & -20 & -23 & -1.7 \\
\hline carboxyl ester lipase & ns & ns & -9.6 & -18 & -21 & ns \\
\hline colipase, pancreatic & ns & ns & -14 & -39 & -41 & ns \\
\hline isopentenyl-diphosphate delta isomerase & ns & -4.2 & -4.2 & -5.2 & -3.3 & ns \\
\hline sterol-C4-methyl oxidase-like & ns & -3.6 & -3.9 & -3.6 & -2.5 & ns \\
\hline acetyl-CoA synthetase 2 (ADP forming) & -1.8 & -2.3 & -3.2 & -3.3 & -2.7 & ns \\
\hline NAD(P) dependent steroid dehydrogenase-like & ns & -2.1 & -2.1 & -2.4 & -2.2 & ns \\
\hline phospholipase A2, group IB, pancreas & ns & ns & -2.9 & -3 & ns & ns \\
\hline sterol-C5-desaturase homolog (S. cerevisae) & -1.4 & -1.4 & -1.5 & -1.5 & ns & ns \\
\hline sulfotransferase, hydroxysteroid preferring 2 & ns & ns & -2.4 & -2.6 & ns & ns \\
\hline phenylalkylamine $\mathrm{Ca} 2+$ antagonist binding protein & ns & ns & -1.6 & ns & ns & ns \\
\hline NADH dehydrogenase $1, \mathrm{a} / \mathrm{b} 1$ & ns & ns & -1.6 & ns & ns & ns \\
\hline fatty acid synthase & ns & ns & ns & -1.5 & ns & ns \\
\hline cytochrome P450, 51 & ns & ns & ns & -2.1 & ns & ns \\
\hline 7-dehydrocholesterol reductase & ns & -2.1 & -2.3 & -2.4 & ns & ns \\
\hline fatty acid binding protein 5 , epidermal & 2.6 & ns & 1.7 & 1.5 & -2.3 & -2.1 \\
\hline lysosomal acid lipase 1 & ns & 1.4 & 1.4 & 1.5 & 1.6 & 1.4 \\
\hline stearoyl-Coenzyme A desaturase 1 & 1.2 & ns & ns & ns & ns & 1.9 \\
\hline fatty acid binding protein 2 , intestinal & 2.6 & 2.9 & 2.7 & 3.2 & 1.6 & 2.2 \\
\hline 3-ketoacyl-CoA thiolase B & 1.4 & 1.5 & ns & 1.5 & 2.4 & 2.8 \\
\hline lipoprotein lipase & ns & 2.2 & 2.8 & 4.2 & 2.2 & 3.3 \\
\hline granulin & ns & 1.4 & ns & 1.6 & 1.5 & ns \\
\hline ATP-binding cassette, sub-family $G, 5$ & ns & 1.7 & 1.5 & 2 & 1.7 & ns \\
\hline prosaposin & ns & 1.8 & 1.8 & 1.9 & 1.6 & ns \\
\hline ATP-binding cassette, sub-family A, 1 & ns & 1.9 & 1.9 & 2.1 & ns & ns \\
\hline stearoyl-Coenzyme A desaturase 2 & ns & 2.8 & 2.6 & 3 & ns & ns \\
\hline fatty acid binding protein 7 , brain & ns & 2.8 & ns & ns & ns & ns \\
\hline phospholipid transfer protein & ns & ns & ns & 2 & ns & ns \\
\hline apolipoprotein B & 1.3 & ns & ns & ns & ns & ns \\
\hline lipopolysaccharide binding protein & 1.6 & 1.7 & 1.6 & 1.6 & ns & ns \\
\hline apolipoprotein A-IV & 3.9 & 3.9 & 4.2 & 4.1 & ns & ns \\
\hline \multicolumn{7}{|l|}{ Inflammatory genes } \\
\hline $\begin{array}{l}\text { C-type lectin, superfamily member } 13 \\
\text { interferon-induced protein with tetratricopeptide }\end{array}$ & ns & 1.8 & 1.9 & 1.6 & ns & -1.5 \\
\hline repeats 1 & 3 & ns & ns & ns & -2.5 & ns \\
\hline orosomucoid 2 & ns & 3.4 & 3.9 & ns & ns & -6.2 \\
\hline serum amyloid A 1 & 6.1 & 7.3 & 9.8 & 5.8 & -9.8 & -26 \\
\hline serum amyloid A 2 & 5.2 & 5.8 & 9 & 4.9 & -7.3 & -17 \\
\hline serum amyloid A 3 & ns & 5.6 & 6 & 3.8 & -2.4 & -6.5 \\
\hline serum amyloid A 4 & 2 & 1.9 & 1.7 & ns & -2.7 & -2.7 \\
\hline
\end{tabular}


Table 1 (continued)

\begin{tabular}{|c|c|c|c|c|c|c|}
\hline gene & $2 \mathrm{dW}$ & $4 \mathrm{dW}$ & $7 \mathrm{dW}$ & $21 \mathrm{dW}$ & $2 \mathrm{dF}$ & $7 \mathrm{dF}$ \\
\hline T-cell specific GTPase & 3 & ns & ns & ns & -4.2 & ns \\
\hline regenerating islet-derived 2 & -4.9 & -10 & -11 & -12 & -1.2 & ns \\
\hline regenerating islet-derived 1 & ns & -3.1 & -19 & -36 & -2.3 & ns \\
\hline phospholipase A2, group IB, pancreas & ns & ns & -2.9 & -3 & -2.7 & ns \\
\hline early growth response 1 & -3.3 & -2.1 & -2.4 & -2.3 & 2.6 & ns \\
\hline heat shock protein 1 , alpha & ns & 1.8 & 1.7 & 1.9 & 3.1 & 2.1 \\
\hline heat shock protein 105 & ns & 1.7 & $\mathrm{~ns}$ & $\mathrm{~ns}$ & 1.9 & ns \\
\hline heat shock protein $1 \mathrm{~B}$ & ns & ns & 3.2 & 3.3 & 5 & ns \\
\hline lectin, galactose binding, soluble 1 & ns & ns & 1.7 & 1.7 & 1.6 & 2 \\
\hline phospholipase A2, group VII & ns & ns & 2 & 2.6 & ns & 2.4 \\
\hline S100 calcium binding protein A8 (calgranulin A) & 2.1 & 2.9 & 2.3 & 3.3 & 1.5 & ns \\
\hline C-type lectin-like receptor 2 & ns & 2.8 & 2.4 & 2.9 & ns & ns \\
\hline cytotoxic $\mathrm{T}$ lymphocyte-associated protein $2 \mathrm{~b}$ & ns & 2.4 & ns & ns & ns & ns \\
\hline eosinophil-associated, ribonuclease A 2 family & ns & 2 & 2.3 & 2.9 & ns & ns \\
\hline glycoprotein (transmembrane) $\mathrm{nmb}$ & ns & ns & 2.8 & 5.2 & ns & ns \\
\hline heat shock protein 8 & ns & ns & ns & 1.5 & ns & ns \\
\hline histocompatibility 2 , class II antigen A, alpha & ns & ns & 2.3 & 2.9 & ns & ns \\
\hline histocompatibility 2 , class II antigen A, beta 1 & $\mathrm{~ns}$ & ns & ns & 2.8 & ns & $\mathrm{ns}$ \\
\hline histocompatibility 2 , class II antigen E beta & ns & ns & 1.9 & 2.3 & ns & ns \\
\hline immunoglobulin heavy chain $6, \operatorname{IgM}$ & ns & 1.7 & ns & ns & ns & ns \\
\hline interferon induced transmembrane protein 2 & ns & 1.6 & 1.4 & 1.3 & ns & ns \\
\hline catenin beta & ns & ns & $\mathrm{ns}$ & 1.5 & ns & ns \\
\hline CD44 antigen & ns & 2.8 & 2.4 & 2.6 & ns & ns \\
\hline CD52 antigen & ns & 2.5 & 2.5 & 2.9 & $\mathrm{~ns}$ & ns \\
\hline CD68 antigen & ns & 3.7 & 3.7 & 4 & ns & ns \\
\hline cDNA sequence BC032204 & ns & 2.3 & ns & 2.6 & ns & ns \\
\hline chemokine (C-C motif) ligand 6 & ns & 3.5 & 3.7 & 4.1 & ns & ns \\
\hline complement component $1, \mathrm{q}$ alpha polypeptide & ns & 1.7 & 1.8 & 2 & ns & ns \\
\hline complement component $1, \mathrm{q}$ beta polypeptide & ns & 2.3 & 2.2 & 2.8 & ns & ns \\
\hline complement component 1 , q gamma polypeptide & ns & 2.3 & 2.4 & 2.9 & $\mathrm{~ns}$ & ns \\
\hline C-type lectin, superfamily member 12 & ns & 3.7 & 4.3 & 5.2 & ns & ns \\
\hline C-type lectin, superfamily member 10 & ns & ns & ns & 2.3 & ns & ns \\
\hline immunoglobulin kappa chain variable 28 & $\mathrm{~ns}$ & 2.8 & ns & 2.4 & ns & $\mathrm{ns}$ \\
\hline interferon activated gene 203 & ns & 2.1 & 2 & 2.3 & ns & ns \\
\hline interferon gamma inducible protein 30 & ns & 2.5 & 2.5 & 2.5 & $\mathrm{~ns}$ & ns \\
\hline lymphocyte antigen 86 & ns & 2.1 & 2.1 & 2.2 & $\mathrm{~ns}$ & ns \\
\hline macrophage receptor with collagenous structure & ns & 2.2 & 2.6 & 2 & ns & ns \\
\hline matrix metalloproteinase 12 & ns & ns & 3 & 4.2 & $\mathrm{~ns}$ & ns \\
\hline procollagen, type I, alpha 1 & $\mathrm{~ns}$ & ns & 2.4 & 2.5 & $\mathrm{~ns}$ & ns \\
\hline procollagen, type III, alpha 1 & ns & 2.8 & 3.7 & 4.3 & $\mathrm{~ns}$ & ns \\
\hline procollagen, type IV, alpha 1 & $\mathrm{~ns}$ & 1.8 & 2.1 & 2.2 & ns & ns \\
\hline $\begin{array}{l}\text { procollagen, type XIV, alpha } 1 \\
\text { protein tyrosine phosphatase,non-receptor type }\end{array}$ & ns & ns & ns & 1.6 & ns & ns \\
\hline substrate 1 & ns & 2.6 & 2.7 & 3.2 & $\mathrm{~ns}$ & ns \\
\hline transforming growth factor, beta induced & ns & 1.6 & ns & 1.8 & $\mathrm{~ns}$ & ns \\
\hline vascular cell adhesion molecule 1 & ns & 2.6 & 2.3 & 2.3 & ns & ns \\
\hline pancreatitis-associated protein & ns & -2.9 & -2.8 & -3.3 & ns & ns \\
\hline
\end{tabular}


Table 1. Lipid-and inflammation-related genes upon feeding a high-fat diet. All genes in this table are regulated by diet only or by diet and fibrate treatment. Fold changes of gene expression of the animals fed the high-fat diet are shown relative to gene expression in the chow-fed group at 2, 4, 7, and 21 days (d) on western diet (W), or W supplemented with fenofibrate (F). Fold changes of the gene expression of the fibrate-treated animals is shown relative to the high-fat treated animals at the same time point.

\section{Validation of the array data}

The regulation of 5 well-known PPAR $\alpha$ responsive genes involved in lipid metabolism (Lpl, Cte1, Cpt1, Acadvl and Acox1) was verified by QPCR. In addition, the expression of two additional genes regulated on a western diet (Ccnd1 and Fdft1) and two inflammatory genes (CD68 antigen and NF-кBia) were also determined (table 2). To correlate the results obtained by QPCR and Affymetrix analysis of the 10 selected genes, the logarithmic values of the fold change obtained by the two techniques were compared (Fig. 5). These results indicate a significant correlation (Pearson correlation coefficient $=0.90 ; \mathrm{p}<0.0001)$.

Biological variation within each pool was checked by QPCR on individual mice for CD68 and Acox1. The degree of up- and down-regulation upon treatment with western diet was found to be consistent for all individual mice (data not shown).

Collectively, the QPCR results were fully compatible with the array data and demonstrate the reliability of the microarray analysis.

\section{Discussion}

In the present study, we show that APOEki mice develop NASH in response to western diet, which can be inhibited by fibrate treatment.

To our knowledge, in all other studies performed with the APOE2ki mice liver morphology was not subject of investigation [5, 15-17]. Interestingly, already within 4 days of high-fat feeding these mice develop a marked liver phenotype characterised by steatosis, inflammation and early fibrosis. The reason for this rapid response is not yet clear. It has been suggested that the ApoE protein, in addition to its role in lipoprotein clearance, has a physiological function in the VLDL assembly-secretion cascade [18]. Thus, it is feasible that the balance between FA uptake and secretion is affected in the APOE2ki mouse due to impaired VLDL secretion. Alternatively, it is possible that the FFA synthesis and esterification or uptake is increased. In addition, it has been shown that ApoE can have a direct effect on tissue macrophage recruitment, independent of lipoprotein metabolism $[19,20]$. Thus, the APOE2ki mice may be highly sensitive to develop inflammation regardless of the steatosis. Other hyperlipidemic mouse models, such as $1 \mathrm{dlr}^{-/-}$mice and apoe $\mathrm{e}^{-/-}$mice also develop a similar phenotype upon long periods 
of high-fat feeding [3, 4]. Moreover, C57B1/6 mice, fed an atherogenic diet for 4-5 weeks, were also shown to induce hepatic lipid and inflammatory genes $[12,21]$ and to develop this phenotype [3].

It has been shown that MCD (methionine and choline deficient) diet-induced fibrosing steatohepatitis in mice can be reversed by treatment with Wy-14,643, a PPARalpha agonist [7]. In our study fibrate administration prevents the accumulation of hepatic TGs, which is consistent with the up-regulation of a large number of genes involved in peroxisomal and mitochondrial $\beta$-oxidation. In addition, it prevents the infiltration of macrophages into the liver, consistent with the regulation of anti-inflammatory genes.

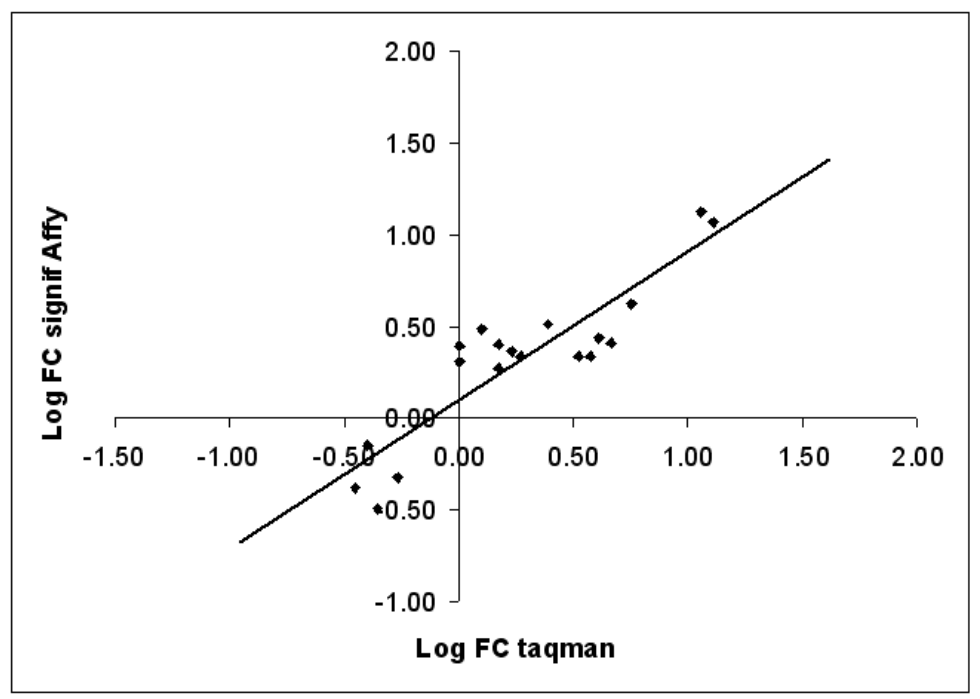

Figure 5. Verification of chip data with QPCR. Graph showing log values of fold changes of both QPCR and microarray data. When plotted, a clear correlation can be seen with a Pearsson correlation coefficient of 0.8971 and $\mathrm{p}<0.0001$.

The high percentage of saturated FAs in the diet $(21 \%$ butter) is most likely to be responsible for the acute inflammatory response [22-24]. Vergnes et al. [25] have shown that cholesterol is also contributing to the induction of genes involved in acute inflammation, including genes of the serum amyloid A family and various cytokinerelated genes.

Comparison between genes regulated by diet and genes regulated by addition of fenofibrate to the diet revealed relatively small overlap. Some of the established PPAR $\alpha$ regulated genes (e.g. Acox1, Cte1) were not regulated when mice were fed a 
western diet. Possibly many of the diet-regulated genes were not detected due to a low level of difference in regulation compared with chow.

Other transcription factors play a more prominent role in regulation of lipid genes. Indeed, changes in lipid genes (e.g. sterol-C4-methyl oxidase-like, sterol-C5-desaturase and FA synthase) are attributable to sterol response element binding factor (SREBP)activation [26]. Similarly, several liver X receptor (LXR)-responsive genes were regulated such as ATP-binding cassette, sub-family A1, stearoyl-coenzyme A desaturase 1 and FA binding protein.

Among the inflammatory genes regulated upon western diet, several genes contained functional NF- $\kappa \mathrm{B}$ binding sites in their promoter regions. NF- $\kappa \mathrm{B}$ plays a crucial role in inflammation, by regulating the production of various cytokines that can trigger several inflammatory reactions [27]. Conversely, the NF- $\mathrm{BB}$ cascade induces alterations in FA metabolism [28] .

The massive repression of inflammatory gene-expression might be related to the ability of PPAR $\alpha$ to interfere with the NF- $\kappa$ B pathway $[29,30]$. The early down-regulation in the expression of inflammatory genes suggests that the prevention of steatohepatitis by fibrates may be a direct consequence of their anti-inflammatory effect.

Strikingly, in this mouse model the increase in macrophages in the liver preceded the accumulation of fat. The function of these macrophages in the pathogenesis of steatosis as observed in these mice is not yet clear. Similarly, the reduction in the expression of inflammatory genes occurred immediately after fibrate treatment, suggesting that inflammation may play an instrumental role during the development of NASH. These data are in contradiction with the current mechanistic concept of the disease in which an initial metabolic disturbance causes steatosis and a second pathogenic event leads to inflammation [31]. In support of our observation, it has been shown that inflammation,

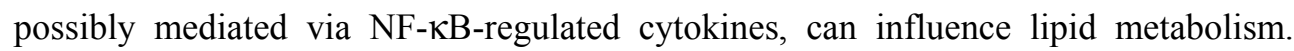
Plasma VLDL levels were found to increase due to enhanced adipose tissue lipolysis, increased de novo hepatic FA synthesis and suppression of FA oxidation [32, 33]. Changes in lipid metabolism during the acute phase response have been attributed to decreases in the level of several nuclear hormone receptors, including PPAR $\alpha$. Pharmacological activation of PPAR $\alpha$ in $\mathrm{C} 57 \mathrm{Bl} / 6$ mice fed the MCD diet resulted in a marked attenuation of the NASH phenotype, affecting both steatosis and inflammation. $[7,34]$. The collective findings suggest that the observed effects are not dependent on the specific model used.

At present, there is no effective treatment for NASH [35] and therefore further studies exploring the role of macrophages in early stages of NASH, can contribute to the design of effective therapeutic strategies for treatment and prevention of NASH. 


\section{Acknowledgments}

We are grateful to Prof. Wim Buurman, Prof. Wout Lamers and Prof. Ger van der Vusse for helpful discussions. We thank Monique Vergouwe, Inge van der Made and Mathijs Groeneweg for technical support. This research is supported by the Netherlands Hart Foundation (NHS) (grant 2002B018) and by the NIH, grant HL42630. M. van Bilsen is an Established Investigator of the Netherlands Heart Foundation. Bart Staels and Marten H. Hofker are part of the European Vascular genomics network (EVGN).

\section{References}

1. Ludwig, J., et al., Nonalcoholic steatohepatitis: Mayo Clinic experiences with a hitherto unnamed disease. Mayo Clin Proc, 1980. 55(7): p. 434-8.

2. Ludwig, J., D.B. McGill, and K.D. Lindor, Review: nonalcoholic steatohepatitis. J Gastroenterol Hepatol, 1997. 12(5): p. 398-403.

3. Yoshimatsu, M., et al., Induction of macrophage scavenger receptor MARCO in nonalcoholic steatohepatitis indicates possible involvement of endotoxin in its pathogenic process. Int J Exp Pathol, 2004. 85(6): p. 33543.

4. Tous, M., et al., Feeding apolipoprotein E-knockout mice with cholesterol and fat enriched diets may be a model of non-alcoholic steatohepatitis. Mol Cell Biochem, 2005. 268(1-2): p. 53-8.

5. Sullivan, P.M., et al., Type III hyperlipoproteinemia and spontaneous atherosclerosis in mice resulting from gene replacement of mouse Apoe with human Apoe*2. J Clin Invest, 1998. 102(1): p. 130-5.

6. Duval, C., J.C. Fruchart, and B. Staels, PPAR alpha, fibrates, lipid metabolism and inflammation. Arch Mal Coeur Vaiss, 2004. 97(6): p. 665-72.

7. Ip, E., et al., Administration of the potent PPARalpha agonist, Wy-14,643, reverses nutritional fibrosis and steatohepatitis in mice. Hepatology, 2004. 39(5): p. 1286-96.

8. Zambon, A., S.I. Hashimoto, and J.D. Brunzell, Analysis of techniques to obtain plasma for measurement of levels of free fatty acids. J Lipid Res, 1993. 34(6): p. 1021-8.

9. Ghesquiere, S.A., et al., Macrophage-specific overexpression of group IIa sPLA2 increases atherosclerosis and enhances collagen deposition. J Lipid Res, 2005. 46(2): p. 201-10.

10. Pelsers, M.M., et al., Fatty acid binding protein in heart and skeletal muscles of the migratory barnacle goose throughout development. Am J Physiol, 1999. 276(3 Pt 2): p. R637-43.

11. Hoogwerf, B.J., et al., Treatment of type III hyperlipoproteinemia with four different treatment regimens. Atherosclerosis, 1984. 51(2-3): p. 251-9.

12. Kim, S., et al., Hepatic gene expression profiles in a long-term high-fat diet-induced obesity mouse model. Gene, 2004. 340(1): p. 99-109.

13. Kreeft, A.J., et al., Identification of differentially regulated genes in mildly hyperlipidemic ApoE3-Leiden mice by use of serial analysis of gene expression. Arterioscler Thromb Vasc Biol, 2001. 21(12): p. 1984-90.

14. Yamazaki, K., J. Kuromitsu, and I. Tanaka, Microarray analysis of gene expression changes in mouse liver induced by peroxisome proliferator- activated receptor alpha agonists. Biochem Biophys Res Commun, 2002. 290(3): p. 1114-22.

15. Knouff, C., et al., Doubling expression of the low density lipoprotein receptor by truncation of the 3'untranslated region sequence ameliorates type iii hyperlipoproteinemia in mice expressing the human apoe 2 isoform. J Biol Chem, 2001. 276(6): p. 3856-62.

16. Hinsdale, M.E., et al., ApoB-48 and apoB-100 differentially influence the expression of type-III hyperlipoproteinemia in APOE*2 mice. J Lipid Res, 2002. 43(9): p. 1520-8.

17. Knouff, C., et al., Defective VLDL metabolism and severe atherosclerosis in mice expressing human apolipoprotein E isoforms but lacking the LDL receptor. Biochim Biophys Acta, 2004. 1684(1-3): p. 8-17.

18. Kuipers, F., et al., Impaired secretion of very low density lipoprotein-triglycerides by apolipoprotein Edeficient mouse hepatocytes. J Clin Invest, 1997. 100(11): p. 2915-22. 
19. Lessner, S.M., et al., Atherosclerotic lesions grow through recruitment and proliferation of circulating monocytes in a murine model. Am J Pathol, 2002. 160(6): p. 2145-55.

20. Grainger, D.J., J. Reckless, and E. McKilligin, Apolipoprotein E modulates clearance of apoptotic bodies in vitro and in vivo, resulting in a systemic proinflammatory state in apolipoprotein E-deficient mice. J Immunol, 2004. 173(10): p. 6366-75.

21. Liao, F., et al., Genetic control of inflammatory gene induction and NF-kappa B-like transcription factor activation in response to an atherogenic diet in mice. J Clin Invest, 1993. 91(6): p. 2572-9.

22. Tripathy, D., et al., Elevation of free fatty acids induces inflammation and impairs vascular reactivity in healthy subjects. Diabetes, 2003. 52(12): p. 2882-7.

23. Doshi, M., et al., Effect of dietary enrichment with n-3 polyunsaturated fatty acids (PUFA) or n-9 PUFA on arachidonate metabolism in vivo and experimentally induced inflammation in mice. Biol Pharm Bull, 2004. 27(3): p. 319-23.

24. Calder, P.C., Fatty acids and gene expression related to inflammation. Nestle Nutr Workshop Ser Clin Perform Programme, 2002. 7: p. 19-36; discussion 36-40.

25. Vergnes, L., et al., Cholesterol and cholate components of an atherogenic diet induce distinct stages of hepatic inflammatory gene expression. J Biol Chem, 2003. 278(44): p. 42774-84.

26. Horton, J.D., et al., Combined analysis of oligonucleotide microarray data from transgenic and knockout mice identifies direct SREBP target genes. Proc Natl Acad Sci U S A, 2003. 100(21): p. 12027-32.

27. Collins, T. and M.I. Cybulsky, NF-kappaB: pivotal mediator or innocent bystander in atherogenesis? J Clin Invest, 2001. 107(3): p. 255-64.

28. Feingold, K.R., et al., Multiple cytokines stimulate hepatic lipid synthesis in vivo. Endocrinology, 1989. 125(1): p. 267-74.

29. Delerive, P., et al., Peroxisome proliferator-activated receptor alpha negatively regulates the vascular inflammatory gene response by negative cross-talk with transcription factors NF-kappaB and AP-1. J Biol Chem, 1999. 274(45): p. 32048-54.

30. Delerive, P., et al., Induction of IkappaBalpha expression as a mechanism contributing to the antiinflammatory activities of peroxisome proliferator-activated receptor-alpha activators. J Biol Chem, 2000. 275(47): p. 36703-7.

31. Day, C.P. and O.F. James, Steatohepatitis: a tale of two "hits"? Gastroenterology, 1998. 114(4): p. 842-5.

32. Feingold, K.R., et al., The effect of diet on tumor necrosis factor stimulation of hepatic lipogenesis. Metabolism, 1990. 39(6): p. 623-32.

33. Khovidhunkit, W., et al., Effects of infection and inflammation on lipid and lipoprotein metabolism: mechanisms and consequences to the host. J Lipid Res, 2004. 45(7): p. 1169-96.

34. Ip, E., et al., Central role of PPARalpha-dependent hepatic lipid turnover in dietary steatohepatitis in mice. Hepatology, 2003. 38(1): p. 123-32.

35. Liangpunsakul, S. and N. Chalasani, Treatment of Nonalcoholic Fatty Liver Disease. Curr Treat Options Gastroenterol, 2003. 6(6): p. 455-463. 


\section{IV}

\section{A central role for cholesterol metabolism and inflammation during the inhibition of non- alcoholic steatohepatitis with a synthetic PPAR alpha agonist}

Kristiaan Wouters ${ }^{1}$, Marc van Bilsen ${ }^{1}$, Veerle Bieghs ${ }^{1}$, Patrick J van Gorp ${ }^{1}$, Dieter Lütjohann ${ }^{2}$, Anja Kerksiek ${ }^{2}$, Bart Staels ${ }^{3}$, Marten H Hofker ${ }^{4}$, and Ronit ShiriSverdlov ${ }^{1}$

1) Depts. of Molecular Genetics, Pathology and Physiology, Nutrition and Toxicology Research (NUTRIM) and Cardiovascular Research (CARIM) Institutes of Maastricht University Maastricht, Maastricht, The Netherlands; 2) Institute of Clinical Chemistry and Pharmacology, D-53105 Bonn, University of Bonn, Bonn, Germany; 3) Institut Pasteur de Lille, Lille F-59019, France; Inserm U545, Lille F-59019 France; Université de Lille 2, Faculté de Pharmacie et Faculté de Médecine, Lille F-59019, France; 4) Dept. of Pathology \& Laboratory Medicine, University Medical Center Groningen, Groningen, Netherlands

\section{Submitted}




\section{Abstract}

Background: Hyperlipidemic APOE2 knock-in (APOE2ki) mice develop non-alcoholic steatohepatitis (NASH) very early, which is inhibited by fenofibrate (FF), a peroxisome proliferator activated receptor alpha (PPAR $\alpha$ ) agonist. Previous transcriptome analysis of livers of these mice revealed that high fat feeding induced many inflammatory genes, but only few PPAR $\alpha$ dependent genes. Current study aims to investigate the effects of diet-induced NASH on hepatic gene expression in detail to clarify how diet and FF supplementation influences gene expression.

Methods: Microarray data from livers from APOE2ki mice fed a high fat, high cholesterol (HFC) diet for 2 and 7 days or HFC supplemented with FF were used for analysis.

Results: Rather than PPAR $\alpha$-induced transcription, HFC diet induced genes under control of cholesterol sensors SREBP $1 / 2$ and LXR, probably due to negative feedback mechanisms initiated by increased levels of hepatic cholesterol and its precursor lathosterol. Genes regulated oppositely by FF supplementation were mainly involved in cholesterol metabolism and inflammation, indicating these are important pathways during NASH inhibition. Additionally, FF supplementation inhibited NF- $\mathrm{KB}$ induced transcription, while up-regulating AP-1 induced transcripts.

Conclusion: Two major pathways appear important during progression and inhibition of NASH, i.e. cholesterol metabolism and inflammation. FF treatment inhibited inflammation via NF- $\mathrm{\kappa B}$ rather than via AP-1. 


\section{I ntroduction}

Non-alcoholic fatty liver disease (NAFLD) is an integral part of the metabolic syndrome and has become an increasing health problem as obesity and insulin resistance are reaching epidemic proportions in Western countries. NAFLD may progress towards a more harmful condition, i.e. non alcoholic steatohepatitis (NASH), which is characterized by hepatic fat accumulation (steatosis) combined with an inflammatory response. Ultimately, NASH may lead to fibrosis, cirrhosis and even liver failure $(37,49)$. Treatment options for NASH remain limited as only weight loss has shown to be effective in rapidly reducing steatosis and hepatic inflammation (14). Until now, only a few controlled clinical studies have been performed for the treatment of NASH, which mostly focused on activators of peroxisome proliferating activated receptor- $\gamma(\operatorname{PPAR} \gamma)$ as a clinical target $(3,37,49)$. However, larger and longer clinical studies are needed to determine long-term beneficial effects. Moreover, the applicability of PPAR $\gamma$ ligands for therapeutical use is under debate (13) as they may increase the risk of heart failure $(39,41)$. Currently, some other randomized controlled clinical trials are being performed in human subjects, testing agents for different promising targets in their efficacy against steatosis and hepatic inflammation (37). One of these targets, PPAR $\alpha$, plays a central role in lipid and glucose metabolism and is a well known target for lipid lowering therapies. PPAR $\alpha$ is a nuclear receptor with fatty acids as natural ligands $(36,44,47)$. Upon ligand binding, this nuclear receptor initiates transcription of specific target genes that are mainly involved in lipid metabolism, such as mitochondrial and peroxisomal fatty acid (FA) oxidation, as well as FA uptake and transport $(17,40)$.

APOE2 knock-in (APOE2ki) mice have the defective human APOE2 isoform instead of their endogenous apoe gene. They display a lipoprotein profile resembling mixed dyslipidemia, as frequently seen in humans $(25,61,65)$. We have shown previously that these mice develop NASH after only a few days of high fat, high cholesterol (HFC) feeding, which was inhibited by co-administrating fenofibrate (FF), a synthetic ligand that activates PPAR $\alpha$. Transcriptome analysis revealed inflammation to be an integral part of the early response to the HFC diet. This inflammatory response was inhibited upon co-administration of FF (HFC+FF), possibly via the known antiinflammatory properties of PPAR $\alpha(15,61)$. Unexpectedly, little overlap of lipid genes was observed between HCF treatment and HFC+FF treatment. These results suggested very little HFC diet-induced PPAR $\alpha$ driven gene expression during the early stages of NASH, despite the abundance of several natural PPAR $\alpha$ ligands present in the HFC diet. Other transcription factors may thus be preferably activated by HFC during the progression of diet-induced NASH. 
In the previous study, data was analyzed based on gene ontology (GO) annotation only. GO clustering reveals biological processes in response to the treatments. However, it does not provide detailed pathway information and does not incorporate gene-gene interactions. The current study aims to elucidate what pathways, other than PPAR $\alpha$ induced transcription, were influenced by HFC feeding during the progression of dietinduced NASH. Additionally, we determined the additional contribution of FF to NASH inhibition and to clarify the exact pathways involved during FF-dependent attenuation of inflammatory gene expression. To this end, Inginuity Pathway Analysis ${ }^{\circledR}$ (IPA) was used, software that performs literature-based gene clustering to reveal the biological significance of the regulated transcripts.

\section{Materials and methods}

\section{Microarray analysis}

Data was analyzed from datasets that were described previously [13]. In short, data was used from hepatic mRNA hybridization to microarrays (Affymetrix ${ }^{\circledR} 430 \mathrm{a}$ ) from 10 female mice fed a HFC diet for 2 and 7 days or from mice fed the HFC diet supplemented with $0,2 \% \mathrm{FF}$. Data derived from mice receiving a standard chow diet only, were used as control.

Biological pathway analysis was done with IPA ${ }^{\circledR}$ (Ingenuity Systems, Redwood City, USA) software, which clusters genes in pathways based on the literature. Moreover, IPA creates functional networks of genes of which the relations are defined according to their co-existence in literature. Each gene cluster and network receives a score that reflects cluster or network size and number of genes regulated.

\section{Real-time quantitative PCR}

Quantification of gene-expression was done by quantitative PCR on a Bio-Rad MyIQ ${ }^{\circledR}$ with the IQ5 v2 software (Bio-Rad, Hercules, CA, USA) by using IQ SYBR Green Supermix with fluorescein (170-5006CUST, Bio-Rad, Hercules, CA, USA) and $10 \mathrm{ng}$ of cDNA. To standardize for the amount of cDNA, Cyclophillin A (Ppia) was used as reference gene. Primer sets were developed with Primer Express version 1.5 (Applied Biosystems) using default settings:

5'-TGTGACCCTTGGCTCTGTTCT-3' (Acox1 forward), 5'-TGTAGTAAGATTCGTGGACCTCTG-3' (Acox1 reverse), 5'-TTCCTCCTTTCACAGAATTATTCCA-3' (Ppia forward), 


\section{5'-CCGCCAGTGCCATTATGG-3' (Ppia reverse).}

Data were analyzed with the IQ5 v2 software (Bio-Rad, Hercules, CA, USA) and Graphpad Prism 4.0. Groups were compared using 2-tailed non-paired $t$-tests. Data is expressed as means \pm SEM and considered significant at $\mathrm{p}<0.05$. Microarray data were validated by QPCR on individual samples as was shown previously [13].

\section{Hepatic cholesterol analysis}

Liver specimens were dried to constant weight in a Speedvac (Savant). Sterols and oxysterols were extracted by chloroform/methanol $(2: 1)$ at $4^{\circ} \mathrm{C}$ overnight. Cholesterol and its precursors were determined after alkaline hydrolysis and derivatization to the corresponding trimethylsilyl-ethers by gas chromatography-flame ionization detection and gas chromatography-mass spectrometry as described before [15].

\section{Results and discussion}

\section{Gene expression induced by HFC and HFC+FF}

To investigate the contribution of PPAR $\alpha$ to HFC-induced hepatic gene expression, genes were selected based on their up-regulation by HFC and $\mathrm{HFC}+\mathrm{FF}$ treatments (table 1A). It was expected that these genes regulated in the same direction by the HFC diet and by FF supplementation, are induced by the HFC diet through PPAR $\alpha$ activation. However, only few genes were regulated by both treatments in the same direction; 5 were classified into the category of "lipid metabolism". This may indicate that HFC diet has only a marginal effect on PPARa activity. The genes included Lipoprotein Lipase (LpL), which hydrolyzes triglycerides (TG) into fatty acids that can consequently be taken up from the plasma; fatty acid binding protein (Fabp2), involved directly in FA transport; Lipase 1 (lip1), monoglyceride lipase (Mgll), which both hydrolyze intracellular TG and cholesteryl-esters derived from plasma lipoproteins (22, 33), and acetyl-CoA acyltransferase 1B (Acalb), a peroxisomale enzyme. Together, these genes enable TG-derived FA to enter oxidative pathways. Mgll, LpL, Acaalb, and FABP2 have been previously identified as PPAR $\alpha$ targets $(56,62,77)$ while Lip1 may be an interesting novel PPARa target gene. Additionally, another possible PPAR $\alpha$ gene was regulated, i.e. phospholipase A2, group 7 (PLA2g7).

Contrary to our data, it has been reported that PPAR $\alpha$ does govern hepatic gene expression upon high fat feeding (51). However, in that study male instead of female mice were used. Female mice were recently found to have much lower PPAR $\alpha$ activity 
in the liver than male mice (12), which might explain the lack of response in the present study. Alternatively, it has been suggested that dietary fatty acids do not activate PPAR $\alpha$ as effectively as de novo synthesized fat (8).

Furthermore, due to the fact that APOE2ki mice have elevated TG levels even when fed a regular diet $(61,66)$, it is feasible that any effect on PPAR $\alpha$ in these mice is masked because PPAR $\alpha$ may already be constitutively activated even without feeding these animals a HFC diet. The elevated activity of PPAR $\alpha$ may result in the impossibility to be activated further by this diet, thereby masking its activity. To exclude this possibility, the expression level of an established PPAR $\alpha$ target gene, i.e. acyl CoA oxidase 1 (Acox1), on a regular chow diet in APOE2ki livers was compared with levels in C57BL6 wild type (WT) mice, the genetic background strain of the experimental APOE2ki mice (fig. 1). These results show no difference between the two groups, indicating that PPAR $\alpha$ activity in APOE2ki mice is not different compared to WT animals. Thus, the elevated TG levels in the basal state do not seem to mask the effect of HFC feeding on PPAR $\alpha$ activity in these mice.

Table 1A

\begin{tabular}{|c|c|c|c|c|c|c|}
\hline ProbeSetID & Gene Name & Symbol & $\begin{array}{l}2 \mathrm{~d} \\
\mathrm{HFC}\end{array}$ & $\begin{array}{l}7 \mathrm{~d} \\
\mathrm{HFC}\end{array}$ & $\begin{array}{l}2 \mathrm{~d} \\
\text { HFCff }\end{array}$ & $\begin{array}{l}7 \mathrm{~d} \\
\text { HFCff }\end{array}$ \\
\hline 1418438_at & fatty acid binding protein 2 & Fabp2 & 2.6 & 2.7 & 1.6 & 2.2 \\
\hline 1415904_at & $\begin{array}{l}\text { lipoprotein lipase } \\
\text { "transglutaminase 2, C }\end{array}$ & Lpl & ns & 2.8 & 2.2 & 3.3 \\
\hline 1417500_a_at & polypeptide" & $\operatorname{Tgm} 2$ & 1.8 & 2.5 & 1.5 & ns \\
\hline 1423846_x_at & tubulin, alpha 2 & Tuba2 & 1.5 & 1.7 & 1.6 & ns \\
\hline 1449436_s_at & ubiquitin B & Ubb & 1.2 & 1.3 & 1.3 & 1.2 \\
\hline 1448169_at & keratin complex 1 , acidic, gene 18 & Krt1-18 & ns & 1.6 & 2.9 & 1.8 \\
\hline 1417339_a_at & dynein, cytoplasmic, light chain 1 & Dnslc1 & 1.6 & 1.8 & 2.1 & 2.2 \\
\hline 1415849_s_at & $\begin{array}{l}\text { stathmin } 1 \\
\text { DNA segment,Chr 17,human }\end{array}$ & Stmn 1 & ns & 1.8 & ns & 1.6 \\
\hline 1417821_at & D6S56E 5 & & ns & 2.6 & ns & 2.4 \\
\hline 1450872_s_at & lysosomal acid lipase 1 & Lip1 & ns & 1.4 & 1.6 & 1.4 \\
\hline 1419091_a_at & annexin $\mathrm{A} 2$ & Anxa2 & ns & 2.3 & 3.7 & 2.5 \\
\hline 1430700_a_at & phospholipase A2, group VII & Pla2g7 & ns & 2 & 1.3 & 2.4 \\
\hline 1455439_a_at & lectin, galactose binding, soluble 1 & Lgals 1 & ns & 1.7 & 1.6 & 2 \\
\hline 1454971_x_at & $\begin{array}{l}\text { transforming growth factor beta } 1 \\
\text { induced transcript } 4\end{array}$ & Tgfb1i4 & 1.8 & 1.8 & ns & 1.7 \\
\hline 1426645_at & heat shock protein 1 , alpha & Hspca & ns & 1.7 & 3.1 & 2.1 \\
\hline 1424451_at & acetyl-Co A acyltransferase 1B & Acaa1b & 1.4 & ns & 2.4 & 2.8 \\
\hline 1424126_at & aminolevulinic acid synthase 1 & Alas 1 & 2 & ns & 2.2 & 2.8 \\
\hline 1448700_at & G0/G1 switch gene 2 & G0s2 & 1.8 & ns & 2.9 & 3.5 \\
\hline 1450391_a_at & monoglyceride lipase & Mgll & 1.7 & ns & 3.4 & 4.5 \\
\hline 1418486_at & vanin 1 & Vnn1 & 1.6 & ns & 4.2 & 4.8 \\
\hline
\end{tabular}


Table 1B

\begin{tabular}{lllllll}
\hline & & & $2 \mathrm{~d}$ & $7 \mathrm{~d}$ & $2 \mathrm{~d}$ & $7 \mathrm{~d}$ \\
ProbeSetID & Gene Name & Symbol & HFC & HFC & HFCff & HFCff \\
\hline 1438612_a_at & --- & $\mathrm{ns}$ & $-24,1$ & $-55,7$ & $-3,6$ \\
1422479_at & acetyl-Coenzyme A synthetase 2 & Acas2 & $-1,8$ & $-3,2$ & $-2,7$ & $\mathrm{~ns}$ \\
1422682_s_at & trypsin 3 & Try3 & $-10,4$ & $-18,4$ & $-2,4$ & $\mathrm{~ns}$ \\
1417464_at & troponin C2, fast & Tnns2 & $-2,2$ & $-7,1$ & $-3,2$ & 17,1 \\
1416139_at & regenerating islet-derived 2 & Reg2 & $-4,9$ & $-10,6$ & $-2,7$ & $\mathrm{~ns}$ \\
& formyltetrahydrofolate & & & & & \\
1424400_aaat & dehydrogenase & Fthfd & $-1,6$ & $-1,7$ & $-2,2$ & $-1,5$ \\
1428102_at & carboxypeptidase B1 (tissue) & Cpb1 & $\mathrm{ns}$ & $-12,6$ & -47 & $-4,8$ \\
1428062_at & carboxypeptidase A1 & Cpa1 & $\mathrm{ns}$ & -12 & $-50,6$ & $-4,6$ \\
1433431_at & pancreatic lipase & Pnlip & $\mathrm{ns}$ & $-11,6$ & $-71,2$ & -7 \\
1448220_at & RIKEN cDNA 2200008D09 gene & & $\mathrm{ns}$ & $-9,1$ & $-33,2$ & $-4,2$ \\
1448281_a_at & elastase 2 & Ela2 & $\mathrm{ns}$ & $-12,8$ & $-66,5$ & $-5,9$ \\
1416055_at & amylase 2, pansreatic & Amy2 & $\mathrm{ns}$ & $-9,4$ & $-140,1$ & $-15,4$ \\
1415954_at & trypsin 4 & Try4 & $\mathrm{ns}$ & $-11,3$ & $-61,7$ & $-7,4$ \\
1416239_at & argininosuccinate synthetase 1 & Ass1 & $-1,7$ & $-1,5$ & $-2,2$ & $\mathrm{~ns}$ \\
1451557_at & tyrosine aminotransferase & Tat & $-1,3$ & $-1,3$ & $-1,3$ & $\mathrm{~ns}$ \\
1449434_at & carbonic anhydrase 3 & Car3 & $-1,5$ & $\mathrm{~ns}$ & $-1,6$ & $-1,5$ \\
& DNA segment, Chr 1, University & & & & & \\
1455540_at & of California at Los Angeles 3 & D1Ucla3 & $-1,4$ & $\mathrm{~ns}$ & $-1,4$ & $\mathrm{~ns}$ \\
\hline
\end{tabular}

Table 1. Genes regulated in the same direction by $H F C$ and $H F C+F F$ treatments. This table shows genes regulated in the same direction by both treatments, derived from the previously found HFC-induced genes [13]. From each gene, the probeset ID, gene title, gene symbol, fold change and p-value of fold change after 2 and 7 days of treatment compared to chow fed animals is shown. P-values smaller than 1.10-6 were considered significant. A. Genes down-regulated by both treatments and B. Genes down-regulated by both treatments.

Other than PPAR $\alpha$, there are several transcription factors that play a role in hepatic lipid metabolism which could have a larger effect on hepatic gene expression. Therefore, we performed an extensive literature search to identify other transcriptional regulators of genes involved in hepatic lipid metabolism, known to be of importance in liver function next to PPAR $\alpha$ : liver X receptor (LXR), pregnane $x$ receptor (PXR), sterol regulatory element-binding protein $1 / 2$ (SREBP) and hepatic nuclear factor $4 \mathrm{~A}$ (HNF4A). Regulation of their target genes present in our dataset was compared to regulation as is known in literature, determined by IPA. This software-mediated gene clustering allowed us to obtain information about the response of these transcription factors upon HFC feeding (table 2). 


\begin{tabular}{|c|c|c|c|c|c|c|c|c|c|c|}
\hline \multirow[t]{2}{*}{ Gene } & \multicolumn{5}{|c|}{ Transcription Factor } & \multicolumn{4}{|c|}{ Regulated } & \multirow[t]{2}{*}{ Ref } \\
\hline & LXR & PPARa & PXR & SREBP & HNF4A & $\begin{array}{l}\mathrm{HFC} \\
2 \mathrm{~d} \\
\end{array}$ & $\begin{array}{l}\mathrm{HFC} \\
7 \mathrm{~d} \\
\end{array}$ & $\begin{array}{l}\text { HFCff } \\
2 \mathrm{~d}\end{array}$ & $\begin{array}{l}\text { HFCff } \\
7 \mathrm{~d}\end{array}$ & \\
\hline ABCA1 & $\uparrow$ & & & & & & 1,9 & & & [47] \\
\hline $\mathrm{ABCC} 3$ & $\uparrow$ & & $\uparrow$ & & & $-1,7$ & $-1,5$ & 2,7 & 2,3 & [48] \\
\hline ABCG5 & $\uparrow$ & & & & & & 1,5 & 1,7 & & [49] \\
\hline ACAA1 & & $\uparrow$ & & & & 1,4 & & 3,1 & 4,1 & {$[50]$} \\
\hline ACAS2 & & $\uparrow$ & & $\uparrow$ & & $-1,8$ & $-3,2$ & $-2,7$ & & {$[51]$} \\
\hline acta1 & & $\uparrow$ & & & & & $-9,3$ & & 24 & {$[52]$} \\
\hline $\mathrm{AHCY}$ & & & $\downarrow$ & & & & $-1,5$ & & & {$[53]$} \\
\hline ApoA4 & & & & & $\uparrow$ & 3,9 & 4,2 & & & [54] \\
\hline ApoB & & & & & $\uparrow$ & 1,3 & & & & {$[26]$} \\
\hline $\arg$ & & $\downarrow$ & & & & $-1,5$ & $-1,6$ & & 1,4 & [53] \\
\hline asl & & $\downarrow$ & & & & $-1,8$ & -2 & & & {$[55]$} \\
\hline CCND1 & & & & & $\uparrow$ & & 2 & & & {$[56]$} \\
\hline crip1 & & & & & $\uparrow$ & & 2,4 & & & [57] \\
\hline $\mathrm{CTH}$ & & & $\uparrow$ & & & $-2,1$ & $-2,4$ & & & [53] \\
\hline ctsb & & & & & $\uparrow$ & & 1,5 & & & [57] \\
\hline Cyp7a1 & $\uparrow$ & $\downarrow$ & $\uparrow$ & $\downarrow$ & & & -2.4 & & & {$[58,59]$} \\
\hline CYP8B1 & & $\uparrow$ & & $\uparrow$ & & $-1,9$ & $-2,5$ & & & {$[60]$} \\
\hline FABP2 & & & & & $\uparrow$ & 2,6 & 2,7 & 1,6 & 2,2 & [61] \\
\hline fdft 1 & $\uparrow$ & & & $\uparrow$ & & & $-3,1$ & & 1,9 & {$[62,63]$} \\
\hline fdps & & & & $\uparrow$ & & & $-2,8$ & $-2,3$ & & [64] \\
\hline gpdh & & $\uparrow$ & & & & & 1,8 & & & [65] \\
\hline GSTA2 & & & $\uparrow$ & & & $-3,6$ & $-2,4$ & 2,5 & 2,5 & {$[60]$} \\
\hline $\operatorname{Lcn} 2$ & & & $\uparrow$ & & & 6,2 & 10,1 & $-3,7$ & $-6,8$ & [53] \\
\hline Lgals3 & & & & & $\uparrow$ & 2,7 & 5,6 & & & [57] \\
\hline Lipa & & & & & $\uparrow$ & & 1,4 & 1,6 & 1,4 & [57] \\
\hline $\mathrm{LpL}$ & $\uparrow$ & $\uparrow$ & & $\uparrow$ & & & 2,8 & 2,2 & 3,3 & {$[60]$} \\
\hline SAT & & $\downarrow$ & & & & & 2 & & & [55] \\
\hline Sc5dl & & & & $\uparrow$ & & & $-1,4$ & & & [66] \\
\hline scd & $\uparrow$ & & & $\uparrow$ & & 1,2 & & & 1,9 & {$[67,68]$} \\
\hline
\end{tabular}




\begin{tabular}{|c|c|c|c|c|c|c|c|c|c|c|}
\hline & LXR & PPARa & PXR & SREBP & HNF4A & $\begin{array}{l}\mathrm{HFC} \\
2 \mathrm{~d}\end{array}$ & $\begin{array}{l}\text { HFC } \\
7 \mathrm{~d}\end{array}$ & $\begin{array}{l}\text { HFCff } \\
2 \mathrm{~d}\end{array}$ & $\begin{array}{l}\text { HFCff } \\
7 \mathrm{~d}\end{array}$ & \\
\hline $\operatorname{scd} 2$ & $\uparrow$ & & & $\uparrow$ & & & 2,6 & & & [67] \\
\hline SREBP & $\uparrow$ & & & & & & 2,1 & & & [69] \\
\hline Tdo2 & & & & & $\uparrow$ & $-1,4$ & $-1,4$ & 1,9 & & [57] \\
\hline Tgm2 & & & $\uparrow$ & & & 1,8 & 2,5 & 2,5 & 1,5 & [53] \\
\hline
\end{tabular}

Table 2. Activation of hepatic transcription factors. This table shows the regulation of genes according to IPA. Up-regulation is shown as $\uparrow$, while genes known to be down-regulated are indicated by $\downarrow$. In numbers, the regulation of these genes in our dataset is shown at each time point. Finally, references, as provided by IPA are shown.

The analysis indicated a prominent role for HNF4a and the cholesterol sensors LXR and SREBP as major activated transcription factors controlling regulation of lipid genes upon HFC feeding.

For HNF4a, most target genes were regulated in the same way as was found in literature, indicating that HNF4a may play an important role in the hepatic response to HFC diet. HNF4a can be activated upon binding of several fatty acid species $(18,26)$ and has been found essential in regulating key processes in the liver (24). However, there is evidence pointing out that the seemingly dominant character of this transcription factor is doubtful for two major reasons. First, table 2 shows that HNF4a regulates a completely specific set of genes while the other transcription factors show more overlap. This lack of overlap may lead to an overestimation of HNF4a activity as none of the other investigated transcription factors can override its effects. Consequently, it is difficult to estimate whether the contribution of HNF4a is in concert with or dominating over the other investigated transcription factors. Second, HNF4a is known to be active even in the absence of exogenous ligands $(24,32)$, suggesting that its activity is not necessarily influenced by the diet. Taken together, the results obtained for HFN4a must be interpreted with caution.

Table 2 shows that SREBP activity was generally inhibited, as several genes that are known to be regulated by this transcription factor were down-regulated. However, several other SREBP target genes were up-regulated, despite the presumed inhibition of SREBP by the elevated circulatory cholesterol levels. It is possible that for these genes, the activation of LXR by oxysterols overrides SREBP inhibition. 


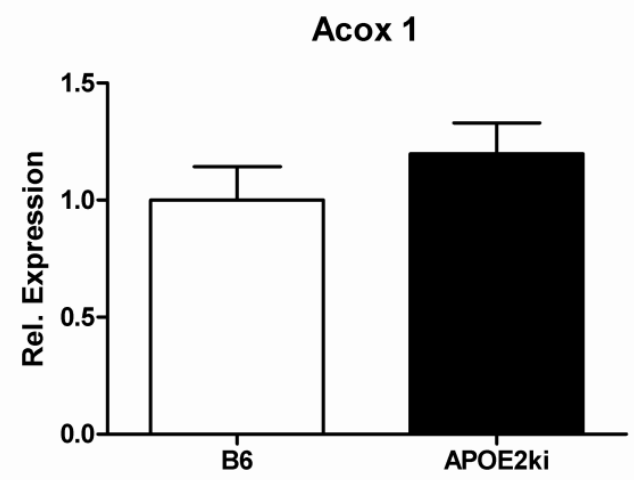

Figure 1. Acoxl gene expression. Relative gene expression of Acyl-CoA oxidase 1, palmitoyl (Acox1) in hepatic mRNA of APOE2ki female mice (black bar) and C57Bl/6 female mice (white bar) on a chow diet. * indicates significant differences between groups.

The observed regulation of these 2 regulators of cholesterol metabolism probably arises from an increased hepatic cholesterol load, which may serve to activate a feedback mechanism that inhibits cholesterol biosynthesis (23). To test this assumption, the cholesterol content of the livers of these mice was investigated in detail with gas chromatography. These data clearly show that cholesterol accumulates in the livers of these mice (Fig. 2A), supporting the notion that the increased cholesterol levels can influence the hepatic transcriptome via LXR and SREBP. Furthermore, in addition to cholesterol, also the cholesterol precursor lathosterol accumulated in the livers of these mice (Fig. 2B). Accumulation of cholesterol and its precursors can lead to inhibition of the cholesterol biosynthesis pathway. This is in excellent agreement with the observed changes in gene expression in response to HFC feeding, as genes of the cholesterol biosynthesis pathway were clearly inhibited, like 3hydroxy-3-methylglutaryl-Coenzyme A synthase 1 (Hmgcs1) and farnesyl diphosphate farnesyl transferase 1 (Fdft1).

Taken together, during the progression of diet-induced NASH, HFC feeding resulted mainly in the activation of cholesterol-induced transcriptional changes via LXR and inhibition of SREBP, rather than the activation of PPAR $\alpha$. These findings argue for a large impact of dietary cholesterol on the hepatic response during the progression of diet-induced NASH. 
A

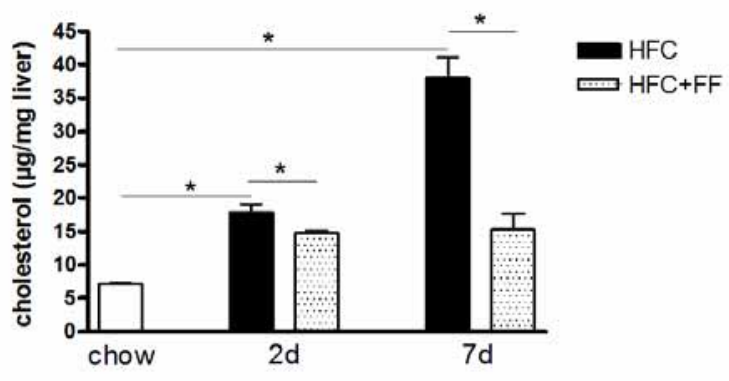

B

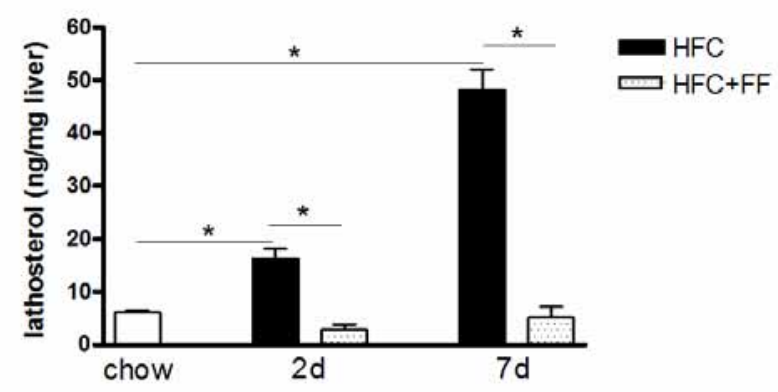

Figure. 2. Hepatic cholesterol and cholesterol precursor levels. Measurement of cholesterol (A) and its precursor lathosterol (B) in the liver of female APOE2ki mice after 2 and 7 days of HFC diet (black bars) and HFC+FF (grey bars) feeding compared to livers of animals fed a chow diet (white bars). * indicates significant differences between groups.

\section{Pathways involved during the inhibition of NASH by FF}

To find pathways involved in the prevention of NASH we focused on genes of which the expression is increased by HFC feeding, but reversed by FF co-treatment. Since FF supplementation was shown to inhibit NASH development (61), the set of genes that is reversed by FF compared to HFC treatment likely contribute to NASH inhibition. Table 3 shows these genes that are regulated oppositely by $\mathrm{HFC}$ and $\mathrm{HFC}+\mathrm{FF}$ treatments. Interestingly, compared to the small number of genes that were regulated similarly by the two interventions, a relatively large number was regulated oppositely by $\mathrm{HFC}$ diet and $\mathrm{HFC}+\mathrm{FF}$.

Of the genes that were down-regulated by the diet and up-regulated by FF (Table 3A), the group of genes involved in cholesterol metabolism was over-represented $(15 \%$ of the regulated genes in this group). These genes included: Hmgcs1 and Fdft1, both 
involved in cholesterol biosynthesis; ATP binding casette $\mathrm{C} 3$ (AbcC3), involved in hepatic bile acid transport (4); and insulin induced gene 2 (Insig2), a regulator of intracellular cholesterol levels (23). This HFC-induced repression of genes involved in cholesterol metabolism is likely due to increased levels of liver cholesterol, which inhibits transcriptional activation of genes of the cholesterol biosynthesis pathway via SREBP (27). FF reduces hepatic levels of both cholesterol and its precursor lathosterol, which could indirectly increase the expression of these genes (Fig. 2A). Furthermore, $\mathrm{HFC}+\mathrm{FF}$ treatment did not produce overt changes in the expression of additional genes involved in cholesterol metabolism: only a few genes classified as "cholesterol metabolism" or "cholesterol biosynthesis" were regulated while these genes were clearly overrepresented in the group of overlapping genes, suggesting that FF exerted its effect mainly on this pathway by normalizing cholesterol levels and had no additional effects. The regulated genes included HMG-CoA lyase (Hmgcl) (upregulated), and VLDL receptor (up-regulated).

In the group of genes up-regulated by the diet and down-regulated by FF (Table 2B), most regulation was found in inflammatory and acute phase genes $(42 \%$ of the regulated genes in this group), i.e. interferon-induced protein with tetratricopeptide repeats 1 (Ifit1), C-type lectin, superfamily member 13 (Clcsf13), lysozyme (Lyzs), Tcell specific GTPase (Tgtp), serum amyloid A (SAA) 1, SAA 2 and SAA 3. Most of these genes were regulated 'back' to the same levels as was seen in chow fed mice. Conversely, SAA1, 2 and 4 expression was diminished to levels below the expression displayed by animals on chow diet.

In conclusion, FF supplementation resulted in the reversal of the observed changes in cholesterol metabolism and in the inhibition of inflammation.

\section{FF further inhibits the inflammatory response by interfering with $N F=\kappa B$ signaling}

In general, literature-based gene clustering by IPA showed that PPAR $\alpha$ activation strongly regulated genes involved in lipid breakdown, and especially $\beta$-oxidation (data not shown), yielding similar results as previous studies with large scale transcriptome analysis in mice $(9,51,76)$, but also in rats (75) and primates (7). Induction of these genes probably contributed to the prevention of NASH development.

$\mathrm{HFC}+\mathrm{FF}$ treatment regulated many inflammatory genes in addition to the inhibition of HFC diet-induced genes. This group is expected to be important for the inhibition of $\mathrm{NASH}$ by $\mathrm{FF}$ as these genes may indicate mechanisms in addition to the reversal of HFC diet-induced gene expression. Many genes further regulated by $\mathrm{HFC}+\mathrm{FF}$ 
treatment were clearly involved in the inflammatory response, as was shown before (61).

Most genes down-regulated by $\mathrm{HFC}+\mathrm{FF}$ treatment were directly involved in the innate immune response. Many of the down-regulated genes are known target genes of the transcription factor $\mathrm{NF}-\kappa \mathrm{B}$ or are readily inducible with lipopolysaccharide (LPS) stimulation, which in turn activates the NF- $\kappa B$ pathway. This is shown in a network in figure 3 . In addition to the reversal of several inflammatory genes to the same level as was observed on the control chow diet, PPAR $\alpha$ activation thus lowers hepatic inflammation further than via inhibiting lipid accumulation only, as postulated earlier (63).

Surprisingly, the network that included genes involved in the AP-1 pathway was strongly up-regulated (Fig. 4). Both the AP-1 components fos, jun, junB and junD, and several genes associated with AP-1 activation were up-regulated by FF treatment. This is in contrast with the proposed inhibitory effect of PPAR $\alpha$ on AP-1 activity in a previous study (15). A possible explanation for this discrepancy may be that the referred study used vascular cells. Additionally, it has been postulated that PPAR $\alpha$ interferes with and inhibits the AP-1 pathway via protein-protein interaction (16), but also in that study (human-derived) vascular cells were used. Conversely, FF has been shown to affect jun levels in murine liver only slightly, as it rather acts by inhibiting jun phosphorylation (21). Supporting our observations, it was recently shown that fos is a direct target gene of PPAR $\gamma(72)$.

It has been suggested by several reports that NF- $\kappa$ B and AP-1 activity can be dissociated in the liver $(6,68)$ and even have different activities between different cell types of the liver compared to hepatocytes, such as in endothelial cells (1) or in Kupffer cells (38). During NASH development there is an increased recruitment of inflammatory cells, such as macrophages, in the liver (61). The increased number of macrophages/Kupffer cells in this setting of NASH may thus have affected the antiinflammatory properties of FF in the used whole-liver samples. This interesting observation merits further investigation regarding the use of FF for the treatment of NASH in a cell-specific manner.

In rodents, PPAR $\alpha$ activation causes hepatic cancer. This secondary response could be due to the increased peroxisomal oxidation of FA, thereby generating reactive oxygen species (ROS), which are potent activators of AP-1 (52). Due to structural differences in the PPAR $\alpha$ protein, this is not the case in human subjects, as mice expressing human PPAR $\alpha$ at physiological levels had a much lower incidence of tumorigenesis than control mice $(10,46)$. Moreover, it is known that human livers express substantially less PPAR $\alpha$ than murine livers (69). 
Together, the activation of PPAR $\alpha$ down-regulated many inflammatory genes, mostly by interfering with NF- $\mathrm{kB}$ rather than AP-1. The activation of NF- $\mathrm{KB}$ may counteract the pro-inflammatory properties of ROS via AP-1 $(29,30)$.

Table 3a

\begin{tabular}{|c|c|c|c|c|c|c|}
\hline ProbeSetID & Gene Name & Symbol & $\begin{array}{l}\mathrm{d} \\
\mathrm{HFC}\end{array}$ & $\begin{array}{l}7 \mathrm{~d} \\
\mathrm{HFC}\end{array}$ & $\begin{array}{l}\mathrm{d} \\
\text { HFCff }\end{array}$ & $\begin{array}{l}7 \mathrm{~d} \\
\text { HFCff }\end{array}$ \\
\hline 1421041_s_at & glutathione S-transferase, alpha 2 & Gsta2 & $-3,6$ & ns & 2,5 & 2,5 \\
\hline 1417065_at & early growth response 1 & Egr1 & $-3,3$ & $-2,4$ & 2,6 & 2 \\
\hline 1428988_at & $\begin{array}{l}\text { ATP-binding cassette, sub-family } \\
\text { C member } 3 \\
\text { insulin-like growth factor binding }\end{array}$ & Abcc3 & $-1,7$ & $-1,5$ & 2,7 & 2,3 \\
\hline 1418918_at & $\begin{array}{l}\text { protein } 1 \\
\text { insulin-like growth factor binding }\end{array}$ & Igfbp1 & $-2,3$ & ns & 2,5 & ns \\
\hline 1454159_a_at & protein 2 & Igfbp2 & $-1,5$ & ns & 1,9 & 2 \\
\hline 1448830_at & dual specificity phosphatase 1 & Dusp1 & $-2,4$ & $-2,3$ & ns & 2,7 \\
\hline 1460167_at & $\begin{array}{l}\text { aldehyde dehydrogenase family } \\
7, \text { member A1 }\end{array}$ & Aldh7a1 & $-1,5$ & $-1,4$ & 1,4 & 1,5 \\
\hline 1419549_at & arginase 1 , liver & Arg1 & $-1,5$ & $-1,6$ & ns & 1,4 \\
\hline 1419456_at & dicarbonyl L-xylulose reductase & Dexr & $-1,4$ & $-1,7$ & ns & 1,8 \\
\hline 1435007_s_at & expressed sequence AI132487 & & $-1,3$ & $-1,3$ & ns & 1,3 \\
\hline 1417982_at & $\begin{array}{l}\text { insulin induced gene } 2 \\
\text { NADH dehydrogenase } 1 \text { beta }\end{array}$ & Insig2 & $-1,5$ & ns & 1,8 & 1,6 \\
\hline 1452184_at & subcomplex,9 & Ndufb9 & $-1,4$ & ns & 1,7 & 1,5 \\
\hline 1419093_at & tryptophan 2,3-dioxygenase & Tdo2 & $-1,4$ & $-1,4$ & 1,8 & 1,9 \\
\hline 1416555_at & etoposide induced $2.4 \mathrm{mRNA}$ & Ei24 & $-1,4$ & ns & 1,6 & 1,6 \\
\hline 1427520_a_at & $\begin{array}{l}\text { myosin, heavy polypeptide } 1 \text {, } \\
\text { skeletal muscle, adult } \\
\text { farnesyl diphosphate farnesyl }\end{array}$ & Myh1 & $-2,4$ & ns & ns & 16,8 \\
\hline 1438322_x_at & transferase 1 & Fdft 1 & $-1,4$ & ns & ns & 1,9 \\
\hline 1427735_a_at & actin, alpha 1 , skeletal muscle & Actal & $-2,4$ & ns & ns & 24 \\
\hline 1416889_at & troponin I, skeletal, fast 2 & Tnni2 & $-1,7$ & ns & ns & 8,4 \\
\hline 1433855_at & 4-aminobutyrate aminotransferase & Abat & $-1,4$ & ns & $\mathrm{ns}$ & 1,9 \\
\hline 1449047_at & RIKEN cDNA $1600020 \mathrm{H} 07$ gene & & $-1,2$ & ns & ns & 1,7 \\
\hline 1419312_at & $\begin{array}{l}\text { ATPase, } \mathrm{Ca}++ \text { transporting, } \\
\text { cardiac muscle, fast twitch } 1\end{array}$ & Atp2a1 & $-1,8$ & ns & ns & 8,9 \\
\hline 1429144_at & RIKEN cDNA 2310032D16 gene & & $-1,3$ & ns & 2,1 & 2,6 \\
\hline 1420541_at & retinol dehydrogenase 6 & Rdh6 & $-1,3$ & ns & 1,8 & 4 \\
\hline 1451203_at & myoglobin & $\mathrm{Mb}$ & $-1,7$ & ns & ns & 6,5 \\
\hline 1455821_x_at & RIKEN cDNA 2400006 N03 gene & & $-1,1$ & ns & 1,5 & 1,8 \\
\hline 1433444_at & $\begin{array}{l}\text { 3-hydroxy-3-methylglutaryl- } \\
\text { Coenzyme A synthase } 1\end{array}$ & Hmgcs 1 & $-1,5$ & ns & ns & 2,9 \\
\hline
\end{tabular}


Table $3 b$

\begin{tabular}{lllllll}
\hline ProbeSetID & Gene Name & Symbol & 2d HFC & 7d HFC & 2d HFCff & 7d HFCff \\
\hline 1416022_at & fatty acid binding protein 5 & Fabp5 & 2,6 & 1,7 & $-2,3$ & $-2,1$ \\
1417290_at & leucine-rich alpha-2-glycoprotein 1 & Lrg1 & 2 & 1,5 & $-1,4$ & $-1,5$ \\
1427747_a_at & lipocalin 2 & Lcn2 & 6,2 & 10,1 & $-3,7$ & $-6,8$ \\
1450788_at & serum amyloid A 1 & Saa1 & 6,1 & 9,8 & $-9,8$ & $-25,8$ \\
1450783_at & interferon-induced protein with & Ifit1 & 3 & $\mathrm{~ns}$ & $-2,5$ & $\mathrm{~ns}$ \\
& tetratricopeptide repeats 1 & & & & & \\
1449009_at & T-cell specific GTPase & Tgtp & 3 & $\mathrm{~ns}$ & $-4,2$ & $\mathrm{~ns}$ \\
1434372_at & expressed sequence AW112010 & & 1,7 & 1,7 & -2 & $-1,6$ \\
1449326_x_at & serum amyloid A 2 & Saa2 & 5,2 & 9 & $-7,3$ & $-17,3$ \\
1424758_s_at & serine (or cysteine) proteinase & Serpina10 1,5 & $\mathrm{~ns}$ & $-1,7$ & $-1,5$ \\
& inhibitor, clade A, member 10 & & & & & \\
1455393_at & ceruloplasmin & Cp & 1,3 & 1,4 & $-1,3$ & $-1,3$ \\
1419319_at & serum amyloid A 4 & Saa4 & 2 & $\mathrm{~ns}$ & $-2,7$ & $-2,7$ \\
1460197_a_at & RIKEN cDNA 1110021O17 gene & & 2 & $\mathrm{~ns}$ & $-2,4$ & $-2,9$ \\
1420928_at & beta galactoside alpha 2,6 & St6gal1 & 1,4 & $\mathrm{~ns}$ & $\mathrm{~ns}$ & $-1,7$ \\
& sialyltransferase 1 & Saa3 & 3 & $\mathrm{~ns}$ & $\mathrm{~ns}$ & $-6,5$ \\
1450826_a_at & serum amyloid A 3 & Orm2 & 2,1 & $\mathrm{~ns}$ & $\mathrm{~ns}$ & $-6,2$ \\
1420438_at & orosomucoid 2 & Lyzs & 1,4 & $\mathrm{~ns}$ & $\mathrm{~ns}$ & $-1,7$ \\
1423547_at & lysozyme & Clecsf 13 & 1 & $\mathrm{~ns}$ & $\mathrm{~ns}$ & $-1,5$ \\
1449905_at & C-type lectin, superfamily member & & & & & \\
\hline
\end{tabular}

Table 3. Genes regulated in opposite directions by HFC and HFC+FF treatments. This table shows genes regulated in the differently by both treatments, derived from the previously found HFCdiet-induced genes [13]. From each gene, the probeset ID, gene title, gene symbol, fold change and p-value of fold change after 2 and 7 days of treatment compared to chow fed animals is shown. P-values smaller than 1.10-6 were considered significant. A. Genes down-regulated by HFC and up-regulated by $\mathrm{HFC}+\mathrm{FF}$ treatment, and B. Genes up-regulated by HFC and down-regulated by HFC+FF treatments.

\section{Conclusion}

This study revealed an interesting pathway that may be of importance during early progression and inhibition of NASH in APOE2ki mice besides inflammation; i.e. cholesterol metabolism. The relation between cholesterol metabolism and inflammation during NASH development is gaining more attention, as several publications recently attributed pro-inflammatory qualities to cholesterol $(31,43,71)$. Recently, we identified dietary cholesterol be a potent inducer of hepatic inflammation (73). The current results argue for a closer relationship between these two, and are of interest for further studies in this field. Further validation of the involvement of cholesterol metabolism during progression of NASH will imply that targeting this pathway, e.g. with statins, may be a sensible approach for treatment strategies against NASH. 
Additionally, modulating inflammation may prove to be a key step in future treatments of NASH. Activating PPAR $\alpha$ clearly inhibited inflammation, mainly due to the

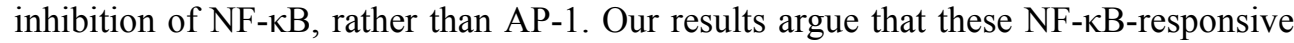
genes may prove to be suitable targets for treating inflammation as a part of therapeutic strategies against NASH.

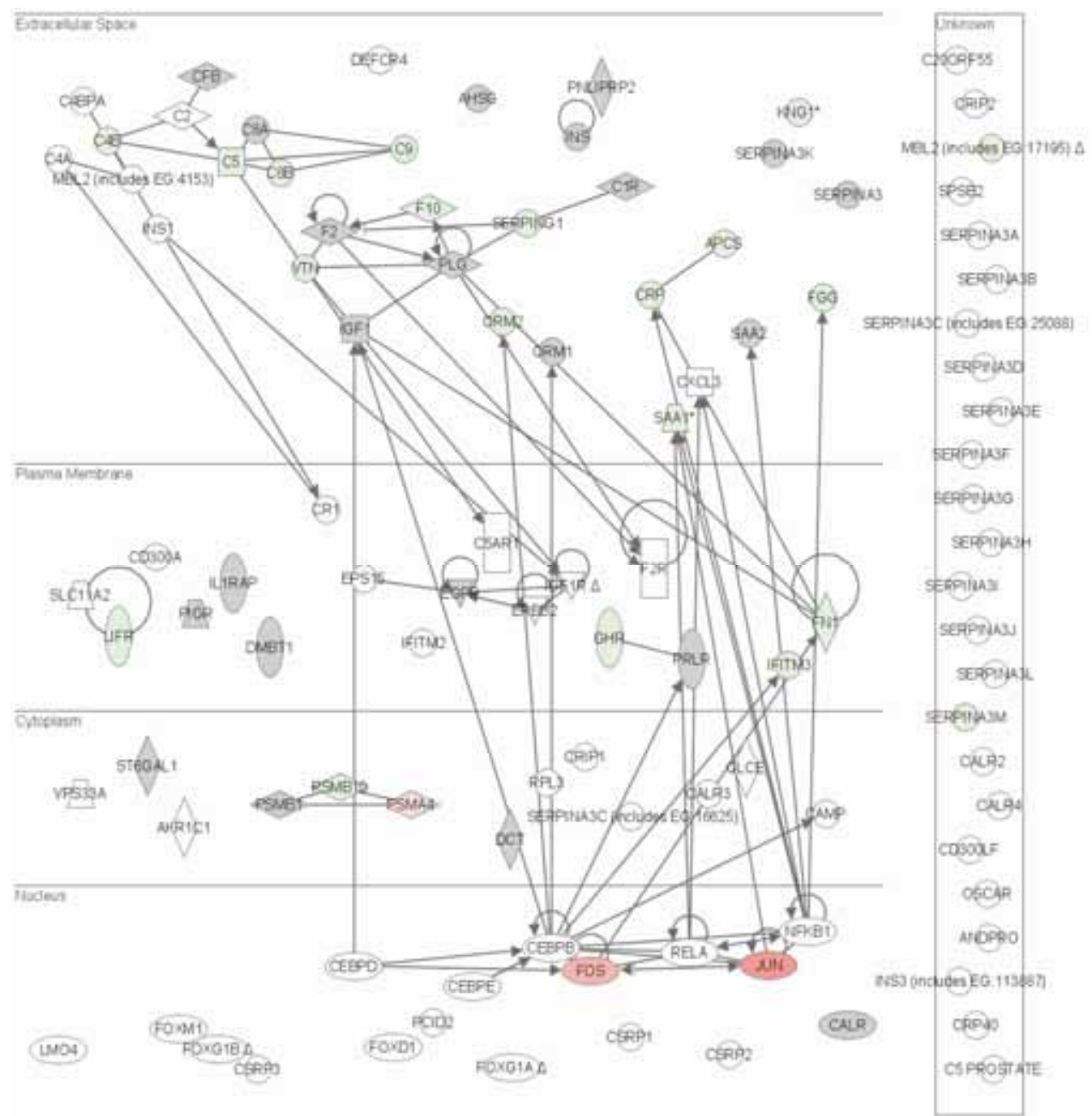

Figure 3. $N F-\kappa B$ genes regulated by $F F$ treatment. Literature-based functional network created in Ingenuity Pathways ${ }^{\circledR}$ software around NF- $\kappa B$. Genes in green are down-regulated in our dataset at both time points, while red indicates up-regulation at both time points. Grey genes are regulated at one of the time points only, while white genes were not found to be regulated in our dataset but are involved in the network according to literature-based clustering. 


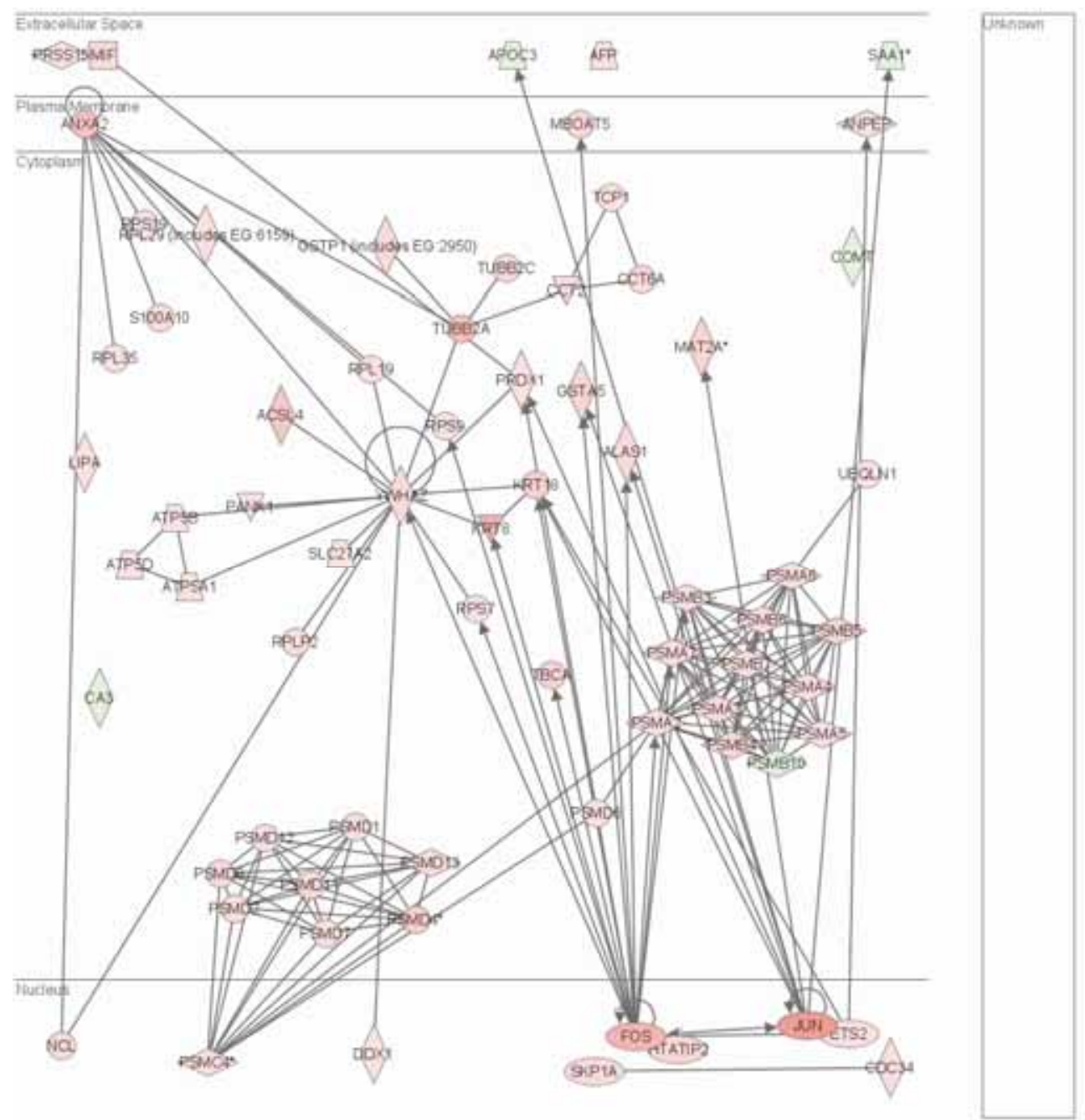

Figure 4. AP-1 genes regulated by FF treatment. Literature-based functional network created by Ingenuity Pathways ${ }^{\circledR}$ software around Fos and Jun, the central components of AP-1. Genes in green are downregulated in our dataset at both time points, while red indicates up-regulation at both time points. Grey genes are regulated at one of the time points only, while white genes were not found to be regulated in our dataset but are involved in the network according to literature-based clustering. 


\section{Acknowledgements}

This research is supported by the Netherlands Heart Foundation (NHS) (grant 2002B18) and the Netherlands Organization for Scientific Research (NWO) (grant 912-04-09). Technical assistance and support of Tim Vanmierlo is gratefully acknowledged. We thank Ellen Loyens for carefully reading the manuscript.

\begin{tabular}{|c|c|c|c|c|c|c|c|c|c|c|}
\hline \multirow[b]{2}{*}{ Present } & \multicolumn{2}{|l|}{ Chow } & \multicolumn{2}{|c|}{ 2d HFC } & \multicolumn{2}{|c|}{ 2d HFCFF } & \multicolumn{2}{|c|}{ 7d HFC } & \multicolumn{2}{|c|}{ 7d HFCFF } \\
\hline & 9473 & $41,7 \%$ & 9496 & $41,9 \%$ & 11193 & $49,3 \%$ & 9478 & $41,8 \%$ & 11507 & $50,7 \%$ \\
\hline Absent & 12749 & $56,2 \%$ & 12713 & $56,0 \%$ & 11106 & $48,9 \%$ & 12720 & $56,1 \%$ & 10777 & $47,5 \%$ \\
\hline Marginal & 468 & $2,1 \%$ & 481 & $2,1 \%$ & 391 & $1,7 \%$ & 492 & $2,2 \%$ & 406 & $1,8 \%$ \\
\hline Regulated & & & 79 & & 986 & & 196 & & 987 & \\
\hline SF & 2,461 & & 2,571 & & 1,515 & & 2,904 & & 1,701 & \\
\hline
\end{tabular}

Supplementary Table 1. This table shows technical aspects of the arrays that were used in this study. At each time point, the total number of probe sets on the array is shown together with the number found to be present, absent or marginally present after hybridization. Furthermore, the genes that were found to be statistically regulated at each time point are depicted together with the correction scaling factor (SF) for each array.

\section{References}

1. Ahmed-Choudhury J, Russell CL, Randhawa S, Young LS, Adams DH, Afford SC. Differential induction of nuclear factor-kappaB and activator protein-1 activity after CD40 ligation is associated with primary human hepatocyte apoptosis or intrahepatic endothelial cell proliferation. Mol Biol Cell 2003 Apr;14(4):1334-1345.

2. Amemiya-Kudo M, Shimano H, Hasty AH, Yahagi N, Yoshikawa T, Matsuzaka T, et al. Transcriptional activities of nuclear SREBP-1a, -1c, and -2 to different target promoters of lipogenic and cholesterogenic genes. J Lipid Res 2002 Aug;43(8):1220-1235.

3. Belfort R, Harrison SA, Brown K, Darland C, Finch J, Hardies J, et al. A placebo-controlled trial of pioglitazone in subjects with nonalcoholic steatohepatitis. N Engl J Med 2006 Nov 30;355(22):2297-2307.

4. Belinsky MG, Dawson PA, Shchaveleva I, Bain LJ, Wang R, Ling V, et al. Analysis of the in vivo functions of Mrp3. Mol Pharmacol 2005 Jul;68(1):160-168.

5. Borst P, Elferink RO. Mammalian ABC transporters in health and disease. Annu Rev Biochem 2002;71:537592.

6. Bradham CA, Schemmer P, Stachlewitz RF, Thurman RG, Brenner DA. Activation of nuclear factor-kappaB during orthotopic liver transplantation in rats is protective and does not require Kupffer cells. Liver Transpl Surg 1999 Jul;5(4):282-293.

7. Cariello NF, Romach EH, Colton HM, Ni H, Yoon L, Falls JG, et al. Gene expression profiling of the PPARalpha agonist ciprofibrate in the cynomolgus monkey liver. Toxicol Sci 2005 Nov;88(1):250-264.

8. Chakravarthy MV, Pan Z, Zhu Y, Tordjman K, Schneider JG, Coleman T, et al. "New" hepatic fat activates PPARalpha to maintain glucose, lipid, and cholesterol homeostasis. Cell Metab 2005 May;1(5):309-322.

9. Cherkaoui-Malki M, Meyer K, Cao WQ, Latruffe N, Yeldandi AV, Rao MS, et al. Identification of novel peroxisome proliferator-activated receptor alpha (PPARalpha) target genes in mouse liver using cDNA microarray analysis. Gene Expr 2001;9(6):291-304.

10. Cheung C, Akiyama TE, Ward JM, Nicol CJ, Feigenbaum L, Vinson C, et al. Diminished hepatocellular proliferation in mice humanized for the nuclear receptor peroxisome proliferator-activated receptor alpha. Cancer Res 2004 Jun 1;64(11):3849-3854. 
11. Chou WC, Prokova V, Shiraishi K, Valcourt U, Moustakas A, Hadzopoulou-Cladaras M, et al. Mechanism of a transcriptional cross talk between transforming growth factor-beta-regulated Smad3 and Smad4 proteins and orphan nuclear receptor hepatocyte nuclear factor-4. Mol Biol Cell 2003 Mar;14(3):1279-1294.

12. Ciana P, Biserni A, Tatangelo L, Tiveron C, Sciarroni AF, Ottobrini L, et al. A Novel Peroxisome Proliferator-Activated Receptor Responsive Element-Luciferase Reporter Mouse Reveals Gender Specificity of Peroxisome Proliferator-Activated Receptor Activity in Liver. Mol Endocrinol 2007 February 1, 2007;21(2):388-400.

13. Cleland JG, Atkin SL. Thiazolidinediones, deadly sins, surrogates, and elephants. Lancet 2007 Sep 29;370(9593):1103-1104.

14. Colles SL, Dixon JB, Marks P, Strauss BJ, O'Brien PE. Preoperative weight loss with a very-low-energy diet: quantitation of changes in liver and abdominal fat by serial imaging. Am J Clin Nutr 2006 Aug;84(2):304311.

15. Delerive P, De Bosscher K, Besnard S, Vanden Berghe W, Peters JM, Gonzalez FJ, et al. Peroxisome Proliferator-activated Receptor alpha Negatively Regulates the Vascular Inflammatory Gene Response by Negative Cross-talk with Transcription Factors NF-kappa B and AP-1. J Biol Chem 1999 November 5, 1999;274(45):32048-32054.

16. Delerive P, De Bosscher K, Besnard S, Vanden Berghe W, Peters JM, Gonzalez FJ, et al. Peroxisome proliferator-activated receptor alpha negatively regulates the vascular inflammatory gene response by negative cross-talk with transcription factors NF-kappaB and AP-1. J Biol Chem 1999 Nov 5;274(45):32048-32054.

17. Desvergne B, Wahli W. Peroxisome proliferator-activated receptors: nuclear control of metabolism. Endocr Rev 1999 Oct;20(5):649-688.

18. Dhe-Paganon S, Duda K, Iwamoto M, Chi Y-I, Shoelson SE. Crystal Structure of the HNF4alpha Ligand Binding Domain in Complex with Endogenous Fatty Acid Ligand. J Biol Chem 2002 October 4, 2002;277(41):37973-37976.

19. Finck BN, Lehman JJ, Leone TC, Welch MJ, Bennett MJ, Kovacs A, et al. The cardiac phenotype induced by PPARalpha overexpression mimics that caused by diabetes mellitus. J Clin Invest 2002 Jan;109(1):121-130.

20. Francis GA, Fayard E, Picard F, Auwerx J. Nuclear receptors and the control of metabolism. Annu Rev Physiol 2003;65:261-311.

21. Gervois P, Kleemann R, Pilon A, Percevault F, Koenig W, Staels B, et al. Global suppression of IL-6-induced acute phase response gene expression after chronic in vivo treatment with the peroxisome proliferatoractivated receptor-alpha activator fenofibrate. J Biol Chem 2004 Apr 16;279(16):16154-16160.

22. Goldstein JL, Dana SE, Faust JR, Beaudet AL, Brown MS. Role of lysosomal acid lipase in the metabolism of plasma low density lipoprotein. Observations in cultured fibroblasts from a patient with cholesteryl ester storage disease. J Biol Chem 1975 November 10, 1975;250(21):8487-8495.

23. Goldstein JL, DeBose-Boyd RA, Brown MS. Protein sensors for membrane sterols. Cell 2006 Jan 13;124(1):35-46.

24. Hayhurst GP, Lee YH, Lambert G, Ward JM, Gonzalez FJ. Hepatocyte nuclear factor 4alpha (nuclear receptor 2A1) is essential for maintenance of hepatic gene expression and lipid homeostasis. Mol Cell Biol 2001 Feb;21(4):1393-1403.

25. Hennuyer N, Tailleux A, Torpier G, Mezdour H, Fruchart JC, Staels B, et al. PPARalpha, but not PPARgamma, activators decrease macrophage-laden atherosclerotic lesions in a nondiabetic mouse model of mixed dyslipidemia. Arterioscler Thromb Vasc Biol 2005 Sep;25(9):1897-1902.

26. Hertz R, Magenheim J, Berman I, Bar-Tana J. Fatty acyl-CoA thioesters are ligands of hepatic nuclear factor4[alpha]. Nature 1998;392(6675):512-516.

27. Horton JD, Shah NA, Warrington JA, Anderson NN, Park SW, Brown MS, et al. Combined analysis of oligonucleotide microarray data from transgenic and knockout mice identifies direct SREBP target genes. Proc Natl Acad Sci U S A 2003 Oct 14;100(21):12027-12032.

28. Hsu MH, Savas U, Griffin KJ, Johnson EF. Identification of peroxisome proliferator-responsive human genes by elevated expression of the peroxisome proliferator-activated receptor alpha in HepG2 cells. J Biol Chem 2001 Jul 27;276(30):27950-27958.

29. Ip E, Farrell G, Hall P, Robertson G, Leclercq I. Administration of the potent PPARalpha agonist, Wy-14,643, reverses nutritional fibrosis and steatohepatitis in mice. Hepatology 2004 May;39(5):1286-1296.

30. Ip E, Farrell GC, Robertson G, Hall P, Kirsch R, Leclercq I. Central role of PPARalpha-dependent hepatic lipid turnover in dietary steatohepatitis in mice. Hepatology $2003 \mathrm{Jul} ; 38(1): 123-132$.

31. Joven J, Rull A, Ferre N, Escola-Gil JC, Marsillach J, Coll B, et al. The results in rodent models of atherosclerosis are not interchangeable: the influence of diet and strain. Atherosclerosis 2007 Dec;195(2):e8592. 
32. Kardassis D, Sacharidou E, Zannis VI. Transactivation of the human apolipoprotein CII promoter by orphan and ligand-dependent nuclear receptors. The regulatory element CIIC is a thyroid hormone response element. J Biol Chem 1998 Jul 10;273(28):17810-17816.

33. Karlsson M, Contreras JA, Hellman U, Tornqvist H, Holm C. cDNA Cloning, Tissue Distribution, and Identification of the Catalytic Triad of Monoglyceride Lipase. EVOLUTIONARY RELATIONSHIP TO ESTERASES, LYSOPHOSPHOLIPASES, AND HALOPEROXIDASES. J Biol Chem 1997 October 24, 1997;272(43):27218-27223.

34. Kersten S, Mandard S, Escher P, Gonzalez FJ, Tafuri S, Desvergne B, et al. The peroxisome proliferatoractivated receptor alpha regulates amino acid metabolism. Faseb J 2001 Sep;15(11):1971-1978.

35. Kim HJ, Kim JY, Kim JY, Park SK, Seo JH, Kim JB, et al. Differential regulation of human and mouse orphan nuclear receptor small heterodimer partner promoter by sterol regulatory element binding protein-1. J Biol Chem 2004 Jul 2;279(27):28122-28131.

36. Kliewer SA, Sundseth SS, Jones SA, Brown PJ, Wisely GB, Koble CS, et al. Fatty acids and eicosanoids regulate gene expression through direct interactions with peroxisome proliferator-activated receptors alpha and gamma. Proc Natl Acad Sci U S A 1997 Apr 29;94(9):4318-4323.

37. Kotronen A, Yki-Jarvinen H. Fatty Liver. A Novel Component of the Metabolic Syndrome. Arterioscler Thromb Vasc Biol 2007 Aug 9.

38. Kuboki S, Okaya T, Schuster R, Blanchard J, Denenberg A, Wong HR, et al. Hepatocyte NF-kappaB activation is hepatoprotective during ischemia-reperfusion injury and is augmented by ischemic hypothermia. Am J Physiol Gastrointest Liver Physiol 2007 Jan;292(1):G201-207.

39. Lago RM, Singh PP, Nesto RW. Congestive heart failure and cardiovascular death in patients with prediabetes and type 2 diabetes given thiazolidinediones: a meta-analysis of randomised clinical trials. Lancet 2007 Sep 29;370(9593):1129-1136.

40. Lefebvre P, Chinetti G, Fruchart JC, Staels B. Sorting out the roles of PPAR alpha in energy metabolism and vascular homeostasis. J Clin Invest 2006 Mar;116(3):571-580.

41. Lipscombe LL, Gomes T, Levesque LE, Hux JE, Juurlink DN, Alter DA. Thiazolidinediones and cardiovascular outcomes in older patients with diabetes. Jama 2007 Dec 12;298(22):2634-2643.

42. Lutjohann D, Brzezinka A, Barth E, Abramowski D, Staufenbiel M, von Bergmann K, et al. Profile of cholesterol-related sterols in aged amyloid precursor protein transgenic mouse brain. J Lipid Res 2002 Jul;43(7):1078-1085.

43. Mari M, Caballero F, Colell A, Morales A, Caballeria J, Fernandez A, et al. Mitochondrial free cholesterol loading sensitizes to TNF- and Fas-mediated steatohepatitis. Cell Metab 2006 Sep;4(3):185-198.

44. Martin PG, Guillou H, Lasserre F, Dejean S, Lan A, Pascussi JM, et al. Novel aspects of PPARalphamediated regulation of lipid and xenobiotic metabolism revealed through a nutrigenomic study. Hepatology 2007 Mar;45(3):767-777.

45. Matsuzaka T, Shimano H, Yahagi N, Amemiya-Kudo M, Yoshikawa T, Hasty AH, et al. Dual regulation of mouse Delta(5)- and Delta(6)-desaturase gene expression by SREBP-1 and PPARalpha. J Lipid Res 2002 Jan;43(1):107-114.

46. Morimura K, Cheung C, Ward JM, Reddy JK, Gonzalez FJ. Differential susceptibility of mice humanized for peroxisome proliferator-activated receptor $\{$ alpha\} to $\mathrm{Wy}-14,643$-induced liver tumorigenesis. Carcinogenesis 2006 May 1, 2006;27(5):1074-1080.

47. Murakami K, Ide T, Suzuki M, Mochizuki T, Kadowaki T. Evidence for direct binding of fatty acids and eicosanoids to human peroxisome proliferators-activated receptor alpha. Biochem Biophys Res Commun 1999 Jul 14;260(3):609-613.

48. Naiki T, Nagaki M, Shidoji Y, Kojima H, Imose M, Kato T, et al. Analysis of gene expression profile induced by hepatocyte nuclear factor 4alpha in hepatoma cells using an oligonucleotide microarray. J Biol Chem 2002 Apr 19;277(16):14011-14019.

49. Parekh S, Anania FA. Abnormal lipid and glucose metabolism in obesity: implications for nonalcoholic fatty liver disease. Gastroenterology 2007 May;132(6):2191-2207.

50. Patsouris D, Mandard S, Voshol PJ, Escher P, Tan NS, Havekes LM, et al. PPAR \{alpha\} governs glycerol metabolism. J Clin Invest 2004 July 1, 2004;114(1):94-103.

51. Patsouris D, Reddy JK, Muller M, Kersten S. Peroxisome proliferator-activated receptor alpha mediates the effects of high-fat diet on hepatic gene expression. Endocrinology 2006 Mar;147(3):1508-1516.

52. Pauley CJ, Ledwith BJ, Kaplanski C. Peroxisome proliferators activate growth regulatory pathways largely via peroxisome proliferator-activated receptor [alpha]-independent mechanisms. Cellular Signalling 2002;14(4):351-358. 
53. Peet DJ, Turley SD, Ma W, Janowski BA, Lobaccaro JM, Hammer RE, et al. Cholesterol and bile acid metabolism are impaired in mice lacking the nuclear oxysterol receptor LXR alpha. Cell 1998 May 29;93(5):693-704.

54. Post SM, Duez H, Gervois PP, Staels B, Kuipers F, Princen HM. Fibrates suppress bile acid synthesis via peroxisome proliferator-activated receptor-alpha-mediated downregulation of cholesterol 7alpha-hydroxylase and sterol 27-hydroxylase expression. Arterioscler Thromb Vasc Biol 2001 Nov;21(11):1840-1845.

55. Rosenfeld JM, Vargas R, Jr., Xie W, Evans RM. Genetic profiling defines the xenobiotic gene network controlled by the nuclear receptor pregnane X receptor. Mol Endocrinol 2003 Jul;17(7):1268-1282.

56. Schoonjans K, Peinado-Onsurbe J, Lefebvre AM, Heyman RA, Briggs M, Deeb S, et al. PPARalpha and PPARgamma activators direct a distinct tissue-specific transcriptional response via a PPRE in the lipoprotein lipase gene. Embo J 1996 Oct 1;15(19):5336-5348.

57. Schuetz EG, Strom S, Yasuda K, Lecureur V, Assem M, Brimer C, et al. Disrupted bile acid homeostasis reveals an unexpected interaction among nuclear hormone receptors, transporters, and cytochrome P450. J Biol Chem 2001 Oct 19;276(42):39411-39418.

58. Schultz JR, Tu H, Luk A, Repa JJ, Medina JC, Li L, et al. Role of LXRs in control of lipogenesis. Genes Dev 2000 Nov 15;14(22):2831-2838.

59. Shimano H, Horton JD, Hammer RE, Shimomura I, Brown MS, Goldstein JL. Overproduction of cholesterol and fatty acids causes massive liver enlargement in transgenic mice expressing truncated SREBP-1a. J Clin Invest 1996 Oct 1;98(7):1575-1584.

60. Shimomura I, Shimano H, Korn BS, Bashmakov Y, Horton JD. Nuclear sterol regulatory element-binding proteins activate genes responsible for the entire program of unsaturated fatty acid biosynthesis in transgenic mouse liver. J Biol Chem 1998 Dec 25;273(52):35299-35306.

61. Shiri-Sverdlov R, Wouters K, van Gorp PJ, Gijbels MJ, Noel B, Buffat L, et al. Early diet-induced nonalcoholic steatohepatitis in APOE2 knock-in mice and its prevention by fibrates. J Hepatol 2006 Apr;44(4):732-741.

62. Staels B, Auwerx J. Perturbation of developmental gene expression in rat liver by fibric acid derivatives: lipoprotein lipase and alpha-fetoprotein as models. Development 1992 Aug;115(4):1035-1043.

63. Stienstra R, Mandard S, Patsouris D, Maass C, Kersten S, Muller M. Peroxisome proliferator-activated receptor alpha protects against obesity-induced hepatic inflammation. Endocrinology 2007 Jun;148(6):27532763.

64. Stoffel M, Duncan SA. The maturity-onset diabetes of the young (MODY1) transcription factor HNF4alpha regulates expression of genes required for glucose transport and metabolism. Proc Natl Acad Sci U S A 1997 Nov 25;94(24):13209-13214.

65. Sullivan PM, Mezdour H, Aratani Y, Knouff C, Najib J, Reddick RL, et al. Targeted replacement of the mouse apolipoprotein E gene with the common human APOE3 allele enhances diet-induced hypercholesterolemia and atherosclerosis. J Biol Chem 1997 Jul 18;272(29):17972-17980.

66. Sullivan PM, Mezdour H, Quarfordt SH, Maeda N. Type III hyperlipoproteinemia and spontaneous atherosclerosis in mice resulting from gene replacement of mouse Apoe with human Apoe*2. J Clin Invest 1998 Jul 1;102(1):130-135.

67. Tobin KA, Ulven SM, Schuster GU, Steineger HH, Andresen SM, Gustafsson JA, et al. Liver X receptors as insulin-mediating factors in fatty acid and cholesterol biosynthesis. J Biol Chem 2002 Mar 22;277(12):1069110697.

68. Toledo-Pereyra LH, Lopez-Neblina F, Lentsch AB, Anaya-Prado R, Romano SJ, Ward PA. Selectin inhibition modulates NF-kappa B and AP-1 signaling after liver ischemia/reperfusion. J Invest Surg 2006 SepOct; $19(5): 313-322$.

69. Tugwood JD, Aldridge TC, Lambe KG, Macdonald N, Woodyatt NJ. Peroxisome proliferator-activated receptors: structures and function. Ann N Y Acad Sci 1996 Dec 27;804:252-265.

70. Venkateswaran A, Laffitte BA, Joseph SB, Mak PA, Wilpitz DC, Edwards PA, et al. Control of cellular cholesterol efflux by the nuclear oxysterol receptor LXR alpha. Proc Natl Acad Sci U S A 2000 Oct 24;97(22):12097-12102.

71. Vergnes L, Phan J, Strauss M, Tafuri S, Reue K. Cholesterol and cholate components of an atherogenic diet induce distinct stages of hepatic inflammatory gene expression. J Biol Chem 2003 Oct 31;278(44):4277442784.

72. Wan Y, Chong LW, Evans RM. PPAR-gamma regulates osteoclastogenesis in mice. Nat Med 2007 Dec;13(12):1496-1503. 
73. Wouters K, van Gorp PJ, Bieghs V, Gijbels MJ, Duimel H, Lutjohann D, et al. Dietary cholesterol, rather than liver steatosis, leads to hepatic inflammation in hyperlipidemic mouse models of nonalcoholic steatohepatitis. Hepatology 2008 Apr 15;48(2):474-486.

74. Xie D, Yin D, Tong X, O'Kelly J, Mori A, Miller C, et al. Cyr61 is overexpressed in gliomas and involved in integrin-linked kinase-mediated Akt and beta-catenin-TCF/Lef signaling pathways. Cancer Res 2004 Mar 15;64(6):1987-1996.

75. Yadetie F, Laegreid A, Bakke I, Kusnierczyk W, Komorowski J, Waldum HL, et al. Liver gene expression in rats in response to the peroxisome proliferator-activated receptor-alpha agonist ciprofibrate. Physiol Genomics 2003 Sep 29;15(1):9-19.

76. Yamazaki K, Kuromitsu J, Tanaka I. Microarray analysis of gene expression changes in mouse liver induced by peroxisome proliferator- activated receptor alpha agonists. Biochem Biophys Res Commun 2002 Jan 25;290(3):1114-1122.

77. Yu S, Cao W-Q, Kashireddy P, Meyer K, Jia Y, Hughes DE, et al. Human Peroxisome Proliferator-activated Receptor alpha (PPARalpha ) Supports the Induction of Peroxisome Proliferation in PPARalpha -deficient Mouse Liver. J Biol Chem 2001 November 2, 2001;276(45):42485-42491.

78. Yu S, Cao WQ, Kashireddy P, Meyer K, Jia Y, Hughes DE, et al. Human peroxisome proliferator-activated receptor alpha (PPARalpha) supports the induction of peroxisome proliferation in PPARalpha-deficient mouse liver. J Biol Chem 2001 Nov 9;276(45):42485-42491. 


\section{V}

\section{Dietary cholesterol, rather than liver steatosis, leads to hepatic inflammation in hyperlipidemic mouse models of NASH}

Kristiaan Wouters ${ }^{1}$, Patrick J van Gorp ${ }^{1}$, Veerle Bieghs ${ }^{1}$, Marion J Gijbels ${ }^{1}$, Hans Duimel $^{1}$, Dieter Lütjohann ${ }^{2}$, Anja Kerksiek ${ }^{2}$, Roger van Kruchten ${ }^{1}$, Nobuyo Maeda ${ }^{3}$, Bart Staels $^{4}$, Marc van Bilsen ${ }^{1}$, Ronit Shiri-Sverdlov ${ }^{1 * \dagger}$, and Marten H Hofker ${ }^{{ }^{*}}$

1) Dept. of Molecular Genetics, Pathology, Physiology and Electron Microscopy Unit, Nutrition and Toxicology Research (NUTRIM) and Cardiovascular Research (CARIM) Institutes of Maastricht University, Maastricht, The Netherlands; 2) Institute of Clinical Chemistry and Pharmacology, University of Bonn, Bonn, Germany; 3) Dept of Pathology and Laboratory of Medicine, University of North Carolina, Chapel Hill, North Carolina, USA; 4) Institut Pasteur de Lille, Lille, France; Inserm U545, Lille F-59019 France; Université de Lille 2, Faculté de Pharmacie et Faculté de Médecine, Lille, France; 5) Dept. of Pathology \& Laboratory Medicine, University Medical Center Groningen, Groningen, Netherlands. * Both senior authors contributed equally to this paper.

Hepatology 2008 Aug;48(2):474-86 


\section{Abstract}

Introduction: Non-alcoholic steatohepatitis (NASH) involves liver lipid accumulation (steatosis) combined with hepatic inflammation. The transition towards hepatic inflammation represents a key step in the pathogenesis, as it will set the stage for further liver damage, culminating in hepatic fibrosis, cirrhosis and liver cancer. The actual risk factors that drive hepatic inflammation during the progression to NASH remain largely unknown.

Aim: Investigate the role of steatosis and dietary cholesterol in the etiology of dietinduced NASH was investigated by using hyperlipidemic mouse models fed a western diet.

Materials and methods: Livers of male and female hyperlipidemic (low density lipoprotein deficient $\left[\mathrm{ldlr}^{-/}\right.$] and apolipoprotein E2 knock-in [APOE2ki]) mouse models were compared with livers of normolipidemic wild-type (WT) C57B1/6 mice after short term feeding with a high fat diet with high cholesterol (HFC) and without cholesterol (HFnC).

Results: Whereas WT mice displayed only steatosis after a short term on HFC diet, female $\mathrm{ldlr}^{-/}$and APOE2ki mice showed steatosis with severe inflammation characterized by infiltration of macrophages and increased nuclear factor kappa beta (NF-kB) signaling. Remarkably, male $\operatorname{ldlr}^{-/-}$and APOE2ki mice developed severe hepatic inflammation in the absence of steatosis after 7 days on HFC diet compared to WT animals. HFC diet induced bloated 'foamy' Kupffer cells in male and female ldlir ${ }^{-/-}$ as well as in APOE2ki mice. Hepatic inflammation was found to be linked to increased plasma very low density lipoprotein (VLDL) cholesterol levels. Omitting cholesterol from the HFC diet lowered plasma VLDL cholesterol and prevented the development of inflammation and hepatic foam cells.

Conclusion: These findings indicate that dietary cholesterol, possibly in the form of modified plasma lipoproteins, is an important risk factor for the progression to hepatic inflammation in diet-induced NASH. 


\section{I ntroduction}

Non-alcoholic fatty liver disease (NAFLD) is a condition ranging from benign lipid accumulation in the liver (steatosis) to steatosis combined with inflammation. The latter is referred to as non-alcoholic steatohepatitis (NASH). NAFLD may be considered the hepatic event in the metabolic syndrome and is, therefore, linked with all common metabolic syndrome risk factors like obesity, insulin resistance, hypertension and dyslipidemia [1]. The prevalence of NAFLD in the general population is increasing, but only a small proportion will develop NASH. Estimates in USA are that only $2-3 \%$ of all adults have NASH, compared to an estimation of $20 \%$ of Americans with NALFD [2].

Steatosis alone is considered a relatively benign and reversible condition. The transition towards NASH represents a key step in pathogenesis, as it will set the stage for further damage to the liver, including fibrosis, cirrhosis and liver cancer. The actual risk factors that drive hepatic inflammation during the progression to NASH remain largely unknown. Therefore, knowledge about events that induce hepatic inflammation is of great importance for the diagnosis and treatment of NASH.

Currently, NASH is thought to develop via the "two-hit model" [3]. According to this hypothesis, hepatic steatosis is the critical first hit and prerequisite for further liver injury to develop. A second hit can be represented by oxidative stress [4]. However, recent reports doubt steatosis being a prerequisite for development of inflammation during NASH progression [5-7]. In line with these observations, we have previously shown that in APOE2 knock-in (APOE2ki) mice, a mouse model with a human-like lipoprotein profile, hepatic steatosis and inflammation (i.e. steatohepatitis) develop very rapidly when fed a western type diet with moderate amounts of fats. Already after 2 days of feeding a western diet enriched with triglycerides (TGs) and cholesterol, female APOE2ki mice show a marked liver inflammation [8]. Inflammation thus developed alongside rather than subsequent to steatosis.

The APOE2ki mouse carries the defective human APOE2 isoform that replaces the endogenous mouse apoe gene. ApoE is highly expressed in macrophages and has been shown to influence several inflammatory processes [9]. Therefore, to exclude defects in ApoE as the cause of such early inflammation in the liver, we first investigated dietinduced NASH development in another hyperlipidemic mouse model that does not have a defect in ApoE, i.e. the $1 \mathrm{dlr}^{-/-}$mouse [10]. C57Bl/6 wild-type (WT) mice, with the genetic background of both mouse models, were used as control. Second, pilot experiments revealed a difference between female and male $1 \mathrm{dll}^{-/-}$and APOE2ki mice as the male mice did not develop steatosis after short term high fat feeding. Consequently, we investigated male hyperlipidemic APOE2ki and $1 \mathrm{dlr}^{-/-}$mice to 
unravel whether steatosis is necessary for hepatic inflammation to develop. Third, based on the results from these diet intervention studies, a correlation was found between plasma total cholesterol (TC) and hepatic inflammation. Therefore, the role of plasma TC was further investigated.

\section{Materials and methods}

\section{Mice and diet}

Mice were housed under standard conditions given free access to food and water. Experiments were performed according to Dutch laws, approved by the Committee for Animal Welfare of Maastricht University. Several experiments were performed. In the first experiment, 12-week old female C57Bl/6 and $1 \mathrm{dlr}^{-/-}$mice were fed a high fat diet containing $21 \%$ milk butter and $0.2 \%$ cholesterol (HFC), for 2, 4, 7 and 21 days. A single group was kept on a standard chow diet until the age of 12 weeks and served as control group. In the second experiment, male C57Bl/6, $\mathrm{dlr}^{-/}$, and APOE2ki mice were put either on HFC for 7 days or were kept on chow diet. In the third experiment, male and female C57Bl/6, $\mathrm{dllr}^{-/}$, and APOE2ki mice were fed HFC or the high fat diet without the added cholesterol (HFnC) for 7 days. The HFnC diet contained only the residual cholesterol derived from the butter component, i.e. $0.05 \%$. Collection of blood, sacrificing of the mice, and tissue isolation was done as described previously [8].

\section{Lipid analysis}

Approximately $50 \mathrm{mg}$ of frozen liver tissue was homogenized as described previously [8]. Both plasma and liver lipid levels were measured with enzymatic color tests (1489232, cholesterol CHOD-PAP, Roche, Basel, Switzerland; TR0100, TG GPOtrinder, Sigma Aldrich, St. Louis, MO, USA; 999-75406, NEFAC, ACS-ACOD, Wako Chemicals, Neuss, Germany) as described before [8].

\section{RNA isolation and first strand cDNA synthesis}

Total RNA was isolated from approximately $25 \mathrm{mg}$ of mouse liver tissues as described previously [8]. All applications were done according to manufacturer's protocols. Total RNA (500 ng) from each individual mouse was converted into first strand cDNA with iScript cDNA synthesis kit (170-8891, Bio-Rad, Hercules, CA, USA) according to the manufacturer's instructions. 


\section{Quantitative PCR}

The changes in gene expression of inflammatory markers were determined by quantitative PCR on a Bio-Rad MyIQ with the IQ5 v2 software (Bio-Rad, Hercules, CA, USA) by using IQ SYBR Green Supermix with fluorescein (170-5006CUST, BioRad, Hercules, CA, USA) and 10 ng of cDNA. For each gene a standard curve was generated with a serial dilution of a liver cDNA pool. To standardize for the amount of cDNA, Cyclophillin A (Ppia) was used as the reference gene. Primer sets for the selected genes were developed with Primer Express version 1.5 (Applied Biosystems, Foster City, CA, USA) using default settings. Primer sequences:

MCP1-forward, 5'-GCTGGAGAGCTACAAGAGGATCA-3'; MCP1-reverse, 5'-ACAGACCTCTCTCTTGAGCTTGGT-3'; CD68-forward, 5'-TGACCTGCTCTCTCTAAGGCTACA-3'; CD68-reverse, 5-TCACGGTTGCAAGAGAAACATG -3';

TNFa-forward, 5'-CATCTTCTCAAAATTCGAGTGACAA-3';

TNFa-reverse, 5'-TGGGAGTAGACAAGGTACAACCC-3'; Ppia-forward, 5'-TTCCTCCTTTCACAGAATTATTCCA-3'; Ppia-reverse, 5'-CCGCCAGTGCCATTATGG-3'.

Data from qPCR were analyzed according to the relative standard curve method.

\section{Taqman ${ }^{\circledR}$ Low Density Arrays}

To perform gene-expression analysis on a medium scale, Taqman Low Density Arrays (TLDA) 96a (PN 4342259) were used. Each TLDA plate contained 4 x 96 annotated and validated individual TaqMan Gene Expression Assays (forward primer, reversed primer and Taqman ${ }^{*}$ Probe) (supplementary table 1). Per individual assay 2 ng cDNA of a single liver was loaded together with the TaqMan ${ }^{\circledR}$ Universal PCR Master Mix (PN 4324018). Of each group, mRNA from 5 individual mice was used. TLDA plates were run on an ABI Prism 7900HT Sequence Detection System with a TaqMan ${ }^{\circledR}$ Low Density Array Upgrade. Data were analyzed by using RQ Manager 1.2 software. Technically failed assays were omitted from analysis. Materials, equipment and software necessary to perform TLDA gene expression studies were obtained from Applied Biosystems, Foster City, CA, USA. All data were normalized to Ppia expression. Significant differences were determined with student t-tests; $p$-values < 0.05 were considered significant. 


\section{Liver histology}

Four $\mu \mathrm{m}$ paraffin embedded liver sections were stained with Haematoxillin/Eosin (HE) and Periodic acid Schiff (PAS)-diastase. Frozen liver sections $(7 \mu \mathrm{m})$ were fixed in acetone and stained with CD68 (FA11) or Mac1 (M1/70). Pictures were taken with a Nikon ${ }^{\circledR}$ digital camera DMX1200 and ACT-1 v2.63 software (Nikon ${ }^{\circledR}$ Corporation, Tokyo, Japan).

\section{Electron microscopy.}

Livers were freshly isolated from the mice, perfused and fixed overnight with $2.5 \%$ glutaraldehyde (Ted Pella, Redding, CA, USA). Tissue fragments were washed and post-fixed in $1 \%$ osmium tetroxide. Tissues were subsequently dehydrated trough $100 \%$ ethanol, cleared with propylene oxide, and embedded in epoxy resin. Sections of $1 \mu \mathrm{m}$ were stained with toluidine blue to identify the presence of foamy Kupffer cells. Next, sections of 70-90 nm were cut on an ultra-microtome, mounted on Formvarcoated (1595E, Merck) 75 mesh copper grids and counterstained with uranyl acetate and lead citrate before analysis on a Philips CM100 transmission electron microscope.

\section{Statistical analysis}

Data were analyzed using Graphpad Prism 4.0. Groups were compared using 2-tailed non-paired t-tests or ANOVA with a Dunnet post test, based on the statistical relevance. Data are expressed as means \pm SEM and considered significant at $\mathrm{p}<0.05$.

\section{Results}

\section{Plasma lipid levels in female hyperlipidemic mouse models}

Female $1 \mathrm{dlr}^{-/}$, APOE2ki and WT mice were fed an HFC diet for up to 3 weeks and changes in plasma lipids were monitored (experiment 1). Results on female APOE2ki mice were published earlier [8] and are included in figure 1 (black bars) for clarity. WT mice only displayed minor changes in their lipid profile. Compared to control chow levels, female $1 \mathrm{dlr}^{-/}$mice showed increased plasma TGs (Fig. 1A) and free fatty acids (FFA) (Fig. 1B) levels and diet-induced hypercholesterolemia (Fig. 1C) upon HFC feeding. Historical data of female APOE2ki mice (black bars) shows that these animals have elevated basal plasma TG levels that tended to decrease within time (Fig. 1A), 
while FFA remained at basal levels (Fig. 1B) and TC levels increased markedly throughout the dietary period (Fig. 1C) [8].

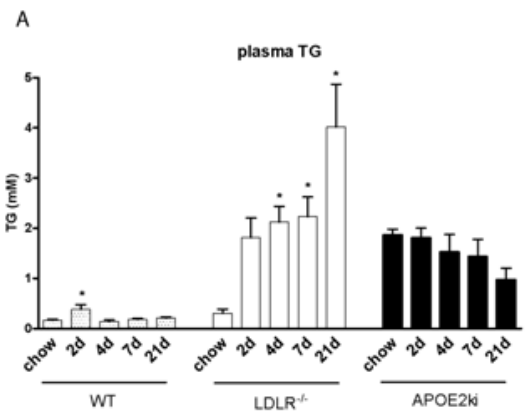

B

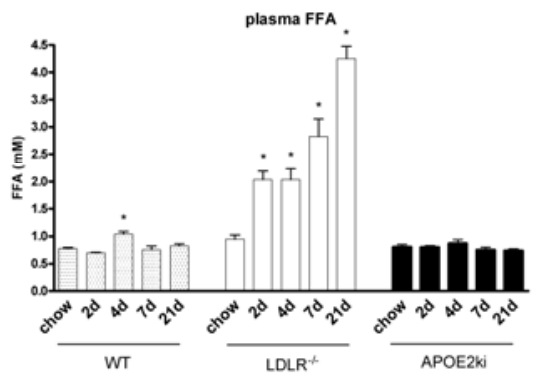

C

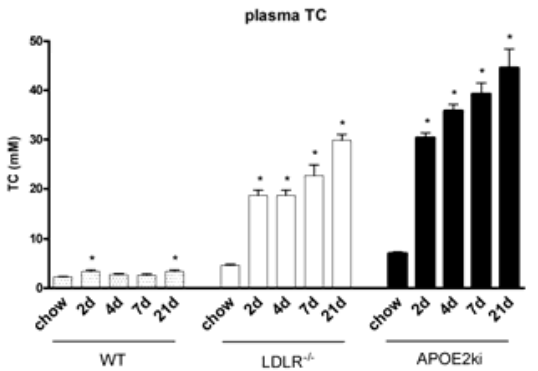

Figure. 1 Plasma lipid levels in female mice. Figure shows plasma lipids of three mouse models at several time points after HFC treatment: 2, 4, 7 and 21 days (d) compared to chow-fed control mice. A. plasma triglycerides (TGs). B. plasma free fatty acids (FFA) and C. plasma total cholesterol (TC). Bars represent time points (2, 4, 7 and 21 days) and are grouped per genotype: WT mice (grey bars), ldlr-/- mice (white bars) and APOE2ki mice (black bars). Statistical analysis was done with one way ANOVA with Dunnet's post test; * indicates significant difference from levels on chow diet. 


\section{Only female Idlr ${ }^{-1-}$ and APOE2ki mice develop liver inflammation}

APOE2ki and $1 \mathrm{dlr}^{-/-}$mice showed equal accumulation of lipid droplets in their livers after 7 days of HFC which was comparable with livers of control WT animals (Fig. 2A). Fig. 2B shows that all mouse models had similar increases of liver TGs after short periods of HFC feeding. Liver TC showed a similar response (Fig. 2C). HFC feeding thus induced a degree of hepatic steatosis in $1 \mathrm{dlr}^{-/-}$and APOE2ki mice similar to what was observed in WT animals. These observations were confirmed by Oil red O (ORO) staining (data not shown).

As HE staining revealed inflammatory clusters in the livers (Fig. 2A), antibodies against the macrophage marker Mac1 were used to identify inflammatory cells. The number of Mac1 positive cells was counted to determine the level of liver inflammation. Interestingly, WT livers were completely free of inflammation upon HFC feeding, while $1 \mathrm{dlr}^{-/-}$mice displayed inflammatory cell clusters similar to those observed previously in APOE2ki mice [8] (Fig. 2D), albeit that inflammation was less severe in $\mathrm{ldlr}^{-/-}$mice.

Gene expression analysis of several inflammatory genes was performed in livers of the mouse models outlined at 2, 4, 7 and 21 days after HFC feeding. These genes were monocyte chemoattractant protein 1 (Mcp1) (Fig. 2E), CD68 (Fig. 2F), a macrophage marker, and tumor necrosis factor (TNF) (Fig. 2G), a cytokine. Expression of these genes in $1 \mathrm{dlr}^{-/-}$and APOE2ki mice was strongly up-regulated after HFC feeding. In contrast, control WT mice showed only a moderate increase in liver gene expression, apparently insufficient to drive an overt inflammatory response as determined by liver histology.

Hence, in HFC-induced fatty liver, female APOE2ki and $\mathrm{ldlr}^{-/}$, but not WT mice, are sensitive to developing inflammation, indicating that diet-induced steatosis does not necessarily lead to the immediate development of an inflammatory response in the liver.

\section{Liver gene expression profiling reveals an inflammatory profile in Idllr ${ }^{-/}$but not in WT female mice}

To investigate the hepatic response to HFC feeding in more detail, custom TLDA assays were designed to compare the expression of 96 genes involved either in lipid transport and metabolism, or in inflammation. The expression of Mcp1, CD68 and TNF, determined by QPCR, was similar between $1 \mathrm{dlr}^{-/-}$and APOE2ki mice (Fig. $2 \mathrm{E}-$ 

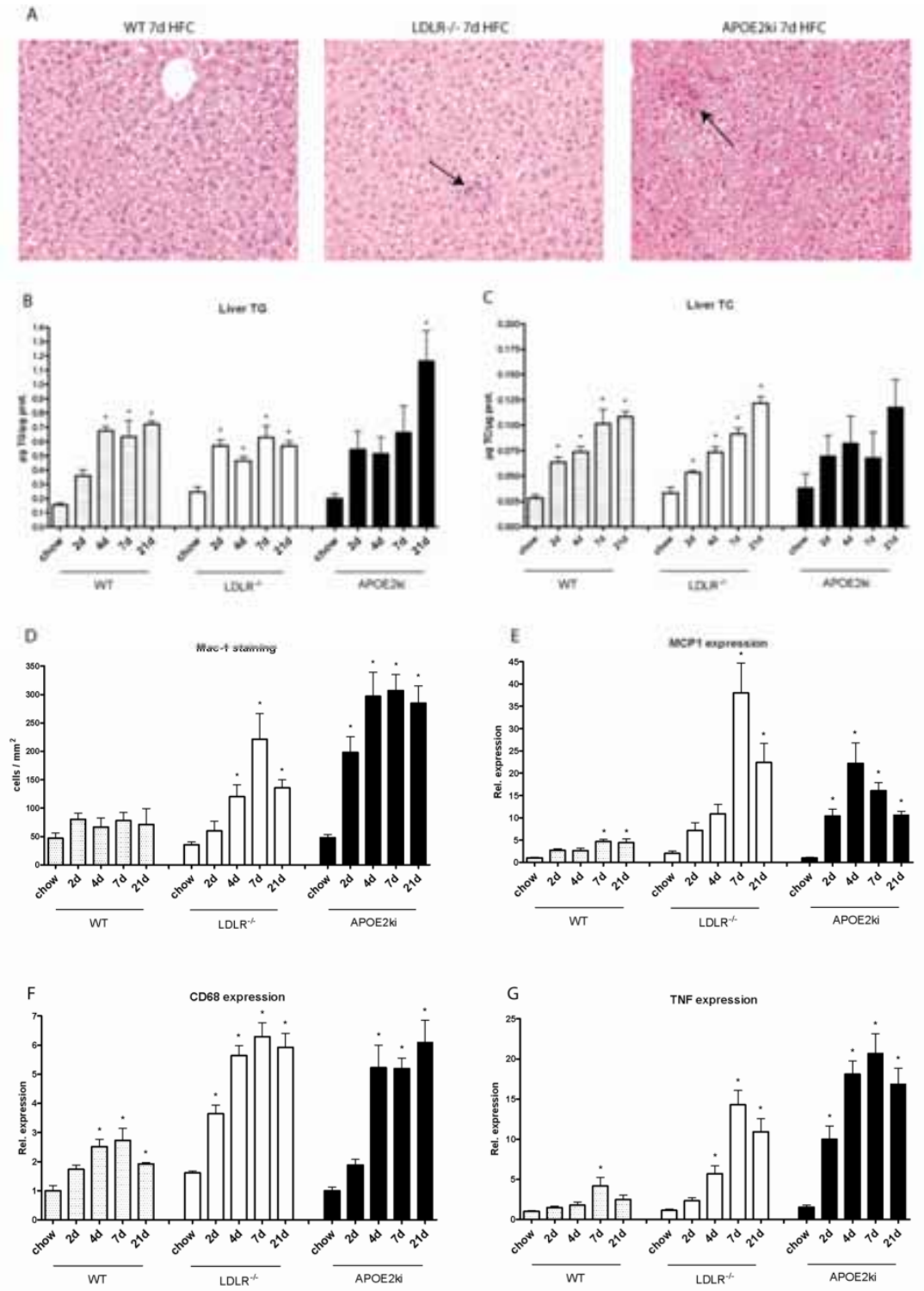

Figure. 2 NASH parameters in female mice. A. Representative pictures (200x) of HE stained liver sections were taken of female mice after 7 days high fat, high cholesterol (HFC) diet. Black arrows indicate inflammatory cell clusters. Liver triglycerides (TGs) (B) and total cholesterol (TC) (C) levels were quantified biochemically. D. Liver sections were stained for Mac1 (CD11b) and counted. Gene expression analysis with quantitative RT-PCR for three known inflammatory marker genes: MCP1 (E), CD68 (F) and TNF (G). Data was set relative to wild-type (WT) animals on chow diet. Bars represent time points $(2,4,7$ and 21 days) and are grouped per genotype: WT mice (grey bars), ldlr-/- mice (white bars) and APOE2ki mice (black bars). Statistical analysis was done with one way ANOVA with Dunnet's post test; * indicates significant difference from levels on chow diet. 
G). Additionally, previous microarray analysis has already shown a profound inflammatory response after feeding female APOE2ki mice HFC diet [8]. The response of $1 \mathrm{dll}^{-/-}$mice to 7 days of HFC feeding was compared to WT mice. Table 1 shows changes in expression levels for these genes and indicates the pathway to which each gene belongs to. Genes involved in lipid metabolism showed only few changes after 7 days of HFC diet in either mouse model (table 1A). Inflammatory gene expression, including several known targets of NF- $\kappa \mathrm{B}$, was markedly up-regulated in female $\mathrm{ldlr}^{-/-}$ mice, but not in female WT mice (table 1B). The inflammatory response consisted mainly of the increased expression of macrophage specific genes (table 1B), like CD68, Fc Gamma receptor 1 and Mac1, but not other immune cell specific genes, like CD19 (B-cells), CD4 (Th-cells), CD8a (Tc-cells), and myeloperoxidase (MPO) (neutrophils). These data suggest that inflammation is mainly related to macrophage accumulation and activation. Also Icam1 and Vcam1, involved in inflammatory cell migration and invasion, were up-regulated. Additionally, genes involved in chemotaxis (table 1B), such as $\operatorname{ccl} 2$ (mcp1), ccl3 and ptgs 2 were strongly regulated, indicating an important role of these gene products in the development of hepatic inflammation.

\section{Steatosis is not necessary for the development of HFC diet- induced hepatic inflammation}

Male $1 \mathrm{dlr}^{-/}$and APOE2ki mice were put either on chow diet or HFC diet for 7 days (experiment 2). Male WT animals were used as control. Both male $1 \mathrm{dlr}^{-/ .}$and APOE2ki mice showed increased diet-induced plasma TGs (Fig. 3A) and TC (Fig. 3B) compared to control mice, although APOE2ki mice were less responsive than $1 \mathrm{dlr}^{-/-}$mice. The changes in TGs were similar to those observed in female mice for the $1 \mathrm{dlr}^{-/ /}$animals, while APOE2ki mice differed in their TG response as female APOE2ki mice had elevated starting levels of TGs that did not change after dietary intervention (Fig. 1A). While in the female animals the APOE2ki mice were more responsive with respect to plasma TC (Fig. 1C), male APOE2ki mice had a smaller increase than $1 \mathrm{dlr}^{-/ /}$mice.

Biochemical assessment of liver lipids showed no increase in liver TG levels in male hyperlipidemic mice. Male WT mice did show an increase in hepatic TGs, however, the levels after 7 days of HFC did not exceed the ones displayed in the $\operatorname{ldlr}^{-/}$and APOE2ki males (Fig. 3C). On the other hand, liver TC levels did rise significantly after HFC in all models (Fig. 3D). Likewise, ORO staining did not reveal overt steatosis (data not shown). 
Table 1. Liver Gene expression

A

\begin{tabular}{|c|c|c|c|}
\hline gene & group & $\begin{array}{l}\text { WT } \\
\text { HFC vs chow }\end{array}$ & $\begin{array}{l}\text { LDLR }^{-1-} \\
\text { HFC vs chow }\end{array}$ \\
\hline $\mathrm{Cd} 36$ & Lipid Uptake & 1.4 & 1 \\
\hline Fabp1 & Lipid Uptake & 1.2 & 0.9 \\
\hline Lipc & Lipid Uptake & 1.1 & 0.9 \\
\hline Lpl & Lipid Uptake & 1.3 & $\underline{3.7}$ \\
\hline Lrp1 & Lipid Uptake & $\underline{1.5}$ & 1.1 \\
\hline Slc27a1 & Lipid Uptake & 1.1 & 0.9 \\
\hline Acaa1a & lipid Oxidation and efflux & 1.3 & 1 \\
\hline Acox 1 & lipid Oxidation and efflux & 1.2 & 0.8 \\
\hline Cpt1a & lipid Oxidation and efflux & 1.5 & 0.8 \\
\hline Crot & lipid Oxidation and efflux & 1.5 & 0.9 \\
\hline Ech1 & lipid Oxidation and efflux & 0.9 & 0.8 \\
\hline Hadha & lipid Oxidation and efflux & 1.1 & 1 \\
\hline Mttp & lipid Oxidation and efflux & 1 & $\underline{0.8}$ \\
\hline Ppara & lipid Oxidation and efflux & 1.4 & 0.9 \\
\hline Ppard & lipid Oxidation and efflux & 1.2 & 1.2 \\
\hline Pparg & lipid Oxidation and efflux & 1.1 & 1.1 \\
\hline Fasn & Lipid Met. Synthesis & $\underline{0.5}$ & 0.4 \\
\hline LXRa & Lipid Met. Synthesis & 1.6 & 1.1 \\
\hline FXR & Lipid Met. Synthesis & 1.1 & 0.7 \\
\hline Scd 1 & Lipid Met. Synthesis & 1.2 & 0.6 \\
\hline Srebf1 & Lipid Met. Synthesis & 1.2 & 1.3 \\
\hline Abca1 & Cholesterol efflux & 1.5 & $\underline{1.7}$ \\
\hline Cyp7a1 & Cholesterol efflux & 2 & 1.6 \\
\hline Scarb1 & Cholesterol efflux & 1.8 & $\underline{1.4}$ \\
\hline Adfp & Intracellular lipid distribution & 1.3 & 0.8 \\
\hline Cav1 & Intracellular lipid distribution & 1.2 & 0.9 \\
\hline Cav2 & Intracellular lipid distribution & 1.2 & 0.9 \\
\hline M6prbp1 & Intracellular lipid distribution & 1.4 & 1 \\
\hline Npc1 & Intracellular lipid distribution & 1 & 0.6 \\
\hline Idi1 & Cholesterol metabolism & $\underline{0.2}$ & $\underline{0.1}$ \\
\hline Insig2 & Cholesterol metabolism & 1.5 & 0.7 \\
\hline Сyp8b1 & Other & 1.3 & $\underline{0.3}$ \\
\hline Cd19 & Cell Markers & 0.8 & $\underline{1.4}$ \\
\hline $\mathrm{Cd} 4$ & Cell Markers & 2 & $\underline{1.3}$ \\
\hline Cd68 & Cell Markers & 1.7 & 3.1 (a) \\
\hline
\end{tabular}


Table 1 (continued) B.

\begin{tabular}{|c|c|c|c|}
\hline gene & group & $\begin{array}{l}\text { WT } \\
\text { HFC vs chow }\end{array}$ & $\begin{array}{l}\text { LDLR }^{-/-} \\
\text {HFC vs chow }\end{array}$ \\
\hline $\mathrm{Cd} 8 \mathrm{a}$ & Cell Markers & 1.4 & 2 \\
\hline Fcgr1 & Cell Markers & 2.2 & $\underline{2.4}$ (a) \\
\hline Itgam/Mac1 & Cell Markers & 1.5 & $\underline{5.7}$ (a) \\
\hline Mpo & Cell Markers & 3 & 7.9 \\
\hline Icam1 & Cell Markers & 1.9 & $\underline{3}$ \\
\hline Vcam1 & Cell Markers & 1 & $\underline{3}$ \\
\hline Vegfa & Cell Markers & 1.1 & 1 \\
\hline $\mathrm{Ccl} 2 / \mathrm{mcp} 1$ & Chemotaxis & 3 & $\underline{9.5}$ (b) \\
\hline $\mathrm{Ccl} 3 / \mathrm{mip} 1$ & Chemotaxis & 3.4 & $\underline{11.2}$ (b) \\
\hline Ccr2 & Chemotaxis & 1.8 & $\underline{1.9}$ (b) \\
\hline Ptgs $2 / \operatorname{Cox} 2$ & Chemotaxis & 1.2 & $\underline{25.4}$ (b) \\
\hline Cat & Oxidative stress & 1.1 & 0.8 \\
\hline Gsta2 & Oxidative stress & $\underline{0.5}$ & $\underline{0.2}$ \\
\hline Hmox 1 & Oxidative stress & 1.8 & $\underline{2.8}$ \\
\hline Ikbkb & Oxidative stress & 1 & 1.3 \\
\hline Por & Oxidative stress & 1.3 & 0.8 \\
\hline $\mathrm{Bcl} 2$ & Apoptosis & 1.2 & $\underline{\mathbf{2}}$ \\
\hline Fasl & Apoptosis & 2 & $\underline{2.2}$ \\
\hline Il10 & Anti-inflammatory & 2.5 & 1.7 \\
\hline Il10ra & Anti-inflammatory & 1.5 & $\underline{2.9}$ \\
\hline Socs1 & Anti-inflammatory & $\underline{2.6}$ & $\underline{2.3}$ \\
\hline Socs 3 & Anti-inflammatory & 1.3 & $\underline{1.9}$ \\
\hline Cd14 & General Inflammation & 1.8 & $\underline{4.5}$ \\
\hline $\mathrm{Cd} 40$ & General Inflammation & 2.1 & $\underline{2.7}$ \\
\hline $\mathrm{Cd} 80$ & General Inflammation & 2.7 & $\underline{2.7}$ \\
\hline $\mathrm{Cd} 86$ & General Inflammation & 2.2 & $\underline{3}$ \\
\hline CsfF & General Inflamm. & 0.6 & 0.9 \\
\hline Cxcl10 & General Inflammation & 3 & $\underline{3.5}$ \\
\hline Ifng & General Inflammation & 1.1 & 1.7 \\
\hline $\mathrm{I} 118$ & General Inflammation & 1 & 0.9 \\
\hline Il18r1 & General Inflammation & 1.9 & $\underline{4}$ \\
\hline $\mathrm{Il} 1 \mathrm{~b}$ & General Inflammation & 1.4 & $\underline{6.3}$ \\
\hline Il1r1 & General Inflammation & 0.8 & $\underline{2}$ \\
\hline $\mathrm{I} 11 \mathrm{r} 2$ & General Inflammation & 1.1 & 5.4 \\
\hline Il6 & General Inflammation & 1.6 & 6 \\
\hline Il6ra & General Inflammation & 0.6 & 0.7 \\
\hline Nfkbia & General Inflammation & 1.2 & 1.4 \\
\hline Saa1 & General Inflammation & 2.3 & 19.9 \\
\hline
\end{tabular}


Table 1 (continued)

\begin{tabular}{llll}
\hline & & WT & LDLR $^{-/}$ \\
gene & group & HFC vs chow & HFC vs chow \\
\hline Stat1 & General Inflammation & 1.8 & $\underline{\mathbf{1 . 8}}$ \\
Stat3 & General Inflammation & 1.2 & 1.4 \\
Tlr2 & General Inflammation & $\underline{\mathbf{2 . 3}}$ & $\underline{\mathbf{4 . 9}}$ \\
Tlr4 & General Inflammation & 1.5 & $\underline{\mathbf{2 . 4}}$ \\
Tnf & General Inflammation & 3 & $\underline{\mathbf{1 0}}$ \\
Tnfrsf1a & General Inflammation & 1.3 & 1 \\
Tnfrsflb & General Inflammation & 1.3 & $\underline{\mathbf{1 . 4}}$ \\
\hline
\end{tabular}

Table 1. Liver gene expression. Table shows gene abbreviation and classification according to function. Expression is shown as fold change compared to levels of animals on standard chow diet for WT and ldlr-/female mice after $7 \mathrm{~d}$ of HFC. Significant changes (student t-tests), compared to chow are shown bold and underlined. A. Genes involved in lipid metabolism and B. Genes involved in inflammation. Regulated genes used as cell markers are marked by (a); regulated genes involved in chemotaxis are marked by (b).

Lipid accumulation is generally considered an initial and causal factor in the progression from steatosis to NASH [11]. Surprisingly, despite the lack of steatosis in male mice, there was a severe inflammatory response, reflected by a 3- to 5-fold increase in Mac1 positive cells (Fig. 3E) and increased gene expression of Mcp1 (Fig. 3F), CD68 (Fig. 3G) and TNF (Fig. 3H) compared to controls. These responses were more pronounced in APOE2ki than in $1 \mathrm{dlr}^{-/-}$male mice. Overall, this indicates that liver lipid accumulation is not a prerequisite for hepatic inflammation to develop in these mouse models.

\section{Foam cells and modified lipoproteins in hyperlipidemic mice}

Previously, we found that female APOE2ki mice displayed an increase in the size of CD68 positive cells after dietary intervention [8]. Immunostaining against CD68 now indicated a comparable increase in size rather than number of CD68 positive cells, i.e. Kupffer cells and macrophages, in livers of male and female $1 \mathrm{dlr}^{-/-}$and APOE2ki mice, but not of WT mice (Fig. 4A) (experiments 1 and 2). Additionally, toluidine blue staining clearly illustrated that these cells with foamy appearance are located in the sinusoidal space of the liver, suggesting that these cells are KCs (Fig. 4B). Further detail was provided with electron microscopy (Fig. 4C). EM pictures showed clear differences between livers of the animals. KCs appeared to have more cytoplasm and filled a larger fraction of the sinus, indicating that these cells are swollen compared to 
A

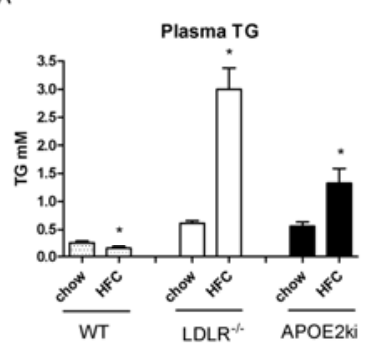

C

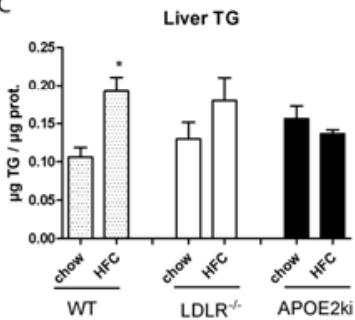

E

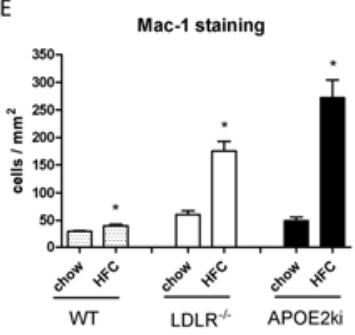

G

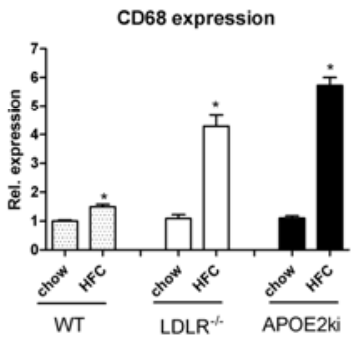

B
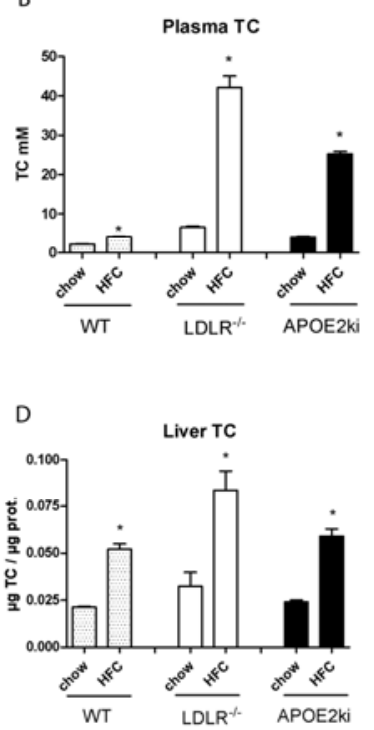

F

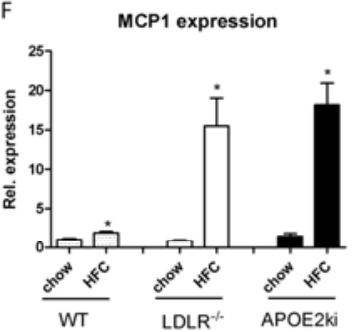

H

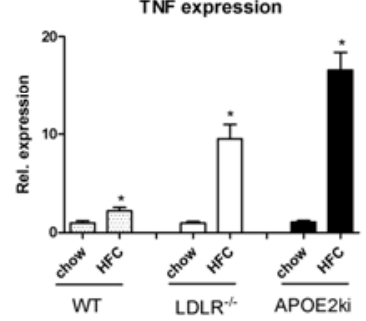

Figure 3. Plasma and liver lipid levels in male mice. Plasma TGs (A) and TC (B) were determined of male mice. Data from animals fed chow diet or 7 days of HFC. Liver triglyceride (C) and cholesterol (D) levels were quantified biochemically. E. Liver sections were stained with antibodies against Mac1 (CD11b) and counted. Gene expression analysis with quantitative RT-PCR for three known inflammatory genes: MCP1 (F), CD68 (G) and TNF (H). Data was set relative to WT animals on chow diet. Bars are grouped per genotype: WT mice (grey bars), ldlr ${ }^{-/}$mice (white bars) and APOE2ki mice (black bars). Statistical analysis was done with student t-tests; * indicates significant difference from levels on chow diet. 
chow fed animals. In HFC fed animals, cytoplasm of KCs contained lipid droplets and filled lysosomes. Moreover, these cells contained cholesterol crystals, which is indicative for the uptake of cholesterol by these cells.

\section{Omitting dietary cholesterol reduces plasma VLDL TC and protects against developing hepatic inflammation}

A consistent finding was that plasma TC was increased in the mouse models that developed hepatic inflammation. Accordingly, we hypothesized that plasma TC is an important determinant of hepatic inflammation. To test this hypothesis, mice (both male and female) were put on the high fat diet with or without added cholesterol (HCF and $\mathrm{HFnC}$; high fat no cholesterol) (experiment 3). Omitting dietary cholesterol induced lower levels of VLDL-TC than HFC diet in both sexes of the hyperlipidemic mice (Fig. 5) and lowered total plasma TC by approximately 50\% in APOE2ki and $1 \mathrm{dlr}^{-/-}$animals (data not shown). Female WT mice also displayed lowering of TC levels, while this was not observed in male WT mice (data not shown).

Omission of dietary cholesterol did result in lower TGs and TC levels in WT controls, while it did not diminish liver TG content in APOE2ki and ldlr $^{-/}$mice (Fig. 6 A, B). In male mice, omitting cholesterol even tended to enhance TG content in the livers (Fig. $6 \mathrm{C})$. The level of liver TC remained low in female APOE2ki mice and in male ldlr $^{-/}$ mice (Fig. 6 B, D).

Strikingly, Mac1 staining of liver sections showed that macrophage infiltration was limited when $\mathrm{ldlr}^{-/}$and APOE2ki mice of both sexes were put on the HFnC diet (Fig. 6 E, F). Control mice did not show hepatic inflammation in any of the conditions. HE staining revealed that upon feeding $\mathrm{HFnC}$ diet, in male and female $\mathrm{ldlr}^{-/}$and APOE2Ki mice no swollen, foamy KCs were detected (Fig. 7). Additional evidence was found with PAS-diastase staining. Figure 8 shows the lack of swollen KCs upon feeding the mice HFnC compared to mice fed HFC diet.

Accordingly, expression levels of Mcp1, CD68 and TNF were down-regulated in female mice fed $\mathrm{HFnC}$ compared to HFC and similar trends were observed in male mice (Fig. 9). Thus, lower levels of diet-induced VLDL-TC are associated with less hepatic inflammation in $\mathrm{ldlr}^{-/-}$and APOE2ki mice. 
A

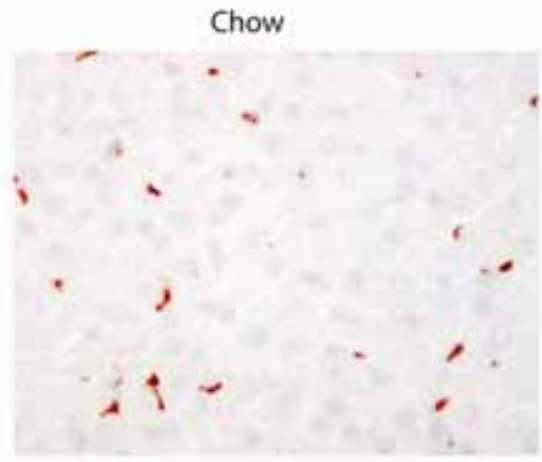

B

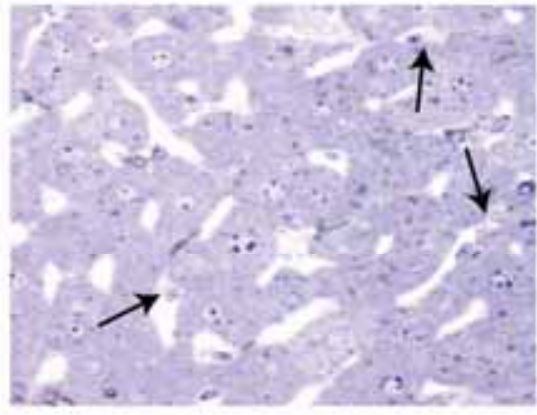

C

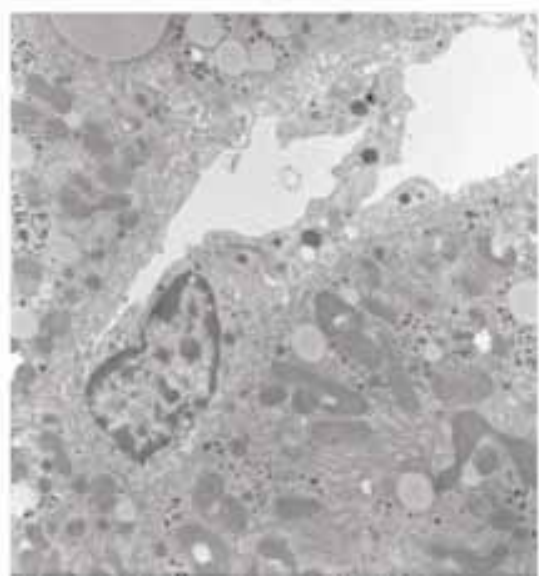

$7 \mathrm{~d}$ HFC
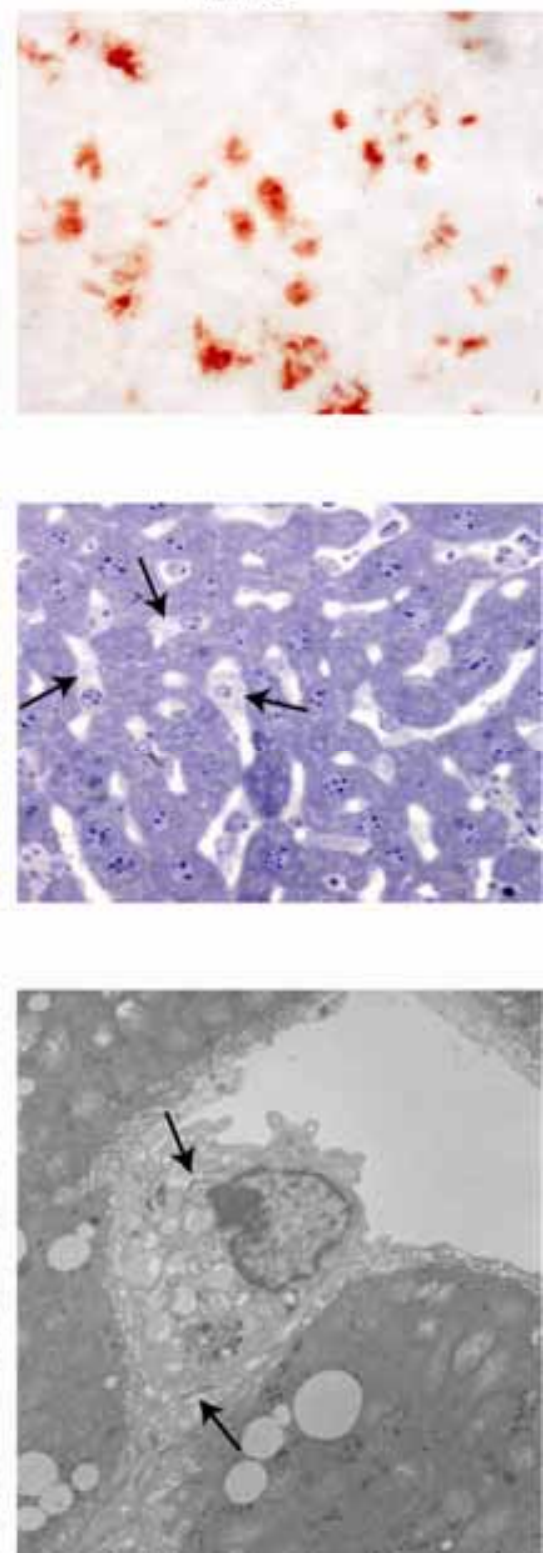

Figure 4. Hepatic foam cells. A. Representative pictures (400x) of female APOE2ki liver sections stained against CD68 on control chow diet and after 7 days of HFC. B. Representative pictures (400x) of toluidinestained liver sections from APOE2ki female mice on a chow diet and after 7 days of HFC. Black arrows indicate foamy Kupffer cells. C. Representative electron microscopy pictures (1550-fold magnification) of female APOE2ki mice fed either chow or HFC diet. Cholesterol crystals are indicated with black arrows. 

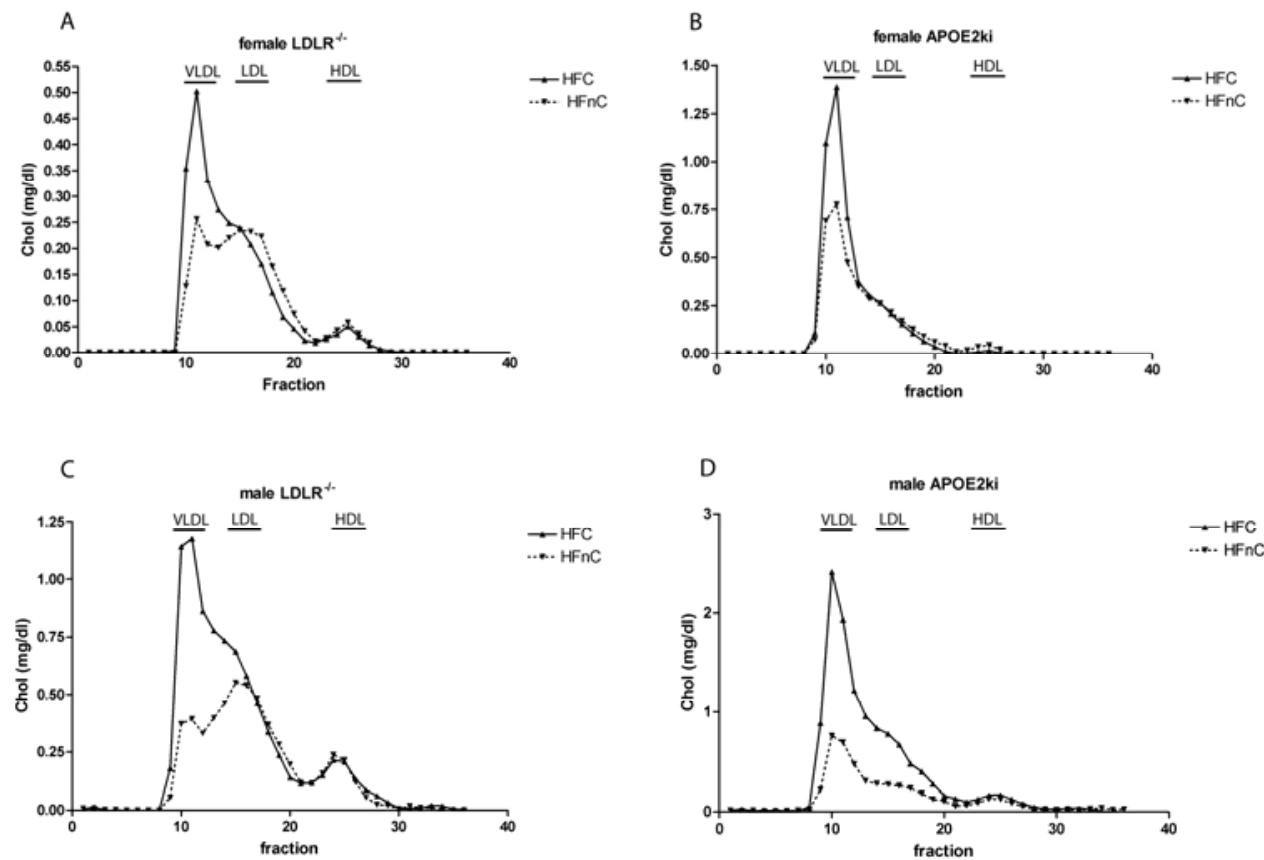

Figure 5. Treatment with HFnC diet lowers VLDL cholesterol levels. Figure shows lipoprotein fractions after 7 days HFC and 7 days HFnC in female ldlr-/- (A), female APOE2ki (B), male $1 \mathrm{dllr}^{-/-}$(C) and male APOE2ki (D) mice.

\section{Discussion}

This study clearly dissociates steatosis and inflammation in the livers of hyperlipidemic mice. HFC feeding induced a very early inflammatory response in the livers of $1 \mathrm{dlr}^{-/}$ and APOE2ki female mice. Contrary, female WT mice developed comparable steatosis but no inflammation. Additionally, we found that in male mice, inflammation increased rapidly in the absence of steatosis. Together, these results suggest that liver inflammation can arise independently of steatosis upon high fat feeding. Subsequent experiments showed that omitting cholesterol from the HFC diet prevented VLDL-TC accumulation and hepatic inflammation, while parameters of steatosis remained largely unaffected. The presence of bloated foamy KCs only in HFC fed hyperlipidemic mice suggests that scavenging of modified lipoproteins by KCs may initiate this early inflammation. 
A

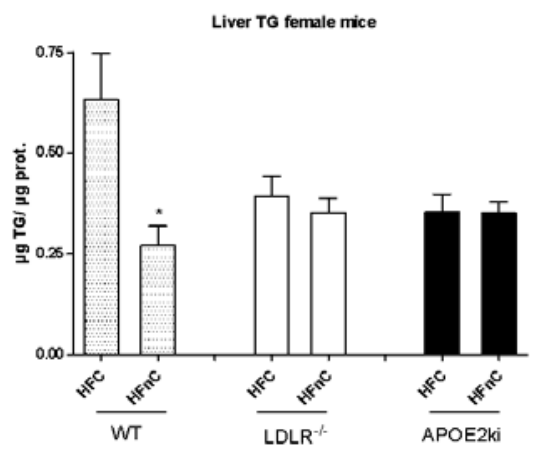

C

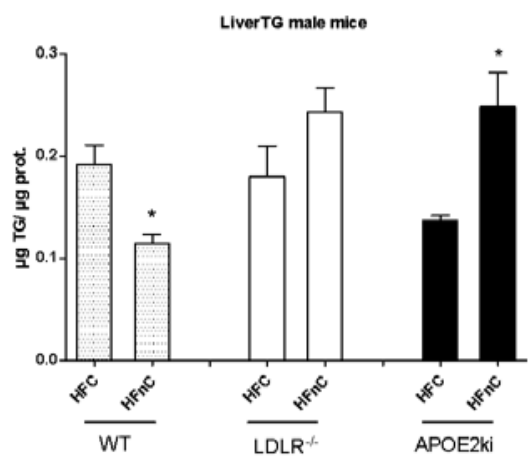

$\mathrm{E}$

Mac-1 staining female mice

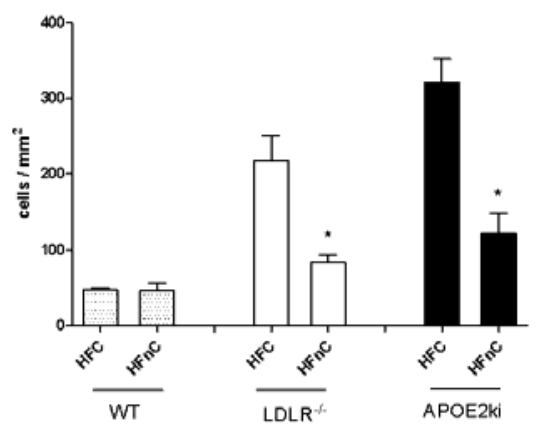

B

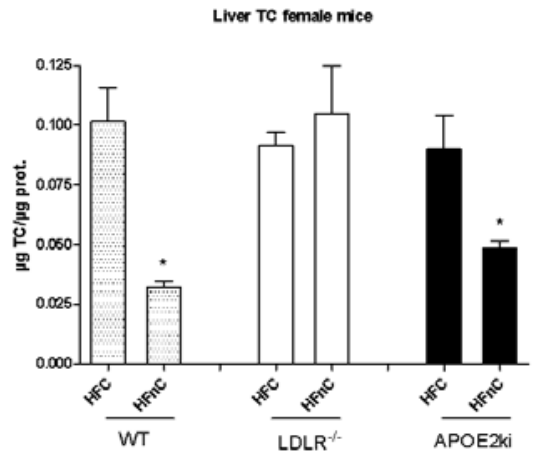

D

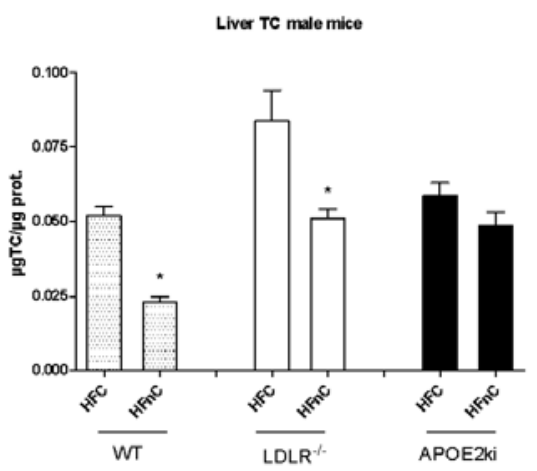

$\mathrm{F}$

Mac-1 staining male mice

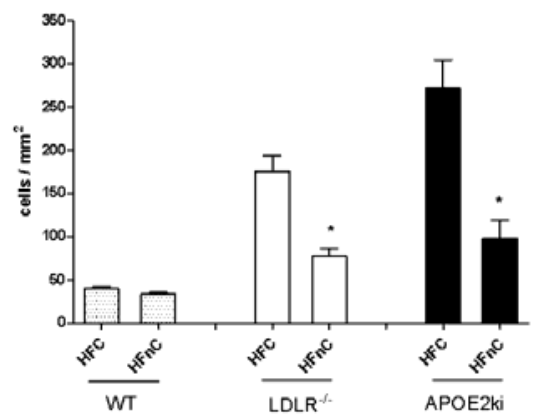

Figure 6. Omitting cholesterol from the high fat diet prevents inflammation development without affecting steatosis. Biochemical measurements of liver lipids are shown for TGs in female (A) and male (C) mice and for TC content in female (B) and male (D) mice after 7 days of treatment with HFC or HFnC. Counting of Mac1 positive cells is shown in liver sections of female (E) and male (F) mice. Data are shown from WT (grey bars), ldlr ${ }^{-/ 2}$ mice (white bars) and APOE2ki mice (black bars). Statistical analysis was done with student t-tests; * indicates significant difference from levels on HFC diet. 


\section{Hyperlipidemic mice are sensitive to develop early diet- induced NASH}

Until now, the best characterized and most known models for NASH are mice deficient for leptin $(\mathrm{Ob} / \mathrm{Ob})$ or mice fed a diet deficient in methionine and choline (MCD) [11]. However, $\mathrm{Ob} / \mathrm{Ob}$ mice do not spontaneously develop liver inflammation but require a second hit, like the administration of lipopolysaccharide (LPS) to activate inflammatory signaling. Furthermore, mutation of the leptin gene is not common in human obese NAFLD patients. MCD fed mice display all hallmarks of NASH, from steatosis to inflammation and fibrosis development. However, MCD fed animals tend to lose weight and display lowered plasma TG levels [11] and are therefore very different from human NASH patients, who are mostly obese and/or hyperlipidemic.

Dyslipidemia is commonly associated with NAFLD. It was postulated that abnormalities in lipid metabolism such as the increase of serum TGs, TC and LDL-TC levels and decrease of HDL-TC may be contributing factors of NASH development [12]. Consequently, hyperlipidemic mice have been shown previously to develop dietinduced NASH, not only in APOE2ki mice [8], but also in $1 \mathrm{dlr}^{-/-}$and ApoE deficient $\left(\right.$ apoe $^{-/}$) mice [13]. Unlike human subjects, WT mice carry most of their lipids in highdensity lipoproteins. In contrast, $\mathrm{ldlr}^{-/ /}$mice and mice with various defects in the ApoE protein have a human-like lipoprotein profile and may serve as physiological mouse models to study the early progression of NASH.

Medium-scale gene expression analysis showed that, despite the presence of steatosis, not many lipid genes were regulated in either $\operatorname{ldlr}^{-/-}$or in WT control mice. This is probably due to the early time point of 7 days of high fat feeding, which might be too early to evoke a large transcriptional response of these genes. In line with this, we have found that HFC-induced expression of genes involved in lipid metabolism increases gradually with time [8]. Alternatively, the physiological response on lipids may also be due to secondary feedback mechanisms regulated on the protein level rather than the gene level, resulting in the lack of transcriptional regulation.

In contrast to the lipid genes, a large set of inflammatory genes was regulated in the HFC fed ldlr-/- mouse, but not in WT mice, confirming our histological data. The data show that the inflammatory response consisted mainly of genes involved in chemotaxis and infiltration of macrophages. Furthermore, many genes that were up-regulated are known targets of the transcription factor NF- $\mathrm{KB}$, suggesting an important role for this transcription factor in response to HFC feeding and NASH development, as was previously postulated in HFC fed APOE2ki mice [8] and in MCD fed mice with C57Bl/6 background [14]. Moreover, in NASH patients, NF- $\mathrm{KB}$ expression was found to be up-regulated and correlated with hepatic inflammation and fibrosis [15]. The 
other regulated genes are involved in several inflammatory signaling pathways, such as IL18, IL1, IL6, TNF and toll-like receptor signaling.

\section{Steatosis is dissociated from the development of hepatic inflammation}

In contrast to the two-hit model, where hepatic steatosis is generally considered as the first hit in the transition towards inflammation [1], male mice had an inflamed liver even without steatosis. The lack of steatosis development in male mice compared to female mice was somewhat surprising, as estrogen is normally known to be protective against NASH. It has been shown that estrogen replacement in deficient mice lowers steatosis development [16]. We postulate that the lack of steatosis in male mice may be explained by the fact that in the livers of male mice, PPAR isoforms are up to 100-fold more active than in livers of female mice [17]. Therefore, it is conceivable that in male mice, activation of PPAR can compensate for the increased lipid load. In support of this, we showed previously that feeding female APOE2ki mice HFC for short periods did not activate PPAR $\alpha$ significantly [8].

Another gender-specific difference was found in APOE2ki mice, as female APOE2ki mice displayed no change in plasma TG levels, while male APOE2ki mice did show increases upon HFC feeding. A possible explanation for this observation may be that estrogens can increase activities of hepatic lipase and lipoprotein lipase [18], which could consequently lead to increased hydrolysis of TGs in the plasma.

Clearly, steatosis is not mandatory for progression towards hepatic inflammation in the mouse models used. In fact, others have postulated TG accumulation in the liver may even serve as a protective mechanism against inflammation development, by acting as a reservoir for harmful FFA's [6].

\section{Plasma cholesterol may mediate hepatic inflammation}

We found a correlation between plasma TC and the development of hepatic inflammation, rather than with steatosis. This observation led us to hypothesize plasma $\mathrm{TC}$ as an important cause for the development of inflammation in these animals. Feeding the animals HFnC diet kept plasma VLDL-TC low and prevented the development of inflammation in all hyperlipidemic mouse models, without diminishing liver TGs. Liver TGs even increased in male APOE2ki mice without any apparent explanation, an observation that further strengthens the dissociation of steatosis from hepatic inflammation. Recent publications also point to the importance of dietary cholesterol in liver inflammation and NASH in both rodents [5, 19] and rabbits [20]. 


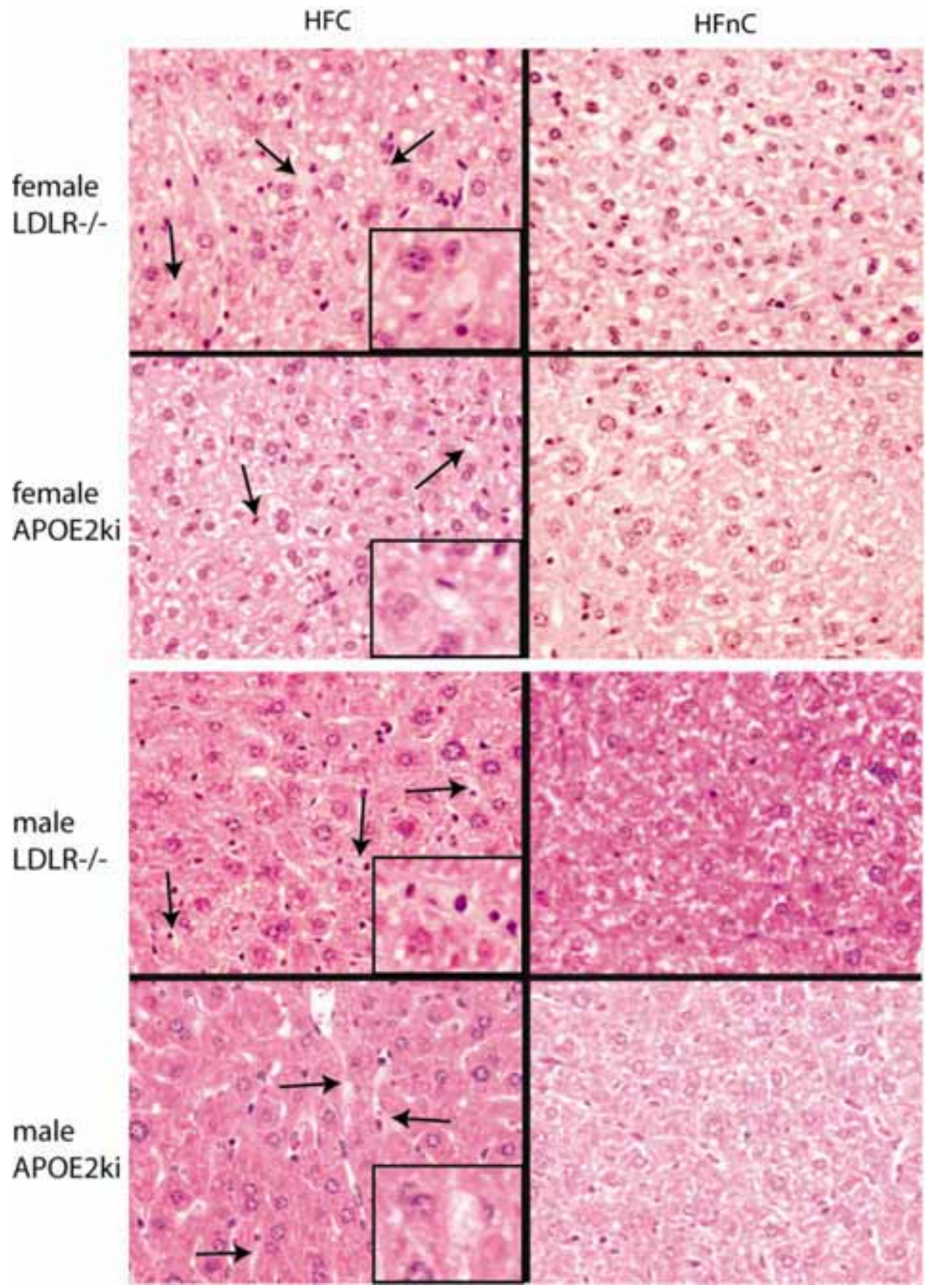

Figure 7. HFnC diet does not induce hepatic foam cells. Representative pictures (400x) of HE-stained liver sections from $\mathrm{ldlr}^{-/}$and APOE2ki male and female mice after 7 days HFC and HFnC. Black arrows indicate foamy Kupffer cells. Inserts show foamy Kupffer cells when present on higher magnification. 
Moreover, in human subjects, it was found that high cholesterol feeding increased Creactive protein and Serum Amyloid A levels [21].
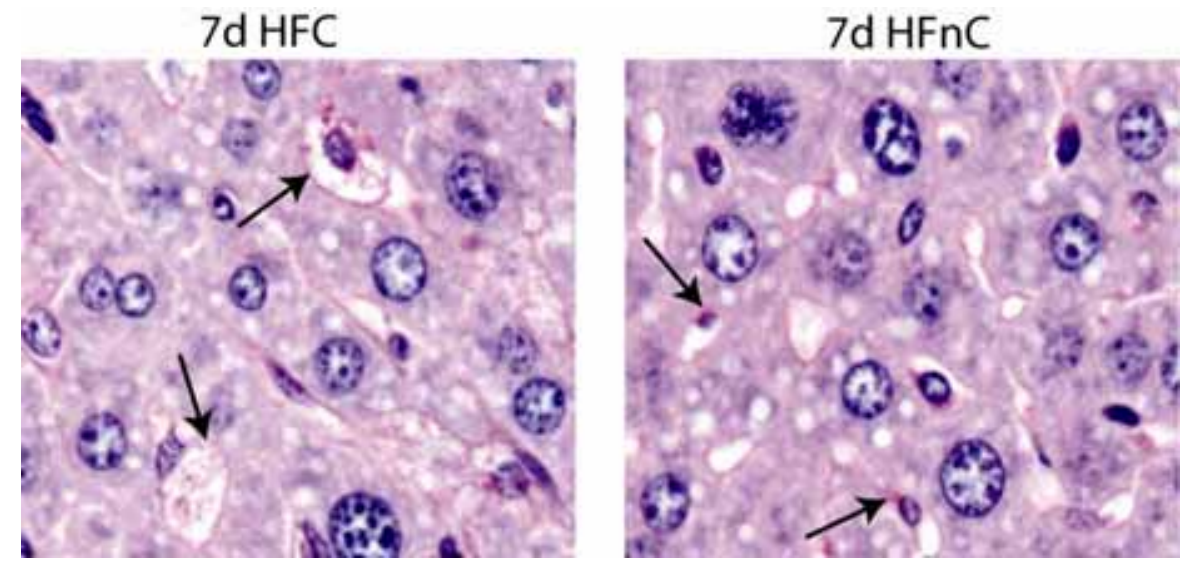

Figure 8. PAS-diastase staining. Representative pictures of liver sections stained with PAS-diastase. The displayed pictures are from male APOE2ki mice that received either HFC diet or HFnC diet. Black arrows indicate Kupffer cells.

Recently, Mari et al. reported that high cholesterol feeding may serve as the first hit that sensitizes rat livers to develop hepatic inflammation after exposure to a second hit, like TNF or fatty acid synthase (FAS) [5]. In contrast, in the current study, we observed that high cholesterol feeding alone is sufficient to cause a very early inflammatory response. Several differences between the studies could explain this dissimilarity. First, Mari et al. used rats, which are known to be more resistant to developing hyperlipidemia than mice [22]. Our current study utilizes mouse models with genetic modifications specifically involved in plasma lipoprotein clearance and lipid metabolism. Consequently, it is possible that other mechanisms may be of greater importance in the rat model that was used in their study. Second, the manner of inducing steatosis was different. In our study, a mild high fat diet was used while Mari et al. used choline deficiency to evoke steatosis in the rats. Moreover, the diet of Mari et al. contained high levels of cholesterol (2\%) supplemented with sodium cholate but no elevated TG content. In these concentrations, both cholesterol and cholate have been shown to induce an inflammatory response in livers of $\mathrm{C} 57 \mathrm{Bl} / 6$ mice [23]. The diet used in our study contained elevated TG levels to evoke steatosis and had cholesterol levels of only $0.2 \%$, which is much closer to the average daily cholesterol intake in humans. Therefore, the diet used in our study appears to be more relevant in terms of induction of NASH in human patients. 
Interestingly, in line with the present observations, male apoe ${ }^{-/-}$mice were shown to develop liver inflammation when fed cholesterol levels of $0.25 \%$ and higher [24]. This again points to an important role for dietary cholesterol in hepatic inflammation. However, this inflammatory response was investigated after several weeks of high fat diet and in the presence of steatosis. Our data suggests a very early impact of dietary cholesterol, possibly in the form of plasma VLDL-TC, on hepatic inflammation regardless of steatosis development.

\section{Kupffer cells may initiate the early hepatic inflammation by scavenging modified lipoproteins}

The mice used in our study are commonly used in atherosclerosis research as they have atherogenic lipoprotein profiles, because of increased modified remnant lipoproteins (oxLDL) [25]. OxLDL binds to the scavenger receptors CD36 and SRA, which are also present on KCs, and can trigger an inflammatory response [26, 27]. In livers of the mice with hepatic inflammation, we found bloated, foamy cells, which resemble lipidladen KCs, as has been described previously [13, 28].

Injection of modified LDL has been shown to result in an immediate uptake preferentially by non-parenchymal cells, such as KCs [29, 30]. Moreover, it has been shown that modified LDL injection in mice activates the hepatic NF- $\mathrm{KB}$ pathway and subsequent inflammation [31]. Therefore, it is possible that in our hyperlipidemic mouse models, circulating levels of modified lipoproteins are scavenged by hepatic $\mathrm{KCs}$, thereby triggering an inflammatory response. In WT mice on the other hand, cholesterol-rich lipoproteins are rapidly cleared from the blood by hepatocytes via the LDLR, before they can be modified and taken up by KCs.

Taken together, it is feasible that oxLDL may be a causal factor for the development of diet-induced hepatic inflammation. Recent papers have shown a correlation between postprandial LDL conjugated dienes and hepatic necroinflammation and fibrosis development in human subjects [32]. LDL levels, possibly in modified form, were also found to be increased in NASH patients [12], confirming the clinical relevance of our findings. 
A

MCP1 female mice

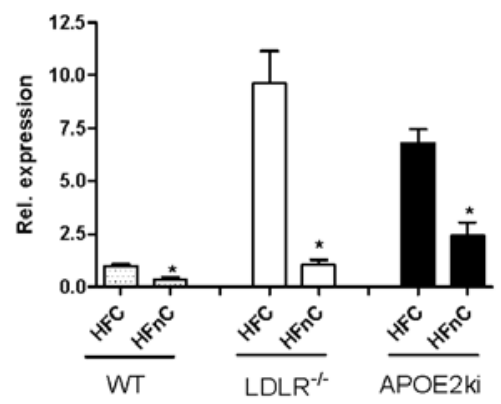

B

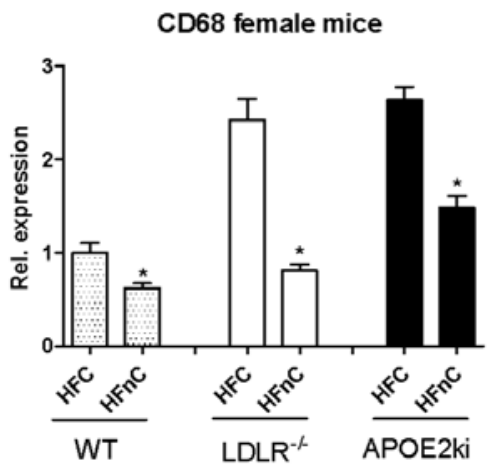

C

TNF female mice

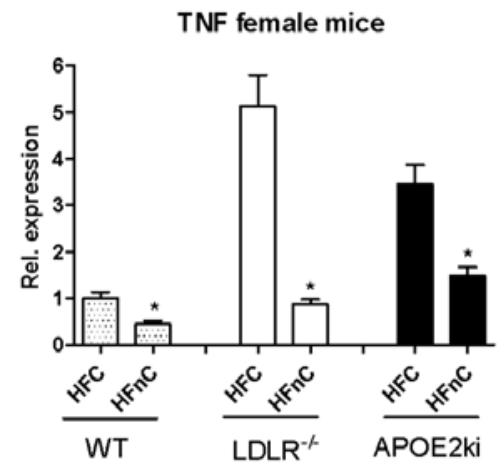

MCP1 male mice

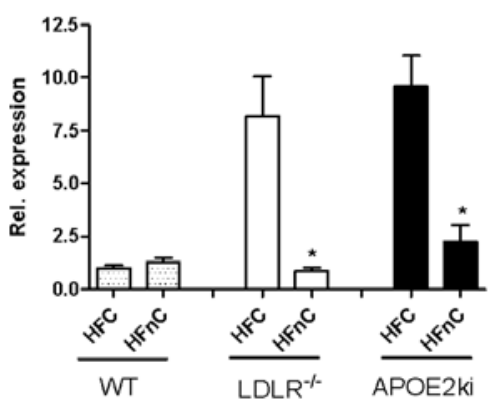

CD68 male mice

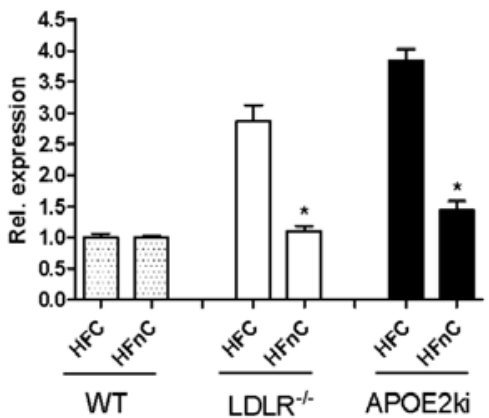

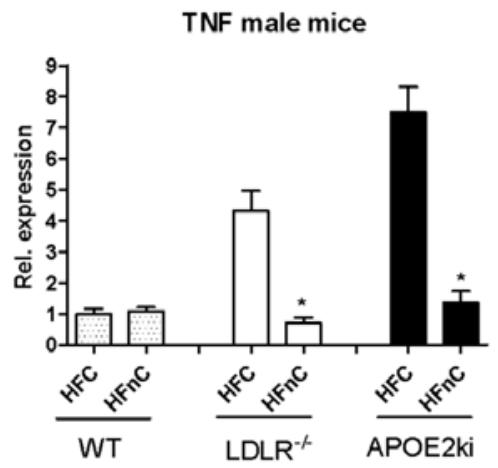

Figure 9. Gene expression in mice fed HFnC diet. Gene expression analysis in female and male mice with quantitative RT-PCR for two known inflammatory genes: MCP1 (A), CD68 (B), and TNF (C). Bars are grouped per genotype: WT mice (grey bars), $1 \mathrm{dlr}^{-/-}$mice (white bars) and APOE2ki mice (black bars). Data was set relative to WT animals on HFC diet). Statistical analysis was done with student t-tests; * indicates significant difference from levels on chow diet. 


\section{Conclusions}

This study demonstrates that dietary cholesterol, possibly in the form of modified plasma lipoproteins, rather than liver steatosis, may be a risk factor for progression of NASH development. Currently, most therapies for NASH patients involve weight loss and most diagnostic tests of NASH severity depend solely on the degree of steatosis. Further studies may unravel the exact contribution of cholesterol to the risk of developing NASH and may provide evidence for alternative strategies for new therapies and markers for diagnostic tests.

\section{Acknowledgements}

We are grateful to Professors Paul Holvoet, Folkert Kuipers, and Wout Lamers for helpful discussions. We thank Inge van der Made, Monique Vergouwe and Ellen Loyens for technical support. Research is supported by the Netherlands Heart Foundation (NHS) (grant 2002B18), Netherlands Organization for Scientific Research (NWO) (grant 912-04-09), and Netherlands Diabetes Fund (grant 2004.00.018).

\section{References}

1. Parekh, S. and F.A. Anania, Abnormal lipid and glucose metabolism in obesity: implications for nonalcoholic fatty liver disease. Gastroenterology, 2007. 132(6): p. 2191-207.

2. McCullough, A.J., The clinical features, diagnosis and natural history of nonalcoholic fatty liver disease. Clin Liver Dis, 2004. 8(3): p. 521-33, viii.

3. Day, C.P. and O.F. James, Steatohepatitis: a tale of two "hits"? Gastroenterology, 1998. 114(4): p. 842-5.

4. Browning, J.D. and J.D. Horton, Molecular mediators of hepatic steatosis and liver injury. J Clin Invest, 2004. 114(2): p. 147-52.

5. Mari, M., et al., Mitochondrial free cholesterol loading sensitizes to TNF- and Fas-mediated steatohepatitis. Cell Metab, 2006. 4(3): p. 185-98.

6. Yamaguchi, K., et al., Inhibiting triglyceride synthesis improves hepatic steatosis but exacerbates liver damage and fibrosis in obese mice with nonalcoholic steatohepatitis. Hepatology, 2007. 45(6): p. 1366-74.

7. Matsuzawa, N., et al., Lipid-induced oxidative stress causes steatohepatitis in mice fed an atherogenic diet. Hepatology, 2007.

8. Shiri-Sverdlov, R., et al., Early diet-induced non-alcoholic steatohepatitis in APOE2 knock-in mice and its prevention by fibrates. J Hepatol, 2006. 44(4): p. 732-41.

9. Zannis, V.I., et al., Transcriptional regulatory mechanisms of the human apolipoprotein genes in vitro and in vivo. Curr Opin Lipidol, 2001. 12(2): p. 181-207.

10. Ishibashi, S., et al., Hypercholesterolemia in low density lipoprotein receptor knockout mice and its reversal by adenovirus-mediated gene delivery. J Clin Invest, 1993. 92(2): p. 883-93.

11. Anstee, Q.M. and R.D. Goldin, Mouse models in non-alcoholic fatty liver disease and steatohepatitis research. Int J Exp Pathol, 2006. 87(1): p. 1-16.

12. Koruk, M., et al., Serum lipids, lipoproteins and apolipoproteins levels in patients with nonalcoholic steatohepatitis. J Clin Gastroenterol, 2003. 37(2): p. 177-82.

13. Yoshimatsu, M., et al., Induction of macrophage scavenger receptor MARCO in nonalcoholic steatohepatitis indicates possible involvement of endotoxin in its pathogenic process. Int J Exp Pathol, 2004. 85(6): p. 33543.

14. Dela Pena, A., et al., NF-kappaB activation, rather than TNF, mediates hepatic inflammation in a murine dietary model of steatohepatitis. Gastroenterology, 2005. 129(5): p. 1663-74. 
15. Ribeiro, P.S., et al., Hepatocyte apoptosis, expression of death receptors, and activation of NF-kappaB in the liver of nonalcoholic and alcoholic steatohepatitis patients. Am J Gastroenterol, 2004. 99(9): p. 1708-17.

16. Hewitt, K.N., et al., Estrogen replacement reverses the hepatic steatosis phenotype in the male aromatase knockout mouse. Endocrinology, 2004. 145(4): p. 1842-8.

17. Ciana, P., et al., A novel peroxisome proliferator-activated receptor responsive element-luciferase reporter mouse reveals gender specificity of peroxisome proliferator-activated receptor activity in liver. Mol Endocrinol, 2007. 21(2): p. 388-400.

18. Mahley, R.W., Y. Huang, and S.C. Rall, Jr., Pathogenesis of type III hyperlipoproteinemia (dysbetalipoproteinemia). Questions, quandaries, and paradoxes. J Lipid Res, 1999. 40(11): p. 1933-49.

19. Tous, M., et al., Dietary cholesterol and differential monocyte chemoattractant protein-1 gene expression in aorta and liver of apo E-deficient mice. Biochem Biophys Res Commun, 2006. 340(4): p. 1078-84.

20. Kainuma, M., et al., Cholesterol-fed rabbit as a unique model of nonalcoholic, nonobese, non-insulin-resistant fatty liver disease with characteristic fibrosis. J Gastroenterol, 2006. 41(10): p. 971-80.

21. Tannock, L.R., et al., Cholesterol feeding increases C-reactive protein and serum amyloid A levels in lean insulin-sensitive subjects. Circulation, 2005. 111(23): p. 3058-62.

22. Russell, J.C. and S.D. Proctor, Small animal models of cardiovascular disease: tools for the study of the roles of metabolic syndrome, dyslipidemia, and atherosclerosis. Cardiovascular Pathology, 2006. 15(6): p. 318-330.

23. Vergnes, L., et al., Cholesterol and cholate components of an atherogenic diet induce distinct stages of hepatic inflammatory gene expression. J Biol Chem, 2003. 278(44): p. 42774-84.

24. Joven, J., et al., The results in rodent models of atherosclerosis are not interchangeable The influence of diet and strain. Atherosclerosis, 2007.

25. Wouters, K., et al., Understanding hyperlipidemia and atherosclerosis: lessons from genetically modified apoe and ldlr mice. Clin Chem Lab Med, 2005. 43(5): p. 470-9.

26. Lu, L., et al., Effects of Kupffer cells stimulated by triglyceride and very low-density lipoprotein on proliferation of rat hepatic stellate cells. Chin Med J (Engl), 1999. 112(4): p. 325-9.

27. Van Berkel, T.J., et al., Uptake and catabolism of modified LDL in scavenger-receptor class A type I/II knock-out mice. Biochem J, 1998. 331 ( Pt 1): p. 29-35.

28. Sano, J., et al., Foam cells generated by a combination of hyperglycemia and hyperlipemia in rats. Pathol Int, 2004. 54(12): p. 904-13.

29. Van Berkel, T.J., et al., Processing of acetylated human low-density lipoprotein by parenchymal and nonparenchymal liver cells. Involvement of calmodulin? Biochem J, 1982. 208(2): p. 493-503.

30. Liao, F., et al., Genetic control of inflammatory gene induction and NF-kappa B-like transcription factor activation in response to an atherogenic diet in mice. J Clin Invest, 1993. 91(6): p. 2572-9.

31. Liao, F., et al., Genetic control of the inflammatory response induced by oxidized lipids. Am J Cardiol, 1995. 75(6): p. 65B-66B.

32. Gambino, R., et al., Polymorphism in microsomal triglyceride transfer protein: a link between liver disease and atherogenic postprandial lipid profile in NASH? Hepatology, 2007. 45(5): p. 1097-107. 


\section{VI}

\section{The role of scavenger receptor $A$ and CD36 in diet induced non- alcoholic steatohepatitis in Idlr/- mice}

Kristiaan Wouters ${ }^{1}$, Ronit Shiri-Sverdlov ${ }^{1}$, Patrick J van Gorp ${ }^{1}$, Ingeborg van der Made $^{1}$, Veerle Bieghs ${ }^{1}$, Kathryn J Moore ${ }^{2}$, Marion J Gijbels ${ }^{1}$, Menno PJ de Winther ${ }^{1}$, Marc van Bilsen ${ }^{1}$, and Marten H Hofker ${ }^{3}$

1) Dept. of Molecular Genetics, Pathology and Physiology, Nutrition and Toxicology Research (NUTRIM) and Cardiovascular Research (CARIM) Institutes of Maastricht University Maastricht, Maastricht, The Netherlands; 2) Lipid Metabolism Unit, Massachusetts General Hospital, Harvard Medical School, Boston, USA; 3) Dept. of Pathology \& Laboratory Medicine, University Medical Center Groningen, Groningen, Netherlands 


\section{Abstract}

Introduction and aim: Non-alcoholic steatohepatitis (NASH) is a disorder which is characterized by steatosis and hepatic inflammation. Currently, it is unknown why some, but not all, people with steatosis will progress towards NASH. We have recently identified dietary cholesterol as a factor that directly leads to hepatic inflammation in hyperlipidemic mouse models. In these animals, Kupffer cells (KCs) were found to be swollen and rich in cholesterol upon high fat feeding, resembling foam cells. We proposed a mechanism where KCs take up modified cholesterol-rich lipoproteins via scavenger receptors (SRs). KCs thereby accumulate cholesterol, may get activated and subsequently trigger an inflammatory response. Scavenging of modified lipoproteins has been shown to depend predominantly on two receptors: SRA and CD36. Therefore, we evaluated the role of these SRs in the development of diet-induced NASH in hyperlipidemic $1 \mathrm{dll}^{-/ /}$mice.

Materials and methods: $1 \mathrm{dlr}^{-/-}$mice were depleted from their hematopoietic system by lethal irradiation and transplanted with bone marrow (BM) from animals lacking SRA and CD36 (double knock-out/dKO). Control mice were injected with wild-type bone marrow.

Results: High fat feeding resulted in equal steatosis levels in mice transplanted with $\mathrm{dKO} \mathrm{BM}$ compared to mice that received control BM as both hepatic triglyceride and cholesterol levels were comparable. Counting of Mac1 positive cells showed that hepatic inflammation was significantly decreased compared to control mice. This response was confirmed by measuring expression levels of known inflammatory mediators, such as tumor necrosis factor. Surprisingly, no difference in hepatic foam cell formation could be found.

Conclusion: Uptake of modified lipoproteins via SRA and/or CD36 is partially responsible for diet induced hepatic inflammation, even without affecting hepatic foam cell formation. 


\section{Introduction}

Non-alcoholic steatohepatitis (NASH) is a disorder characterized by hepatic lipid accumulation (steatosis) and inflammation. It is currently thought to develop via a series of events or "hits" in the liver [1]. The first hit leads to the accumulation of lipids and sensitizes the liver to a second hit, which subsequently causes inflammation. While steatosis itself is generally considered benign and reversible, the presence of inflammation may lead to further progression of NASH, possibly resulting in liver fibrosis, cirrhosis, and even liver failure and hepatocellular carcinoma [2]. Thus, the progression towards hepatic inflammation represents a key step in NASH development. Currently, it is unknown why some, but not all, people with steatosis will develop NASH. Although several processes have been identified to participate during hepatic inflammation, like increased oxidative stress [3], lipid peroxidation [4], endoplasmatic reticulum stress [5], and ceramide accumulation [6,7], the actual trigger causing an inflammatory response is still unclear.

We and others have recently identified cholesterol as a factor that can directly lead to inflammation in the liver (chapter 5) [8,9]. We have shown that hyperlipidemic mice, but not normolipidemic wild-type (WT) animals, developed hepatic inflammation as early as after 4 days of high fat feeding (chapter 5) [10]. The fact that hepatic inflammation is induced at this early stage, argues that cholesterol is a very powerful trigger for an inflammatory reaction to develop. In the livers of these animals, bloated Kupffer cells (KCs) were found, resembling foam cells. These foam cells were also identified previously in other studies in the sinusoidal space of the liver [11, 12]. Omitting cholesterol from the diet resulted in complete inhibition of hepatic inflammation and foam cell formation. An attractive hypothesis is that due to the decreased lipoprotein uptake by hepatocytes in these mice, lipoproteins have a longer residence time in the plasma and are therefore prone to be modified and subsequently scavenged by KCs. This process can result in KC activation, which may be responsible for triggering the hepatic inflammation and foam cell formation (chapter 5).

It has been shown that KCs express scavenger receptors (SRs) as typical macrophages [13], making them capable of taking up modified lipoproteins. Moreover, the liver is the major site for taking up acetylated low density lipoproteins (acLDL) [14]. Additionally, injection of oxidized LDL (oxLDL) into the circulation of mice has been shown to cause hepatic inflammation, leading to a similar gene expression pattern that was observed mice fed a high fat diet [15].

Foam cell formation has been shown to majorly depend on two different SRs, i.e. SRA and CD36 [16]. SRA was found to account for the majority (80\%) of macrophage uptake of acLDL, but to have lower affinity for oxLDL $[16,17]$. CD36 was shown not 
to bind acLDL but rather binds moderately oxidized LDL [18], and was found necessary for oxLDL-induced C-Jun N-terminal kinase (JNK) activation [19]. These observations suggest a role for these SRs in hepatic foam cell formation and subsequent activation. To test the possible role of oxLDL and these SRs during NASH development, we performed bone marrow transplantation (BMT) of donor bone marrow from mice lacking SRA, and CD36 (double knock-out/dKO) to ldlr deficient $\left(\mathrm{ldlr}^{-1}\right)$ recipient mice. This generated animal model lacks these SRs in hematopoietic cells, like KCs and macrophages, but not in other cell types. We predicted that they would fail to generate hepatic foam cells, thereby leading to decreased inflammation in their livers.

\section{Materials and methods}

\section{Mice, diet and bone marrow transplantation}

Mice were housed under standard conditions given free access to food and water. Experiments were performed according to Dutch laws, approved by the Committee for Animal Welfare of Maastricht University. Ten week old female $1 \mathrm{dll}^{-/ /}$mice were put in filter-top cages. The mice received acidified water supplemented with neomycin (100 $\mathrm{mg} / \mathrm{l})$ and polymyxin B sulphate $(60,000 \mathrm{U} / \mathrm{l})$ during one week before transplantation. One day before transplantation, the mice were irradiated with a lethal dose of 10 Gray röntgen. The bone marrow of five female wild-type mice and five female dKO littermates was collected and pooled. Bone marrow cells were derived by flushing the femur and tibia of the mice. For transplantation, 7 mice received wild-type bone marrow and 8 mice received transgenic bone marrow. Bone marrow cells $\left(10^{7}\right)$ were injected in the tail vein of each animal. After a recovery period of 9 weeks, mice were given high fat, high cholesterol (HFC) diet, containing 21\% butter and 0,2\% cholesterol, for 12 weeks. Blood was collected before the dietary period, after 7 weeks of HFC feeding and at the day of sacrifice (12 weeks). Collection of blood, sacrificing of the mice, and tissue isolation was done as described previously [10].

\section{Lipid analysis}

Approximately $50 \mathrm{mg}$ of frozen liver tissue was homogenized as described previously [10]. Both plasma and liver lipid levels were measured with enzymatic colour tests (1489232, cholesterol CHOD-PAP, Roche, Basel, Switzerland; TR0100, TG GPOtrinder, Sigma Aldrich, Sigma Aldrich, St. Louis, MO, USA; 999-75406, NEFAC, ACS-ACOD, Wako Chemicals, Neuss, Germany) as described before [10]. 


\section{RNA isolation and quantitative PCR}

Total RNA was isolated from approximately $25 \mathrm{mg}$ of mouse liver tissue as described previously [10]. All applications were done according to manufacturer's protocols. Total RNA (500 ng) from each individual mouse was converted into first strand cDNA with the iScript cDNA synthesis kit (170-8891, Bio-Rad, Hercules, CA, USA) according to the manufacturer's instructions.

The changes in gene expression of inflammatory markers were determined by quantitative PCR (QPCR) on a Bio-Rad MyIQ with the IQ5 v2 software (Bio-Rad, Hercules, CA, USA) by using IQ SYBR Green Supermix with fluorescein (1705006CUST, Bio-Rad, Hercules, CA, USA) and $10 \mathrm{ng}$ of cDNA. For each gene a standard curve was generated with a serial dilution of a liver cDNA pool. To standardize for the amount of cDNA, Cyclophillin A (Ppia) was used as the reference gene. Primer for the selected genes were developed with Primer Express version 1.5 (Applied Biosystems, Foster City, CA, USA) using default settings. Primer sequences: MCP1-forward, 5'-GCTGGAGAGCTACAAGAGGATCA-3'; MCP1-reverse, 5'-ACAGACCTCTCTCTTGAGCTTGGT-3'; CD68-forward, 5'-TGACCTGCTCTCTCTAAGGCTACA-3'; CD68-reverse, 5-TCACGGTTGCAAGAGAAACATG -3';

TNFa-forward, 5'-CATCTTCTCAAAATTCGAGTGACAA-3';

TNFa-reverse, 5'-TGGGAGTAGACAAGGTACAACCC-3';

Mac1-forward, 5'-ACTTTCAGAAGATGAAGGAGTTTGTCT-3';

Mac1-reverse, 5'-TGTGATCTTGGGCTAGGGTTTC-3';

ICAM1-forward, 5'-CTACCATCACCGTGTATTCGTTTC-3';

ICAM1-reverse, 5'-CGGTGCTCCACCATCCA-3';

IL6-forward, 5'-GCTACCAAACTGGATATAATCAGGAAA-3';

IL6-reverse, 5'-CTTGTTATCTTTTAAGTTGTTCTTCATGTACTC-3';

Ppia-forward, 5'-TTCCTCCTTTCACAGAATTATTCCA-3';

Ppia-reverse, 5'-CCGCCAGTGCCATTATGG-3'.

Data from QPCR were analyzed according to the relative standard curve method.

\section{Liver histology}

Four $\mu \mathrm{m}$ paraffin embedded liver sections were stained with Haematoxillin/ Eosin (HE). Frozen liver sections $(7 \mu \mathrm{m})$ were fixated in acetone and stained against Mac1 (M1/70). Pictures were taken with a Nikon ${ }^{\circledR}$ digital camera DMX1200 and ACT-1 v2.63 software from Nikon ${ }^{\circledR}$ Corporation. 


\section{Statistical analysis}

Data were analyzed using Graphpad Prism 4.0. Groups were compared using 2-tailed non-paired t-tests or ANOVA. Data are expressed as means \pm SEM and considered significant at $\mathrm{p}<0.05$.

\section{Results and discussion}

We investigated the involvement of SRA and CD36 in triggering hepatic inflammation during the progression of NASH. In order to generate animals that lack these SRs in inflammatory cells only, we performed BMT of donor bone marrow from mice lacking these two SRs (double knock-out/dKO) to $1 \mathrm{dlr}^{-/ /}$recipient mice.

HFC increased plasma triglycerides (TGs) and total cholesterol (TC) levels in both groups (Fig. 1A, B). However, dKO animals displayed lower TG levels than animals that received WT bone marrow (Fig. 1A). Free fatty acid (FFA) levels decreased in response to HFC feeding in the control group while this could not be observed in the experimental animals. However, there was a trend towards decreased FFA levels after 12 weeks of HFC in these mice. Between the two groups, t-tests failed to show significant differences in FFA levels (Fig. 1C). Interestingly, plasma TC levels increased in both groups after high fat feeding, but no difference was observed between the two groups (Fig. 1B).

Previous publications with animals systemically lacking either CD36 or SRA show mixed results concerning plasma lipids. In a female apoe deficient (apoe-/-) background, deficiency of these scavenger receptors has been reported to increase plasma TGs and FFA, but not TC, a finding that contradicts our data [20]. Both CD36 and SRA were found to influence these parameters separately. In line with our data, it has also been reported that systemic disruption of CD36 resulted in a decrease in plasma TGs but not plasma TC on an apoe ${ }^{-/-}$background [21]. It is important to note that both these experimental models were created by cross-breeding of mice. This difference in experimental setting may explain differences with our results. Moreover, there may have been differences in the purity of the background strain, depending on the amount of backcrossing that was performed prior to the experiments. Genetic background has been suggested before to influence experimental outcome and may explain the contradicting results [22]. In similar experimental settings as described in this paper, $1 \mathrm{dlr}^{-/-}$mice transplanted with SRA-deficient bone marrow were shown not to display altered plasma lipids upon high fat feeding [23]. This result suggests that not 


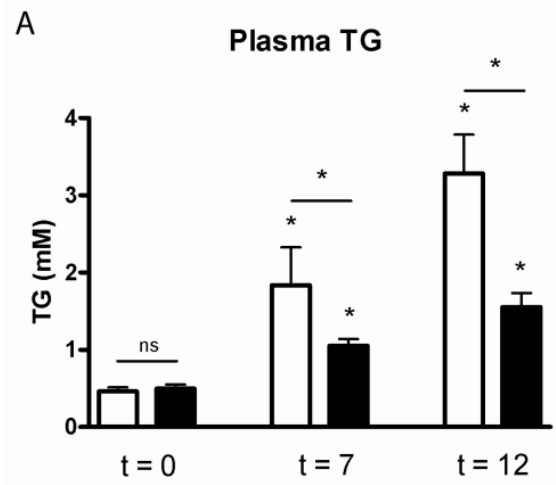

B

Plasma TC

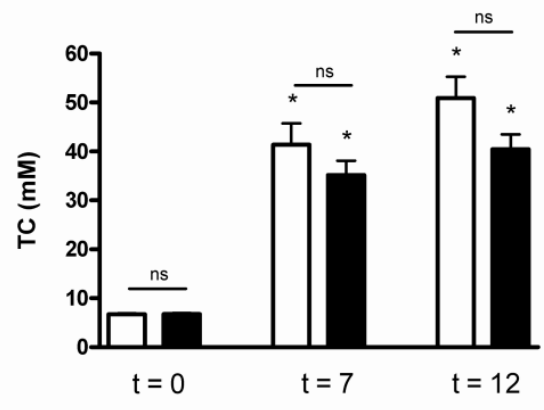

C

Plasma FFA

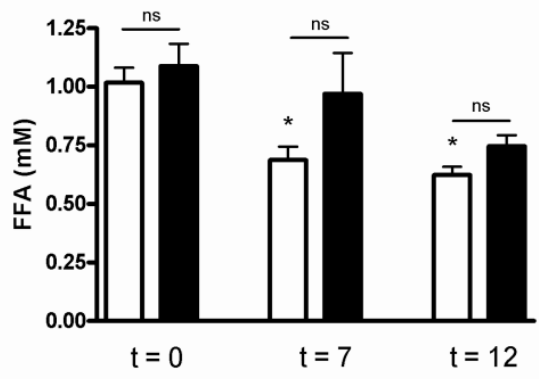

Figure 1. Plasma lipds. White bars represent animals transplanted with wild-type (WT) bone marrow, while black bars represent animals that received double knock-out (dKO) bone marrow, all at time points 0,7 , and 12 weekd of high fat feeding. A. plasma triglycerides (TGs); B. plasma total cholesterol (TC); C. plasma free fatty acids (FFA). * indicates significant differences with the same groups on $\mathrm{t}=0$. Differences between the groups are indicated above the graphs with $*+$ line. 
SRA, but rather CD36, is mainly responsible for the observed differences in plasma TGs. Confirming this point of view, apoe ${ }^{-/-}$female mice transplanted with CD36 deficient bone marrow were shown to display decreases in plasma TGs, but not in other plasma parameters [24]. This effect was attributed to the absence of CD36 in its capacity as a fatty acid transporter, and was previously noted in CD36 null mice [25]. Since the KCs should theoretically fail to incorporate modified cholesterol-rich lipoproteins in the used experimental model, lower liver TC levels were expected in the animals that received $\mathrm{dKO}$ bone marrow. However, no such difference was observed (fig. 2B), which could be due to the fact that KCs make up only a relatively small fraction of total liver mass, making any difference too subtle to detect.

High fat feeding during 12 weeks resulted in the development of equal levels of steatosis in both groups. Neither hepatic TG levels, nor hepatic TC differed between the two groups (Fig. 2A, B). This observation was confirmed by HE-stained liver sections, which were scored blindly by a pathologist (data not shown). The observed liver lipid levels are indicative for the presence of steatosis as was described previously (chapter 5). Thus, differences in hepatic steatosis cannot affect the development of inflammation in this model.

Liver sections were stained with antibodies against Mac1 to determine the degree of hepatic inflammation in these animals. Counting of Mac1-positive cells showed that hepatic inflammation was decreased in the animals that received dKO bone marrow compared to control. The animals that received WT bone marrow displayed more mac1 positive cells in their livers compared to the animals that received dKO bone marrow (Fig. 3A). Counting these cells indicated a decrease from $235 \pm 86$ to $171 \pm 34$ cells (Fig. 3B). This indicates that hepatic inflammation is attenuated in the $\mathrm{dKO}$ group.

To further define the differences between the two groups, gene expression analysis of several genes known to be involved in inflammation was performed: monocyte chemoattractant protein 1 (MCP1), a chemokine (Fig. 4A); CD68, a macrophage and Kupffer cell marker (Fig. 4); Mac1, a macrophage marker (Fig. 4C); tumour necrosis factor (TNF) and interleukin 6 (IL6), both pro-inflammatory cytokines (Fig. 4D, E); and intracellular adhesion molecule 1 (Icam1), a cellular adhesion molecule (Fig. 4F). Expression levels of TNF were significantly lower in the dKO mice, clearly confirming the observed decrease in inflammation. All the other tested genes failed to reach statistical significance, but they all displayed trends towards lower expression levels, adding to the observed effect on hepatic inflammation. 
A

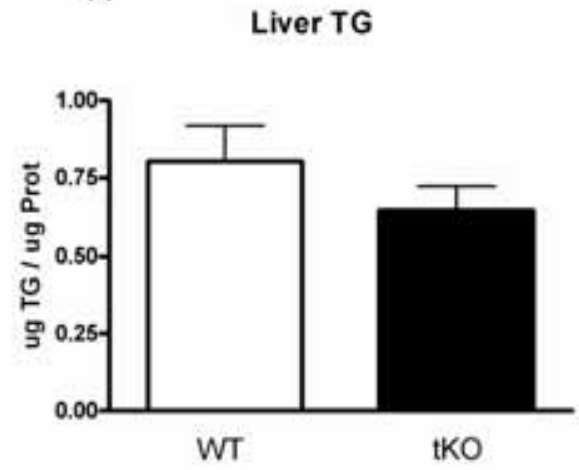

B

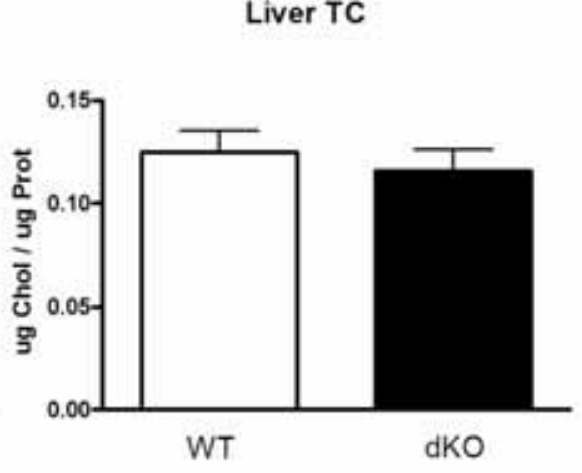

Figure 2. Liver lipds. White bars represent animals transplanted with WT bone marrow, while black bars represent animals that received dKO bone marrow A. liver triglycerides (TGs); B. liver total cholesterol (TC); * indicates significant differences.

Surprisingly, despite an effect on inflammation, scoring HE-stained sections did not reveal differences between the two groups in the presence or size of foamy KCs (Fig. 3C), which may indicate that SRA and CD36 are not the major SRs responsible for uptake of modified lipoproteins in KCs. These observations can explain why plasma and liver TC failed to display the expected trends. Even though SRA and CD36 have been proposed to be the most important SRs in foam cell formation [16-18], it has to be appreciated that modified lipoproteins can also be taken up by alternative SRs [18]. Additionally, there are other routes of modified lipoprotein uptake possible which do not involve SRs and do not require lipoproteins to be modified, like pinocytosis [18]. The role of SRs in the uptake of modified lipoproteins is extensively studied in the field of atherosclerosis. While clear effects of SRA and CD36 in cholesterol uptake and foam cell formation could be found in vitro, without any compensation by other SRs [16], in vivo results showed less clear results [18], ranging from less foam cell formation and atherosclerosis to no effect or even more foam cell formation and atherosclerosis in different mouse models lacking one or more of these SRs [18, 26]. These discrepancies have also been found in studies in the liver. Uptake of acLDL by SRA accounted for $50 \%$ in vitro, this was not reflected in vivo, as SRA deficient mice were shown to have of only $17 \%$ decrease in uptake [27].

Taken together, the in vivo mechanisms of modified lipoprotein uptake appear to be complicated and difficult to address. Despite the fact that there was no effect on foam cell formation, there was a significant effect on hepatic inflammation in the animals that received dKO bone marrow. 

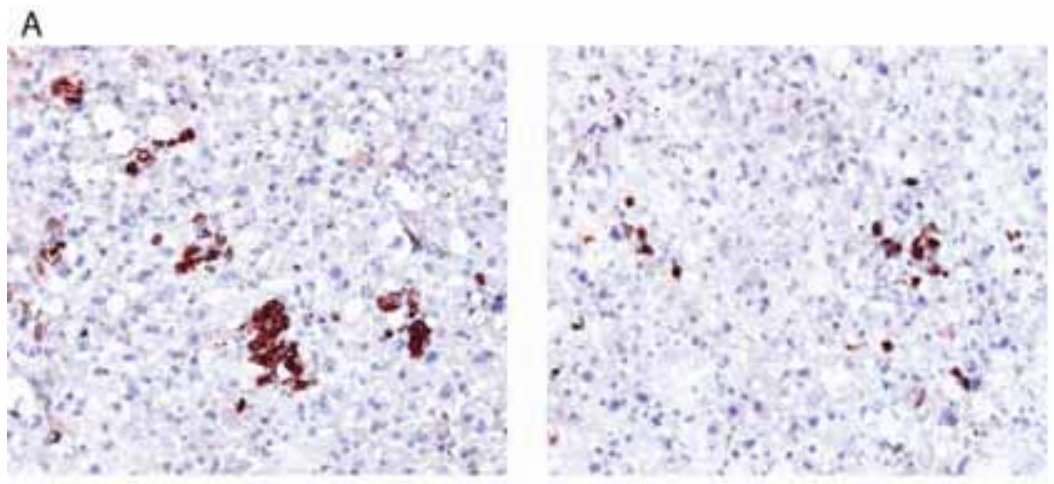

B

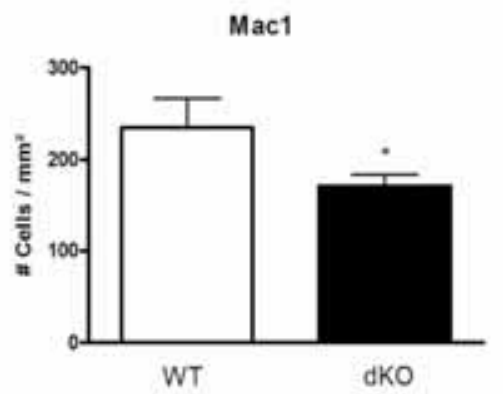

C

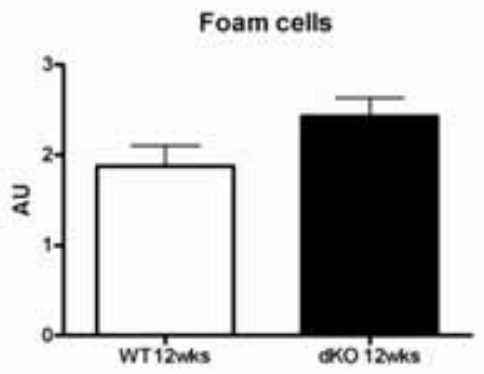

Figure 3. Liver inflammation. A. Representative pictures of Mac1-stained liver sections of animals that received WT (left panel) or dKO (right panel) bone marrow; B. Quantification of Mac1 positive cells; C. Scoring of hepatic foams cells on HE-stained liver sections. White bars represent animals transplanted with WT bone marrow, while black bars represent animals that received dKO bone marrow. * indicates significant differences with the same groups.

These observations indicate that lacking these SRs have effects other than on foam cell formation. It has been shown that CD36 deficiency does not influence macrophage motility [28]. Thus, lacking CD36 is unlikely to affect migration of macrophages into the liver directly. Alternatively, several roles have been attributed to CD36 which may influence inflammatory status. Binding of apoptotic cells to CD36 has been shown to result in an anti-inflammatory phenotype [29]. Contrary, CD36 has been proposed to play a role in the innate immune response as it was shown to be essential to some tolllike receptor 2/6 responses which induce NF-KB activation [30]. Additionally, oxLDL 
A

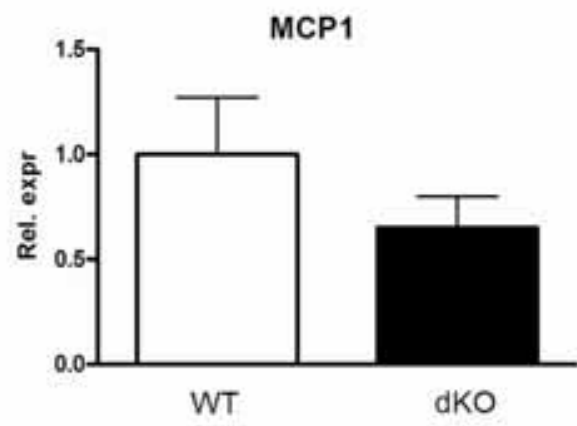

C

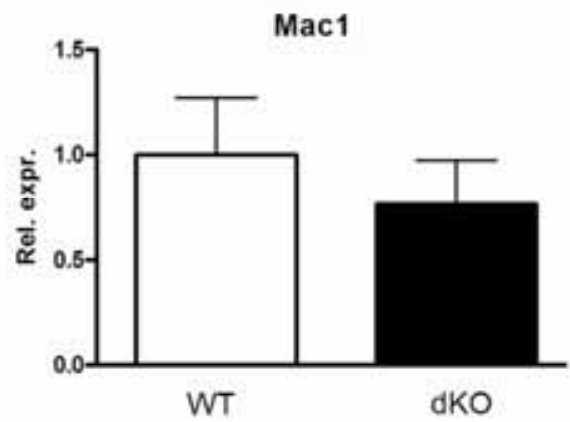

$E$

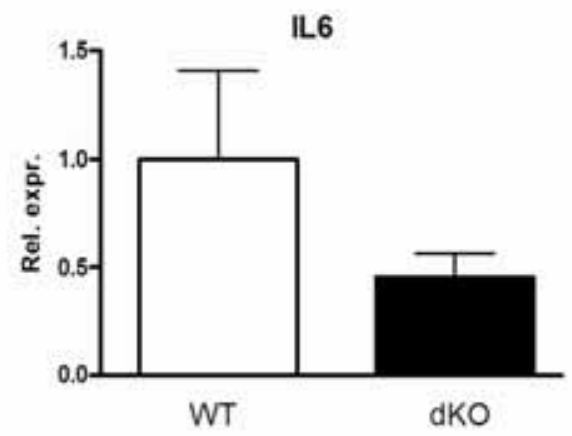

B

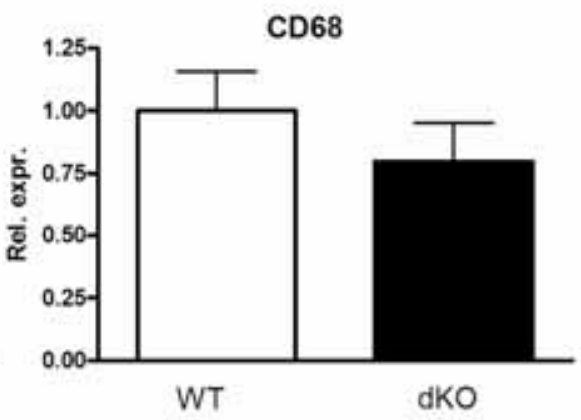

D

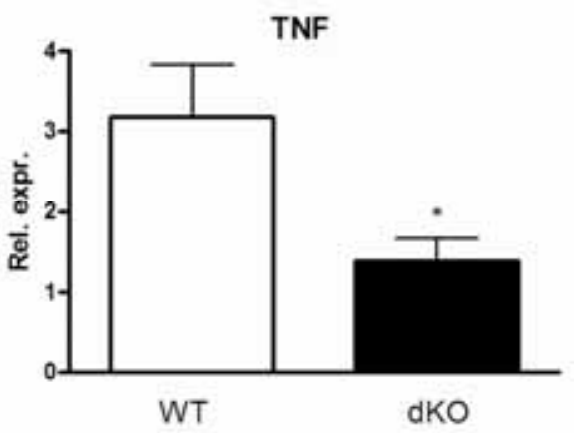

$\mathrm{F}$

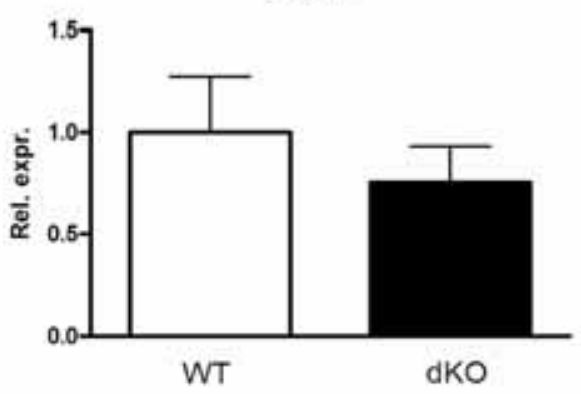

Figure 4. Liver inflammatory gene expression. Gene expression of inflammatory genes in the liver, relative to control animals that received WT bone marrow. A. MCP1, B. CD68, C. Mac1, D. TNF, E. IL6, and F. Icam1. White bars represent animals transplanted with WT bone marrow, while black bars represent animals that received dKO bone marrow. * indicates significant differences with the same groups. 
has been shown to activate CD36-dependent signaling resulting in JNK activation, which can consequently lead to inflammation [19]. Therefore, lacking this SR may lead to attenuated inflammatory responses due to its known role in innate immunity, SR activity, NF-KB activation, and consequent cytokine production [31]. Additionally, it has been shown that SRA deficient macrophages display slower adherence rates than WT macrophages [17]. Together, these processes may contribute to the effect seen on inflammation and indicate that further research is needed to elucidate the role of SRs in the development of NASH.

\section{Conclusions}

SRA and/or CD36 are partially responsible for diet-induced hepatic inflammation, even without a marked effect on foam cell formation. Investigating the individual contribution of SRA and CD36 to hepatic inflammation should resolve the contribution to hepatic inflammation and what pathways, other than foam cell formation, are involved.

These results can be of major importance, as the involvement of mechanisms similar to atherosclerosis may lead to the use of known drugs, targeting foam cell formation in the treatment of NASH. These options should be subject of further research.

\section{References}

1. Day, C.P. and O.F. James, Steatohepatitis: a tale of two "hits"? Gastroenterology, 1998. 114(4): p. 842-5.

2. Parekh, S. and F.A. Anania, Abnormal lipid and glucose metabolism in obesity: implications for nonalcoholic fatty liver disease. Gastroenterology, 2007. 132(6): p. 2191-207.

3. Matsuzawa, N., et al., Lipid-induced oxidative stress causes steatohepatitis in mice fed an atherogenic diet. Hepatology, 2007.

4. Browning, J.D. and J.D. Horton, Molecular mediators of hepatic steatosis and liver injury. J Clin Invest, 2004. 114(2): p. 147-52.

5. Hotamisligil, G.S., Inflammation and metabolic disorders. Nature, 2006. 444(7121): p. 860-7.

6. Ruvolo, P.P., Intracellular signal transduction pathways activated by ceramide and its metabolites. Pharmacol Res, 2003. 47(5): p. 383-92.

7. Summers, S.A., Ceramides in insulin resistance and lipotoxicity. Prog Lipid Res, 2006. 45(1): p. 42-72.

8. Joven, J., et al., The results in rodent models of atherosclerosis are not interchangeable The influence of diet and strain. Atherosclerosis, 2007.

9. Vergnes, L., et al., Cholesterol and cholate components of an atherogenic diet induce distinct stages of hepatic inflammatory gene expression. J Biol Chem, 2003. 278(44): p. 42774-84.

10. Shiri-Sverdlov, R., et al., Early diet-induced non-alcoholic steatohepatitis in APOE2 knock-in mice and its prevention by fibrates. J Hepatol, 2006. 44(4): p. 732-41.

11. Yoshimatsu, M., et al., Induction of macrophage scavenger receptor MARCO in nonalcoholic steatohepatitis indicates possible involvement of endotoxin in its pathogenic process. Int J Exp Pathol, 2004. 85(6): p. 33543.

12. Sano, J., et al., Foam cells generated by a combination of hyperglycemia and hyperlipemia in rats. Pathol Int, 2004. 54(12): p. 904-13.

13. Naito, M., et al., Tissue distribution, intracellular localization, and in vitro expression of bovine macrophage scavenger receptors. Am J Pathol, 1991. 139(6): p. 1411-23. 
14. Van Berkel, T.J., et al., Processing of acetylated human low-density lipoprotein by parenchymal and nonparenchymal liver cells. Involvement of calmodulin? Biochem J, 1982. 208(2): p. 493-503.

15. Liao, F., et al., Genetic control of inflammatory gene induction and NF-kappa B-like transcription factor activation in response to an atherogenic diet in mice. J Clin Invest, 1993. 91(6): p. 2572-9.

16. Kunjathoor, V.V., et al., Scavenger receptors class A-I/II and CD36 are the principal receptors responsible for the uptake of modified low density lipoprotein leading to lipid loading in macrophages. J Biol Chem, 2002. 277(51): p. 49982-8.

17. Suzuki, H., et al., A role for macrophage scavenger receptors in atherosclerosis and susceptibility to infection. Nature, 1997. 386(6622): p. 292-6.

18. Moore, K.J. and M.W. Freeman, Scavenger receptors in atherosclerosis: beyond lipid uptake. Arterioscler Thromb Vasc Biol, 2006. 26(8): p. 1702-11.

19. Rahaman, S.O., et al., A CD36-dependent signaling cascade is necessary for macrophage foam cell formation. Cell Metab, 2006. 4(3): p. 211-21.

20. Kuchibhotla, S., et al., Absence of CD36 protects against atherosclerosis in ApoE knock-out mice with no additional protection provided by absence of scavenger receptor A I/II. Cardiovasc Res, 2008.

21. Febbraio, M., et al., Targeted disruption of the class B scavenger receptor CD36 protects against atherosclerotic lesion development in mice. J Clin Invest, 2000. 105(8): p. 1049-56.

22. Lusis, A.J., J. Yu, and S.S. Wang, The problem of passenger genes in transgenic mice. Arterioscler Thromb Vasc Biol, 2007. 27(10): p. 2100-3.

23. Babaev, V.R., et al., Reduced atherosclerotic lesions in mice deficient for total or macrophage-specific expression of scavenger receptor-A. Arterioscler Thromb Vasc Biol, 2000. 20(12): p. 2593-9.

24. Febbraio, M., D.P. Hajjar, and R.L. Silverstein, CD36: a class B scavenger receptor involved in angiogenesis, atherosclerosis, inflammation, and lipid metabolism. J Clin Invest, 2001. 108(6): p. 785-91.

25. Febbraio, M., E. Guy, and R.L. Silverstein, Stem cell transplantation reveals that absence of macrophage CD36 is protective against atherosclerosis. Arterioscler Thromb Vasc Biol, 2004. 24(12): p. 2333-8.

26. Witztum, J.L., You are right too! J Clin Invest, 2005. 115(8): p. 2072-5.

27. Van Berkel, T.J., et al., Uptake and catabolism of modified LDL in scavenger-receptor class A type I/II knock-out mice. Biochem J, 1998. 331 ( Pt 1): p. 29-35.

28. Truman, L.A., et al., Macrophage chemotaxis to apoptotic Burkitt's lymphoma cells in vitro: role of CD14 and CD36. Immunobiology, 2004. 209(1-2): p. 21-30.

29. Voll, R.E., et al., Immunosuppressive effects of apoptotic cells. Nature, 1997. 390(6658): p. 350-1.

30. Hoebe, K., et al., CD36 is a sensor of diacylglycerides. Nature, 2005. 433(7025): p. 523-7.

31. Febbraio, M. and R.L. Silverstein, CD36: implications in cardiovascular disease. Int J Biochem Cell Biol, 2007. 39(11): p. 2012-30. 
-132 - 


\section{VII}

\section{Hyperactivation of inflammatory signaling inhibits hepatic steatosis during high fat feeding in hyperlipidemic mice}

Kristiaan Wouters $^{1, *}$, Ronit Shiri-Sverdlov ${ }^{1, *}$, Sofia Xanthoulea ${ }^{1}$, Patrick J van Gorp ${ }^{1}$, Veerle Bieghs ${ }^{1}$, Mohammed Hadfoune ${ }^{1}$, Marion J Gijbels ${ }^{1}$, Menno PJ de Winther ${ }^{1}$, Marc van Bilsen and Marten H Hofker².

1) Dept. of Molecular Genetics, Pathology, Physiology and General Surgery, Nutrition and Toxicology Research (NUTRIM) and Cardiovascular Research (CARIM) Institutes of Maastricht University Maastricht, Maastricht, The Netherlands; 2) Dept. of Pathology \& Laboratory Medicine, University Medical Center Groningen, Groningen, Netherlands

* Both authors contributed equally to this paper 


\section{Abstract}

Non-alcoholic steatohepatitis (NASH) is characterized by pathological alterations ranging from steatosis and inflammation to cell degeneration, fibrosis and cirrhosis. The current concept for the pathogenesis of NASH is a two-hit model where steatosis precedes inflammation. In contrast, we previously showed that upon a high-fat, high cholesterol diet (HFC), hyperlipidemic ldlr knock-out $\left(\operatorname{ldll}^{-/}\right)$mice develop NASH characterized by very early inflammation. These observations indicate that inflammation may play an early role in the etiology of NASH. Therefore, we investigated the role of inflammation on steatosis during the development of NASH.

First, we investigated whether a correlation existed between the development of hepatic inflammation and steatosis by comparing $1 \mathrm{dlr}^{-/-}$mice with C57Bl/6 wild-type (WT) mice after long term high fat diet feeding. $\mathrm{Ldlr}^{-/ /}$mice, displaying increased hepatic inflammation, developed $25 \%$ less accumulation of liver lipids than WT animals that did not develop inflammation in their livers. Next, in order to determine whether hepatic inflammation was causal for the decrease in steatosis, we aimed to generate $\mathrm{ldlr}^{-/ 2}$ mice with increased hepatic inflammation. These mice were created by transplantation of bone marrow from TNF receptor non-sheddable mice, displaying increased TNF signaling, to lethally irradiated $\mathrm{ldlr}^{-/-}$mice. These animals displayed a doubling of hepatic inflammation and a subsequent reduction in liver lipids of $25 \%$. Finally, we have preliminary data which indicates that inhibiting the anti-inflammatory interleukin 10 (IL10) pathway in high fat diet fed $\mathrm{ldll}^{-/-}$mice with neutralizing antibodies resulted in a decrease in liver triglycerides. However, at present we have not yet detected an effect of IL10 removal on hepatic inflammation.

Conclusion: Hyper-activation of inflammatory signaling, either by increasing TNFR signaling, or by inhibiting IL10 signaling, inhibited liver lipid accumulation in a hyperlipidemic mouse model of NASH. 


\section{Introduction}

Non-alcoholic steatohepatitis (NASH) is characterized by pathological alterations ranging from steatosis and inflammation to cell degeneration, fibrosis and cirrhosis, which develop in the absence of excessive alcohol intake [1]. It is considered the hepatic event in the metabolic syndrome and is therefore strongly associated with obesity, hyperlipidemia, artherosclerosis and insulin resistance. Currently, 2-3\% of adults are estimated to meet the diagnostic criteria for NASH [2]. As the prevalence of obesity and diabetes continues to increase rapidly, an equivalent increase is expected in the prevalence of NASH and its associated morbidity.

NASH is currently believed to develop via the "two-hit model" [3]. According to this hypothesis, hepatic steatosis is the critical first hit and prerequisite for additional insults (second hits), such as oxidative stress, resulting in development of an inflammatory response [4]. We have previously shown that when fed a high-fat diet, hyperlipidemic APOE2 knock-in (APOE2ki) and ldlr deficient $\left(\mathrm{ldll}^{-/}\right)$mice develop hepatic inflammation very early next to steatosis [5] (chapter 5). Consequently, the presence of an inflammatory response this early during NASH development suggested that inflammation could play a modulating role during the early stages of this condition.

There are indeed several lines of evidence for a direct role of inflammation in lipid metabolism, including observations that some cytokines acutely induce higher serum triglyceride (TG) levels and can increase de novo fatty acid (FA) and TG production [6, 7]. More specifically, experimental evidence suggests that steatosis and tumor necrosis factor (TNF) production are tightly related $[8,9]$. TNF is one of the major activators of nuclear factor kappa beta (NF-kB), a transcription factor that plays a crucial role in inflammation and regulates the production of TNF and multiple other cytokines [10]. In addition to activation of the inflammatory response, TNF promotes insulin resistance [11]. However, actual data regarding the role of inflammatory signaling on hepatic steatosis remain contradictive [12].

In the current paper we aim to determine the effect of inflammatory signaling on steatosis during NASH progression. $\mathrm{Ldlr}^{-/-}$mice have been shown to develop liver inflammation very early upon feeding them a high fat, high cholesterol diet (HFC), while wild-type (WT) animals fail to develop hepatic inflammation on this diet (chapter 5). We exploited this difference in search of a correlation between hepatic inflammation and lipid accumulation. Hereto, $1 \mathrm{dlr}^{-/-}$mice were compared to C57B1/6 (WT) animals after long term high fat feeding to assess whether the development of hepatic inflammation can influence steatosis levels. Interestingly, WT animals developed higher levels of steatosis than the inflammatory $\operatorname{ldlr}^{-/-}$mice. These data 
indicated that an inverse correlation between hepatic inflammation and liver steatosis exists.

Consequently, we investigated whether increased inflammation was causal for the lower levels of steatosis by enhancing TNF signaling selectively in hematopoietic cells. This was done by performing a bone marrow transplantation (BMT) to lethally irradiated hyperlipidemic $1 \mathrm{dlr}^{-/-}$mice, using a graft from a novel mouse line, i.e. p55TNFR non-sheddable (TNFRns) mice in which impaired shedding of the TNFR leads to enhanced inflammatory signaling. These mice have been shown to be hyperinflammatory and to spontaneously develop hepatic inflammation [13].

Additionally, we injected HFC fed $\mathrm{ldlr}^{-/-}$mice with IL10 neutralizing antibodies. IL10 is a potent anti-inflammatory cytokine that normally inhibits the action of TNF and other pro-inflammatory cytokines. Therefore, acutely neutralizing this antiinflammatory cytokine is expected to result in increased inflammatory signaling. These complementary mouse models of increased hepatic inflammation were used to determine the contribution of inflammation to steatosis development.

\section{Materials and methods}

\section{Mice and diet}

Female $1 \mathrm{dlr}^{-/}$mice were housed under standard conditions given free access to food and water. Experiments were performed according to Dutch laws, approved by the Committee for Animal Welfare of Maastricht University. Up until the age of 12 weeks, animals were kept on regular chow diet (ssniff Spezialdiäten GmbH, Soest, Germany). In the first experiment, $1 \mathrm{dlr}^{-/ .}$and WT mice were give high fat, high cholesterol (HFC) diet, containing 21\% butter and 0,2\% cholesterol (diet 1635, Scientific Animal Food and Engineering, Villemoisson-sur-orge, France) for 13 weeks. Blood was collected before the dietary period, after 8 weeks of HFC feeding and at the day of sacrifice. A second experiment was done with mice that were transplanted with either TNFRns bone marrow (TNFRnsBMT mice) or WT bone marrow (WTBMT mice). Mice were put on HFC diet for 11 weeks and blood was collected before, after 4 and 8 weeks of HFC feeding, and at the end of the experimental period. Neutralizing IL10 was done by injection of IL10 neutralizing antibodies in PBS or injection of vehicle the day before the start of the dietary period. Mice were re-injected after 3 days of HFC and sacrificed after 7 days of HFC feeding. Blood was collected before and after the dietary period. Collection of blood, sacrificing of the mice, and tissue isolation was performed as described previously [5]. 


\section{Bone marrow transplantation}

Ten week old female $1 \mathrm{dlr}^{-/}$mice were put in filter-top cages. The mice received acidified water supplemented with neomycin $(100 \mathrm{mg} / \mathrm{l})$ and polymyxin B sulphate $(60,000 \mathrm{U} / \mathrm{l})$ during one week before transplantation. One day before the actual transplantation, the mice were irradiated with a lethal dose of 10 Gray röntgen. The bone marrow of five female wild-type mice and five female TNFRns littermates was collected and pooled. Bone marrow cells were derived by flushing the femur and tibia of the mice with PBS. For transplantation, 20 mice received wild-type bone marrow and 20 mice received transgenic bone marrow. The cells $\left(10^{7}\right)$ were injected in the tail vein of each mouse.

\section{Lipid analysis}

Approximately $50 \mathrm{mg}$ of frozen liver tissue was homogenized as described previously [5]. Both plasma and liver lipid levels were measured with enzymatic color tests (1489232, cholesterol CHOD-PAP, Roche, Basel, Switzerland; TR0100, TG GPOtrinder, Sigma Aldrich, Sigma Aldrich, St. Louis, MO, USA; 999-75406, NEFAC, ACS-ACOD, Wako Chemicals, Neuss, Germany) as described before [5].

\section{RNA isolation and quantitative PCR}

Total RNA was isolated from approximately $25 \mathrm{mg}$ of mouse liver tissues as described previously [5]. All applications were done according to manufacturer's protocols. Total RNA (500 ng) from each individual mouse was converted into first strand cDNA with the iScript cDNA synthesis kit (170-8891, Bio-Rad, Hercules, CA, USA) according to the manufacturer's instructions.

The changes in gene expression of inflammatory markers were determined by quantitative PCR on a Bio-Rad MyIQ with the IQ5 v2 software (Bio-Rad, Hercules, CA, USA) by using IQ SYBR Green Supermix with fluorescein (170-5006CUST, BioRad, Hercules, CA, USA) and 10 ng of cDNA. For each gene a standard curve was generated with a serial dilution of a liver cDNA pool. To standardize for the amount of cDNA, Cyclophillin A (Ppia) was used as the reference gene. Primer sets for the selected genes were developed with Primer Express version 1.5 (Applied Biosystems, Foster City, CA, USA) using default settings. Primer sequences:

MCP1-forward, 5'-GCTGGAGAGCTACAAGAGGATCA-3'; MCP1-reverse, 5'-ACAGACCTCTCTCTTGAGCTTGGT-3'; CD68-forward, 5'-TGACCTGCTCTCTCTAAGGCTACA-3'; CD68-reverse, 5-TCACGGTTGCAAGAGAAACATG -3'; 
TNFa-forward, 5'-CATCTTCTCAAAATTCGAGTGACAA-3';

TNFa-reverse, 5'-TGGGAGTAGACAAGGTACAACCC-3';

Ppia-forward, 5'-TTCCTCCTTTCACAGAATTATTCCA-3';

Ppia-reverse, 5'-CCGCCAGTGCCATTATGG-3'.

Data from qPCR was analyzed according to the relative standard curve method.

\section{Taqman ${ }^{\circledR}$ Low Density Arrays}

To perform gene expression analysis on a medium scale, Taqman ${ }_{\circledast}$ Low Density Arrays (TLDA) 96a (PN 4342259) were used. Each TLDA plate contained 4 x 96 annotated and validated individual TaqMan ${ }^{\circledR}$ Gene Expression Assays (forward primer, reversed primer and Taqman ${ }_{\circledast}$ Probe) (supplementary table 1). Per individual assay 2 ng cDNA of a single liver was loaded together with the TaqMan ${ }^{\circledR}$ Universal PCR Master Mix (PN 4324018). Of each group, mRNA from 5 individual mice was used. TLDA plates were run on an ABI Prism 7900HT Sequence Detection System with a TaqMan ${ }_{\circledast}$ Low Density Array Upgrade. Data was analyzed by using RQ Manager 1.2 software. Technically failed assays were omitted from analysis. Materials, equipment and software necessary to perform TLDA gene expression studies were obtained from Applied Biosystems, Foster City, CA, USA. All data were normalized to Ppia expression. Significant differences were determined with student t-tests; p-values < 0.05 were considered significant.

\section{Liver histology}

Four $\mu \mathrm{m}$ paraffin embedded liver sections were stained with Haematoxillin/Eosin (HE). Frozen liver sections $(7 \mu \mathrm{m})$ were fixated in acetone and stained with CD68 (FA11) or Mac1 (M1/70). Pictures were taken with a Nikon ${ }^{\circledR}$ digital camera DMX1200 and ACT-1 v2.63 software from Nikon ${ }^{\circledR}$ Corporation.

\section{Statistical analysis}

Data were analyzed using Graphpad Prism 4.0. Groups were compared using 2-tailed non-paired t-tests or ANOVA. Data is expressed as means \pm SEM and considered significant at $\mathrm{p}<0.05$. 


\section{Results}

\section{Liver inflammation is inversely correlated with liver TGs}

Plasma parameters of female WT C57Bl/6 and $\mathrm{ldlr}^{-/-}$mice before and after 7 and 13 weeks of HFC are displayed in figure 1 . As expected, $1 \mathrm{dll}^{-/-}$mice appeared to be more responsive to HFC feeding than WT animals. These WT mice displayed a very small increase in total cholesterol (TC) (Fig. 1A), which only reached statistical significance after 13 weeks. Plasma TG levels were decreased at both time points in WT mice (Fig 1B). Conversely, both TC (Fig. 1A) and TGs (Fig. 1B) levels in plasma of $1 \mathrm{dlr}^{-/}$mice $^{-}$ were dramatically increased after 7 weeks and 13 weeks of high fat feeding.

The amount of Mac1 positive cells was counted as a measure of inflammation (Fig 1C). WT animals did not develop hepatic inflammation while $\operatorname{ldlr}^{-/}$mice displayed a clear inflammatory response in their livers. Gene expression analysis for three inflammatory markers, i.e. TNF (Fig. 1E), MCP1 (Fig. 1F) and CD68 (Fig. 1G) also showed much higher expression levels in livers of $1 \mathrm{dlr}^{-/-}$mice than in livers of WT mice, confirming the Mac1 staining.

Both mouse models developed steatosis as can be concluded from TG levels in their livers (Fig. 1C). The observed levels are much higher than the levels that are usually detected when these animals are fed a standard chow diet (chapter 5). Remarkably, liver TG measurements showed that $1 \mathrm{dlr}^{-/-}$mice accumulated less TGs (25\% reduction) in their livers compared to WT mice. Scoring HE-stained liver sections confirmed all of these observations (data not shown).

\section{Liver hyper-inflammation results in inhibition of steatosis in Idllr $r^{-/}$mice}

To investigate whether the increased inflammation was causal for the lower TG levels in the liver, a model of increased hepatic inflammation was created without directly altering hepatocyte function. Hereto, bone marrow transplantation was performed with $1 \mathrm{dl} \mathrm{r}^{-/-}$recipient mice, using donor bone marrow of TNFRns animals.

Plasma parameters showed that these mice responded well to HFC diet with significant increases in plasma TC (Fig. 2A) and TG levels (Fig. 2B). Interestingly, mice that received the mutant bone marrow displayed lower plasma TC (Fig. 2A) and TG levels (fig. 2B) than controls, while these parameters were equal before the start of the diet.

Recipient $1 \mathrm{dlr}^{-/-}$mice with TNFRns bone marrow (TNFRnsBMT mice) displayed a twofold increase in Mac-1 positive cells (Fig. 2C), indicative of a good experimental model for hyper-inflammation in the liver. Table 1 shows regulation of genes involved 
in inflammation in the livers of TNFRnsBMT mice. As expected, most inflammation genes tested showed trends towards up-regulation in TNFRnsBMT mice compared to control mice that received bone marrow from WT animals (WTBMT mice).

A

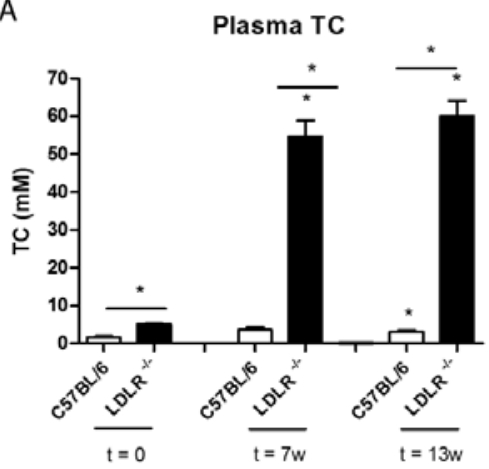

C

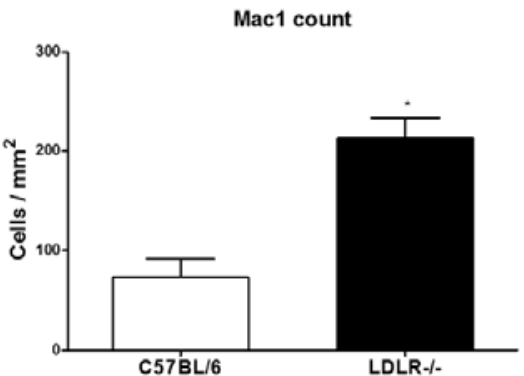

B

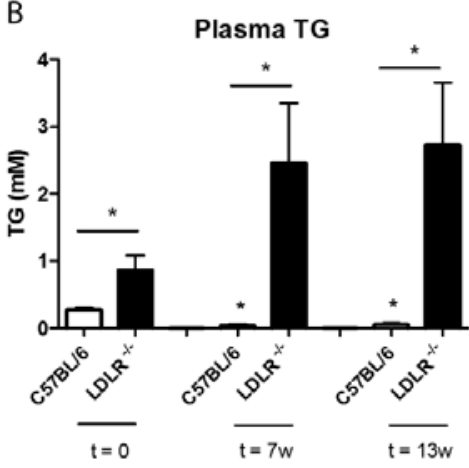

D

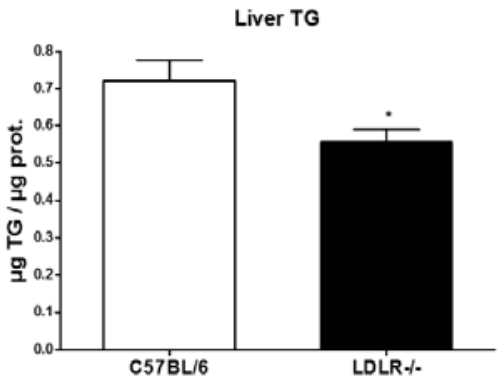

G

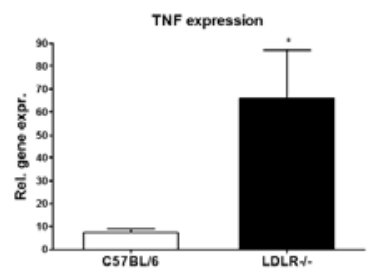

Figure 1. Liver inflammation and steatosis show an inverse correlation. White bars represent WT C57Bl/6 mice and black bars represent $1 \mathrm{dlr}^{-/-}$mice. A. plasma total cholesterol (TC) and B. plasma triglycerides (TGs) of mice fed HFC on $\mathrm{t}=0, \mathrm{t}=7$ weeks (w), and $\mathrm{t}=13 \mathrm{w}$. C. Quantification of Mac1 positive cells after 13 weeks HFC feeding. Liver TG levels after 13 weeks HFC. Relative gene expression in livers of mice fed HFC during 13 weeks of mcp1 (E), CD68 (F), and TNF (G). * indicates significant differences between the mouse models. 
However, only a part of these genes could reach statistical significant changes in their expression levels, partially due to high variation within the groups. Among these genes, there were pro-inflammatory proteins and cytokines, like Icam1, CD40, IL6, SAA1 and TNF. Interestingly, there were also anti-inflammatory genes regulated; i.e. IL10 and Stat3, suggesting increased IL10 signaling in livers of these mice.

TNRFnsBMT mice clearly showed less steatosis development as is clear from biochemical assessment of liver TGs (Fig. 3D). Comparable with the correlation that was found between inflammation and steatosis in WT and $1 \mathrm{dlr}^{-/-}$mice fed the HFC, this reduction in steatosis was approximately $25 \%$. Genes involved in lipid metabolism were also investigated (table 2) to unravel the pathways responsible for the altered steatosis levels. However, except for one of the tested genes, i.e. lipin C (LipC), we found none of them to be regulated.

\section{Blocking the anti-inflammatory cytokine I L10 inhibits steatosis in Idllr ${ }^{-/}$mice}

Additionally to the described experiments, a pilot study was performed to systemically inhibit IL10 function. Hereto, $\mathrm{ddlr}^{-/-}$mice were injected with IL10 neutralizing antibodies before and during feeding HFC diet for 7 days. Control animals received PBS vehicle.

Interestingly, while the control animals remained at the same weight, anti IL10 treated animals showed a significant lowering of body weight (data not shown). Plasma TC did not differ between treated and untreated animals, but did increase in both groups after dietary intervention (Fig. 3A). The experimental group treated with anti IL10 had significantly higher plasma TG levels compared to control mice (Fig. 3B).

Surprisingly, no difference in Mac1 positive cells was found between treated and untreated animals (Fig. 3C). Indeed, analysis of the inflammatory gene expression of anti IL10 treated animals vs control revealed regulation of only a very few inflammatory genes (table 1): Vcam1 (up), Cxcl10 (down), IL1b (down), IL6Ra (up). Contrary, the anti-inflammatory suppressors of cytokine signaling (SOCS) 1 and 3 were both down-regulated compared to control mice. Also plasma levels of the inflammatory marker amyloid P component (SAP) were measured and showed no difference between the two groups. SAP levels were moderately higher than levels before dietary intervention in both groups (data not shown).

Despite the absence of an effect on hepatic inflammation levels, there was a clear inhibition of steatosis development (Fig. 3D). Hepatic TG levels showed to be comparable to levels seen in normal livers (chapter 5). Gene expression analysis 
revealed none of the tested genes involved in lipid metabolism to be regulated upon IL10 treatment (table 2).

A

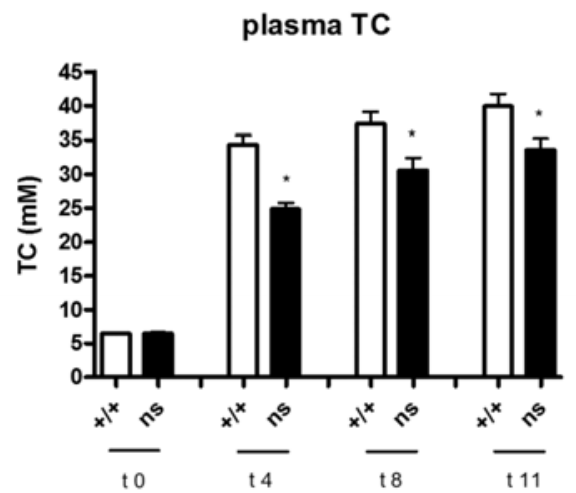

C

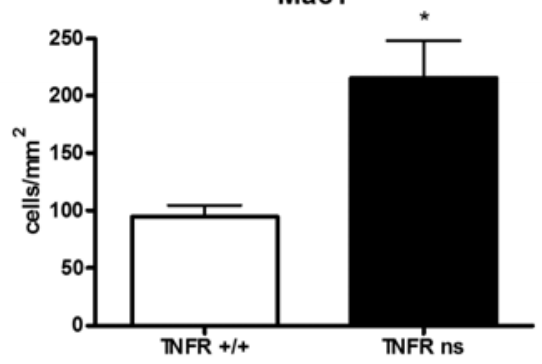

B

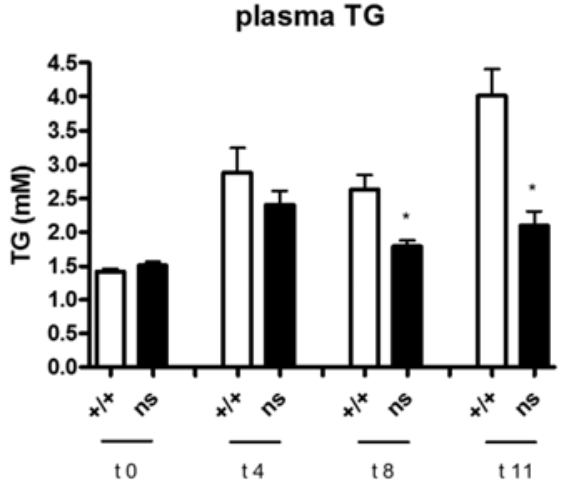

D

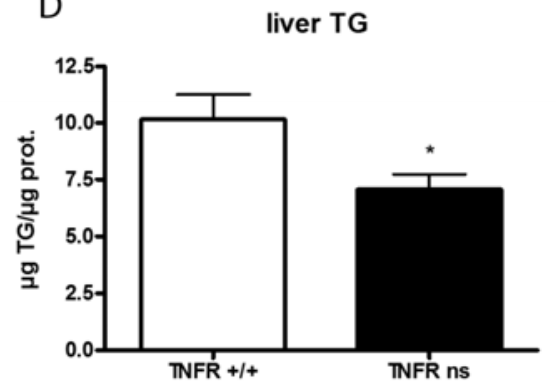

Figure 2. TNFRns BMT mice display increased liver inflammation and lower steatosis levels. White bars represent WT C57Bl/6 mice and black bars represent $1 \mathrm{dlr}^{-/-}$mice. A. plasma total cholesterol (TC) and B. plasma triglycerides (TGs) of mice fed HFC on $\mathrm{t}=0, \mathrm{t}=4$ weeks ( $\mathrm{w}$ ), $\mathrm{t}=8 \mathrm{w}$ and $\mathrm{t}=11 \mathrm{w}$. C. Quantification of Mac1 positive cells after 11 weeks HFC feeding. Liver TG levels after 11 weeks HFC. * indicates significant differences between the mouse models.

\section{Discussion}

In this paper, we show that mice displaying hepatic inflammation have less steatosis compared to animals that do not develop inflammation in their livers. These results argue for an inverse correlation between inflammation and lipid accumulation in the liver. To investigate whether a causal link exists, we performed two complementary experiments. First, we used a model of TNF hyper-signaling in hematopoietic cells, thereby creating a mouse model with increased hepatic inflammation. Indeed, these 
mice displayed reduced liver lipids upon high fat feeding. Second, in a pilot study, we injected neutralizing antibodies against IL10, a well known anti-inflammatory cytokine. In these animals, steatosis development was inhibited. Together, these results suggest that increased inflammation leads to a decrease of diet-induced steatosis.

A

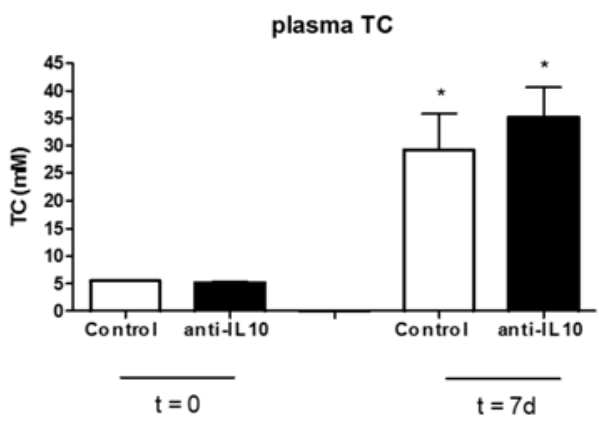

C

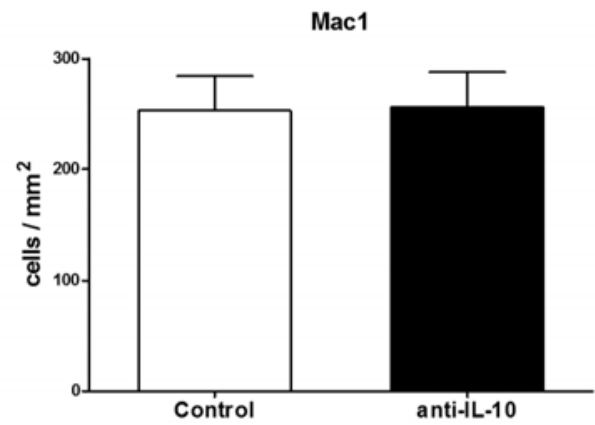

B

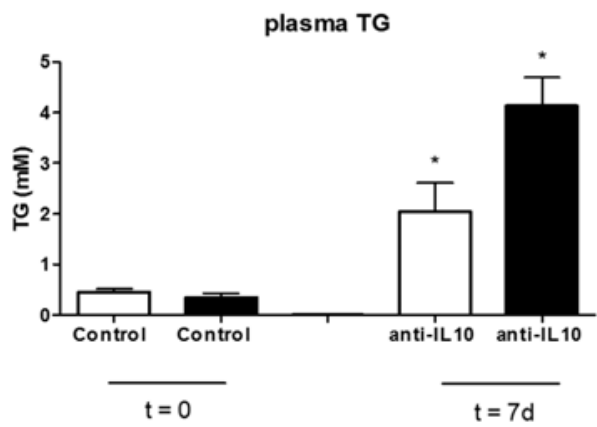

D

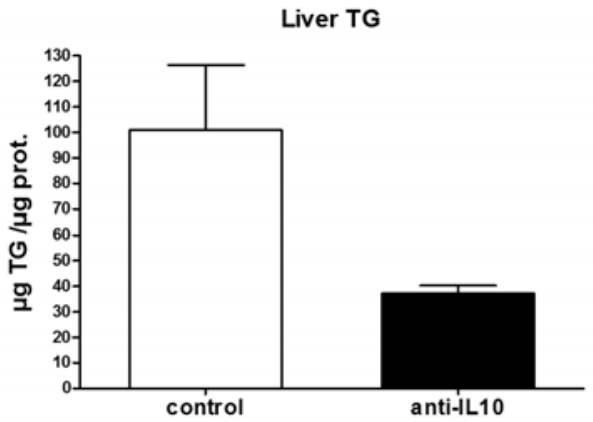

Figure 3. Inhibiting IL10 does not influence inflammation but inhibits steatosis development. White bars represent control $\mathrm{ldlr}^{-/-}$mice and black bars represent $1 \mathrm{dlr}^{-/-}$mice injected with anti-IL10 antibodies. A. plasma total cholesterol (TC) and B. plasma triglycerides (TGs) of mice before $(\mathrm{t}=0)$ and after lice were fed HFC for 7 days $(t=7 d)$. C. Quantification of Mac1 positive cells after 7 days HFC feeding. Liver TG levels after 7 days HFC. * indicates significant differences between the mouse models.

\section{Liver inflammation is inversely correlated with liver TGs}

In this study, we show an inverse correlation between hepatic inflammation and steatosis development, which is to our knowledge unreported until now. We have previously shown that WT mice do not develop hepatic inflammation upon short term high fat feeding while $1 \mathrm{dlr}^{-/}$mice show an inflammatory response already after a few 
days (chapter 5). The current observation shows that this phenotype is retained even after longer periods of dietary stress.

$\mathrm{Ldlr}^{-/ /}$mice, showing an increase of Mac1 positive cells in their livers, had 25\% less liver TGs compared to WT animals without hepatic inflammation. A possible explanation for this observation is that less lipid-containing lipoproteins are taken up due to the loss of the ldlr in these mice. However, the LDL particles that remain in the circulation in this way contain mostly cholesterol and not TGs. The latter are mainly hydrolyzed in the peripheral tissues, making it improbable that less TGs enters the liver via this mechanism. Moreover, we have previously shown that short term high fat feeding resulted in equal steatosis levels in both $\mathrm{ldlr}^{-/}$and WT mice (chapter 5), indicating that the loss of the ldlr does not affect hepatic steatosis directly. Consequently, it is feasible that the effect on liver lipids is due to the chronic presence of an inflammatory response in the liver.

The presence of inflammatory cells results in augmented levels of inflammatory mediators in the micro-environment of hepatocytes, as analysis of gene expression revealed an increase in several inflammatory markers after 13 weeks of high fat feeding, like TNF, MCP1, and CD68. These inflammatory mediators probably can influence hepatocyte function. It has been repeatedly shown that TNF can directly influence lipid metabolism $[11,14,15]$ although the exact contribution of TNF remains somewhat controversial. Consequently, in a follow-up experiment, we focused on TNF signaling to delineate the exact contribution of pro-inflammatory signaling to lipid deposition in the liver.

\section{Liver hyper-inflammation inhibits steatosis in Idllr-/ - mice}

With BMT, we created a mouse model with increased inflammation in their livers without directly influencing hepatocyte TNF signaling. It has been postulated that Kupffer cells (KCs) are the major source of hepatic TNF [16]. Therefore, the exact contribution of infiltrating inflammatory cells and of activated KCs can be identified in this manner. Murine KCs were shown to have a life span of approximately 21 days [17] which is also the replacement time of KCs in mice after BMT [18].

Our results show that increased inflammation due to macrophage-specific hyperactivation of TNF signaling leads to decreased steatosis development.

It should be noted that plasma lipid levels of the hyper-inflammatory mice was slightly lower than what was found in control mice. Although decreased food intake of hyperinflammatory mice cannot be excluded, other mechanisms are more likely to play a role. It has been well documented that inflammation and whole body lipid and lipoprotein metabolism can influence each other in several ways [14]. We propose that 
due to a decrease in liver TG levels, VLDL production is hampered, thereby decreasing both plasma TGs and TC. Additional experiments, using metabolic cages and measuring VLDL production will address this issue. The role of TNF in steatosis is controversial as several lines of evidence show different results. It has been well established that TNF may be detrimental for the liver and that it can induce liver inflammation and fibrosis [9, 16]. Additionally, contrary to our results, deletion or inhibition of TNF has been repeatedly shown to be protective against liver lipid accumulation both via neutralizing antibodies $[9,19]$, and by using genetically modified animal models [20]. The detrimental effect of TNF has been proposed to happen due to its known effect of promoting insulin resistance (IR) [21, 22], which can indirectly lead to steatosis, as described in chapter 1. Alternatively, TNF can have direct effects on lipogenic gene expression, including effects on genes as stearoyl CoA desaturase 1 (SCD1) [9] and fatty acid synthase (FAS) [23], possibly via the induction of Sterol Regulatory Element Binding Protein 1c (SREBP1c) [24, 25]. Not only TNF, but several other pro-inflammatory cytokines and signaling pathways have been shown to promote lipogenesis, e.g. via the regulation of mitochondrial TG transfer protein (MTP) expression by IL1 and LPS [26], increased lipoprotein uptake induced by macrophage-derived factors [27] or toll-like receptor (Tlr) induced down-regulation of PPAR $\alpha$ [28]. A major difference with these studies, however, is that in our experiments a model is used that specifically targets inflammatory cells rather than the whole organism.

Contrary to these publications and in line with our data, several studies question this proposed contribution of TNF to steatosis development. Memon et al. indicated that TNF is not the cause of a fatty liver in obese diabetic mice [29], showing similar liver lipid content between $\mathrm{Ob} / \mathrm{Ob}$ and $\mathrm{Ob} / \mathrm{Ob}-\mathrm{p} 55 / \mathrm{p} 75$-null animals, lacking both receptors for TNF. Moreover, an inverse relationship has been found between TNF and steatosis in mice lacking TNF upon high cholesterol feeding [30]. Interestingly, rather than TNF itself, hepatic NF- $\mathrm{KB}$ signaling has been implied to induce hepatic inflammation in NASH [31]. In addition, Cai et al. found that in mice with hepatocyte-specific constitutive up-regulation of NF- $\mathrm{KB}$ activity, liver lipids were shown to be decreased by about $30 \%$ and that hepatocyte-specific activation of NF- $\mathrm{KB}$ signaling promoted whole-body IR in a mechanism relying on IL6 [21]. Next to an induction of TNF expression, our results show up-regulation of the pro-inflammatory cytokine IL6 in the livers of TNFRnsBMT mice compared to WTBMT mice. IL6 is a target gene of TNF and was shown to reduce liver lipid levels, partially by inducing increased FA oxidation in a PPAR $\alpha$ dependent manner, in addition to increased excretion of TGs and TC from hepatocytes $[32,33]$. 
Table 1: Inflammatory genes.

\begin{tabular}{|c|c|c|c|}
\hline gene & group & $\begin{array}{l}\text { TNFRns } \\
\text { vs C56BL/6 }\end{array}$ & $\begin{array}{l}\text { anti-IL10 } \\
\text { vs control }\end{array}$ \\
\hline Cd19 & Cell Markers & 1,9 & 0,7 \\
\hline $\mathrm{Cd} 4$ & Cell Markers & 3,8 & 0,6 \\
\hline Cd68 & Cell Markers & 1,2 & 1,1 \\
\hline Cd8a & Cell Markers & 1,8 & 1,5 \\
\hline Fcgr1 & Cell Markers & 1,3 & 0,9 \\
\hline Itgam/Mac1 & Cell Markers & 1,7 & 1,0 \\
\hline Мро & Cell Markers & 1,6 & 4,7 \\
\hline Icam1 & Cell Markers & $\underline{1,7}$ & 0,8 \\
\hline Vcam1 & Cell Markers & 1,6 & $\underline{1,6}$ \\
\hline Vegfa & Cell Markers & 1,0 & 1,3 \\
\hline $\mathrm{Ccl} 2 / \mathrm{mcp} 1$ & Chemotaxis & 1,2 & 0,8 \\
\hline Ccl3/mip1 & Chemotaxis & 1,2 & 1,1 \\
\hline Ccr2 & Chemotaxis & 2,1 & 1,1 \\
\hline Ptgs2/Cox2 & Chemotaxis & 1,8 & 0,5 \\
\hline Cat & Oxidative stress & 0,9 & 1,0 \\
\hline Gsta2 & Oxidative stress & 1,4 & 0,7 \\
\hline Hmox 1 & Oxidative stress & 1,9 & 1,1 \\
\hline Ikbkb & Oxidative stress & $\underline{1,3}$ & 0,9 \\
\hline Por & Oxidative stress & 1,3 & 1,1 \\
\hline $\mathrm{Bcl} 2$ & Apoptosis & 1,2 & 0,9 \\
\hline Fasl & Apoptosis & 2,9 & 1,0 \\
\hline Il10 & Anti-inflammatory & $\underline{2,5}$ & 0,8 \\
\hline Il10ra & Anti-inflammatory & 1,6 & 0,9 \\
\hline Socs1 & Anti-inflammatory & 2,2 & $\underline{0,7}$ \\
\hline Socs 3 & Anti-inflammatory & 2,9 & $\underline{0,7}$ \\
\hline Cd14 & General Inflammation & 1,6 & 1,1 \\
\hline $\mathrm{Cd} 40$ & General Inflammation & $\underline{3,1}$ & 1,0 \\
\hline $\mathrm{Cd} 80$ & General Inflammation & 1,3 & 1,1 \\
\hline $\mathrm{Cd} 86$ & General Inflammation & 1,2 & 0,9 \\
\hline CsfF & General Inflamm. & 1,1 & 1,2 \\
\hline Cxcl10 & General Inflammation & 2,0 & $\underline{0,6}$ \\
\hline Ifng & General Inflammation & 3,3 & 0,8 \\
\hline Il18 & General Inflammation & 1,1 & 1,0 \\
\hline Il18r1 & General Inflammation & 1,1 & 0,7 \\
\hline Illb & General Inflammation & 1,6 & $\underline{0,5}$ \\
\hline I11r1 & General Inflammation & 1,8 & 1,3 \\
\hline $\mathrm{I} 11 \mathrm{r} 2$ & General Inflammation & 1,9 & 2,0 \\
\hline
\end{tabular}


Table 1 (continued)

\begin{tabular}{llll}
\hline gene & group & $\begin{array}{l}\text { TNFRns } \\
\text { vs C56BL/6 }\end{array}$ & $\begin{array}{l}\text { anti-IL10 } \\
\text { vs control }\end{array}$ \\
\hline Il6 & General Inflammation & $\underline{\mathbf{2 , 8}}$ & 0,3 \\
Il6ra & General Inflammation & 1,5 & $\underline{\mathbf{1 , 8}}$ \\
Nfkbia & General Inflammation & 1,2 & 1,0 \\
Saa1 & General Inflammation & $\underline{\mathbf{3 , 7}}$ & 1,2 \\
Stat1 & General Inflammation & 1,7 & 0,9 \\
Stat3 & General Inflammation & $\underline{\mathbf{1 , 6}}$ & 0,9 \\
Tlr2 & General Inflammation & 1,6 & 0,8 \\
Tlr4 & General Inflammation & 1,2 & 1,2 \\
Tnf & General Inflammation & $\underline{\mathbf{2 , 7}}$ & 0,7 \\
Tnfrsfla & General Inflammation & 1,2 & 1,0 \\
Tnfrsflb & General Inflammation & 1,2 & 1,4 \\
\hline
\end{tabular}

Table 1. Liver inflammatory gene expression. Table shows gene abbreviation and classification according to function. Expression is shown as fold change compared to levels of control animals. Significant changes (student t-tests), compared to control are shown bold and underlined.

Indeed, IL6 is known to induce hyperlipidemia [34]. However, our data do show that plasma TG and TC levels were lower in TNFRnsBMT mice then in WTBMT mice, arguing against increased excretion of lipids by the liver.

Moreover, we could not find any clear change in gene expression involved in liver lipid homeostasis. Therefore, any change in hepatocyte lipid metabolism that could lead to the decreased level of steatosis, may be present on the protein level. Additionally, the observed reduction in steatosis may originate from the high energy demand of the increased inflammation [35], leading to increased FA-usage for mitochondrial oxidation in the high number of inflammatory cells.

Further studies investigating the oxidation and the secretion of hepatic lipids may reveal what mechanisms are responsible for the effects observed in the performed experiments. 
Table 2: Lipid genes

\begin{tabular}{|c|c|c|c|}
\hline gene & group & $\begin{array}{l}\text { TNFRns } \\
\text { vs C56BL/6 }\end{array}$ & $\begin{array}{l}\text { anti-IL10 } \\
\text { vs control }\end{array}$ \\
\hline $\mathrm{Cd} 36$ & Lipid Uptake & 0,9 & 1,0 \\
\hline Fabp1 & Lipid Uptake & 0,6 & 0,9 \\
\hline Lipc & Lipid Uptake & $\underline{0,7}$ & 1,0 \\
\hline Lpl & Lipid Uptake & 1,1 & 0,9 \\
\hline Lrp1 & Lipid Uptake & 1,2 & 0,8 \\
\hline Slc27a1 & Lipid Uptake & 1,1 & 0,9 \\
\hline Acaa1a & lipid Oxidation and efflux & 1,0 & 0,9 \\
\hline Acox 1 & lipid Oxidation and efflux & 1,0 & 0,9 \\
\hline Cptla & lipid Oxidation and efflux & 1,2 & 0,9 \\
\hline Crot & lipid Oxidation and efflux & 0,9 & 1,0 \\
\hline Ech1 & lipid Oxidation and efflux & 0,9 & 1,0 \\
\hline Hadha & lipid Oxidation and efflux & 1,0 & 1,0 \\
\hline Mttp & lipid Oxidation and efflux & 1,1 & 1,1 \\
\hline Ppara & lipid Oxidation and efflux & 1,0 & 1,0 \\
\hline Ppard & lipid Oxidation and efflux & 1,2 & 1,0 \\
\hline Pparg & lipid Oxidation and efflux & 1,0 & 1,0 \\
\hline Fasn & Lipid Met. Synthesis & 0,5 & 1,0 \\
\hline LXRa & Lipid Met. Synthesis & 1,1 & 1,1 \\
\hline FXR & Lipid Met. Synthesis & 1,1 & 1,0 \\
\hline Scd1 & Lipid Met. Synthesis & 0,9 & 1,3 \\
\hline Srebf1 & Lipid Met. Synthesis & 1,0 & 0,9 \\
\hline Abca1 & Cholesterol efflux & 1,1 & 1,0 \\
\hline Cyp7a1 & Cholesterol efflux & 1,1 & 1,2 \\
\hline Scarb1 & Cholesterol efflux & 1,0 & 0,9 \\
\hline Adfp & Intracellular lipid distribution & 1,0 & 0,8 \\
\hline Cav1 & Intracellular lipid distribution & 0,9 & 0,9 \\
\hline Cav2 & Intracellular lipid distribution & 0,9 & 0,9 \\
\hline M6prbp1 & Intracellular lipid distribution & 1,1 & 0,9 \\
\hline Npc1 & Intracellular lipid distribution & 1,2 & 0,9 \\
\hline Idi1 & Cholesterol metabolism & 1,1 & 1,1 \\
\hline Insig2 & Cholesterol metabolism & 1,0 & 1,3 \\
\hline Cyp8b1 & Other & 1,2 & 1,2 \\
\hline
\end{tabular}

Table 2. Liver lipid gene expression. Table shows gene abbreviation and classification according to function. Expression is shown as fold change compared to levels of control animals. Significant changes (student t-tests), compared to control are shown bold and underlined. 


\section{Blocking the anti-inflammatory cytokine IL10 may inhibit steatosis in IdIIr/- mice}

Gene expression data from TNFRnsBMT mice suggested increased IL10 signaling in their livers due to regulation of IL10 and Stat3.

Therefore, we performed a pilot experiment to increase hepatic inflammation by blocking the anti-inflammatory cytokine IL10. Hereto, $\mathrm{ldll}^{-/-}$mice were injected with antibodies that neutralize IL10. Control mice were injected with PBS (vehicle). As expected, anti-inflammatory gene expression was down-regulated, as can be seen by the inhibition of two known target genes of IL10 signaling, i.e. SOCS1 and SOCS3 $[36,37]$. However, injection of IL10 neutralizing antibodies failed to increase the amount of Mac1 positive cells and pro-inflammatory gene expression, despite the well described effect of this antibody [38, 39]. A possible explanation for the lack of effect on hepatic inflammation may be that HFC induces only mild inflammation, which does not result in overt IL10 expression. In line with this possibility, we found only moderate increases of plasma SAP levels after 1 week of HFC, and no differences were observed between the groups at any time point. Therefore, any effect of neutralizing this small amount of IL10 in HFC fed $1 \mathrm{dlr}^{-/-}$mice may be too subtle to have effect on hepatic inflammation.

As was seen in TNFRnsBMT mice, anti-IL10 treatment inhibited steatosis development. It is known that SOCS-3 can up-regulate the expression of the lipogenic enzymes acyl-CoA carboxylase (ACC) and FAS via inhibition of STAT3 phosphorylation and a subsequent increase in SREBP1c expression [40]. Therefore, inhibition of this pathway via neutralizing IL10 could lower liver lipid synthesis. Unfortunately, we were unable to find transcriptional evidence for this mechanism. As the other tested lipid genes were not significantly affected by anti-IL10 treatment, the observed effect in lipid metabolism may be present on protein rather than on transcriptional level. A possible mechanism may be an increase in VLDL production and secretion from the liver, resulting in decreased liver TGs. In line with this, we found a doubling of plasma TG levels in the mice treated with antibodies against IL10. It has been previously found by Caligiuri et al. that systemic IL10 deficiency could have an effect on lipoprotein metabolism [41]. However, in that study, no differences were observed in plasma total plasma TG levels. Future experiments to measure VLDL secretion should be performed to confirm this mechanism. Moreover, although the equal plasma cholesterol levels in the groups suggest equal ingestion of the diet, we found that body weight of treated animals dropped significantly. Therefore, it remains unsure whether experimental animals consumed equal amounts of food as control animals. Pair-wise feeding of the groups may resolve this issue. Additionally, 
differences in energy utilization and activity should also be investigated in metabolic cages.

Interestingly, den Boer et al. found endogenous IL10 to be protective against dietinduced hepatic steatosis [42] without altering whole-body insulin sensitivity, a finding contradicting our data. Moreover, no effect on body weight was observed. A possible explanation for these differences is the fact that den Boer et al. used whole body IL10 deficient mice, which chronically lack IL10 from birth. Our experiments neutralize IL10 in an acute manner. Therefore, it is possible that there are compensating mechanisms that impact results in the IL10 deficient animals, which were not established yet in our experimental model due to the short time span.

It should be noted that there are some major differences between the experiments we performed (TNFRnsBMT vs anti-IL10). Differences in terms of Mac1 positive cells, steatosis level, and plasma lipids between the experiments suggest that the mechanisms lowering liver TG levels in these experimental models are different. While TNFRnsBMT animals may display a reduction in hepatic lipids due to the presence of actual inflammation, animals treated with IL10 neutralizing antibodies may be effected more by direct effects in the IL10 signaling pathway of hepatocytes rather than inflammation itself.

A final major issue remains to be addressed. A proper control was lacking for the experiment using Abs neutralizing IL10. The control group was injected with vehicle instead of an isotype control Ab. Therefore, it cannot be excluded that the lack of an effect on hepatic inflammation and the observed effects on liver lipids are due to an unexpected artifact created by the Ab itself rather than by neutralizing IL10. This could also serve as an explanation for the marked differences with the TNFRnsBMT mice in terms of liver and plasma lipids. Consequently, repeating the current experiment with a proper $\mathrm{Ab}$ control will be crucial to ensure that the effect we have observed on liver lipids is not due to the $\mathrm{Ab}$ itself instead of a biological consequence of neutralizing IL10. Additionally, repeating this experiment in the previously used APOE2ki mice will also strengthen our conclusions. The data currently described should therefore be viewed as preliminary evidence that remains to be confirmed.

\section{Conclusions}

Our current study suggests that hepatic inflammation may inhibit hepatic lipid accumulation. The current results raise some questions about the role of hepatic inflammation. Initially, any inflammatory response is initiated in an attempt to exert beneficial effects. Therefore, it is feasible that early inflammation in response to acute hepatic lipid influx assists the liver in coping with the increased metabolic stress. 
However, when this response fails to repair injury due to persistent hepatic lipid overload, this inflammatory reaction may become chronic and gradually exerts the negative effects that are known in NASH and IR. This may explain why several studies find contradicting results in terms of the relation between inflammation and steatosis, depending on which inflammatory "window" the experiments are performed. The clinical relevance of these studies remains uncertain until this issue is resolved. The final question remains whether lipid accumulation per se is detrimental, or whether steatosis becomes only a problem when chronic inflammation establishes itself.

\section{Acknowledgements}

The IL10 neutralizing antibody was kindly provided by Prof. Dr. WA Buurman.

\section{References}

1. Parekh, S. and F.A. Anania, Abnormal lipid and glucose metabolism in obesity: implications for nonalcoholic fatty liver disease. Gastroenterology, 2007. 132(6): p. 2191-207.

2. Neuschwander-Tetri, B.A. and S.H. Caldwell, Nonalcoholic steatohepatitis: summary of an AASLD Single Topic Conference. Hepatology, 2003. 37(5): p. 1202-19.

3. Day, C.P. and O.F. James, Steatohepatitis: a tale of two "hits"? Gastroenterology, 1998. 114(4): p. 842-5.

4. Day, C. and S. Saksena, Non-alcoholic steatohepatitis: Definitions and pathogenesis. J Gastroenterol Hepatol, 2002. 17 Suppl 3: p. S377-S384.

5. Shiri-Sverdlov, R., et al., Early diet-induced non-alcoholic steatohepatitis in APOE2 knock-in mice and its prevention by fibrates. J Hepatol, 2006. 44(4): p. 732-41.

6. Feingold, K.R., et al., Multiple cytokines stimulate hepatic lipid synthesis in vivo. Endocrinology, 1989. 125(1): p. 267-74.

7. Feingold, K.R., et al., The effect of diet on tumor necrosis factor stimulation of hepatic lipogenesis. Metabolism, 1990. 39(6): p. 623-32.

8. Crespo, J., et al., Gene expression of tumor necrosis factor alpha and TNF-receptors, p55 and p75, in nonalcoholic steatohepatitis patients. Hepatology, 2001. 34(6): p. 1158-63.

9. Li, Z., et al., Probiotics and antibodies to TNF inhibit inflammatory activity and improve nonalcoholic fatty liver disease. Hepatology, 2003. 37(2): p. 343-50.

10. Te Sligte, K., et al., Non-alcoholic steatohepatitis: review of a growing medical problem. Eur J Intern Med, 2004. 15(1): p. 10-21.

11. Hotamisligil, G.S., N.S. Shargill, and B.M. Spiegelman, Adipose expression of tumor necrosis factor-alpha: direct role in obesity-linked insulin resistance. Science, 1993. 259(5091): p. 87-91.

12. Leclercq, I.A., et al., Insulin resistance in hepatocytes and sinusoidal liver cells: mechanisms and consequences. J Hepatol, 2007. 47(1): p. 142-56.

13. Xanthoulea, S., et al., Tumor necrosis factor (TNF) receptor shedding controls thresholds of innate immune activation that balance opposing TNF functions in infectious and inflammatory diseases. J Exp Med, 2004. 200(3): p. 367-76.

14. Khovidhunkit, W., et al., Effects of infection and inflammation on lipid and lipoprotein metabolism: mechanisms and consequences to the host. J Lipid Res, 2004. 45(7): p. 1169-96.

15. Kitamura, K., et al., Pathogenic roles of tumor necrosis factor receptor p55-mediated signals in dimethylnitrosamine-induced murine liver fibrosis. Lab Invest, 2002. 82(5): p. 571-83.

16. Tomita, K., et al., Tumour necrosis factor alpha signalling through activation of Kupffer cells plays an essential role in liver fibrosis of non-alcoholic steatohepatitis in mice. Gut, 2006. 55(3): p. 415-24.

17. Crofton, R.W., M.M. Diesselhoff-den Dulk, and R. van Furth, The origin, kinetics, and characteristics of the Kupffer cells in the normal steady state. J Exp Med, 1978. 148(1): p. 1-17. 
18. Paradis K, B.B., Sharp HL, Rapid repopulation and maturation of Kupffer cells from the bone marrow in a murine bone marrow transplant model. Wisse E, Knoonk DL, eds. Cells of the Hepatic Sinusoid, 1989. 2(Rijswijk: Kupffer Cell Foundation): p. 410-2.

19. Barbuio, R., et al., Infliximab reverses steatosis and improves insulin signal transduction in liver of rats fed a high-fat diet. J Endocrinol, 2007. 194(3): p. 539-50.

20. De Taeye, B.M., et al., Macrophage TNF-alpha contributes to insulin resistance and hepatic steatosis in dietinduced obesity. Am J Physiol Endocrinol Metab, 2007. 293(3): p. E713-25.

21. Cai, D., et al., Local and systemic insulin resistance resulting from hepatic activation of IKK-beta and NFkappaB. Nat Med, 2005. 11(2): p. 183-90.

22. Diehl, A.M., et al., Cytokines and the pathogenesis of non-alcoholic steatohepatitis. Gut, 2005. 54(2): p. 3036.

23. Lin, H.Z., et al., Metformin reverses fatty liver disease in obese, leptin-deficient mice. Nat Med, 2000. 6(9): p. 998-1003.

24. Lawler, J.F., Jr., et al., Tumor necrosis factor-alpha stimulates the maturation of sterol regulatory element binding protein-1 in human hepatocytes through the action of neutral sphingomyelinase. J Biol Chem, 1998. 273(9): p. 5053-9.

25. Kanda, H., et al., MCP-1 contributes to macrophage infiltration into adipose tissue, insulin resistance, and hepatic steatosis in obesity. J Clin Invest, 2006. 116(6): p. 1494-505.

26. Navasa, M., et al., Regulation of microsomal triglyceride transfer protein mRNA expression by endotoxin and cytokines. J Lipid Res, 1998. 39(6): p. 1220-30.

27. Grove, R.I., et al., Macrophage-derived factors increase low density lipoprotein uptake and receptor number in cultured human liver cells. J Lipid Res, 1991. 32(12): p. 1889-97.

28. Rivera, C.A., et al., Toll-like receptor-4 signaling and Kupffer cells play pivotal roles in the pathogenesis of non-alcoholic steatohepatitis. J Hepatol, 2007. 47(4): p. 571-9.

29. Memon, R.A., C. Grunfeld, and K.R. Feingold, TNF-alpha is not the cause of fatty liver disease in obese diabetic mice. Nat Med, 2001. 7(1): p. 2-3.

30. Schnyder-Candrian, S., et al., Hepatic steatosis in the absence of tumor necrosis factor in mice. Cytokine, 2005. 32(6): p. 287-95.

31. Dela Pena, A., et al., NF-kappaB activation, rather than TNF, mediates hepatic inflammation in a murine dietary model of steatohepatitis. Gastroenterology, 2005. 129(5): p. 1663-74.

32. Hong, F., et al., Interleukin 6 alleviates hepatic steatosis and ischemia/reperfusion injury in mice with fatty liver disease. Hepatology, 2004. 40(4): p. 933-41.

33. Nelson, T.L. and M.S. Hickey, Acute changes in dietary omega-3 fatty acid intake lowers soluble interleukin6 receptor in healthy adult normal weight and overweight males. Cytokine, 2004. 26(5): p. 195-201.

34. Esteve, E., W. Ricart, and J.M. Fernandez-Real, Dyslipidemia and inflammation: an evolutionary conserved mechanism. Clin Nutr, 2005. 24(1): p. 16-31.

35. Peters, A., The energy request of inflammation. Endocrinology, 2006. 147(10): p. 4550-2.

36. Lang, R., et al., Shaping gene expression in activated and resting primary macrophages by IL-10. J Immunol, 2002. 169(5): p. 2253-63.

37. Antoniv, T.T. and L.B. Ivashkiv, Dysregulation of interleukin-10-dependent gene expression in rheumatoid arthritis synovial macrophages. Arthritis Rheum, 2006. 54(9): p. 2711-21.

38. Daemen, M.A., et al., Involvement of endogenous interleukin-10 and tumor necrosis factor-alpha in renal ischemia-reperfusion injury. Transplantation, 1999. 67(6): p. 792-800.

39. ter Steege, J.C., et al., The role of endogenous IFN-gamma, TNF-alpha and IL-10 in LPS-induced nitric oxide release in a mouse model. Cytokine, 1998. 10(2): p. 115-23.

40. Ueki, K., et al., Central role of suppressors of cytokine signaling proteins in hepatic steatosis, insulin resistance, and the metabolic syndrome in the mouse. Proc Natl Acad Sci U S A, 2004. 101(28): p. 10422-7.

41. Caligiuri, G., et al., Interleukin-10 deficiency increases atherosclerosis, thrombosis, and low-density lipoproteins in apolipoprotein E knockout mice. Mol Med, 2003. 9(1-2): p. 10-7.

42. den Boer, M.A., et al., Endogenous interleukin-10 protects against hepatic steatosis but does not improve insulin sensitivity during high-fat feeding in mice. Endocrinology, 2006. 147(10): p. 4553-8. 


\section{VII}

\section{General Discussion}


In the prize-winning documentary "Supersize me", Morgan Spurlock describes a "one man experiment" of a human subject (himself) eating a high fat regime for a period of 30 days. During this period, he was not allowed to eat anything that wasn't sold at McDonalds. Additionally, he decreased his physical activity to simulate a sedentary lifestyle. Spurlock starts the experiment in excellent physical condition. Before the experiment, most doctors predict no drastic outcome, as the human body is thought of as extremely adaptable. However, besides gaining weight, about $11 \mathrm{~kg}$ in 30 days, only 20 days of high fat feeding resulted in plasma values that are indicative of hepatic steatosis and damage, next to increased plasma lipid levels.

The documentary described above illustrates that in a relatively short time span, high fat feeding can result in dramatic changes in the body, especially in terms of body weight, plasma lipids and the liver. Although actual liver inflammation was not assessed, it shows that a severe liver phenotype may develop as early as after 20 days of high fat feeding, which is in line with the findings described in this thesis. Clearly, ethical issues hamper similar large scale studies in human subjects. Therefore, the use of mouse models is imperative for the investigation of the hepatic effects of such diets. This thesis describes the early development of non-alcoholic steatohepatitis (NASH) in a mouse model which is relatively new in this field of research, i.e. hyperlipidemic mice fed a diet enriched in triglycerides and cholesterol (HFC diet). This experimental model was the first to incorporate very early time points to study pathways involved during the early stages of NASH. Additionally, while studying the important transition to harmful steatohepatitis, dietary cholesterol was identified as a strong risk factor for the development of hepatic inflammation. Finally, the impact of early inflammation on steatosis development was investigated.

In this chapter the major findings of this thesis will be discussed in the light of the current state of the field and its clinical implications. Finally, some future perspectives, in relation to the obtained results, will be addressed.

\section{From steatosis to inflammation to steatosis}

\section{From steatosis to inflammation}

NASH has been proposed to develop via a series of hits [1]. The first of which leads to increased liver steatosis, thereby sensitizing the liver for further insults, collectively called, second hit. In this view, steatosis development is generally thought of as a prerequisite for further propagation of the disease and liver damage. In this thesis 
however, we describe how hyperlipidemic mouse models develop NASH almost immediately when fed a high fat diet. Rather than hepatic lipid accumulation, plasma cholesterol was found to directly lead to hepatic inflammation regardless of steatosis development. Collectively, our data argue against the need of a "second hit" in NASH development. Contrary, we found that cholesterol was responsible for an immediate "strike out" of the liver. Although the two-hit hypothesis is generally accepted within the field of research, the current results shed some new insights on the pathogenesis of NASH.

More specifically, in chapter 3 of this thesis, we found that high fat feeding resulted in NASH development very rapidly. Inflammation developed alongside with, rather than subsequent to, steatosis in female APOE2 knock-in (ki) mice, an unexpected finding in view of the two-hit hypothesis. These results were confirmed in chapter 5, where another female hyperlipidemic mouse model (ldlr deficient/ldlr ${ }^{-/-}$mice) displayed a similar response. Furthermore, we showed that male hyperlipidemic mice failed to develop steatosis after 7 days of high fat feeding, while they did develop an inflammatory response in the liver, thereby completely disconnecting hepatic inflammation development from steatosis. To our knowledge, up until now, hepatic inflammation has always been associated with increased liver lipids [2-5]. Other evidence also exists that argues against hepatic triglycerides (TGs) predisposing to liver inflammation: hepatic TGs have for example been found protective rather than harmful for the liver. TGs were thought to form an inert pool that may protect the liver from lipotoxicity by free fatty acids (FFAs) [6].

Chapter 5 showed that normolipidemic animals failed to develop hepatic inflammation although they developed equal levels of steatosis. When combined, these findings clearly illustrate that steatosis does not necessarily lead to the development of hepatic inflammation; moreover, it was found not to be required for the propagation of hepatic inflammation. These findings created an interesting window in which we could explore why some animals develop full NASH, while other mice develop steatosis only. This is of clinical relevance because an important hallmark of NASH is the transition from benign steatosis towards an inflamed liver. It is believed that the presence of inflammation is required for liver disease to progress towards fibrosis, cirrhosis, and subsequent liver failure and/or liver cancer [5]. However, the actual trigger that determines why some, but not most, patients with steatosis will develop NASH remains unknown.

We could thus not establish a correlation between steatosis and the development of hepatic inflammation. Alternatively, we did find a correlation between hepatic inflammation and plasma total cholesterol levels. Additional hints in the direction of cholesterol as an important risk factor for NASH were found in chapter 4. Microarray 
analysis showed the "cholesterol metabolism" pathway to be overrepresented among regulated liver gene transcripts during the early progression of NASH in APOE2ki mice.

Together, these findings led us to the hypothesis that, at least in our experimental mouse models, plasma cholesterol, and not steatosis, determines whether an inflammatory reaction establishes itself in the liver. This hypothesis was tested by an experiment where cholesterol was omitted from the HFC diet. Indeed, animals receiving this diet showed a similar response in terms of steatosis, but hepatic inflammation was completely inhibited. In this manner, the involvement of dietary cholesterol was proven. Omitting cholesterol from the diet resulted in a clear reduction of cholesterol-rich lipoproteins in the plasma, suggesting that this form of plasma cholesterol plays a major role.

The importance of alternative mechanisms rather than liver lipid accumulation per se, is gaining more interest. This is illustrated by the fact that the potential role of cholesterol in NASH development is more and more appreciated [7, 8]. Collectively, our results suggest that hyperlipidemia, and cholesterol in particular, may be an important diagnostic marker to explain why some patients develop hepatic inflammation and others do not.

Unfortunately, clinical data on the sequence of events during NASH progression and the involvement of plasma and/or dietary cholesterol are scarce. Only a few studies have shown a correlation between low density lipoprotein (LDL) conjugated dienes (as a marker for oxidized LDL) and hepatic inflammation and fibrosis development in human subjects [9]. LDL levels, possibly in modified form, were also found to be increased in NASH patients [10], confirming the clinical relevance of our findings. In addition, a recent report has shown a progressive increase of free cholesterol levels in patients with non-alcoholic fatty liver disease (NAFLD) to NASH compared to controls [11].

In search of a molecular mechanism by which plasma cholesterol induces hepatic inflammation, we observed Kupffer cells (KCs) to be increased in size, rather than in number, after high fat feeding of hyperlipidemic mouse models (chapters 3 and 5). It has been shown that depletion of KCs blunted histological evidence of steatohepatitis [12], indicating that $\mathrm{KCs}$ are of major importance for NASH development. The working hypothesis that emerged was the following: due to the increased residence time of lipoproteins in the plasma of the hyperlipidemic animals, these lipoproteins are modified (e.g. oxidized, acetylated) and subsequently scavenged by KCs in the liver. To test this hypothesis, we performed a bone marrow transplantation (BMT) experiment where irradiated $1 \mathrm{dlr}^{-/-}$animals were injected with bone marrow lacking SRA and CD36, the scavenger receptors (SR) that are known to be mostly responsible 
for modified lipoprotein uptake and foam cell formation. As hypothesized, these animals displayed less hepatic inflammation when fed the HFC diet. However, no effect on actual foam cell formation could be found (chapter 6), arguing for alternative mechanisms via which binding of modified lipoproteins to SRs could affect inflammation in the liver, which is discussed in more detail in chapter 6 . These results are interesting, as they put forward the involvement of $\mathrm{KCs}$ in triggering inflammation by scavenging modified lipoproteins, a hypothesis that is new in the field and definitively deserves more attention as it can open the door to new insights and therapeutic options.

\section{From inflammation to steatosis}

Inflammation and lipid metabolism have been described to influence each other considerably. Not only in the sense as described in the previous section, that lipids, and cholesterol in particular, can induce an inflammatory status, but also inflammation itself has been described to induce marked changes in lipid metabolism [13, 14]. As we found inflammation to be a very early player in the development of NASH in our experimental models, it was conceivable that inflammatory cells release mediators such as chemokines and cytokines in the micro-environment of the liver. Accordingly, these could have their effect on hepatic lipid metabolism and consequently on steatosis.

In general, inflammation is thought to aggravate fatty liver as several inflammatory mediators are known to increase de novo lipid synthesis and insulin resistance (IR), both of which may therefore lead to increased hepatic lipid levels [15-20]. Surprisingly, as described in chapter 7, we found an inverse correlation between hepatic inflammation and steatosis levels. To investigate whether a causal relationship existed between increased inflammation and a decrease in steatosis, we generated mouse models with increased inflammation in their livers, by using two complementary approaches. This was either done by BMT of bone marrow cells of mice with increased tumor necrosis factor (TNF) signaling to $1 \mathrm{dlr}^{-/-}$recipient mice, or by inhibiting the anti-inflammatory cytokine interleukin 10 (IL10) with neutralizing antibodies. Interestingly, we found that these models had reduced levels of liver TGs, indicating that increased inflammation may lead to decreased steatosis. The two models used in this study suggest roles for both TNF and IL10 signaling pathways in this process.

Besides being described to worsen steatosis and NASH, TNF has been identified to be identical to cachectin [21]. Cachectin was known to decrease body weight and increase plasma lipids [22], by decreasing lipoprotein lipase (LpL) activity and expression, and by increasing hormone sensitive lipase (HSL) activity and VLDL production and 
secretion [23]. Despite this catabolic function attributed to TNF, in 1993, TNF was proposed to play an important role in obesity and IR by Hotamisligil et al. [24]. These findings are now well accepted and thus attribute both anabolic and catabolic roles to TNF. The actual role that TNF plays in the development of steatosis may depend on the relative amounts of TNF that are expressed and the presence of other cytokines and hormones in the micro-environment, as proposed before [23].

Collectively, our results raise an important question. Our previous data suggested that inflammation is a very early event in the development of NASH. Therefore, it could be sensible to target inflammation in therapeutical strategies against NASH. However, the results in chapter 7 suggest inflammation to "protect" against steatosis development. On the one hand, this could lead to a protective view on inflammation in terms of lipid levels. On the other hand, it has to be kept in mind that inflammation can set the stage for fibrosis and further damage to the liver, which will lead to severe liver disease [1, 25]. Therefore, these results indicate that caution has to be applied when targeting inflammation only in treatment of NASH. In this regard, several issues remain to be resolved.

First, the central issue is whether increased steatosis per se is such a detrimental outcome when inhibiting inflammation. As a normal physiogical response to fasting, the liver is known to be able to accumulate TGs, following the increased flux of FFA derived from increased lipolysis in the adipose tissue. This response is needed for the energy demands of the body, which are regulated via the liver [26, 27]. Thus, steatosis may not be that harmful, but can be viewed as a normal physiological process. Therefore, rather than targeting steatosis only, lowering liver inflammation may be a first concern in the treatment of NASH, despite a possible increase in hepatic lipid levels.

Second, there is substantial evidence that key metabolic and immune functions have evolved from common ancestral structures, which implies that there are continuous and direct interactions between these two. The inflammatory response has evolved throughout the years as a protective mechanism against pathogens invading the body, which has led to a system equipped with a powerful, yet sometimes oversensitive immune response [28]. Given this possible evolutionary relationship between lipid metabolism and the immune system, it is conceivable that the immune system also reacts to metabolic insults. A well known example of this is the involvement of tolllike receptors (Tlrs) in FFA-induced inflammation. FAs have been found to directly activate Tlr4 signaling, consequently activating several inflammatory pathways of the innate immune system [29], possibly also in KCs [12]. Interestingly, also CD36 has been proposed to play a role in the innate immune response. This SR was shown to be 
essential to some toll-like receptor $2 / 6$ responses which induce nuclear factor kappa beta $(\mathrm{NF}-\kappa \mathrm{B})$ activation [30].

As we have shown in this thesis, the immune response to lipids can be very fast and robust. The presence of inflammation in the liver relatively early after a metabolic challenge could therefore serve as a mechanism which helps the liver coping with the lipid overload. As we have shown in chapter 7, the presence of inflammation may indeed attenuate steatosis, thereby assisting the liver during the disposal of excess lipids. However, due to a persistent overload, the once protective inflammation response may become chronic and exert its detrimental effects. Therefore, the problem may not be the response itself, but rather the persistence of the stimulus [14].

\section{How, when, where?}

The relation between lipid accumulation and hepatic inflammation in the light of the findings of this thesis is represented in figure 1 as a circle. Collectively, our data show that the current view on the sequence of events (Fig. 3 of chapter 1) may be bypassed by cholesterol (Fig. 1, from left to right), thereby leading to hepatic inflammation directly, even without being preceded by the accumulation of hepatic TGs.

It is known that inflammation can influence hepatic lipid accumulation (represented in Fig. 1 from right to left). However, the exact contribution of inflammatory mediators remains elusive, as several reports display conflicting results. While our data attribute an inhibitory role to inflammation in terms of steatosis development, several other studies have shown the opposite. It is possible that the outcome of such experiments relies heavily on the timing and the type of immune response that is affected. This possibility is nicely illustrated in an elegant experimental model where macrophages can be selectively depleted at any given moment. Depending on the timing of macrophage depletion, a mouse model of hepatic fibrosis displayed either amelioration or worsening of fibrotic lesions. Hereby, it was shown that macrophages could play distinctive roles in tissue injury and repair, even over a period as short as two days [31, 32]. In conclusion, whether going from lipid accumulation towards inflammation and subsequent NASH development, or from inflammation to lipid accumulation, the outcome may determined by how, where, and when the circle is entered. 


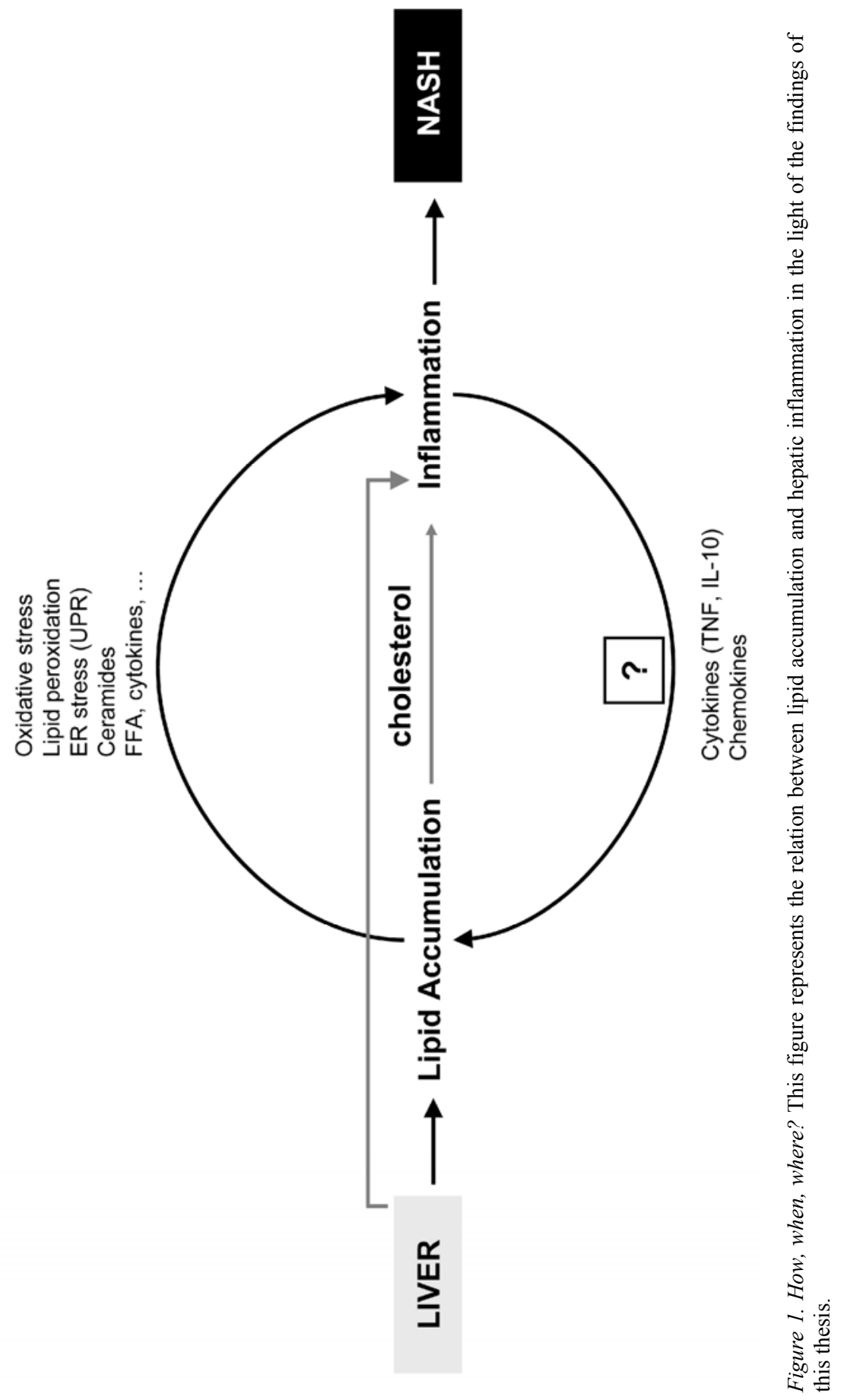




\section{Animal models of NASH}

Due to ethical issues and practical difficulties in the diagnosis of human subjects, animal models are of crucial importance to investigate the molecular pathogenesis of NASH. Animal models, and specifically mouse models, have several advantages as was extensively portrayed in chapter 2 . Until now, the most frequently used animal models of $\mathrm{NASH}$ are the $\mathrm{Ob} / \mathrm{Ob}$ mouse and mice fed methionine and choline deficient (MCD) diet. Although these animal models are very well described and widely used, they have several drawbacks, as was put forward in the introduction section.

In this thesis, we used hyperlipidemic mouse models which are fed a diet enriched in TGs, sucrose, and cholesterol. In chapter 3, we have shown that feeding APOE2ki mice a high fat diet induces both steatosis and inflammation in their livers fast. Additionally, we found another genetically modified mouse model to develop a similar phenotype, i.e. the $1 \mathrm{dlr}^{-/-}$mouse (chapter 5). The hyperlipidemic mouse models used in this thesis develop NASH when fed a diet only moderately enriched in TGs and cholesterol, resembling the diet consumed in industrialized countries. Hyperlipidemic mouse models thus elegantly incorporate elements that also occur during the natural course of NASH in human patients, like the consumption of a high caloric diet rich in fat and the subsequent consequences, like hyperlipidemia.

In chapter 3, we show that APOE2ki mice displayed increased levels of collagen A1 gene expression, which may indicate that there is activation of stellate cells [33], although fibrosis development itself has not yet been identified in these animals. The lack of fibrosis in this animal model is not necessarily a disadvantage, as in human subjects there is also no fibrosis development during the early stages of NASH. MCD diet induces fibrosis relatively rapid in mice [34]. Therefore, hyperlipidemic mouse models may have an extra advantage particularly in the study of the early stages of NASH.

Interestingly, we found in chapter 5 that inflammation was present in the liver even before there was detectable steatosis. These mice may thus be of particular interest to further study the contribution of early inflammation to NASH development as inflammation actually precedes steatosis. Additionally, it has been shown that male mice develop obesity and IR more easily than female mice $[35,36]$, and that APOE2ki mice do not develop obesity and IR, thereby uncoupling NASH development from these conditions in this model [37]. Contrary, $1 \mathrm{~d} l \mathrm{r}^{-/-}$mice do develop glucose intolerance on a diet similar to the one used in our study [8]. These differences between gender and strain open interesting opportunities to delineate additional risk factors for the development of NASH and IR. 


\section{Clinical implications of the results}

\section{Atherosclerosis}

The liver is a known source of plasma inflammatory markers in response to the diet. In line with our results, it has been shown that liver-derived inflammatory markers, such as $\mathrm{c}$ reactive protein 1 (CRP1) and serum amyloid A (SAA), are augmented in the plasma after only a few days of high fat feeding [38]. These inflammatory proteins may contribute to an increased inflammatory status. Inflammation is known to be of major importance for the development of atherosclerosis.

As was reviewed in chapter 2, the hyperlipidemic models used in this thesis are known for their contribution to the research field of atherosclerosis. Hypercholesterolemia itself may predispose to foam cell formation in the vessel wall on the one hand, but also may lead to a very early pro-inflammatory status in the body, originating from the NASH development, on the other hand. In line with this, an increased incidence of cardiovascular disease (CVD) was found in patients with type 2 diabetes and NASH [39]. The presence of NASH early during the pathogenesis of CVD may thus be more important than currently envisioned. Supporting this view, it has been shown that circulating CRP levels are able to accelerate atherosclerosis development [40]. Moreover, it has been recently shown that hepatic IR, which may originate from $\mathrm{NASH}$, is sufficient to produce an atherogenic lipoprotein profile and increased susceptibility to atherosclerosis [41].

\section{Diagnosis of NASH}

As was described in the introduction, NAFLD patients usually remain asymptomatic, unless cirrhosis is present [42]. Therefore, evaluation of patients with possible NAFLD or NASH mainly includes assessment of features of the metabolic syndrome (MetS), which are all associated with these liver disorders [43]. Additional criteria are mostly based on the levels of liver enzymes in the plasma. However, these tests have been shown not to be very specific. The gold standard for the diagnosis of NASH is taking a liver biopsy, as it is the only reliable method for diagnosing, staging and grading of $\mathrm{NASH}$. However, it is an invasive procedure which is not pleasant for the patient, not suitable for routine use, and is not completely without risk [43]. Non-invasive procedures, like magnetic resonance imaging (MRI), are non-quantitative and fail to detect the presence of inflammation consistently in steatohepatitis [5].

The identification of cholesterol as a potent risk factor for the development of hepatic inflammation may contribute to the regular criteria of MetS to identify patients at risk 
that are in need of a liver biopsy, in combination with the current features of MetS. Additional to some existing clinical studies that report correlations between cholesterol and hepatic inflammation and/or fibrosis [9, 10, 44], the value of plasma cholesterol as a diagnostic predictor of hepatic inflammation needs to be investigated in greater detail and in human subjects.

\section{Treatment of NASH}

Until now, features of NASH can not be targeted directly, making treatment options limited. Therefore, treatment of NASH depends largely on reducing body weight and other components of MetS [5, 45], like hypertriglyceridemia, IR and type 2 diabetes.

Thiazolidinediones (TZDs) have been widely used to treat type 2 diabetes and some reports about their efficiency for NASH treatment have been published [46, 47]. However, the efficacy of TZDs against NASH remains unclear. Despite some promising results, a recent report showed a 10-fold increase in hepatic TG content upon treatment of $\mathrm{Ob} / \mathrm{Ob}$ mice with rosiglitazone [48]. Moreover, it has been shown that any beneficial effect was not sustained in human subjects after discontinuation of the treatment with TZDs [49]. Additionally, contributing to the debate on the use of TZDs, it was recently claimed that patients receiving TZDs to treat type 2 diabetes are at increased risk of developing congestive heart failure and subsequent cardiovascular death [50-52], which has started an intense debate on TZD safety [53]. Collectively, there is a clear deficiency in large-scale, well-controlled double blind clinical studies that show clear effects in ameliorating NASH. Moreover, there are many contradictive reports, which argue against large-scale use of TZDs to treat $\mathrm{NASH}$, indicating the need for alternative strategies. Additionally, NASH itself, i.e. hepatic lipid accumulation, inflammation, and fibrosis, is impossible to target locally. Treatment mainly focuses on systemic abnormalities, linked to MetS.

Agonists of peroxisome proliferator activated receptor alpha (PPAR $\alpha$ ) have been used for several years for the treatment of dyslipidemia, especially hypertriglyceridemia and in combination with statins [54]. Several reports, including in this thesis, have shown that fenofibrate, a potent activator of PPAR $\alpha$ inhibits NASH development (chapter 3 and chapter 4). Additionally, $\operatorname{PPAR} \alpha$ agonists have been shown to reverse the development of NASH in mice [34]. The applicability of these agonists in the treatment of NASH in human subjects has not been intensively studied, although it has been suggested that they might be useful [54]. Notably, in chapter 4 we found that PPAR $\alpha$ activation inhibited the inflammatory response via inhibition of NF- $\kappa B$, rather than activating protein 1 (AP-1). In contrast, we found that AP-1 target genes, mostly known tumour promoter genes, were induced. However, this response is not present in 
humans, where PPAR $\alpha$ activation also leads to down-regulation of AP-1 target genes [55]. On a further note, no increased risk of liver cancer has been reported in mice with human PPAR $\alpha[56,57]$. This effect is partially due to the fact that humans only express $5 \%$ to $10 \%$ of the amount of PPAR $\alpha$ in their livers compared to mice [58] and due to structural differences between human and murine PPAR $\alpha$ [56, 57].

From human studies, fibrates appeared to be relatively safe, with some minor side effects including muscle toxicity, increased plasma creatine levels, and increased plasma homocysteine levels [59]. From the tested fibrates, fenofibrate appears to elicit the fewest side effects in combination with statins [60]. However, a report of the FIELD (fenofibrate intervention and event lowering in diabetes) study indicated that fenofibrate effects on clinical outcome was less than expected [61]. Other fibrates were shown to be more cardioprotective, in particular gemfibrozil, in patients with elevated plasma TG levels or other components of MetS [60]. NASH is often associated with several aspects of MetS; therefore the applicability of fenofibrate and other PPAR $\alpha$ agonists as a treatment for NASH should be investigated in further detail.

The findings of this thesis that identify plasma cholesterol as a possible cause of hepatic inflammation, indicate that existing cholesterol-lowering strategies may be effective to treat at least the inflammatory component of NASH. Indeed, a recent prospective, non-randomized and uncontrolled study showed some promising results. The HMG-CoA reductase inhibitor atorvastatin was found to be efficient in the treatment of dyslipidemia- and hypertension-associated NASH in human subjects, by improving both biochemical parameters, steatosis and inflammation [62]. However, this study failed to identify an improvement of ongoing fibrosis. Other reports also report atorvastatin to be effective and safe in NASH patients with hyperlipidemia [63, 64]. In addition to its cholesterol-lowering abilities, statins possess direct antiinflammatory effects, as was shown in apoe ${ }^{-/-}$mice, in which cholesterol levels do not respond to statin treatment [65].

Finally, as described in the introduction of this thesis, weight loss remains currently the most effective in the battle against NASH. Bariatric surgery has been shown to be very effective as it improves hepatic features in all patients [5]. However, this procedure is very invasive, and therefore not pleasant for the patient and not without risk. Currently, techniques are being developed that bypass the first part of the small intestine, which inhibits food to be digested properly. This duodenal-jejunal bypass sleeve can be delivered to the patient in an endoscopic manner, reducing discomfort and risk for the patient [66].

Despite the current advances in achieving weight loss via surgical procedures, although probably less effective $[67,68]$, weight loss via a modified diet should remain the first 
option. The current findings can also be of importance for determining the choice of diet that is used to achieve weight loss. For example, the Atkins diet, which focuses on high-protein and high-fat intakes and extremely low carbohydrate intakes, has been shown to induce significant weight loss. However, probably due to ad libitum fat intake, people on this diet were shown to have increased plasma cholesterol levels, including increased LDL levels [69]. Therefore, this diet may not be suitable in order to reduce ones risk to develop hepatic inflammation. Several other diets do reduce plasma cholesterol together with body weight [70]. Thus, diets should be specifically selected for their ability to lower plasma cholesterol, rather than on their effect on body weight alone.

\section{Future perspectives}

Research almost always gives rise to additional questions and new opportunities. This thesis is not different and raised some interesting issues and questions for further studies. Both mechanistically and clinically, there are several issues that remain elusive.

First, the mechanism by which cholesterol causes inflammation very early is only partially resolved. In chapter 6 , we have shown that the scavenger receptors SRA and CD36 are probably part of the picture. Since we could not find a complete inhibition of hepatic inflammation, suggesting that other mechanisms also contribute to hepatic inflammation in the performed experiment. Next to the uptake of cholesterol, mechanisms known to be involved in intracellular cholesterol transport and efflux can be investigated. Interesting targets are ATP binding cassette (ABC) transporters, more specifically $\mathrm{ABC}-\mathrm{A} 1$ and $\mathrm{ABC}-\mathrm{G} 1$. These are known to be expressed by macrophages and together, they account for the majority of cholesterol efflux [71, 72]. Macrophages lacking these receptors are known to accumulate intracellular cholesterol and may contribute to hepatic inflammation, in a process similar to atherosclerosis. It was shown that macrophages lacking both these transporters displayed increased inflammation and aggravated atherosclerosis development [73].

Second, as a lot of discussion exists about the precise role of inflammation during steatosis and NASH development, it is interesting to determine whether there are differences in early, potentially "protective" inflammation and late, chronic inflammation. An emerging concept is the existence of different populations of macrophages, so called "classically activated" M1 macrophages, and "alternatively activated" M2 macrophages. While M1 macrophages propogate inflammatory responses and secrete pro-inflammatory cytokines, M2 macrophages promote tissue repair and secrete more anti-inflammatory cytokines. As the molecular signature of 
these subsets can differ dramatically [74], they may have distinct effects on liver function. It has been shown that dietary factors are able to alter the hepatic immune system in mice with NALFD [75], indicating the potential function of macrophage polarization in response to dietary insults.

Third, it has to kept in mind that the body does not solely consist out of liver. Therefore, it will be crucial to link NASH development in our mouse models to events in other parts of the organism. A primary candidate is the adipose tissue, as this is the most important lipid depot and an important player in MetS. A major question to be addressed is whether the fat also reacts similar to the high fat feeding in concert with the liver in terms of inflammation or whether it lags behind. Adipose tissue is a dynamic structure which is capable of releasing many mediators important for the development of steatosis and hepatic inflammation. Next to the release of FFA into the plasma, which contributes directly to hepatic lipid accumulation, adipose tissue is an endocrine organ. Several of the molecules known to be excreted by adipose tissue have been shown to influence different stages of NASH development, such as TNF, IL6 adiponectin, leptin, and resistin [76].

Furthermore, as the mouse models used in our study are known for their atherogenic properties, the possible contribution of early hepatic inflammation to atherosclerosis development should be investigated.

Finally, several clinical studies can be envisioned in light of our results. Although there were some indications that plasma cholesterol and LDL levels correlate with the degree of hepatic inflammation and fibrosis, larger association studies are surely needed to determine the importance of our findings in human patients. Because only steatosis, but not hepatic inflammation is readily detectable with non-invasive methods, such as MRI, measuring plasma LDL cholesterol may prove to become an important diagnostic criterium. Such tests may help to determine what people are at risk for the development of hepatic inflammation and would consequently benefit of taking a liver biopsy to determine their stage of NASH. Moreover, such an association should automatically lead to large clinical trials investigating the efficacy of cholesterol-lowering drugs, such as statins, against NASH. As the safety of this class of drugs is established and several different analogues are already on the market, this may rapidly lead to treatments against NASH. The same holds true for PPAR $\alpha$ agonists, which have already been used in a clinical setting, but may reveal to be beneficial for NASH treatment, possibly in combination with statins.

\section{References}

1. Day, C.P. and O.F. James, Steatohepatitis: a tale of two "hits"? Gastroenterology, 1998. 114(4): p. 842-5. 
2. Matsuzawa, N., et al., Lipid-induced oxidative stress causes steatohepatitis in mice fed an atherogenic diet. Hepatology, 2007.

3. Anstee, Q.M. and R.D. Goldin, Mouse models in non-alcoholic fatty liver disease and steatohepatitis research. Int J Exp Pathol, 2006. 87(1): p. 1-16.

4. London, R.M. and J. George, Pathogenesis of NASH: animal models. Clin Liver Dis, 2007. 11(1): p. 55-74, viii.

5. Parekh, S. and F.A. Anania, Abnormal lipid and glucose metabolism in obesity: implications for nonalcoholic fatty liver disease. Gastroenterology, 2007. 132(6): p. 2191-207.

6. Yamaguchi, K., et al., Inhibiting triglyceride synthesis improves hepatic steatosis but exacerbates liver damage and fibrosis in obese mice with nonalcoholic steatohepatitis. Hepatology, 2007. 45(6): p. 1366-74.

7. Mari, M., et al., Mitochondrial free cholesterol loading sensitizes to TNF- and Fas-mediated steatohepatitis. Cell Metab, 2006. 4(3): p. 185-98.

8. Joven, J., et al., The results in rodent models of atherosclerosis are not interchangeable The influence of diet and strain. Atherosclerosis, 2007.

9. Gambino, R., et al., Polymorphism in microsomal triglyceride transfer protein: a link between liver disease and atherogenic postprandial lipid profile in NASH? Hepatology, 2007. 45(5): p. 1097-107.

10. Koruk, M., et al., Serum lipids, lipoproteins and apolipoproteins levels in patients with nonalcoholic steatohepatitis. J Clin Gastroenterol, 2003. 37(2): p. 177-82.

11. Puri, P., et al., A lipidomic analysis of nonalcoholic fatty liver disease. Hepatology, 2007. 46(4): p. 1081-90.

12. Rivera, C.A., et al., Toll-like receptor-4 signaling and Kupffer cells play pivotal roles in the pathogenesis of non-alcoholic steatohepatitis. J Hepatol, 2007. 47(4): p. 571-9.

13. Khovidhunkit, W., et al., Effects of infection and inflammation on lipid and lipoprotein metabolism: mechanisms and consequences to the host. J Lipid Res, 2004. 45(7): p. 1169-96.

14. Esteve, E., W. Ricart, and J.M. Fernandez-Real, Dyslipidemia and inflammation: an evolutionary conserved mechanism. Clin Nutr, 2005. 24(1): p. 16-31.

15. Li, Z., et al., Probiotics and antibodies to TNF inhibit inflammatory activity and improve nonalcoholic fatty liver disease. Hepatology, 2003. 37(2): p. 343-50.

16. Barbuio, R., et al., Infliximab reverses steatosis and improves insulin signal transduction in liver of rats fed a high-fat diet. J Endocrinol, 2007. 194(3): p. 539-50.

17. De Taeye, B.M., et al., Macrophage TNF-alpha contributes to insulin resistance and hepatic steatosis in dietinduced obesity. Am J Physiol Endocrinol Metab, 2007. 293(3): p. E713-25.

18. Diehl, A.M., et al., Cytokines and the pathogenesis of non-alcoholic steatohepatitis. Gut, 2005. 54(2): p. $303-$ 6.

19. Lin, H.Z., et al., Metformin reverses fatty liver disease in obese, leptin-deficient mice. Nat Med, 2000. 6(9): p. 998-1003.

20. Lawler, J.F., Jr., et al., Tumor necrosis factor-alpha stimulates the maturation of sterol regulatory element binding protein-1 in human hepatocytes through the action of neutral sphingomyelinase. J Biol Chem, 1998. 273(9): p. 5053-9.

21. Beutler, B. and A. Cerami, Cachectin and tumour necrosis factor as two sides of the same biological coin. Nature, 1986. 320(6063): p. 584-8.

22. Cerami, A., et al., Weight loss associated with an endotoxin-induced mediator from peritoneal macrophages: the role of cachectin (tumor necrosis factor). Immunol Lett, 1985. 11(3-4): p. 173-7.

23. Spiegelman, B.M. and G.S. Hotamisligil, Through thick and thin: wasting, obesity, and TNF alpha. Cell, 1993. 73(4): p. 625-7.

24. Hotamisligil, G.S., N.S. Shargill, and B.M. Spiegelman, Adipose expression of tumor necrosis factor-alpha: direct role in obesity-linked insulin resistance. Science, 1993. 259(5091): p. 87-91.

25. Angulo, P. and K.D. Lindor, Non-alcoholic fatty liver disease. J Gastroenterol Hepatol, 2002. 17 Suppl: p. S186-90.

26. Seitz, H.J., et al., Coordinate control of intermediary metabolism in rat liver by the insulin/glucagon ratio during starvation and after glucose refeeding. Regulatory significance of long-chain acyl-CoA and cyclic AMP. Arch Biochem Biophys, 1977. 183(2): p. 647-63.

27. Hashimoto, T., et al., Defect in peroxisome proliferator-activated receptor alpha-inducible fatty acid oxidation determines the severity of hepatic steatosis in response to fasting. J Biol Chem, 2000. 275(37): p. 28918-28.

28. Hotamisligil, G.S., Inflammation and metabolic disorders. Nature, 2006. 444(7121): p. 860-7.

29. Shi, H., et al., TLR4 links innate immunity and fatty acid-induced insulin resistance. J Clin Invest, 2006. 116(11): p. 3015-25.

30. Hoebe, K., et al., CD36 is a sensor of diacylglycerides. Nature, 2005. 433(7025): p. 523-7. 
31. Duffield, J.S., et al., Selective depletion of macrophages reveals distinct, opposing roles during liver injury and repair. J Clin Invest, 2005. 115(1): p. 56-65.

32. Friedman, S.L., Mac the knife? Macrophages- the double-edged sword of hepatic fibrosis. J Clin Invest, 2005. 115(1): p. 29-32.

33. Friedman, S.L., Seminars in medicine of the Beth Israel Hospital, Boston. The cellular basis of hepatic fibrosis. Mechanisms and treatment strategies. N Engl J Med, 1993. 328(25): p. 1828-35.

34. Ip, E., et al., Administration of the potent PPARalpha agonist, Wy-14,643, reverses nutritional fibrosis and steatohepatitis in mice. Hepatology, 2004. 39(5): p. 1286-96.

35. Agardh, C.D., et al., Long-standing hyperglycemia in C57BL/6J mice does not affect retinal glutathione levels or endothelial/pericyte ratio in retinal capillaries. J Diabetes Complications, 2000. 14(3): p. 146-53.

36. Tortoriello, D.V., J. McMinn, and S.C. Chua, Dietary-induced obesity and hypothalamic infertility in female DBA/2J mice. Endocrinology, 2004. 145(3): p. 1238-47.

37. Hennuyer, N., et al., PPARalpha, but not PPARgamma, activators decrease macrophage-laden atherosclerotic lesions in a nondiabetic mouse model of mixed dyslipidemia. Arterioscler Thromb Vasc Biol, 2005. 25(9): p. $1897-902$.

38. Tannock, L.R., et al., Cholesterol feeding increases C-reactive protein and serum amyloid A levels in lean insulin-sensitive subjects. Circulation, 2005. 111(23): p. 3058-62.

39. Targher, G., et al., Increased prevalence of cardiovascular disease in Type 2 diabetic patients with nonalcoholic fatty liver disease. Diabet Med, 2006. 23(4): p. 403-9.

40. Paul, A., et al., C-reactive protein accelerates the progression of atherosclerosis in apolipoprotein E-deficient mice. Circulation, 2004. 109(5): p. 647-55.

41. Biddinger, S.B., et al., Hepatic insulin resistance is sufficient to produce dyslipidemia and susceptibility to atherosclerosis. Cell Metab, 2008. 7(2): p. 125-34.

42. Mofrad, P., et al., Clinical and histologic spectrum of nonalcoholic fatty liver disease associated with normal ALT values. Hepatology, 2003. 37(6): p. 1286-92.

43. Delgado, J.S., Evolving trends in nonalcoholic fatty liver disease. Eur J Intern Med, 2008. 19(2): p. $75-82$.

44. Singh, D.K., et al., Independent Predictors of Steatohepatitis and Fibrosis in Asian Indian Patients with NonAlcoholic Steatohepatitis. Dig Dis Sci, 2007.

45. Luyckx, F.H., P.J. Lefebvre, and A.J. Scheen, Non-alcoholic steatohepatitis: association with obesity and insulin resistance, and influence of weight loss. Diabetes Metab, 2000. 26(2): p. 98-106.

46. Belfort, R., et al., A placebo-controlled trial of pioglitazone in subjects with nonalcoholic steatohepatitis. $\mathrm{N}$ Engl J Med, 2006. 355(22): p. 2297-307.

47. Juurinen, L., et al., Rosiglitazone Reduces Liver Fat and Insulin Requirements While Improving Hepatic Insulin Sensitivity And Glycemic Control In Patients With Type 2 Diabetes Requiring High Insulin Doses. J Clin Endocrinol Metab, 2007.

48. Garcia-Ruiz, I., et al., Effects of rosiglitazone on the liver histology and mitochondrial function in ob/ob mice. Hepatology, 2007. 46(2): p. 414-23.

49. Lutchman, G., et al., The effects of discontinuing pioglitazone in patients with nonalcoholic steatohepatitis. Hepatology, 2007. 46(2): p. 424-9.

50. Lago, R.M., P.P. Singh, and R.W. Nesto, Congestive heart failure and cardiovascular death in patients with prediabetes and type 2 diabetes given thiazolidinediones: a meta-analysis of randomised clinical trials. Lancet, 2007. 370(9593): p. 1129-36.

51. Lipscombe, L.L., et al., Thiazolidinediones and cardiovascular outcomes in older patients with diabetes. Jama, 2007. 298(22): p. 2634-43.

52. Singh, S., Y.K. Loke, and C.D. Furberg, Thiazolidinediones and heart failure: a teleo-analysis. Diabetes Care, 2007. 30(8): p. 2148-53.

53. Cleland, J.G. and S.L. Atkin, Thiazolidinediones, deadly sins, surrogates, and elephants. Lancet, 2007. 370(9593): p. 1103-4.

54. Zambon, A. and K. Cusi, The role of fenofibrate in clinical practice. Diab Vasc Dis Res, 2007. 4 Suppl 3: p. S15-20.

55. Delerive, P., et al., Peroxisome Proliferator-activated Receptor alpha Negatively Regulates the Vascular Inflammatory Gene Response by Negative Cross-talk with Transcription Factors NF-kappa B and AP-1. J. Biol. Chem., 1999. 274(45): p. 32048-32054.

56. Morimura, K., et al., Differential susceptibility of mice humanized for peroxisome proliferator-activated receptor alpha to Wy-14,643-induced liver tumorigenesis. Carcinogenesis, 2006. 27(5): p. 1074-80.

57. Cheung, C., et al., Diminished hepatocellular proliferation in mice humanized for the nuclear receptor peroxisome proliferator-activated receptor alpha. Cancer Res, 2004. 64(11): p. 3849-54. 
58. Holden, P.R. and J.D. Tugwood, Peroxisome proliferator-activated receptor alpha: role in rodent liver cancer and species differences. J Mol Endocrinol, 1999. 22(1): p. 1-8.

59. Rubenstrunk, A., et al., Safety issues and prospects for future generations of PPAR modulators. Biochim Biophys Acta, 2007. 1771(8): p. 1065-81.

60. Barter, P.J. and K.A. Rye, Is there a role for fibrates in the management of dyslipidemia in the metabolic syndrome? Arterioscler Thromb Vasc Biol, 2008. 28(1): p. 39-46.

61. Keech, A., et al., Effects of long-term fenofibrate therapy on cardiovascular events in 9795 people with type 2 diabetes mellitus (the FIELD study): randomised controlled trial. Lancet, 2005. 366(9500): p. 1849-61.

62. Georgescu, E.F. and M. Georgescu, Therapeutic options in non-alcoholic steatohepatitis (NASH). Are all agents alike? Results of a preliminary study. J Gastrointestin Liver Dis, 2007. 16(1): p. 39-46.

63. Hatzitolios, A., et al., Efficacy of omega-3 fatty acids, atorvastatin and orlistat in non-alcoholic fatty liver disease with dyslipidemia. Indian J Gastroenterol, 2004. 23(4): p. 131-4.

64. Kiyici, M., et al., Ursodeoxycholic acid and atorvastatin in the treatment of nonalcoholic steatohepatitis. Can J Gastroenterol, 2003. 17(12): p. 713-8.

65. Wang, Y.X., et al., Anti-atherosclerotic effect of simvastatin depends on the presence of apolipoprotein E. Atherosclerosis, 2002. 162(1): p. 23-31.

66. Gersin, K.S., et al., Duodenal- jejunal bypass sleeve: a totally endoscopic device for the treatment of morbid obesity. Surg Innov, 2007. 14(4): p. 275-8.

67. Yanovski, S.Z. and J.A. Yanovski, Obesity. N Engl J Med, 2002. 346(8): p. 591-602.

68. Wadden, T.A., et al., Dieting and the development of eating disorders in obese women: results of a randomized controlled trial. Am J Clin Nutr, 2004. 80(3): p. 560-8.

69. Foster, G.D., et al., A randomized trial of a low-carbohydrate diet for obesity. N Engl J Med, 2003. 348(21): p. 2082-90.

70. Zivkovic, A.M., J.B. German, and A.J. Sanyal, Comparative review of diets for the metabolic syndrome: implications for nonalcoholic fatty liver disease. Am J Clin Nutr, 2007. 86(2): p. 285-300.

71. Out, R., et al., Combined deletion of macrophage ABCA1 and ABCG1 leads to massive lipid accumulation in tissue macrophages and distinct atherosclerosis at relatively low plasma cholesterol levels. Arterioscler Thromb Vasc Biol, 2008. 28(2): p. 258-64.

72. Out, R., et al., Coexistence of foam cells and hypocholesterolemia in mice lacking the ABC transporters $\mathrm{A} 1$ and G1. Circ Res, 2008. 102(1): p. 113-20.

73. Yvan-Charvet, L., et al., Combined deficiency of ABCA1 and ABCG1 promotes foam cell accumulation and accelerates atherosclerosis in mice. J Clin Invest, 2007. 117(12): p. 3900-8.

74. Martinez, F.O., et al., Transcriptional profiling of the human monocyte-to-macrophage differentiation and polarization: new molecules and patterns of gene expression. J Immunol, 2006. 177(10): p. 7303-11.

75. Li, Z., M.J. Soloski, and A.M. Diehl, Dietary factors alter hepatic innate immune system in mice with nonalcoholic fatty liver disease. Hepatology, 2005. 42(4): p. 880-5.

76. Rector, R.S., et al., Non-alcoholic fatty liver disease and the metabolic syndrome: An update. World J Gastroenterol, 2008. 14(2): p. 185-92. 
- 170 - 


\section{Summary/ Samenvatting}




\section{Summary}

In chapter 1, NASH was introduced as the hepatic consequence of the metabolic syndrome. It consists of the hepatic accumulation of lipids accompanied by an inflammatory response. As described in the two-hit hypothesis, NASH is thought to develop via a series of hits of which the first consists of the excessive accumulation of lipids in hepatocytes. This first hit sensitizes the liver for a second hit, which would susequently lead to an inflammatory response in the liver. Once this inflammation is established, the disease readily progresses to more advanced stages, including fibrosis, cirrhosis, liver failure and possibly liver cancer. Although several processes have been identified to occur during the development of liver inflammation, the exact trigger(s) that induces liver inflammation and worsen disease outcome remains to be identified. In this thesis, we used hyperlipidemic mouse models to investigate the early pathogenesis of NASH. The mouse models used are described in detail in chapter 2 . These models are based on mutations in genes that have been found to be directly involved in hyperlipidemia and atherosclerosis risk, i.e. the low density lipoprotein receptor (LDLR) and apolipoprotein E (APOE). Chapter 2 compares the different models and their use in atherosclerosis research, as this is the field of research where they were mostly used up to date. It becomes clear that every model has its particular advantages and disadvantages and that the choice of model should depend of the type of information that is desired. For example, although the ApoE deficient mouse has been primarily used for atherosclerosis studies, the use of these mice is not suitable to test certain hypothesis. Because these mice do not respond to several lipid-lowering drugs, such as statins and fibrates, other mouse models should be preferably used.

Next, in chapter 3, we described how one of the described hyperlipidemic mouse models, i.e. the APOE2 knock-in mouse, develops NASH very rapidly when fed a diet enriched in triglycerides and cholesterol. By combining histological and biochemical approaches with large scale gene expression analysis, we revealed that inflammation was present much earlier than could be explained by the two-hit model. Macrophage infiltration and inflammatory gene expression was already present after only two days of high fat feeding, and it progressed at an higher rate than lipid accumulation. This suggested that inflammation plays a more important role in the early development of NASH than previously assumed. Furthermore, we showed that fenofibrate, a synthetic agonist of peroxisome proliferater activated receptor alpha (PPAR $\alpha$ ), could inhibit NASH development when supplemented to the high fat diet.

To unravel the exact mechanisms how NASH was induced by diet and inhibited by fenofibrate supplementation, hepatic gene expression changes during progression and inhibition of NASH were studied in further detail in chapter 4. Using specialized 
software that clusters genes according to their occurrence in literature, we aimed to identify pathways that were essential in these processes. We found two major pathways to be of particular importance during the progression and inhibition of diet-induced NASH: i.e. cholesterol metabolism and inflammation. Changes in cholesterol metabolism were probably induced by negative feedback mechanisms induced by increased hepatic cholesterol content. Fenofibrate normalized cholesterol metabolism decreasing the hepatic content of cholesterol and its precursors. Surprisingly, fenofibrate inhibited inflammation probably by interfering with NF- $\mathrm{B}$, while upregulating pathways around AP-1.

The link between cholesterol and inflammation was firmly established in chapter 5 . We were able to show that dietary cholesterol directly leads to hepatic inflammation. In this chapter, we compared the response high fat, high cholesterol feeding in different mouse models. In addition to the previously used APOE2ki mice, we used ldlr deficient mice as a hypercholesterolemic model that originates from a different mutation. Surprisingly, we found that normolipidemic wild-type mice did not develop hepatic inflammation while they did develop steatosis. Contrary, both used female hyperlipidemic mouse models, i.e. APOE2ki mice and ldlr knock-out mice, developed steatosis accompanied with inflammation. Clearly, steatosis does not necessarily lead to hepatic inflammation. Furthermore, we established that in male mice, hepatic increases of inflammatory cells could be induced even without the presence steatosis, clearly dissociating the development of hepatic lipid accumulation from hepatic inflammation. In search of the causal factor of the development of inflammation, we found that only diet-induced hypercholesterolemia correlated with the presence of inflammation. In addition, we found bloated 'foamy' Kupffer cells in these mice, filled with lipid droplets and cholesterol crystals. To test whether a causal relationship was present between the consumption of cholesterol and inflammation in the liver, we compared the response of the used mouse models to the same diet without cholesterol added. This resulted in a clear diminishing of plasma VLDL and LDL levels and a complete inhibition of hepatic inflammation and in the absence of bloated Kupffer cells. These important findings indicate that dietary cholesterol, possibly in the form of modified plasma lipoproteins, is an important risk factor to develop hepatic inflammation. Our results led to the hypothesis that hyperlipidemic mice display an increase of modified plasma lipoproteins upon high cholesterol feeding that leads to an increased clearance by Kupffer cells. Kupffer cells may get subsequently activated and initiate an inflammatory response.

Subsequently, in chapter 6, we investigated whether uptake of modified lipoproteins by Kupffer cells is indeed the mechanism by which inflammation is initialized in hyperlipidemic mice. Two scavenger receptors are known to be important for the 
majority of the uptake of modified lipoproteins by macrophages, i.e. SR-A and CD36. With the technique of bone marrow transplantation were created animals that lack these two scavenger receptors in their immune cells. This led to deficiency of both scavenger receptors in hepatic immune cells, i.e. Kupffer. When challenged with a high fat diet, we found a significant decrease, but no inhibition, in the development of inflammation in the animals with SR-1 and CD36 deficient Kupffer cells. Surprisingly, foam cell formation remained unaffected, indicating that this is not the mechanism by which inflammation was inhibited. These results indicate that these scavenger receptors play important roles during hepatic inflammation development, although the exact mechanism remains to be determined.

In chapter 7 we hypothesized that the presence of inflammation this early during NASH development may influence the further course of the disease. The mouse models previously used were compared with wild-type mice in terms of their response to long term high fat feeding. Interestingly, an inverse correlation was found between the presence of hepatic inflammation and the degree of liver lipid accumulation. To investigate whether increased inflammation was causal for the lower steatosis levels, we created animals with high hepatic inflammation. This was done with bone marrow transplantation of ldlr-/- mice with bone marrow of hyper-inflammatory TNF receptor non-sheddable mice, which display increased TNF signaling. These animals displayed a doubling of hepatic inflammation and a significant decrease in steatosis levels. Even without affecting hepatic inflammation directly, we observed an inhibition of steatosis in mice that were injected with antibodies neutralizing the anti-inflammatory cytokine IL10.

In the final chapter, the main results of this thesis are discussed and placed in the current state of the field. Moreover, future applications are discussed. In conclusion, this thesis shows that cholesterol is an important risk factor for the development of hepatic inflammation. Moreover, in contrast to the currently believed two-hit hypothesis, cholesterol was shown to directly lead to hepatic inflammation, disregarding the presence of a first hit, thereby serving as a direct "strikeout" of the liver. 


\section{Samenvatting}

In hoofdstuk 1 werd NASH voorgesteld als het gevolg in de lever van het metabool syndroom. Deze aandoening bestaat uit de opstapeling van vetten in levercellen gecombineerd met een ontstekingsreactie. Zoals is beschreven in de "twee-hit hypothese", wordt er momenteel gedacht dat NASH ontstaat uit een opeenvolging van gebeurtenissen of 'hits'. De eerste hit bestaat uit een overmatige opeenstapeling van vetten in de levercellen. Deze gebeurtenis maakt de lever gevoeliger voor verdere schade, oftewel een tweede hit die een ontsteking in de lever veroorzaakt. De aanwezigheid hiervan zorgt ervoor dat de aandoening verergert. Mogelijke gevolgen hiervan zijn: bindweefselvorming (fibrose), verstijving van de lever (cirrhose), leverfalen en zelfs leverkanker. Tot op heden zijn een aantal processen die deel uitmaken van de progressie naar ontsteking geïdentificeerd, maar de exacte oorzaken zijn tot nog toe onbekend.

In deze thesis zijn hyperlipidemische muizen gebruikt om de vroege gebeurtenissen te onderzoeken tijdens de ontwikkeling van NASH. De gebruikte muismodellen zijn in detail beschreven in hoofdstuk 2. Deze muismodellen zijn gebaseerd op mutaties in sleutelgenen die bekend staan omwille van hun rol in hyperlipidemie en het risico op de vorming van aderverkalking. Deze genen zijn de low density lipoproteïne receptor (LDLR) en apolipoproteïne E (APOE). Hoofdstuk 2 vergelijkt de bestaande modellen en hun gebruik in het hart- en vatenonderzoek, vermits dit het onderzoeksveld is waarin ze tot op heden het meest gebruikt worden. Elk muismodel heeft zo zijn voor- en nadelen en de keuze van het te gebruiken muismodel hangt af van het soort informatie dat gewenst is. Zo is bijvoorbeeld de ApoE deficiënte muis de het meest gebruikte model in het aderverkalkingsonderzoek, maar is het niet het geschikte model voor alle soorten hypotheses. Omdat deze muis geen respons vertoont als reactie op bepaalde vetverlagende geneesmiddelen, zoals statines en fibraten, worden beter andere muismodellen gebruikt om deze stoffen te onderzoeken.

Vervolgens, in hoofdstuk 3, wordt aangetoond dat een van de beschreven hyperlipidemische muismodellen, de APOE2 knock-in muis, zeer snel NASH ontwikkelt wanneer het wordt gevoed met een dieet met hoge hoeveelheden triglyceriden en cholesterol. Door histologische en biochemische technieken te combineren met genexpressie analyse hebben we ontdekt dat de ontstekingsreactie in de lever veel vroeger aanwezig is dan kan worden verklaard met het twee-hit model. Al na 2 dagen op het vetrijke dieet konden macrofaaginfiltratie en inflammatoire genexpressieveranderingen worden waargenomen die sneller optraden dan vetophoping. Deze resultaten suggerren dat ontsteking een belangrijkere speelt tijdens de ontwikkeling van de ziekte dan eerder gedacht. Daarenboven hebben we aangetoond 
dat het toedienen fenofibraat, een synthetische agonist van proliferater activated receptor alpha (PPAR $\alpha)$, de ontwikkeling van NASH kan tegengaan.

Om vervolgens te onderzoeken via welke mechanismsen NASH wordt geïnduceerd door dieet en gïnhibeert door fenofibraat, zijn de genexpressieveranderingen in meer detail bestudeerd in hoofdstuk 4. Met gespecialiseerde software die genen groepeert volgens hun voorkomen in de literatuur, beoogden we om belangrijke pathways te identificiëren. Twee pathways waren van specifiek belang tijdens de ontwikkeling en de inhibitie van NASH. Deze waren het cholesterol metabolims en inflammatie of ontsteking. De geobserveerde veranderingen in het cholesterol metabolisme werden waarschijnlijk veroorzaakt door terugkoppelingsmechanismen als gevolg van een verhoogde hoeveelheid cholesterol in de lever. Deze verhoging werd genormaliseerd door het toedienen van fenofibraat. Het was verrassend om te vinden dat fenofibraat de ontsteking in de lever warschijnlijk inhibeerde door te storen in de NF- $\kappa B$ signalisatie, terwijl de expressieniveaus van AP-1 en zijn doelwit genen werden verhoogd.

Deze opmerkelijke relatie tussen cholesterol en ontsteking werd duidelijk bevestigd in hoofdstuk 5. Hier konden we aantonen dat cholesterol uit het dieet rechtstreeks tot een ontstekingsreactie in de lever leidt. In dit hoofdstuk werden de eerder gebruikte APOE2ki muizen gebruikt samen met een ander bekend hyperlipidemisch muismodel, nl. de ldlr deficiënte (ldlr $\left.{ }^{-/}\right)$muis. Deze muizen vertonen, net als de APOE2ki muizen, meer vetten in het bloed veroorzaakt door een andere mutatie. Het was verrassend om vast te stellen dat normolipidemische wild-type muizen geen ontsteking vertoonden in hun levers terwijl er toch steatose optrad. De gebruikte hyperlipidemische muismodellen daarentegen vertoonden een hevige ontstekingsreactie samen met de vetophoping. Deze vaststelling laat duidelijk zien dat steatose niet altijd hoeft te leiden tot ontsteking in de lever. Daarenboven hebben we aangetoond dat in mannelijke muizen er zelfs een ontstekingsreactie in de lever aanwezig kan zijn zonder vetopstapeling. Deze bevinding koppelt de twee processen duidelijk los van elkaar. Vervolgens gingen we op zoek naar de directe oorzaak van het ontstekingsproces in de lever. Het werd duidelijk dat er een relatie bestond tussen de verhoogde cholesterolwaardes in het bloed die door het dieet werden veroorzaakt, en de aanwezigheid van ontstekingscellen in de lever. Bovendien was het opgevallen dat in de lever van deze dieren gezwollen Kupffer cellen aanwezig waren gevuld met vetdruppels en cholesterolkristallen.

Om te zien of er een oorzakelijk verband bestond tussen cholesterol en ontsteking in de lever, hebben we de reactie onderzocht in deze muizen op hetzelfde vetrijke dieet maar dan zonder de toegevoegde cholesterol. Het weglaten van cholesterol uit het dieet resulteerde in een vermindering van "slechte cholesterol" in het bloed (VLDL en LDL) en dit inhibeerde volledig deze ontstekingsreactie in de lever. Deze belangrijke 
bevindingen geven aan dat cholesterol uit het dieet, mogelijk in de vorm van gemodificeerde plasma lipoproteïnen, een belangrijke risicofactor is voor het ontwikkelen van een ontsteking in de lever. Hieruit volgde de hypothese dat in de hyperlipidemische muizen een verhoging optreedt van gemodificeerde plasma lipoproteïnen als ze gevoed worden met een cholesterolrijk dieet. Dit zou kunnen leiden tot een verhoogde opname door Kupffer cellen, welke hierdoor geactiveerd worden en de ontstekingsreactie in gang zetten.

In het volgende hoofdstuk hebben we onderzocht of de opname van gemodificeerde lipoproteïnen door Kupffer cellen het mechanisme is waardoor een ontsteking op gang komt in de lever van hyperlipidemische muizen. Twee zogenaamde scavenger receptoren staan bekend om verantwoordelijk te zijn voor het grootste deel van de opname van gemodificeerde lipoproteïnen door macrofagen: SR-A en CD36. Met beenmergtransplantaties hebben we daarom muizen gecreëerd die deze twee scavenger receptoren niet hebben in hun immuuncellen, wat ook leidt tot de afwezigheid ervan in de immuuncellen van de lever: de Kupffer cellen. Deze dieren vertoonden een verlaging, maar geen volledige inhibitie, van de ontsteking in de lever wanneer een vetrijk dieet werd gegeven. Verrassend genoeg bleef de hoeveelheid gezwollen Kupffer cellen gelijk, wat erop duidt dat deze receptoren belangrijk zijn in de ontwikkeling van ontsteking in de lever, maar het exacte mechanisme blijft voorlopig onduidelijk.

Het feit dat ontsteking in de lever veel vroeger optreedt dan verwacht leidde toe de hypothese dat de aanwezigheid ervan een rol kan spleen tijdens de verdure ontwikkeling van NASH. Vandaar werden in hoofdstuk 7 de twee eerder gebruikte hyperlipidemische muismodellen vergeleken met normolipidemische controle muizen wat betreft hun respons op het toedienen van vetrijke voeding gedurende een langere periode. We vonden een omgekeerde correlatie tussen de aanwezigheid van ontsteking in de lever en de hoeveelheid opgestapeld vet. Om te onderzoeken of een er sprake was van een oorzakelijk verband, hebben we dieren gecreëerd met een verhoogde ontsteking in de lever. Hiertoe werden beenmergtransplantaties gebruikt. Ldlr-/muizen werden bestraald en getransplanteerd met beenmerg van hyper-inflammatoire TNF receptor non-sheddable muizen, welke een verhoogde TNF signalering vertonen. Deze dieren hadden een verdubbeling van het aantal ontstekingscellen in de lever, en dit leidde tot een verlaging van de vetopstapeling in de lever. Daarenboven hebben we gevonden dat de opstapeling van vetten in de lever volledig werd geïnhibeerd na het neutraliseren van het anti-inflammatoir cytokine IL10 met antilichamen. Dit gebeurde zelfs zonder een verandering van de hoeveelheid ontsteking in de lever.

In het laatste hoofdstuk worden de belangrijkste resultaten uit deze thesis besproken in het licht van de huidige stand van zaken. Daarenboven worden de mogelijke toepassingen en gevolgen besproken. We kunnen besluiten dat in deze thesis wordt 
aangetoond dat cholesterol een belangrijke risicofactor is om ontsteking in de lever te ontwikkelen. In tegenstelling tot het huidig geaccepteerde twee-hit model, heeft deze thesis aangetoond dat cholesterol mogelijk rechtstreeks leidt tot leverinflammatie, ongeacht de aanwezigheid van een eerste "hit". Cholesterol zorgt daardoor voor een onmiddellijke "strike out" van de lever. 


\section{Curriculum Vitae}


Kristiaan Wouters was born on March 8 in Hasselt, Belgium. In 1999 he acquired his diploma from secondary school at Humaniora Kindsheid Jesu (Hasselt, Belgium). In September of the same year, he started to study Biomedical Sciences at the LUC (Limburgs Universitair Centrum) in Diebenbeek, Belgium, where he got his candidate diploma cum laude in 2001. He continued his education in Diepenbeek to obtain his Master (Licenciate) Magna Cum Laude in Biomedical Sciences at the transnationale Universiteit Limburg (tUL), a cooperation between the LUC and Universiteit Maastricht (UM) in 2003. For this degree he performed an internship of 7 months at the BIOMED research institute in Diepenbeek, Belgium. He participated in a project titled "Study of the gene expression pattern of parity-induced differentiation of human mammary tissue in relation to the development of breast cancer by using SAGE (Serial Analysis of Gene Expression)."

During his internship, Kristiaan Wouters got intereseted to perform scientific research. Therefore, in August 2003 he started to work as a PhD student (Assistant in Opleiding, AiO) at the department of Molecular Genetics at the University of Maastricht, The Netherlands, headed by Prof. Dr. Marten Hofker. Dr. Hofker participated in the supervision together with Dr. Ronit Shiri-Sverdlov and Dr. Marc van Bilsen on a project funded by the Netherlands Heart Foundation: "Genomic analysis of the APOE2 knock-in mouse to identify novel genes involved in Hyperlipidemia". During this time, he assisted at several practical courses for Medicin students (FdG blok 2.1), and he mentored several master students during their internships. He also participated to several national and international conferences where he was able to present his research both orally and by poster presentations. He was awarded the Young Investigator Award at the 'Drugs Affecting Lipid Metabolism' conference in Venice, Italy in 2004 and the travel scholarship to attend the Keystone symposium on Nuclear Receptors and the metabolic syndrome in Steamboat, Co, USA in 2007.

From March 2008 untill present, he works in the laboratory of Bart Staels in Lille, France, on a project to investigate the role of macrophage $\mathrm{p} 16^{\mathrm{INK} 4 \mathrm{~A}}$ in atherosclerosis and metabolic diseases in collaboration with Dr. Menno de Winther from Maastricht University. For this project he obtained funding from the European Atherosclerosis Society (EAS) and Maastricht University (Kootstra fellowship). 


\section{List of publications}

- $\quad$ Wouters K, Van Gorp PJ, Bieghs V, Gijbels MJ, Duimel H, Lütjohann D, Kerksiek A, Van Kruchten R, Maeda N, Staels B, Van Bilsen M, Shiri-Sverdlov R, Hofker MH. Dietary cholesterol, rather than liver steatosis, leads to hepatic inflammation in hyperlipidemic mouse models of NASH.

Hepatology. 2008 Aug;48(2):474-86 (IF=10.73)

- Wouters K, Shiri-Sverdlov R, van Gorp PJ, Gijbels MJ, Noel B, Buffat L, Staels B, Maeda N, van Bilsen M, Hofker MH. Early diet-induced non-alcoholic steatohepatitis in APOE2 knock-in mice and its prevention by fibrates. J Hepatol. 2006 Apr;44(4):732-41 (IF=6.64)

- $\quad$ Wouters K, Shiri-Sverdlov R, van Gorp PJ, van Bilsen M, Hofker MH. Understanding hyperlipidemia and atherosclerosis: lessons from genetically modified apoe and ldlr mice.

Clin Chem Lab Med. 2005; 43(5):470-9. Review (IF=1.74)

- Verlinden I, Gungor N, Wouters K, Janssens J, Raus J, Michiels L. Parity-induced changes in global gene expression in the human mammary gland.

Eur J Cancer Prev. 2005 Apr; 14(2):129-37 (IF=1.63)

- Vanschoonbeek K, Wouters K, van der Meijden PE, van Gorp PJ, Schurgers LJ, Feijge MA, Hofker MH, de Maat MP, and Heemskerk JW. Anticoagulant effect of dietary fish oil in hyperlipidemia: a study of hepatic mRNA expression in APOE2 knock-in mice.

Arterioscl Throm Vas Biol. 2008 (IF=7.22)

- Wouters K, van Bilsen M, Bieghs V, van Gorp PJ, Lütjohann D, Kerksiek A, Staels B, Hofker MH, and Shiri-Sverdlov R. A central role for cholesterol metabolism and inflammation during the inhibition of non-alcoholic steatohepatitis with a synthetic PPARalpha agonist.

Submitted 


\section{Poster presentations}

- "Genomic analysis of the APOE knock-in mouse model" NHS-dag, Leiden 15 april 2004

- "The APOE2 knock-in mouse as a sensitive model for steatosis and inflammation" Drugs Affecting Lipid Metabolism2004, Lorenzini Foundation. Venice 24-27 October 2004 (Awarded with a Young Investigator Award)

- "Genomic analysis of the APOE2 knock-in mouse model" CARIM Symposium, Maastricht, 17th November 2004

- "Hyperlipidemic mice are more sensitive to diet-induced hepatic inflammation." Gordon Research Conference on Lipoprotein Metabolism. Boston, USA 2 July 2006 - 9 July 2006.

- "Hyperactivation of macrophage TNF signaling inhibits steatosis" Keystone Symposia: Nuclear Receptors and the metabolic syndrome. March 26-April 12007

- "Lowering plasma VLDL inhibits the development of liver inflammation in hyperlipidemic mice.” European Lipoprotein Club, Tutzing, september 2007

\section{Oral presentations}

- "The APOE2 knock-in mouse as a model for type III hyperlipidemia and steatohepatitis." ZonMw Genetica retraite, Congrescentrum Rolduc, Kerkrade. 3rd March 2005

- " "PPARalpha induced gene-expression.” EVGN Summer School, 28th June 2005

- "Diet-induced steatohepatitis in APOE2 knock-in mice and its reversal by fibrates" European Lipoprotein Club, Tutzing, 13th September 2005

- "Early diet-induced steatohepatitis in APOE2 knock-in mice and its reversal by fibrates" Nederlandse Vereniging voor Diabetes Onderzoek, 2nd December 2005

- "The APOE2 knock-in mouse as a model for type III hyperlipidemia and steatohepatitis." ZonMw Genetica retraite, Congrescentrum Rolduc, Kerkrade, 10th March 2006

- "Hyperlipidemic mice are more sensitive to diet-induced hepatic inflammation." European Lipoprotein Club, Tutzing, 6th september 2006

- "Hyperlipidemic mice are more sensitive to diet-induced hepatic inflammation" Nederlandse Vereniging voor Diabetes Onderzoek 2006, 2nd November 2006

- "Hyperactivation of macrophage TNF signaling inhibits steatosis" Keystone Symposia: Nuclear Receptors and the metabolic syndrome. 29th March 2007 (travel scholarship awarded) 


\section{Dankwoord}


Zo, hier is het dan eindelijk: mijn dankwoord. Ik heb er al een aantal zien passeren en eindelijk is het aan mij om een te schrijven. Ik heb een dikke vier jaar een enorm fijne tijd gehad (naast het hard labeur uiteraard) en nu is het hoog tijd om de mensen, die mede verantwoordelijk zijn geweest voor de leuke momenten en het harde werk te vermelden.

Beste Marten, in de eerste plaats bedankt om mijn promotor te zijn. Van in het begin had ik het gevoel gehad dat je in me geloofde en vertrouwen in me had. Dit heb ik altijd erg geapprecieerd en heeft me bovenal gestimuleerd. Gaandeweg heb je me meer en meer vrijheid gegeven om mezelf op wetenschappelijk gebied te ontplooien, zelfs wanneer we het niet helemaal eens waren. Daar pluk ik nu de vruchten van. Altijd stond jouw deur open om eventjes met een prangende vraag binnen te springen.

De volgende in lijn is uiteraard Ronit. Hoewel het in het begin even schrikken was toen ik voor de eerste keer bij je op gesprek kwam en ik een hoogzwangere vrouw zag in plaats van de Meneer Sverdlov waar ik naar vroeg, is het toch nog goed gekomen. Het was leuk samenwerken met je. Samen hebben we iets moois gemaakt van het project wat er lag. Het was nooit te veel voor je om even naar me te luisteren (omtrent werkelijk alles). Jouw opmerkzaamheid en begrip waren enorm!

Marc, jij vervolledigde het promotieteam. Je bracht vaak ideeën aan vanuit een ander perspectief en dat was vaak erg verhelderend. Ik wil je ook nog extra bedanken voor de tijd die je graag spendeerde om me raad te geven wanneer het nodig was. Jouw uitspraak over draagbare computers vertel ik nog steeds aan iedereen die het horen wil!

En dan is er Patrick. Van bij de aanvang was je mijn steun en toeverlaat op Molgen. Toen het in het begin niet zo makkelijk voor mij was, heb je me volledig op mijn gemak gesteld. De labtechnieken die ik van je heb geleerd zijn ontelbaar, maar vooral de manier van werken die je me hebt bijgebracht is onbetaalbaar en is iets waar ik nog lang plezier van zal hebben. Daarbovenop hebben we ook nog gewoon veel gelachen en plezier gemaakt. Hoewel niet iedereen het daar mee eens was, vond ik de België vs Nederland grapjes enorm leuk. Natuurlijk waren er ook nog andere legendarische momenten à la "Marseillaise-Marechaussee" en "Dr. Hooters with the black chicks" die me altijd bij zullen blijven. Bedankt ook om mijn paranimf te willen zijn. Als ik aan jou iets vraag weet ik dat, net zoals op het lab, het wel goed komt. Dit is een luxe die ik nu al mis! Ik hoop in ieder geval nog vaak samen met je te kunnen lachen. 
Dit brengt me naadloos naar de kamer waar ik begon te werken. Naast Patrick zat ik er met Monique en Inge. Ook jullie twee waren geweldige collega's en altijd bereid me te helpen. Jullie technische bagage is dan ook indrukwekkend. Monique, bedankt voor de hulp, de erg leuke momenten en de plagerijtjes: het was altijd bibberen als ik je in de gang me hoorde roepen: "Meneer Wouters...!" ;-). Inge, ook jij hebt me veel bijgebracht en we hebben een leuke tijd gehad, niet alleen op het werk maar ook daarbuiten; dat Pukkelpop nog maar enkele jaartjes doorgaat in Hasselt!

Met het vertrek van Sander ben ik dan verhuisd naar de AiO kamer. Bedankt voor die goede energie op je oude werkplek Sander! Op die kamer was het erg gezellig en vaak heel erg lollig. Soms misschien een beetje "te", maar er werd ook gewerkt. Roy, jouw muziekkeuze was erg goed en je deelde dit graag met de rest. Stijn, jouw creatieve geest waarmee prehistorische waterdieren, koosjere kippen en slakken werden gekweekt, zal ik me altijd blijven herinneren. Niet enkel deze organische speciën, maar ook robotten passeerden de revue samen met experimenten om het temperatuurbereik van een speelgoedtelefoon te meten: hilarisch! Mathijs, ik zal voortaan je knuffels moeten missen. Gelukkig was jij er om alle computerproblemen op te lossen. Jij hebt me ook geïntroduceerd in het leven van de CARIM AiO cursussen, waar we ons altijd heel erg goed hebben geamuseerd, en het naaktzwemmen in Tutzing. Ik wens je nog goede moed voor het afronden van je proefschrift, je komt er zeker wel! Petra, jij was zo een beetje de moederkloek van de kamer en altijd op de hoogte van de laatste weetjes. Je was altijd in om mee te lachen en af en toe een leuke, scherpe opmerking te geven. Daphna, als het even wat rustiger werd, was er altijd wel wat tijd voor een gesprek, ondanks dat we ver uit elkaar verwijderd waren in de kamer. Jij ook veel geluk met de laatste loodjes. Jana, ook met jou had ik regelmatig leuke en soms noodzakelijke gesprekken. Ik wens je nog veel succes in Groningen! Remco (ook al is dat niet een van je voornamen), ik heb enorm genoten van de korte tijd die je bij ons op de kamer hebt gespendeerd. Ik ben blij dat je je goed voelt in je nieuwe baan. Veerle (C.), ook jij ben maar kort een kamergenoot geweest. Ook jou wens ik veel succes in je nieuwe carrière. Ellen (D.), ondanks dat jij er ook nog niet zo heel lang zit, hebben we met jou toch ook al veel gelachen ;-)! Veerle, ik ben blij dat jij mijn werk opvolgt. Ik denk dat het met jou zeker goedkomt, zeker samen met Patrick en Ronit. Ik wil je graag extra bedanken voor de hulp voor het klaarkrijgen van het paper. En last but not least: onze Pi! Pieter, met jou klikte het vrijwel meteen, niet alleen op vlak van muziek maar ook op vlak van humor en wetenschap. Soms begrepen we elkaar zelfs zonder woorden en was een blik al voldoende om in lachen uit te barsten. Ik hoop met jou nog vaak concertjes te doen. Misschien kom je wel eens bij mijn ouders eten? Laat het duidelijk 
zijn dat ik me heel erg thuis voelde bij jullie allemaal en dat het echt een onvergetelijke tijd was! Lauran, ik denk dat jij je daar ook wel goed gaat voelen.

Naast de genoemde kamergenoten waren er natuurlijk nog andere leuke collega-AiO's waarmee we geweldige koffiepauzes en andere momenten mee hebben gespendeerd, zoals pokeravonden. Hanneke, veel geluk op pathologie en met je naderende promotie. Frank, laat me nog maar iets weten wanneer er gevoetbald wordt en nog veel succes met het vergaren van de laatste data. Wino, ondanks alle doodsbedreigingen die ik van je heb gekregen heb je mijn eeuwig respect voor het wereldrecord "langste appelschil". Let in het vervolg wel op als je weer iemand gaat tackelen! Céline, j'espère que tout va bien avec toi et avec tes enfants. Peggy, met jou is er altijd wel plezier (soms misschien wel wat overenthousiasme als het over mijn oor gaat?). Laura, veel succes met je onderzoek. En dan waren er ook nog Debby en Susan, ik herinner me nog goed dat jullie twee, samen met Daphna, alle prijzen wegkaapten van de voetbalpronostiek!

Guillaume, met jou was het ook altijd lachen. Maar je was ook altijd klaar voor een serieus gesprek dat af en toe wel eens nodig was. Samen met jou en Claudia het labuitje organiseren was erg leuk. Menno, jij was wetenschappelijk altijd wel een voorbeeld en ik ben blij dat we nog even blijven samenwerken. Bedankt voor de hulp bij de voorbije beursaanvragen. Jan, ook jij hebt me goed geholpen om verder te kunnen na mij AiO schap. Marion, hoewel ik in het begin een beetje aan je moest wennnen, is jouw bijdrage achter de microscoop (oftewel scoren!) essentieel geweest voor het project en dit proefschrift. Het waren in ieder geval erg gezellige uurtjes. Wilma, jij bent zeker een vermelding waard. De energie waarmee je mij en iedereen wilde helpen was ongelooflijk. Ik hoop dat je geniet van je verdiend pensioen!

En er waren nog een pak meer mensen op Molgen die mee de goede sfeer bepaald hebben op en naast de werkvloer: Anne, Arjen, Daniëlle (bedankt voor het faute feestje!), Franky, Iris, Joost, Le, Maurice, Mohammed, Raymond, Robert, Sofia, en Willem. Will, met jou discusiëren over politiek, sossen en xenofobe Belgen was zalig.

Een deel van de resultaten uit deze thesis, en een deel dat er jammer genoeg net niet in geraakt is, is bij elkaar gepipeteerd door enkele studenten. Ook met jullie was het fijn samenwerken. Bedankt Silvie, Caroline en Roger.

Buiten Molgen waren er nog een hoop mensen die hebben bijgedragen aan de toffe sfeer, verdeeld over de verschillende afdelingen van de UM en het CPV: Kees, Wim, Wout, Leo, Sonia, Tine, Kees, Hans, Pascal, Linda, Paola, Johan, Kristof, Remels, 
Karen, Nejla, Andries, Ronald, Mieke, Marie-Hélène, Francien, Ruben, Ann, Bianca, Torik, Rosy, Erica, Richard, Paulien, Allard, Rik, Nadien, Marlies en ongetwijfeld nog vele anderen die mij jammer genoeg niet te binnen schieten (met mijn welgemeende excuses).

Er waren ook nog een deel mensen van buiten de UM die hebben bijgedragen aan deze thesis. Dieter, many thanks for your availability and for the time you worked on our livers. Prof. Holvoet, jammer dat dat de resultaten niet onmiddellijk bruikbaar waren. Ik heb uw medewerking zeker op prijs gesteld. Bart, jij hebt vaak je ideën gegeven over onze data en dat heeft zeker bijgedragen tot de kwaliteit van deze thesis. Ik ook erg blij met de kans die je me hebt gegeven om bij jou in Rijsel/Lille te komen werken.

Naast het lab waren ook nog andere mensen belangrijk voor het welslagen van deze thesis, al was het maar om af en toe voor wat afleiding te zorgen of een luisterend oor. Ik heb jullie de laatste tijd veel te weinig gezien, laten we hopen dat het nu weer wat beter gaat gaan! Bleu, je bent samen met Annelies en je twee schatten van kinderen zo goed als familie geworden. Ik ben heel erg vereerd en dankbaar dat ik de peter mag zijn van Mitu. Ik zal ook nooit vergeten op welke manier jullie me steeds met open armen hebben opgevangen wanneer het nodig was. Ik had me dan ook niemand anders als paranimf kunnen voorstellen. Tim, je bent begonnen als student op Molgen en zo via carpoolmaat uitgegroeid tot echte vriend. Samen met Bleu hebben we een geweldige tijd gehad samen in de auto waar het af en toe ook nog eens serieus aan toe ging. Een dikke proficiat voor jou en Evy met jullie kindje. Roeland, ik hoop dat we nu dat we allebei onze thesis af hebben, er weer wat meer tijd komt voor plezier. Veel succes in Parijs en met de kleine (ook aan Daisy). Cédric, ook jij hebt al een belangrijke rol gespeeld in mijn leven: al meer dan 14 jaar vriendschap die alles heeft kunnen doorstaan. Met gemak doen we er nog een heel deel jaren bij! In dit rijtje mag zeker ook Vis niet ontbreken en de harde kern van ZVK Echternach: Michel, Brecht, (nog eens) Tim (nog een keer) Johannes, Eric, Doully, Roger en Peter.

Naast deze vrienden heb ik het geluk om een geweldige familie te hebben waar ik ongeacht wanneer en waarom bij terecht kan. Mama en Papa, jullie hebben me alle kansen gegeven die maar mogelijk waren. Belangrijker nog, jullie hebben me altijd gestimuleerd om deze kansen te grijpen en te gaan voor wat ik waard was. Het was thuis altijd een liefdevolle, gezellige en erg aangename plaats om te vertoeven. Dankzij jullie ben ik geworden wie ik ben en sta ik waar ik sta. Het resultaat dat jullie nu in jullie handen hebben, is ook voor een deel jullie verdienste! 
Brecht, mijn broer, ik ben blij dat we de laatste tijd zo naar elkaar zijn gegroeid. Ook aan jou heb ik een echte vriend waarop ik weet dat ik altijd zal kunnen bouwen. Véronique, ook al zien we elkaar niet meer zo vaak, heb ik het altijd leuk gevonden om je in huis te hebben. Mareine en Moeke, ook jullie hebben altijd in me geloofd en zijn altijd trots op me geweest. Dat is een fijn gevoel.

En dan zijn er ook nog Jos en Angèle (en Koen, we hebben nog niet echt de kans gehad elkaar beter te leren kennen maar ik hoop dat dat snel verandert). Jullie hebben me vanaf de eerste dag in jullie armen gesloten en me onmiddellijk doen thuis voelen. Ook van jullie krijg ik heel veel steun. Bedankt voor de warmte!

Ellen, wie had gedacht (buiten heel Molgen dan) dat jij nu naast mij zou staan? De steun die ik van je heb gekregen tijdens het schrijven van deze thesis is ongelooflijk. Je hebt me laten werken terwijl je de rest van het huishoudelijke werk op je nam, zelfs toen we nog niet samenwoonden. Ik heb van je onvoorwaardelijke steun en begrip gehad op de momenten dat het wat minder ging. Jij hebt echt enorm bijgedragen aan deze thesis en daar ben ik enorm dankbaar voor. Ik hoop dat ik voor jou hetzelfde zal mogen doen binnen enkele jaren, je bent in ieder geval al erg goed op weg...

Mijn lief Elleke, sinds jij in mijn leven gekomen bent is alles beter geworden, inclusief ik. Je geeft me de vrijheid om te zijn wie ik ben en om me verder te kunnen ontplooien. Niets is je te veel als je weet dat het me blij maakt. Het is echt een wonderlijk gevoel om te weten dat er iemand zo achter je staat en van je houdt zoals jij dat doet. Vanaf nu gaan we wat meer tijd hebben voor elkaar en ik ben er zeker van dat het een aaneenschakeling van mooie momenten gaat zijn. Ik hoop dat deze momenten de rest van ons leven blijven duren met jou aan mijn zijde als mijn vrouw, als je wil.

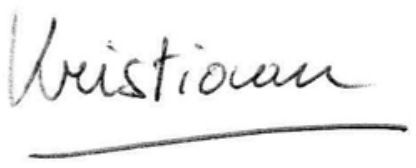




\section{List of abbreviations}


A $\quad \mathrm{Abc}$

ABCC3

$\mathrm{ACC}$

acLDL

Acox-1

AP-1

Apo

APOE3L

APOE2TG

$\mathrm{ASH}$

ATF6

B BMT

C ChREBP

CETP

Clcsf13

$\mathrm{CM}$

CMR

Cpt1

CRP1

CVD

CYP2E1

D Dko

E eQTL

ER

EVGN

F FA

FABP2

FAS

FD

Fdft1

FF

FFA

$\mathrm{FH}$

G $\quad \mathrm{GO}$

GC-FID

GC-MS

H HDL

HE

$\mathrm{HFC}$

$\mathrm{HFC}+\mathrm{FF}$

HFD

HFnC

HLP
Adenosine Triphosphate binding cassette

ATP Binding Casette 3

Acyl-CoA Carboxylase

acetylated Low Density Lipoproteins

Acyl CoA oxidase 1

Activating Protein-1

Apolipoproteins

APOE3 Leiden

APOE2 Transgene

Alcoholic Steatohepatitis

Activating Transcription Factor 6

Bone Marrow Transplantation

Carbohydrate Response Element Binding Protein

Cholesteryl Ester Transfer Protein

C-type Lectin, SuperFamily 13

Chylomicrons

Chylomicron remnants

Carnitine acyl-carnitine translocase 1

C Reactive Protein 1

CardioVascular Disease

Cytochrome P450 2E1

Double knock-out

expression Quantitative Trait Loci

Endoplasmatic Reticulum

European Vascular Genomics Network

Fatty acids

Fatty Acid Binding Protein 2

Fatty Acid Synthase

Familial Dysbetalipoproteinemia

Farnesyl Disphosphate Farnesyl Transferase 1

Fenofibrate

Free Fatty Acid

Familial Hypercholesterolemia

Gene ontology

Gas Chromatography-Flame Ionization Detection

Gas Chromatography-Mass Spectrometry

High Density Lipoprotein

Heamatoxilin/Eosin

High Fat, High Cholesterol diet

High Fat, High Cholesterol diet with FF

High Fat Diet

High Fat Diet without Cholesterol

HyperLipoProteinemia 


$\begin{array}{lll} & \text { HMG-CoA } & \text { 3-Hydroxy-3-MethylGlutaryl-Coenzyme A } \\ \text { Hmgc1 } & \text { HMG-CoA lyase } \\ \text { HMGCS } & \text { HMG-CoA Synthase } \\ \text { Hmgcs } & \text { HMG-CoA Synthetase } \\ \text { HNE } & \text { trans-4-Hydroxy-2-Noneal } \\ \text { HNF4A } & \text { Hepatic Nuclear Factor 4A } \\ \text { HSL } & \text { Hormone Sensitive Lipase } \\ \text { I } & \text { Intracellular Adhesion Molecule 1 } \\ \text { IDF } & \text { International Diabetes Federation } \\ \text { Ifit1 } & \text { Interferon-Induced protein with tetratricopeptide } \\ & \text { repeats 1 } \\ \text { IKK } \beta & \text { IאB Kinase beta } \\ \text { IL } & \text { Interleukin } \\ \text { Insig2 } & \text { Insulin Induced Gene 2 } \\ \text { IR } & \text { Insulin Resistance } \\ \text { IRE-1 } & \text { Inositol-Requiring Enzyme 1 } \\ \text { IPA } & \text { Ingenuity Pathway Analysis } \\ \text { JNK } & \text { C-Jun N-terminal Kinase } \\ \text { KC } & \text { Kupffer cells } \\ \text { Ki } & \text { Knock-in } \\ \text { Ko } & \text { Knock-out } \\ \text { LDL } & \text { Low Density Lipoproteins } \\ \text { Ldlr- } & \text { Low Density Lipoproteins Deficient } \\ \text { LDLR } & \text { LDL Receptor } \\ \text { Lip1 } & \text { Lipase 1 } \\ \text { LipC } & \text { Lipin C } \\ \text { LpL } & \text { Liprotein Lipase } \\ \text { LPS } & \text { Lipopolysacharide } \\ \text { Lrp } & \text { Low Density Lipoproteins Receptor Related Protein } \\ \text { LXR } & \text { Liver X Receptor } \\ \text { Lyzs } & \text { Lysozyme } \\ \text { MCD } & \text { Methionine and Choline Deficient } \\ \text { Mcp-1 } & \text { Monocyte Chemoattractant Protein 1 } \\ \text { MDA } & \text { Malondialdehyde } \\ \text { MetS } & \text { Metabolic Syndrome } \\ \text { Mgll } & \text { Monoglyceride Lipase } \\ \text { MRI } & \text { Magnetic Resonance Imaging } \\ \text { MTP } & \text { Mitochondrial TG Transfer Protein } \\ \text { NAFLD } & \text { Non-Alcoholic Fatty Liver Disease } \\ \text { NASH } & \text { Non-Alcoholic Steatohepatitis } \\ \text { NCEP } & \text { National Cholesterol Education Program } \\ \text { NF-kB } & \text { Nuclear Factor Kappa B } \\ \text { NHS } & \text { Netherlands Heart Foundation } \\ & \\ & \end{array}$




\begin{tabular}{|c|c|c|}
\hline \multirow{3}{*}{$\mathbf{O}$} & NWO & Netherlands Organization for Scientific Research \\
\hline & ORO & Oil Red O \\
\hline & oxLDL & Oxidized Low Density Lipoproteins \\
\hline \multirow[t]{9}{*}{$\mathbf{P}$} & PAS & Periodic Acid Schiff \\
\hline & $\mathrm{PC}$ & Phosphatidylcholine \\
\hline & PE & Phosphatidylethanolamine \\
\hline & PERK & PKR like Endoplasmatic Reticulum Kinase \\
\hline & PUFA & Poly-Unsaturated Fatty Acid \\
\hline & PPAR & Peroxisome Proliferating Activated Receptor \\
\hline & Ppia & Cyclophillin A \\
\hline & PPRE & Peroxisome Proliferator Response Elements \\
\hline & PXR & Pregnane X Receptor \\
\hline \multirow[t]{2}{*}{$\mathbf{Q}$} & QPCR & Real-Time Quantitative PCR \\
\hline & QTL & Quantitative Trait Loci \\
\hline $\mathbf{R}$ & ROS & Reactive Oxygen Species \\
\hline \multirow[t]{9}{*}{$\mathbf{S}$} & SRA-1 & Scavenger Receptor A1 \\
\hline & SAA & Serum Amyloid A \\
\hline & SAP & Serum Amyloid P \\
\hline & $\mathrm{SC}$ & Scavenger Receptor \\
\hline & SCD1 & Stearoyl CoA Desaturase 1 \\
\hline & $\mathrm{SF}$ & Scaling Factor \\
\hline & SOCS & Suppressor of Cytokine Signaling \\
\hline & SRBI & Scavenger Receptor B type I \\
\hline & SREBP-1c & Sterol Regulatory Element-Binding Protein 1c \\
\hline \multirow[t]{11}{*}{$\mathbf{T}$} & $\mathrm{T} 2 \mathrm{D}$ & Type 2 Diabetes \\
\hline & $\mathrm{TC}$ & Total Cholesterol \\
\hline & TG & Triglycerides \\
\hline & TGF- $\beta$ & Transforming Growth Factor beta \\
\hline & Tgtp & T-cell specific GTPase \\
\hline & TLDA & Taqman-Low Density Array \\
\hline & Tlr & Toll like receptor \\
\hline & TNF & Tumor Necrosis Factor \\
\hline & TNFR & Tumor Necrosis Factor Receptor \\
\hline & TNFRns & Tumor Necrosis Factor Receptor non-sheddable \\
\hline & TZD & Thiazolidinediones \\
\hline $\mathbf{U}$ & UPR & Unfolded Protein Response \\
\hline \multirow[t]{2}{*}{$\mathbf{V}$} & VLDL & Very Low Density Lipoproteins \\
\hline & VLDLR & Very Low Density Lipoproteins Remnants \\
\hline \multirow[t]{2}{*}{ W } & WBC & White Blood Cells \\
\hline & WT & Wild-Type \\
\hline
\end{tabular}

